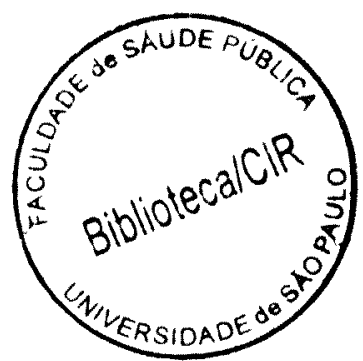

ANTONIO BENEDITO MARANGONE CAMARGO

\title{
MORTALIDADE POR CAUSAS EXTERNAS NO ESTADO DE SÃO PAULO E SUAS REGIÕES
}

Tese a ser apresentada à Faculdade de Saúde Pública - USP para obtenção de título de Doutor em Saúde Pública

ORIENTADOR: Prof. Dr. Augusto Hasiak Santo

São Paulo

Janeiro

2002 


\section{AGRADECIMENTOS}

Ao Professor Dr. Augusto Hasiak Santo, orientador desta Tese, pelo incentivo recebido no decorrer deste trabalho, pelas sugestões, leituras, conselhos e amizade;

À Fundação Sistema Estadual de Análise de dados - SEADE - principal fonte das informações utilizadas neste estudo e pelo apoio recebido durante este Curso de Doutorado;

Aos professores Dr. Roberto Nascimento Rodrigues, Dra. Maria Helena de Mello Jorge, Dr. João Yunes e Dr. Carlos Eugenio de Carvalho Ferreira, pelas sugestões e criticas que contribuiram para a melhoria deste trabalho;

À Bernadette Waldvogel, pela grande amizade, o incentivo em todo este curso, sugestōes e o constante apoio no decorrer deste trabalho;

A Elizabeth Fuzisaki, pelo excelente trabalho de revisão do texto, a elaboração dos gráficos, tabelas e mapas. Agradeço imensamente seu apoio e dedicação na elaboração de todas as partes deste estudo;

À Luis Patricio Ortiz, pelas conversas e sugestões sobre a elaboração deste estudo e pelo apoio recebido;

À Paulo Borlina Maia, pelas conversas, discussões, sugestōes e o apoio técnico contribuindo com informações, textos e explicaçōes;

À Deise Oushiro, pelo apoio e pela organização das séries de dados utilizado neste estudo;

À Magali Valente pela revisão da bibliografia, a obtenção de dados e textos e a pesquisa bibliográfica do tema;

À Vânia Regina pela revisão minuciosa deste texto;

À Aparecida Vieira de Melo, pelo apoio e contribuição com sugestões, textos e informações;

À Sidnei Ferreira e Rodrigo Fonseca, pela organização dos dados das regiōes do Estado;

À Luciane, Rosana, Lilian e Mônica, pelas informações e no apoio técnico; 
À Glauber e Júnior, pelo apoio técnico prestado;

Aos técnicos da GEPOP que me apoiaram e incentivaram durante este Curso de Doutorado;

À Maria Aparecida Teixeira, Miriam Vaz e Vanessa, secretárias do GEPOP pelo apoio;

À minha família que me incentivou em todos os momentos da elaboração deste estudo;

Aos amigos e colegas da Fundação SEADE, da Faculdade de Saúde Pública, NEPO, CEDEPLAR, IBGE e da ABEP, que direta ou indiretamente me apoiaram e contribuíram de diversas formas para a elaboração deste estudo;

E finalmente ao Maior de todos, sem o que nada seria possível nem viável, pela força, incentivo, inspiração e paciência em todas as horas. 


\section{RESUMO}

Camargo, Antonio Benedito Marangone. Mortalidade por Causas Externas no Estado de São Paulo e suas Regiões. São Paulo; 2002. [Tese de Doutorado Faculdade de Saúde Púbica da USP]

Este trabalho objetivou estudar a magnitude e a tendência da mortalidade por causas externas no Brasil, no Estado de São Paulo e em suas regiões e municípios, especialmente nas duas últimas décadas.

Até o final dos anos 70 , as causas externas de morte eram superadas por várias outras como as doenças do aparelho circulatório, neoplasias, doenças infecciosas e parasitárias e as doenças do aparelho respiratório no Brasil, mas com o seu rápido crescimento, passaram a se constituir na segunda mais importante. Entre os homens, essa participação é maior, devido, em grande parte, ao aumento dos homicídios, que, desde o início dos anos 90, são a principal causa externa de morte no país. Os coeficientes de mortalidade passaram de cerca de 10 óbitos por cem mil habitantes ao final da década de 70 , para mais de 25 a partir da metade dos anos 90 .

Em São Paulo, o panorama é ainda mais complexo, pois os homicídios já se constituem na principal causa externa desde o início da década de 80 . As taxas, que se mantiveram abaixo de 10 óbitos por 100 mil habitantes, até o final dos anos 70 , elevam-se de forma acentuada, ultrapassando, nos últimos anos, a 40 óbitos por 100 mil pessoas, níveis altíssimos quando comparados com outras áreas do mundo. Os acidentes de transportes/veiculos a motor, em geral, também apresentam coeficientes elevados, mas vêm mantendo-se com certa estabilidade, com cerca de 20 óbitos por 100 mil habitantes.

As regiōes do Estado de São Paulo, também apresentam níveis de mortalidade por causas externas muito altos, especialmente em Santos, na Região Metropolitana de São Paulo e em Registro. Observa-se ainda que estas taxas vêm aumentando consideravelmente nos últimos anos, nas regiões de São José dos 
Campos, Campinas e Ribeirão Preto. No oeste do Estado, os niveis ainda mantêm-se relativamente estáveis e menores.

Ao se medir o impacto da mortalidade por causas externas nessas regiões, observa-se que, se estas deixassem de ocorrer, haveria um ganho de 4,7 anos na esperança de vida da população masculina de Santos, de 4,4 na Região Metropolitana de São Paulo e de 4,0 em Registro. Esta última apresenta os maiores coeficientes de mortalidade por acidentes de transporte do Estado de São Paulo, enquanto nas duas outras o impacto maior deve-se à mortalidade por homicídios.

Entre as mulheres a eliminação das causas externas de morte proporcionaria um ganho de menos de um ano na esperança de vida ao nascer com a eliminação das causas externas de morte. 


\section{SUMMARY}

Camargo, Antonio Benedito Marangone. Mortality from external causes in São Paulo and its areas: a recent view. São Paulo, SP, 2002

The objective of this study was to describe the magnitude and trend of the mortality from external causes in Brazil, in São Paulo and its areas and municipalities, especially on the last two decades.

Up to the end of the decade of 70 these causes were overcome by others, both in Brazil and in São Paulo, but along with its quick increase they turned into the second most important. Among men this participation appears larger mainly due to the increase of homicides that since the beginning of the 90 's was turned into the main cause of violent mortality in the country. These mortality rates increased from about 10 deaths by one hundred thousand inhabitants to over 25 since the middle of the 90's.

In São Paulo the view is even more complex, because since the beginning of the decade of 80 homicides constitute the main cause of death. Their rates that had been maintained under 10 up to the end of the 70's were strongly elevated overcoming, in recent years, 40 deaths by one hundred thousand inhabitants, which are very high levels if compared to other areas around the world. Transport and motor vehicles accidents usually present high rates too, nevertheless maintaining some stability and approaching 20 deaths by one hundred thousand inhabitants.

São Paulo areas also present high levels of mortality by external causes, especially in Santos, São Paulo's Metropolitan Area and in Registro, which has also been increasing considerably in São José dos Campos, Campinas and Ribeirão Preto. On the West of the State mortality levels still are maintained relatively stable and lower. 
The impact of the mortality from external causes on life expectancy in areas of the State of São Paulo, was measured by means of competing risks. There would be a gain of 4,7 years in the life expectancy of the male population of Santos, of 4,4 years in São Paulo's Metropolitan Area and of 4,0 in Registro. This last region presents the highest mortality rates due to transport accidents in the State of São Paulo, while in the other two the biggest impact is due to the mortality from homicides.

Among women the impact is smaller, and it does not get to one year in the life expectancy at birth. 


\section{ÍNDICE GERAL}

ÍNDICE DE TABELAS

ÍNDICE DE GRÁFICOS

ÍNDICE DE MAPAS

INTRODUÇÃO

As Causas Externas no Mundo e no Brasil 2

OBJETIVOS 16

$\begin{array}{ll}\text { Objetivo Geral } & 17\end{array}$

Objetivos Especificos $\quad 17$

MATERIAL E MÉTODOS

Fonte dos Dados $\quad 19$

Qualidade das Informações $\quad 22$

Indicadores Utilizados 24

A Tábua de Mortalidade de Múltiplo Decremento 29

RESULTADOS E DISCUSSÃO $\quad 32$

As Causas Externas no Brasil 33

Contextualização Histórica 33

A Estrutura das Causas de Morte 37

As Causas Externas 43

As Causas Externas nas Áreas do Brasil 50

As Causas Externas por Sexo e Grupos Etários 54

O Impacto das Causas Externas $\quad 56$

As Causas Externas no Estado de São Paulo 58

As Informações para São Paulo 58

Evolução das Causas de Morte $\quad 60$

As Causas Externas 69

O Impacto das Causas Externas 85 
As Causas Externas nas Regiões de São Paulo 89

Caracterização das Regiões $\quad 89$

As Causas de Morte 95

A Mortalidade por Causas Externas 101

Mortalidade por Homicídios 101

Acidentes de Veículos a Motor/Acidentes de Transporte $\quad 109$

Mortalidade por Suicidio nas Regiōes de São Paulo 116

Demais Acidentes $\quad 123$

A Mortalidade por Causas Externas 125

O Impacto das Causas Externas de Morte sobre os Indicadores de

Mortalidade 133

O CONTEXTO DAS CAUSAS EXTERNAS NO ÂMBITO MUNDIAL 145

Contextualização Histórica da Violência 146

A Estrutura das Causas de Morte 147

As Causas Externas 151

A Mortalidade por Acidentes de Veículos a Motor 155

A Mortalidade por Demais Acidentes 157

A Mortalidade por Suicídios $\quad 160$

A Mortalidade por Homicídios 163

Panorama Geral 165

São Paulo e o Brasil no Panorama Mundial 166

Homicídios 166

Acidentes de Veículos a Motor $\quad 169$

Suicídios 171

Panorama Geral 173

CONSIDERAÇÓES FINAIS $\quad 174$

BIBLIOGRAFIA $\quad 179$

ANEXO 192 


\section{ÍNDICE DE QUADROS E TABELAS}

Quadro 1 Causas Externas segundo os grupos - CID-9 e CID-10

Tabela 1 Esperança de Vida ao Nascer, por Sexo - Estado de

São Paulo - 1940-98

Tabela 2 Esperança de Vida ao Nascer Total e com Eliminação

das Causas Externas, por Sexo, segundo Grupos de

Causas - Estado de São Paulo - 1980-99

Tabela 3 Ganho de Anos na Esperança de Vida ao Nascer com

a Eliminação das Causas Externas, por Sexo, segundo

Grupos de Causas - Estado de São Paulo - 1980-1999

Tabela 4 População, Taxa de Crescimento Populacional, Grau de Urbanização e Densidade Demográfica - Regiões Administrativas do Estado de São Paulo - 1991-2000

Tabela 5 Esperança de Vida ao Nascer, por Sexo-Regiōes Administrativas do Estado de São Paulo - 1979-1997

Tabela 6 Distribuição dos Óbitos da População Masculina, por Principais Causas - Regiões Administrativas do Estado de São Paulo - 1980-1999

Tabela 7 Distribuição dos Óbitos da População Feminina, por

Principais Causas - Regiōes Administrativas do Estado de São Paulo - 1980-1999

Tabela 8 Coeficientes de Mortalidade da População Masculina, por Principais Causas - Regiões Administrativas do Estado de Săo Paulo - 1980-1999

Tabela 9 Coeficientes de Mortalidade da População Feminina, por Principais Causas - Regiōes Administrativas do Estado de São Paulo - 1980-1999

Tabela 10 Coeficientes de Mortalidade por Homicídios - Estado de São Paulo e Municipios - 1980-1999

Tabela 11 Coeficientes de Mortalidade por Acidentes de Transporte - Estado de São Paulo e Municípios - 19801999

Tabela 12 Coeficientes de Mortalidade por Suicídios - Estado de São Paulo e Municípios - 1980-1999

Tabela 13 Coeficientes de Mortalidade por Causas Externas, segundo Grupos - Regiões Administrativas do Estado de São Paulo - 1998-99 
Tabela 14 Coeficientes de Mortalidade por Causas Externas -

Estado de São Paulo e Municípios - 1980-1999

Tabela 15 Ganhos de Anos na Esperança de Vida ao Nascer ao

Eliminar Grupos de Causas de Morte Violentas, por

Sexo - Regiōes Administrativas do Estado de São

Paulo - 1980-1999

Tabela 16 Esperança de Vida ao Nascer, por Sexo - Países

Selecionados - 1950-1995

Tabela 17 Coeficientes de Mortalidade por Causas Externas, por

Grupos de Causas - Países Selecionados - 1991 1997

Tabela 18 Coeficientes de Mortalidade por Causas Externas -

Paises Selecionados - 1980-95

Tabela 19 Coeficientes de Mortalidade por Acidentes de Veiculos

a Motor - Países Selecionados - 1980-95

Tabela 20 Coeficientes de Mortalidade por Quedas - Países

Selecionados - 1980-95

Tabela 21 Coeficientes de Mortalidade por Outros Acidentes -

Países Selecionados - 1980-95

Tabela 22 Coeficientes de Mortalidade por Suicídios - Países

Selecionados - 1980-95

Tabela 23 Coeficientes de Mortalidade por Homicídios - Países

Selecionados - 1980-95 


\section{ÍNDICE DE GRÁFICOS}

Gráfico 1 Óbitos segundo as Principais Causas - Capitais Brasileiras 1930-75

Gráfico 2 Óbitos segundo as Principais Causas - Brasil - 1977-98

Gráfico 3 Óbitos, por Sexo, segundo as Principais Causas - Brasil -197798

Gráfico 4 Coeficientes de Mortalidade por Causas Externas, por Sexo -

Brasil -1977-98

Gráfico 5 Coeficientes de Mortalidade por Causas Externas, por Tipos Brasil 1979-98

Gráfico 6 Distribuição dos Óbitos por Causas Externas de Morte, segundo Tipos - Brasil - 1979-98

Gráfico 7 Coeficientes de Mortalidade por Causas Externas por Sexo, segundo Tipos - Brasil - 1979-98

Gráfico 8 Coeficientes de Mortalidade por Causas Externas, por Sexo e Grupos de Idade - Brasil - 1979-98

Gráfico 9 Óbitos Gerais, segundo as Principais Causas de Morte -

Estado de São Paulo - 1971-99

Gráfico 10 Coeficientes de Mortalidade da População Masculina, segundo

Principais Causas - Estado de São Paulo - 1971-99

Gráfico 11 Coeficientes de Mortalidade da População Feminina, segundo

Principais Causas - Estado de São Paulo - 1971-99

Gráfico 12 Coeficientes de Mortalidade por Causas Externas, segundo Sexo - Estado de São Paulo - 1970-2000

Gráfico 13 Coeficientes de Mortalidade por Causas Externas, segundo Tipos - Estado de São Paulo - 1969-99

Gráfico 14 Coeficientes de Mortalidade por Causas Externas, por Tipos, segundo Sexo - Estado de São Paulo - 1969-99

Gráfico 15 Coeficientes de Mortalidade por Homicídios, segundo Sexo e Grupos de Idade - Estado de São Paulo - 1971-1999

Gráfico 16 Coeficientes de Mortalidade por Acidentes de Veículos a

Motor, segundo Sexo e Grupos de Idade - Estado de São

Paulo - 1971-1999

Gráfico 17 Coeficientes de Mortalidade por Demais Acidentes, segundo

Sexo e Grupos de Idade - Estado de São Paulo -1971-1999

Gráfico 18 Coeficientes de Mortalidade por Suicídios, segundo Sexo e

Grupos de Idade - Estado de São Paulo - 1971-1999

Gráfico 19 Coeficientes de Mortalidade por Causas Externas, segundo

Sexo e Grupos de Idade - Estado de São Paulo -1971-1999

Gráfico 20 Coeficientes de Mortalidade da População Masculina por

Causas Externas, segundo Tipos e Grupos de Idade - Estado de São Paulo - 1971-1999 
Gráfico 21 Coeficientes de Mortalidade da População Feminina por

Causas Externas, segundo Tipos e Grupos de Idade - Estado de São Paulo - 1971-1999

Gráfico 22 Comparação entre as Probabilidades de Morte Observadas $\left(q_{x}\right)$

e Liquida $\left(q_{x o}\right)$ Eliminando-se os Grupos de Causas como Fator

de Risco de Morte, por Sexo - Estado de São Paulo - 1998-99

Gráfico 23 Coeficientes de Mortalidade por Homicídios - Regiões

Administrativas do Estado de São Paulo - 1980-99

Gráfico 24 Coeficiente de Mortalidade por Acidentes de Transporte -

Regiōes Administrativas do Estado de São Paulo - 1980-99

Gráfico 25 Coeficientes de Mortalidade por Suicidios-Regiões

Administrativas do Estado de São Paulo - 1980-1999

Administrativas do Estado de São Paulo - 1980-95

Gráfico 27 Coeficientes de Mortalidade por Causas Externas - Regiōes

Administrativas do Estado de São Paulo - 1980-99

Gráfico 28 Probabilidades de Morte Observadas $\left(q_{x}\right)$ e Líquida $\left(q_{x 0}\right)$

Eliminando-se os Grupos de Causas Externas como Fator de Risco de Morte, da População Masculina, segundo a Idade Região Metropolitana de São Paulo, Bauru, Campinas e Franca - 1998-99

Gráfico 29 Probabilidades de Morte Observadas $\left(q_{x}\right)$ e Líquida $\left(q_{x o}\right)$

Eliminando-se os Grupos de Causas Externas como Fator de Risco de Morte, da População Feminina, segundo a Idade Região Metropolitana de São Paulo, Bauru, Campinas e Franca - 1998-99

Gráfico 30 Probabilidades de Morte Observadas $\left(q_{x}\right)$ e Líquida ( $q_{x o}$ )

Eliminando-se as Causas Externas como Fator de Risco de Morte, da População Masculina, segundo a Idade - Região Metropolitana de São Paulo, Bauru, Campinas e Franca - 19981999

Gráfico 31 Probabilidades de Morte Observadas $\left(q_{x}\right)$ e Líquida $\left(q_{x o}\right)$

Eliminando-se as Causas Externas como Fator de Risco de Morte, da População Feminina, segundo a Idade - Região Metropolitana de São Paulo, Bauru, Campinas e Franca - 19981999

Gráfico 32 Coeficientes de Mortalidade por Homicídios segundo Sexo e Grupos de Idade de Paises Selecionados - 1992-98

Gráfico 33 Coeficientes de Mortalidade por Acidentes de Veículo a Motor segundo Sexo e Grupos de Idade de Paises Selecionados 1992-98

Gráfico 34 Coeficientes de Mortalidade por Suicídios segundo Sexo e Grupos de Idade de Paises Selecionados - 1992-98 


\section{RELAÇÃO DE MAPAS}

Mapa 1 Regiōes Administrativas e de Governo 90

Mapa 2 Coeficientes da Mortalidade por Homicidios - Regiões de Governo do Estado de São Paulo - 1980-1999

Mapa 3 Coeficientes de Mortalidade por Homicídios - Municípios do Estado de São Paulo - 1980-1999

Mapa 4 Coeficientes de Mortalidade por Acidentes de Transporte Regiões de Governo do Estado de São Paulo - 1980-1999

Mapa 5 Coeficientes de Mortalidade por Acidentes de Transporte Municípios do Estado de São Paulo - 1980-1999

Mapa 6 Coeficientes de Mortalidade por Suicídios - Regiões de Governo do Estado de São Paulo - 1980-1999

Mapa 7 Coeficientes de Mortalidade por Suicídios - Municípios do Estado de São Paulo - 1980-1999

Mapa 8 Coeficientes de Mortalidade por Causas Externas Municípios do Estado de São Paulo - 1980-1999 


\section{RELAÇĀO DE TABELAS DO ANEXO}

Tabela 1 Óbitos segundo as Principais Causas - Capitais Brasileiras - 193075

Tabela 2 Óbitos segundo as Principais Causas - Brasil - 1977-98

Tabela 3 Óbitos segundo as Principais Causas da População Masculina Brasil -1977-98

Tabela 4 Coeficientes de Mortalidade por Causas Externas, segundo Sexo Brasil -1977-98

Tabela 5 Coeficientes de Mortalidade por Causas Externas, segundo Tipos Brasil 1979-98

Tabela 6 Distribuição dos Óbitos por Causas de Morte, segundo Tipos Brasil - 1979-98

Tabela 7 Coeficientes de Mortalidade por Causas Externas por Sexo, segundo Tipos - Brasil - 1979-98

Tabela 8 Coeficientes de Mortalidade por Causas Externas, segundo Sexo e Grupos de Idade - Brasil - 1979-98

Tabela 9 Óbitos Gerais, segundo as Principais Causas de Morte - Estado de São Paulo - 1971-99

Tabela 10 Coeficientes de Mortalidade da População Masculina, segundo Principais Causas - Estado de São Paulo - 1971-99

Tabela 11 Coeficientes de Mortalidade da População Feminina, segundo

Principais Causas - Estado de São Paulo - 1971-99

Tabela 12 Coeficientes de Mortalidade por Causas Externas, segundo Sexo Estado de São Paulo - 1970-2000

Tabela 13 Coeficientes de Mortalidade por Causas Externas, segundo Tipos Estado de São Paulo - 1969-99

Tabela 14 Coeficientes de Mortalidade por Causas Externas, por Tipos, segundo Sexo - Estado de São Paulo - 1969-99

Tabela 15 Coeficientes de Mortalidade por Homicídios, segundo Sexo e Grupos de Idade - Estado de São Paulo - 1971-1999

Tabela 16 Coeficientes de Mortalidade por Acidentes de Veículos a Motor, segundo Sexo e Grupos de Idade - Estado de São Paulo - 197199

Tabela 17 Coeficientes de Mortalidade por Demais Acidentes, segundo Sexo e Grupos de Idade - Estado de São Paulo -1971-1999

Tabela 18 Coeficientes de Mortalidade por Suicídios, segundo Sexo e Grupos de Idade - Estado de São Paulo - 1971-1999

Tabela 19 Coeficientes de Mortalidade por Causas Externas, segundo Sexo e Grupos de Idade - Estado de São Paulo -1971-1999

Tabela 20 Coeficientes de Mortalidade da População Masculina por Causas Externas, segundo Tipos e Grupos de Idade - Estado de São Paulo . 1971-1999 
Tabeia 21 Coeficientes de Mortalidade da População Feminina por Causas

Externas, segundo Tipos e Grupos de Idade - Estado de São Paulo 1971-1999

Tabela 22 Comparação entre as Probabilidades de Morte Observadas $\left(q_{x}\right)$ e Líquida $\left(q_{\mathrm{xo}}\right)$ Eliminando-se os Grupos de Causas como Fator de Risco de Morte, por Sexo - Estado de São Paulo - 1998-99

Tabela 23 Coeficientes de Mortalidade por Homicídios - Regiões

Administrativas do Estado de São Paulo - 1980-99

Tabela 24 Coeficientes de Mortalidade por Acidentes de Transporte-Regiões

Administrativas do Estado de São Paulo - 1980-99

Tabela 25 Coeficientes de Mortalidade por Suicidios - Regiões Administrativas do Estado de São Paulo - 1980-1999

Tabela 26 Coeficientes de Mortalidade por Demais Acidentes - Regiões

Administrativas do Estado de São Paulo - 1980-95

Tabela 27 Coeficiente de Mortalidade por Causas Externas - Regiões

Administrativas do Estado de São Paulo - 1980-99

Tabela 28 Probabilidades de Morte Observadas $\left(q_{x}\right)$ e Líquida $\left(q_{x o}\right)$ Eliminando-

se os Grupos de Causas Externas como Fator de Risco de Morte, da População Masculina, segundo a Idade - Região Metropolitana de São Paulo, Bauru, Campinas e Franca - 1998-99

Tabela 29 Probabilidades de Morte Observadas $\left(q_{x}\right)$ e Liquida $\left(q_{x o}\right)$ Eliminandose os Grupos de Causas Externas como Fator de Risco de Morte, da População Feminina, segundo a Idade - Região Metropolitana de São Paulo, Bauru, Campinas e Franca - 1998-99

Tabela 30 Probabilidades de Morte Observadas (qx) e Líquida (qxo)

Eliminando-se as Causas Externas como Fator de Risco de Morte, da População Masculina, segundo a Idade - Região Metropolitana de São Paulo, Bauru, Campinas e Franca - 1998-99

Tabela 31 Probabilidades de Morte Observadas (qx) e Líquida (qxo)

Eliminando-se as Causas Externas como Fator de Risco de Morte, da População Feminina, segundo a Idade - Região Metropolitana de São Paulo, Bauru, Campinas e Franca - 1998-99

Tabela 32 Coeficientes de Mortalidade por Homicídios segundo Sexo e Grupos de Idade de Países Selecionados e Estado de São Paulo 1992-98

Tabela 33 Coeficientes de Mortalidade por Acidentes de Veículos a Motor segundo Sexo e Grupos de Idade de Países Selecionados - 1992. 98

Tabela 34 Coeficientes de Mortalidade por Suicídios segundo Sexo e Grupos de Idade de Países Selecionados - 1992-98 
INTRODUÇÃO 


\section{As causas externas no mundo e no Brasil}

Os homicídios, os suicídios e os acidentes de diferentes tipos, que constituem o grupo das causas externas de morte, têm sido responsáveis por significativo número de óbitos em muitas regiōes do mundo. Tanto nas áreas mais desenvolvidas como nas que se encontram em desenvolvimento, estas causas ocorrem em maior ou menor grau e aparecem, atualmente, entre as principais causas de morte em muitos paises.

Ainda que a violência seja uma das maiores preocupações dos dias atuais, existem relatos e informações que mostram a sua presença em todos os períodos e nas mais diferentes civilizações, embora possam haver exageros ou imprecisões sobre suas conseqüências e estimativas do número de vítimas.

MELLO JORGE (1980) ressalta que no livro do Gênesis, um dos mais antigos documentos existentes, é mencionado o primeiro caso de homicídio da história, que foi aquele cometido por Caim contra seu irmão Abel. Este é apenas um entre os vários casos de violência encontrados nos livros que compõem a Bíblia. Muitos outros são narrados entre os diversos povos, desde os mais antigos, como egípcios, persas, hebreus, gregos, romanos, passando depois pelos hunos, visigodos, bizantinos, vikings, otomanos, chineses, saxões e normandos até chegar aos dias atuais. Na conquista de continentes, como a América e a Oceania, ou na dominação da África e da Ásia, encontram-se exemplos de extrema violência, que levaram muitos povos à escravidão ou mesmo à extinção.

Além das guerras entre os diferentes povos e países, a violência interna e aquela resultante das tragédias naturais, como os terremotos, as erupções vulcânicas, os incêndios $e$ as inundaçōes, também tiveram e ainda têm grande impacto sobre a humanidade. Entre estas destacam-se, especialmente, as provocadas por terremotos, que se caracterizam não apenas pelo elevado número de mortes, mas também pelas suas conseqüências, como por exemplo, aquele ocorrido em 1201, no Oriente Médio (Egito e Síria), onde morreram cerca de 1,1 
milhão de pessoas, e o de 1556, em Shaan-si, na China, com cerca de 830 mil vítimas (TERREMOTOS HISTÓRICOS 2000). Estes são os casos mais graves, pois muitos outros causaram elevado número de mortos e continuam freqüentes até os dias atuais. Além das perdas humanas, geralmente as tragédias naturais provocam inúmeros outros problemas, tais como epidemias, fome e destruição das habitaçōes, das plantações e dos equipamentos existentes. No passado, estes acontecimentos adquiriam proporções ainda mais dramáticas devido as péssimas condições de higiene e de saúde.

Em relação à criminalidade dentro das próprias fronteiras e nas áreas conquistadas, os governantes procuravam combatê-la aplicando pesadas penalidades tanto àqueles que cometiam assassinato, roubo, adultério e estupro quanto aos que desrespeitassem suas autoridades. Ainda que essas medidas pudessem inibir, em parte, tais delitos, por muito tempo as cidades foram consideradas áreas altamente inseguras. "Nas grandes cidades do mundo, desde a Roma antiga até a Tóquio moderna, a sociedade respeitável sempre existiu lado a lado com sua imagem em negativo: o submundo sombrio dos criminosos e revoltados que exploram a comunidade ao redor." (TIME-LIFE, 1993:57)

Além da preocupação com a violência, somavam-se aquelas relacionadas às doenças e à fome. As precárias condições de saúde, de trabalho, nutrição, higiene, saneamento, habitação, além do desconhecimento da etiologia das doenças, fazia com que estas proliferassem largamente, gerando taxas de mortalidade extremamente elevadas e agravadas nos períodos de tragédias naturais, guerras ou epidemias. Entre estas últimas, destaca-se a de peste bubônica, denominada Peste Negra, que atingiu a Europa entre 1.347 e 1.352 e devastou o continente. A população européia, estimada em 48 milhões de pessoas no ano 1.000 , chegou a 75 milhões em 1.347, mas, cinco anos depois, reduziu-se para cerca de 50 milhões, devido à morte de aproximadamente 25 milhões de pessoas, ou seja, um terço do total (THE BLACK DEATH: BUBONIC PLAGUE 1994) 
Os períodos de fome também foram comuns. Um dos episódios mais conhecidos foi o que ocorreu na Irlanda, já em meados do século XIX, resultante da praga que atingiu as plantações de batatas. Morreram cerca de um milhão de pessoas e 2 milhões migraram para outros países, especialmente os Estados Unidos, reduzindo a população irlandesa à metade (IRISH HOLOCAUST 2000)

Observa-se, em grande parte da história, que as taxas de mortalidade mantiveram-se extremamente altas e a esperança de vida ao nascer raramente ultrapassava os 35 anos, uma vez que as condições de saúde eram muito precárias, além de estarem constantemente expostas aos riscos das guerras, da violência e da fome (DURAND 1977).

À medida que as condiçōes de saúde melhoraram, muitas doenças foram desaparecendo ou tornando-se menos importantes, possibilitando a redução das taxas de mortalidade. Com isso, outras causas passaram a representar maiores percentuais em relação ao total de óbitos e a merecer maior atenção, sendo estes os casos das doenças do aparelho circulatório, das neoplasias e também das causas externas.

Em relação a este último grupo, ressalta-se que algumas das causas que o compõem, como os homicídios, os suicidios e determinados tipos de acidentes, acontecem desde o início da humanidade, enquanto outras, como os acidentes de veículos a motor e de aviões, as guerras, os acidentes nucleares e aqueles provocados por determinados equipamentos, máquinas ou substâncias tóxicas, passam a ocorrer posteriormente e estão muito associadas ao desenvolvimento tecnológico, que se dá principalmente a partir do final do século XIX. O poder de destruição e, consequentemente, o número de vítimas nos conflitos também tornam-se muito maiores, especialmente no século $X X$, quando o desenvolvimento atinge seu auge. Devido a tais fatos, alguns pesquisadores, como GLOVER (2000), por exemplo, consideram esse o século mais violento da história. "A barbárie de modo algum foi exclusividade dos últimos cem anos, mas ainda é verdade que a maior parte do século 20 foi uma surpresa desagradável. Este foi o século de Passchendaele, Dresden, Nanquim, Nagasaki e Ruanda; da solução final, do gulag, do grande salto para a frente, do ano zero e da limpeza étnica, 
palavras que representam matanças de milhares ou milhões de pessoas e um sofrimento incompreensível. O progresso tecnológico que inspirou otimismo dos vitorianos também representou a multiplicação dos efeitos da maldade à moda antiga e da criminalidade imbecil." (GLOVER, 2000:1).

Estima-se que somente nos conflitos desse século morreram cerca de 100 milhões de pessoas, passando para 155 milhões quando se incluem as mortes provocadas pela fome e pelas doenças relacionadas a eles. Somente as duas Grandes Guerras Mundiais fizeram cerca de 65 milhões de vítimas entre civis e militares, sendo 15 milhões, na Primeira, e 50 milhões, na Segunda.

Vários países, entre os quais o Congo, o Camboja, a Polônia e a África do Sul perderam pelo menos $20 \%$ de suas populações em cada conflito em que estiveram envolvidos neste século. Em outros, como a antiga União Soviética, Alemanha, Turquia, Romênia e Líbano, as proporções foram entre 10 e $20 \%$ (30 WORST ATROCITIES OF THE $20^{\text {th }}$ CENTURY 2000).

Segundo as Nações Unidas, as guerras e as demais causas externas, causaram 5,75 milhōes de mortes em todo o mundo, somente em 1997, o que corresponde a cerca de $11 \%$ do total dos óbitos ocorridos. Isto as colocavam como a quarta principal causa de morte, superadas apenas pelas doenças do aparelho circulatório, pelas neoplasias e pelas doenças infecciosas e parasitárias. Em determinadas áreas, no entanto, estas causas já aparecem como a segunda mais importante, especialmente quando se considera a população masculina (NAÇÕES UNIDAS 1999).

Quanto à situação nas várias partes do mundo, informações disponiveis para 1990 apontam que as causas externas já apareciam como a segunda mais importante na América Latina e na região denominada como África Sub-Saariana, com $17,7 \%$ e $16,6 \%$, respectivamente, do total dos óbitos. Nesta última região, as doenças infecciosas e parasitárias eram a principal causa de morte com cerca de $40 \%$ do total, enquanto na América Latina as doenças cardiovasculares estavam em primeiro lugar, com $24 \%$. Nos paises mais desenvolvidos, as causas violentas representavam $8 \%$ do total de óbitos, ficando na terceira posição, após as doenças cardiovasculares, com cerca de $41 \%$ do total, e as neoplasias, com $27 \%$. 
Nas demais áreas consideradas pelas Nações Unidas, o percentual das causas externas situava-se entre $9,4 \%$ para a Índia, e $15 \%$ para os ex-paises socialistas.

Diferenças significativas também são registradas quando se desagrega o grupo das causas violentas: na África Sub-Saariana, as guerras eram a principal delas e a sétima entre todas as causas de morte. Na América Latina, os acidentes de veículos e os homicídios estavam muito próximos, ocupando a quinta e a sexta posições entre as principais causas. Nos antigos países socialistas e naqueles desenvolvidos, os óbitos por acidentes de veículos constituiam as principais causas violentas, aparecendo, respectivamente, na sexta e na nona posiçōes das causas de morte. Os suicídios eram a quinta principal causa de morte, na China, e a sexta, nos então paises socialistas (NAÇÕES UNIDAS 1999).

É provável que esta situação tenha se alterado de forma significativa desde 1990 em várias dessas áreas, inclusive no que refere-se às causas externas.

Especificamente em relação aos conflitos, destaca-se que somente na última década, houve pelo menos vinte guerras ou disputas em diversas partes do mundo, provocadas por motivos políticos, étnicos ou religiosos. Entre estes, ressaltam-se os ocorridos ou ainda existentes na Indonésia, Sudão, Congo (exZaire), Irlanda do Norte, Afeganistão, Iraque, Rússia, Turquia, lugoslávia, Ruanda, entre outros. Somente nos recentes conflitos do Congo teriam morrido cerca de um milhão de pessoas, número semelhante ao registrado em Ruanda, em 1994, que envolveu hutus e tutsis. Além do significativo número de mortos, estas guerras geralmente provocam grande quantidade de refugiados, especialmente nos paises mais próximos. As Nações Unidas estimam que mais de 22 milhões de pessoas estariam em tais condiçōes, espalhadas por várias partes do mundo, sendo a situação do Afeganistão a mais grave. Antes dos recentes conflitos já havia cerca de 3 milhões de refugiados desse país, alojados principalmente no Paquistão e no Irã (NAÇǑES UNIDAS 1999).

Observa-se, portanto, que as causas externas têm surgido de forma importante na história do mundo e por isso, provavelmente, o século $\mathrm{XX}$ aparece, em termos absolutos, como o de maior número de vítimas. Em termos relativos, 
porém, torna-se difícil apontar qual teria sido esse periodo, uma vez que a violência sempre esteve presente no cotidiano da humanidade. Considerando-se os últimos 6.000 anos de história, estima-se que apenas umas poucas centenas foram de paz contínua na Terra (GLOVER 2000).

Em relação ao Brasil, não se registra grande envolvimento em conflitos externos no último século, mas, a exemplo do que se observa em muitos outros paises, as causas externas têm aparecido com grande importância, especialmente em décadas mais recentes, provocando cerca de 120 mil mortes a cada ano.

Estes fatos fazem com que as causas externas já se constituam na segunda causa de morte mais importante, havendo grande preocupação com o crescimento da violência no país, que aparece com mais ênfase a partir dos anos 80. Isto se reflete também nos estudos realizados, como mostra, por exemplo, o da FUNDAÇÃO OSWALDO CRUZ (1985), um dos primeiros a tratar desse tema, para o país "Nos últimos anos, no Brasil a violência vem desempenhando um papel cada vez mais importante como fator de mortalidade. A nossa taxa de mortalidade por homicídios é uma das mais altas do mundo. (..) De 1979 a 1980 , o coeficiente de mortalidade por causas externas passou de 56,4 para 59,0 (por 100.000 habitantes) mostrando um aumento relativo de 4,6\%. Para o mesmo período, as doenças cardiovasculares e as neoplasias cresceram $3 \%$, enquanto as doenças infecciosas e parasitárias mostraram declínio de $7 \%$. Estes dados revelam a importância crescente que os acidentes e a violência vêm ocupando como causa de mortalidade no País." (FUNDAÇÃO OSWALDO CRUZ, 1985:1).

Pesquisa do Instituto Gallup, realizada em 1985 em 21 paises, mostrou que, no Brasil, um terço da população havia sido assaltada no período de 1979 a 1984 e $21 \%$ um ano antes. Estes valores eram inferiores apenas aos observados na Colômbia, onde os percentuais eram de, respectivamente, $49 \%$ e $33 \%$. Os menores valores correspondiam ao Japão, com cerca de $6 \%$ e $2 \%$.

Verifica-se, ainda para o Brasil, que os percentuais destacados tinham associação positiva com o tamanho das cidades, ou seja, aumentavam nas de maior população. Nos cinco anos anteriores à pesquisa, $46 \%$ das pessoas residentes nas capitais haviam sido assaltadas, enquanto nas cidades com mais 
de 50 mil habitantes o percentual era de $35 \%$. Nas localidades com 10 a 50 mil habitantes, este valor diminuía para $24 \%$ e, nas de menos de 10 mil habitantes, para $19 \%$.

Observava-se que a criminalidade crescia no pais, embora os efetivos policias de 1984 fossem duas vezes maiores que o de 1937. Em 1984 havia um policial para 485 habitantes, enquanto em 1937 esse número era de um para 820 habitantes. Entre as cidades analisadas, constatou-se que na década de 70 , o número de homicídios não registrou aumento significativo em Belo Horizonte, enquanto o de roubos disparou. Já em São Paulo, a violência ganhou contornos mais agudos, aproximando-se dos niveis observados no Rio de Janeiro (RETRATOS DO BRASIL 1985).

Segundo COELHO (1988), a explicação para o aumento da criminalidade e, especificamente, o número de homicídios, no início da década de 80 , encontravase na "atividade organizada no conflito entre quadrilhas que fazem o tráfico de entorpecentes e na atividade clandestina dos 'esquadrões da morte' e das 'polícias mineiras', enquanto antes estariam mais associados à natureza passional. Assim não haviam mudado apenas os padrões do crime, mas principalmente as taxas de criminalidade que teriam aumentado consideravelmente nesse periodo. Para o autor, "A segurança passou ao primeiro plano na agenda das demandas das populaçōes metropolitanas, tanto mais que a percepção generalizada é de que a situação vem-se agravando rapidamente" (COELHO,1988:145).

As informações relativas à criminalidade para as duas principais Regiões Metropolitanas do país - Rio de Janeiro e São Paulo - indicavam a alta ocorrência de roubos, latrocínios, lesões corporais, estupros, homicídios e tentativas de homicidios, alguns dos quais vinham aumentando de forma significativa, especialmente a partir de 1983. Entre estes, Coelho destaca o crescimento das taxas de mortalidade por homicídios na Região Metropolitana do Rio de Janeiro, o qual define como "espetacular", com o coeficiente passando de 18 óbitos por 100 mil habitantes, em 1977, para 50 por 100 mil, em 1986. Em São Paulo, a situação 
era muito semelhante, com o Índice de Criminalidade ${ }^{1}$ aumentando em ritmo mais acelerado que no Rio de Janeiro e o número de homicídios crescendo muito a partir de 1982

Ao analisar o comportamento da mortalidade no país também para a década de 80, SOUZA (1993) destaca alguns aspectos semelhantes aos apresentados por COELHO em relação ao aumento da criminalidade. Além da deterioração das condições sociais e econômicas nesse período, os crimes denominados de "colarinho branco" tornavam-se mais visiveis, enquanto os outros passam a apresentar maior organização em torno do narcotráfico e do narcoterrorismo. A violência no trânsito também atingia níveis muito elevados, levando à "intensificação das mortes por causas externas de lesões e envenenamentos ou simplesmente causas violentas" que passam do quarto para - segundo lugar na mortalidade geral, ficando em 1989 abaixo apenas das doenças do aparelho circulatório. (...) O perfil da mortalidade por violência no Brasil dos anos 80 esteve basicamente composto pela violência no trânsito e pelos homicídios. Estes últimos foram os grandes vilōes e principais responsáveis pelo maior impacto da violência na mortalidade da população brasileira." Outra importante característica dessa mortalidade era que quase $90 \%$ das vítimas de homicídios ocorridos no pais, entre 1980 e 1988, correspondiam a pessoas do sexo masculino, cujas taxas de mortalidade haviam passado de 21,2 para 31,3 por 100 mil habitantes nesse período, sendo que as maiores taxas concentravam-se nos grupos de 20 a 29 anos e de 30 a 39 anos (SOUZA, 1994:45).

Outros resultados importantes referem-se à evolução da mortalidade nas capitais das regiöes metropolitanas, no periodo de 1980 a 1989 . Entre as nove capitais somente Belém e Fortaleza apresentaram diminuição dos coeficientes de mortalidade por causas externas, enquanto nas demais registrou-se crescimento: $59 \%$ em Recife; $41 \%$ em São Paulo; $36 \%$ em Porto Alegre; $28 \%$ no Rio de Janeiro; $22 \%$ em Salvador; $14 \%$ em Curitiba e $8 \%$ em Belo Horizonte. Em Recife e

\footnotetext{
' $O$ Índice de Criminalidade Violenta foi defínido como a soma dos homicídios, tentativas de homicídios, lesões corporais dolosas, roubos, estupros e latrocínios em relação a 100 mil habitantes.
} 
no Rio de Janeiro, o coeficiente de mortalidade, em 1989, ultrapassou a 100 óbitos por 100 mil habitantes e, em São Paulo, chegou próximo, com 98 óbitos por 100 mil. Em Porto Alegre, Curitiba e Salvador, este coeficiente situava-se entre 78 e 87 por 100 mil, enquanto Belém registrava o menor valor com 55 óbitos por 100 mil, vindo depois Fortaleza e Belo Horizonte com, respectivamente, 59 e 69 óbitos por 100 mil habitantes.

Além de a mortalidade por causas violentas ter aumentado no país, o fenômeno não estava restrito às maiores capitais como São Paulo e Rio de Janeiro. Em Porto Alegre, Salvador, Curitiba e, principalmente, em Recife, registravam-se altos coeficientes de mortalidade.

Em outro estudo, que incluiu Goiânia ao grupo dessas cidades, MINAYO e SOUZA (1993) verificaram que, em todas elas, as causas externas apareciam entre as quatro principais causas de morte. Em Goiânia, estas causas eram responsáveis por quase $18 \%$ dos óbitos. Ao analisarem mais detalhadamente a situação dos municipios da Região Metropolitana do Rio de Janeiro, os autores verificaram que os coeficientes de mortalidade para o total das causas externas eram superiores na capital, mas, nos municípios periféricos, os coeficientes por homicídios eram maiores (MINAYO e SOUZA, 1993:74).

Em relação aos fatos apresentados, os autores também destacam que 0 crescimento da violência no país, na década de 80 , apresenta-se "como fenômeno cujas facetas são objeto de apreensão do cotidiano, pelo desencadeamento de temor generalizado aos assaltos, seqüestros e assassinatos. Ela também passa a ser objeto de reflexão por parte de várias áreas do saber, entre elas a Saúde Pública, pelo papel que assume diante da morbi-mortalidade, vitimizando crianças, jovens, adultos e idosos indiscriminadamente. As formas específicas de violência estão presentes, em maior ou menor intensidade, em todas as regiões do pais e nos diversos grupos sociais. Perpassam as várias fases da vida e se instauram nas mais variadas relaçōes humanas. Juntos, os diversos tipos de violência, constituem uma rede intrinseca e complexa, na qual todos (cada um a seu modo) são vítimas e autores a um só tempo" (MINAYO e SOUZA, 1993:65). 
A importância que o estudo da violência no campo da saúde adquiriu nesse período fica evidente em levantamento bibliográfico realizado por MINAYO em 1990. Entre os quase 400 textos recolhidos, 83 correspondiam à área de epidemiologia e destes, apenas $3 \%$ eram anteriores a $1969,11 \%$ dos anos 70 e $86 \%$ da década de 80 , "quando então a produção cresce em número, abrangência, inclusão de disciplinas e complexidade nas abordagens. Se fizermos uma observação bem geral sobre o material, diriamos que toda a literatura aqui comentada sobre a violência no Brasil hoje, reunida e sintetizada, corresponde a uma ampla reflexão e cobre os mais diferentes ramos do conhecimento: medicina, saúde pública, psicanálise, psicologia, psiquiatria, sociologia, economia, jornalismo, ecologia, ciência política, filosofia, teologia, demografia e direito." O autor destaca, ainda, que o aumento observado na produção de textos que abordam esse tema ocorre também pelo aumento de consciência para os problemas, ressaltando que "acompanha o avanço de um processo social marcadamente preocupante no Brasil, em termos de violência do estado e de seus aparelhos repressivos, de violência das relações de produção e de propriedade no campo, da delinqüência nos grandes centros urbanos, afetando de forma muito particular a cotidianeidade dos cidadãos, pela perplexidade e pelo medo." (MINAYO, 1990:12).

Apesar do aumento expressivo de estudos que mostravam a situação da mortalidade por causas externas na década de 80 e as conseqüencias sobre a vida da população brasileira, não se registrou a implementação de medidas mais significativas que pudessem alterar o panorama vigente e também o dos anos seguintes.

Os estudos realizados nos anos 90 , bem como a observação das informações existentes, mostram que a violência continuou a aumentar no país, especialmente nas grandes regiões metropolitanas e nas áreas urbanas, onde concentrava-se cerca de $75 \%$ da população brasileira. Quando comparados a outros paises, observava-se que os niveis de mortalidade provocados pelas causas externas no Brasil encontravam-se em patamar intermediário, mas com grande presença de homicídios, o que agravava a situação da violência no país. 
O estudo de MELLO JORGE et alii (1997) destaca aspectos relacionados à evolução destas causas entre 1977 e 1994 e à qualidade das informações. Observava-se que, na primeira metade da década de 90 , os coeficientes de mortalidade por causas externas mantiveram-se constantes, mas elevados, aproximando-se de 70 óbitos por 100 mil habitantes. Entre as causas desse grupo, também não se verificavam alterações nos coeficientes de mortalidade nesse período. Em relação a estas causas, destaca-se que, desde 1990, os homicídios passaram a constituir a principal causa externa de morte do pais, com coeficientes próximos de 20 óbitos por cem mil habitantes, mantendo-se nesse patamar até 1994. Os acidentes de trânsito, que apareciam como a principal causa externa de morte em grande parte do período 1977-90, passaram para a segunda posição, com coeficientes de 18 a 20 óbitos por 100 mil, muito próximos do grupo dos "demais acidentes". Já os coeficientes de mortalidade por suicídios mantêm-se baixos e próximos de 3,5 por 100 mil nesse período.

Utilizando informaçōes referentes ao Registro Civil, ALBUQUERQUE E OLIVEIRA (1996) destacam a participação das causas externas no total de óbitos para várias áreas do Brasil, no período 1974-94, indicando que estas localidades "experimentaram um aumento generalizado". Nas Grandes Regiōes do país, ressalta-se a situação do Centro-Oeste e do Norte: na primeira, o percentual das causas externas passou de $15,8 \%$ para $19,5 \%$ entre a população masculina, enquanto na segunda aumentou de $11,6 \%$ para $16,9 \%$. Ao final do período considerado, o percentual chegou a $14 \%$, nas Regiões Sudeste e Sul, e a $12 \%$, no Nordeste. Para as mulheres também registraram-se aumentos importantes nesse período, porém, bem abaixo daqueles observados para os homens. Os maiores percentuais corresponderam mais uma vez, às Regiōes Centro-Oeste e Norte, com, respectivamente, $7,3 \%$ e $5,7 \%$ do total em 1994 . Nas demais os valores ficaram em torno de 4\% (ALBUQUERQUE e OLIVEIRA, 1996:87).

Entre as regiōes metropolitanas, os maiores percentuais desses óbitos, para a população masculina, em 1994, corresponderam a Salvador $(19,4 \%)$, seguida pela de São Paulo (17,2\%), do Rio de Janeiro (17\%) e de Curitiba com $(16,1 \%)$. Nas regiões de Belém, Recife, Fortaleza e Porto Alegre, o percentual 
aproximou-se de $15 \%$ e a de Belo Horizonte apresentou o menor valor, com $11,5 \%$. Entre as mulheres, o maior percentual foi registrado em Curitiba, com 5,7\% do total dos óbitos em 1994, seguida pela Região Metropolitana de Fortaleza $(4,9 \%)$. Nas demais, a exemplo do que ocorreu para o Brasil, o percentual ficou próximo de $4 \%$.

Entre as Unidades da Federação que são apresentadas, os maiores percentuais de mortes por causas externas para a população masculina, em 1994 , corresponderam a Rondônia, com $28,5 \%$ do total, seguindo-se o Distrito Federal (22\%), Rio de Janeiro (17,2\%) e São Paulo (14,5\%). Entre as mulheres, Rondônia e Distrito Federal ficaram mais uma vez à frente das demais, com $12,2 \%$ e $7,8 \%$, respectivamente, do total dos óbitos, vindo a seguir São Paulo (4,4\%), Amazonas $(4,3 \%)$ e Rio de Janeiro $(3,2 \%)$.

O estudo destaca ainda que o aumento da mortalidade por causas externas provocou grandes alterações nas taxas de mortalidade do Brasil, inclusive alterando seu padrão etário e que a simples suavização da curva de mortalidade masculina implicaria aumento de um ano em sua esperança de vida ao nascer (ALBUQUERQUE e OLIVEIRA, 1996:90).

Entre as capitais, Recife, Vitória, Cuiabá, São Paulo, Macapá e Rio de Janeiro foram destacadas, recentemente, como as de maiores coeficientes de mortalidade por assassinatos no país, mostrando assim que a situação vem tornando-se complexa em várias regiōes (LIRA e DRUMOND 2000).

Estudos referentes aos municípios do Estado de São Paulo também mostram que a criminalidade tem aumentado em várias áreas do interior especialmente naquelas situadas no entorno da Região Metropolitana de São Paulo. Segundo os critérios utilizados pelo INSTITUTO FERNANDO BRAUDEL (2000), os municípios de Praia Grande, Santos, Campinas, Ribeirão Preto e Jacareí apresentaram o maior índice de ocorrências policiais do Estado, entre 1995 e 1998, superando os municípios da Região Metropolitana de São Paulo, mesmo os que se encontravam nas primeiras posições, como Diadema e São Bernardo do Campo. 
Assim, ao terminar o século, observa-se que os coeficientes de mortalidade por causas violentas são elevados em todo o país, ressaltando como fato positivo apenas a redução dos óbitos por acidentes de veículos a motor após 1998 (VASCONCELOS E LIMA 1998).

Os coeficientes de mortalidade por causas externas do Brasil cerca de 75 óbitos por 100 mil habitantes em 1998 - e de várias áreas são considerados muito elevados quando comparados com outras partes do mundo. CHESNAIS (1999) os denomina como "atípicos", por superar os observados em áreas com problemas muito maiores

Diante dessa situação, tem sido elaboradas algumas políticas voltadas para a prevenção da violência, destacando-se, que a mais recente, prioriza quatro regiões consideradas mais críticas: São Paulo, Rio de Janeiro, Recife e Vitória, para as quais espera-se que as ações a serem empreendidas apresentem resultados mais significativos em um prazo de dois anos (ANTAR 2001 e MINISTÉRIO DA SAÚDE 2001).

Em termos mais gerais e considerando todas as informações apresentadas, percebe-se que, além das que envolvem as causas externas, outras modificações importantes vêm ocorrendo na mortalidade, indicando que o processo de transição epidemiológica ainda encontra-se em plena evolução. O pais mantém-se, porém, ainda em seu estágio intermediário, com a esperança de vida aproximando-se atualmente de 68 anos e as doenças do aparelho circulatório, as causas externas e as neoplasias constituindo-se nas principais causas de morte, responsáveis por cerca de $60 \%$ dos óbitos gerais. Por outro lado, as doenças vinculadas ao subdesenvolvimento, como a desnutrição, a diarréia, a malária, a tuberculose, a tripanossomíase e várias outras causas infecciosas e parasitárias, continuam a ter importância em determinadas regiões do país.

A comparação com indicadores de outros países mostra que as taxas de mortalidade ainda podem diminuir acentuadamente no Brasil, uma vez que várias causas seriam evitáveis com medidas adequadas. Entre estas, as externas podem contribuir para tal redução de forma significativa, pois, além de apresentarem altos 
coeficientes, concentram-se nas faixas jovens que resultam em elevado número de anos de vida perdidos.

Nesse sentido, a disponibilidade de informações e o conhecimento detalhado da mortalidade constituem subsídios importantes para a elaboração de políticas que permitam alterar esse panorama (RUZICKA 1990). Este é o caso que será apresentado a seguir referente ao Estado de São Paulo, onde a participação das causas externas e as taxas de mortalidade aparecem entre as mais elevadas do país. Este panorama pode ser observado por meio de vários indicadores, ressaltando-se a evolução dos coeficientes de mortalidade para o total das causas externas e também para os grupos de causas, como os homicídios, os suicídios e os acidentes. Em relação às áreas geográficas, apresenta-se não apenas o Estado, mas também as suas regiões Administrativas e de Governo - e eventualmente os municípios. Em termos de abrangência temporal, será dada maior ênfase à evolução observada nas duas últimas décadas.

Porém, antes de serem apresentados esses resultados, mostra-se um breve panorama da evolução das causas externas para o Brasil, uma vez que, em muitos dos estudos feitos para o pais, inclui-se o Estado de São Paulo. Geralmente isso ocorre por meio da capital ou da região metropolitana, pois as áreas do interior ainda têm sido pouco estudadas.

Ao final, incluem-se também algumas considerações sobre a situação mundial, visando observar o comportamento das causas externas em alguns países, bem como servir de parâmetro para o que vem ocorrendo no Brasil e em suas áreas, principalmente no Estado de São Paulo. 
OBJETIVOS 


\section{Objetivo Geral}

O objetivo deste estudo é descrever a mortalidade por causas externas para o Estado de São Paulo e suas Regiões - Administrativas e de Governo -, especialmente no período 1980-99.

\section{Objetivos Especificos}

- Descrever a evolução da mortalidade por causas externas para o Estado de São Paulo.

- Descrever a evolução das causas externas segundo os principais grupos: homicídios, suicídios, acidentes de veículos a motor e outros acidentes, para as 15 Regiões Administrativas e as 42 Regiões de Governo do Estado de São Paulo.

- Estudar os coeficientes de mortalidade por causas externas nos municípios do Estado.

- Medir o impacto da mortalidade por tais causas sobre os indicadores demográficos das 15 Regiões Administrativas.

- Tecer considerações sobre a mortalidade das causas externas para o Brasil e o mundo.

- Comparar a situação do Estado de São Paulo e de suas 15 Regiões perante o panorama nacional e mundial. 
MATERIAL E MÉTODOS 


\section{Fonte dos Dados}

Os dados utilizados para o estudo da evolução da mortalidade para o Estado de São Paulo, suas regiões e municípios foram obtidos na Fundação Seade. As informações anteriores a 1980 estão disponiveis em publicações, microfichas e microfilmes e para os anos seguintes, encontram-se em sistemas informatizados, como os de Mortalidade por Causas e o de Mortalidade por Aids. O primeiro é subdividido em mortalidade geral e infantil, destacando as causas de morte segundo os Capítulos da Classificação Internacional de Doenças - CID, as principais causas e a de causas detalhadas (com três dígitos). Posteriormente, incluiu-se também a classificação segundo a Lista Brasileira de Mortalidade (CID$B R)$.

Os dados referentes ao Estado de São Paulo estão desagregados para as Regiōes Administrativas e de Governo, as Direções Regionais de Saúde (DIRs), os municípios e os distritos do Município de São Paulo. Atualmente o Estado de São Paulo possui 645 municípios e a capital tem 96 distritos.

Deve-se ressaltar que, em relação aos dados de mortalidade, as tabulações mais detalhadas correspondem ao total do Estado de São Paulo e à Capital, sendo que para os municípios geralmente limitam-se às principais causas de morte.

Além disso, no período em que este estudo dá maior ênfase, foram utilizadas duas revisões da Classificação Internacional de Doenças, a Nona Revisão (CID-9) e a Décima Revisão (CID-10), o que certamente traz alguns problemas de comparação entre os dados.

As tabulações mais agregadas classificam as causas externas em cinco grupos, segundo a CID-9, e em oito, para a CID-10.

Para a CID-9, estes agrupamentos são os seguintes:

-Acidentes de Veículos a Motor (E810-E819);

-Demais Acidentes (E800-E807, E820-E949);

-Suicídios e Lesões Auto-Infligidas (E950-E959); 
-Homicidios (E960-E969);

-Demais Causas Externas (E970-E978, E980-E999).

Com a utilização da CID-10, a partir de 1996, implementaram-se alteraçōes tanto na relação das causas como nas regras de classificação, além de novas propostas de tabulações. No caso das causas externas, os grupos são os seguintes:

-Acidentes de Transporte (V01-V99);

-Quedas (WOO-W19);

-Afogamentos e Submersão Acidentais (W65-W74);

-Exposição ao Fumo, ao Fogo e às Chamas (X00 -X09);

-Envenenamento, Intoxicação por ou Exposição a Substâncias Nocivas (X40-X49);

-Lesões Autoprovocadas Voluntariamente (X60 - X84);

-Agressões (X85-Y09);

-Todas as Outras Causas Externas (W20-W64, W75-W99, X10-X39, X50$\mathrm{X} 59, \mathrm{Y} 10-\mathrm{Y} 89$ ).

Assim, para utilizar uma série compatível de dados para estas causas e mantendo os grupos da CID-9, é necessário fazer alguns ajustamentos e até processamentos a partir da própria base.

Em relação aos suicídios e aos homicídios, não há maiores problemas em utilizar os próprios grupos, pois os totais são compatíveis com os da CID-10, ainda que nesta existam novas denominações: lesões autoprovocadas voluntariamente e agressões, respectivamente. Deve-se ressaltar que, nas informações utilizadas para o Estado de São Paulo, incluíram-se, entre os homicídios, os óbitos classificados em "Intervenções Legais e Operações de Guerra" cujos códigos são E970-E978 e E990-E999 para a CID-9 e Y35-Y36 para a CID-10. Já os acidentes de transporte eram um pouco mais abrangentes que os acidentes de veículos a motor, como pode ser observado nas tabulações da CID-BR, no período 1979-95. Cerca de $98 \%$ dos óbitos por acidentes de transporte corresponderam aos de veículos a motor, de forma que, utilizando o primeiro grupo para atualizar a série em anos posteriores a 1995, encontram-se diferenças em torno de $1 \%$ a $2 \%$. Para 
- periodo de 1996-99 optou-se por utilizar as informações de acidentes de transporte, uma vez que a obtenção de dados para os acidentes de veículos a motor seria muito complexa. Em relação ao grupo dos "demais acidentes", os problemas eram maiores, pois na nova classificação estes estavam divididos em vários grupos e, para compatibilizá-los com a CID-9, não bastava somá-los, porque parte destes acidentes foi classificada no item "todas as outras causas externas", que já não correspondiam ao grupo anterior denominado "demais causas externas". Assim, para que fosse possivel reconstituir o grupo dos demais acidentes, agregaram-se os totais excluindo-se aqueles referentes aos códigos Y10 a Y34 e de Y40 a Y89 (Quadro 1).

Quadro 1

Causas Externas segundo os grupos

CID-9 e CID-10

\begin{tabular}{|c|c|c|c|}
\hline \multicolumn{2}{|c|}{ CID-9 } & \multicolumn{2}{|l|}{ CID-10 } \\
\hline Causas & Códigos & Causas & Códigos \\
\hline $\begin{array}{l}\text { Acidentes de Veículos a } \\
\text { Motor }\end{array}$ & E810-E819 & Acidentes de Transporte & V01-V99 \\
\hline Demais Acidentes & $\begin{array}{l}\text { E800-E807, } \\
\text { E820-E949 }\end{array}$ & $\begin{array}{l}\text { Quedas } \\
\text { Afogamento e Submersão } \\
\text { Acidentais } \\
\text { Exposição ao Fumo, ao Fogo e a } \\
\text { Chamas } \\
\text { Envenenamento, Intoxicaçăo por ou } \\
\text { Exposição a Substâncias Nocivas } \\
\text { Demais Acidentes }\end{array}$ & $\begin{array}{l}W 00-W 19 \\
W 65-W 74 \\
x 00-x 09 \\
x 40-X 49 \\
\\
W 20-W 64 \\
W 75-W 99 \\
\times 10-\times 39 \\
x 50-x 59\end{array}$ \\
\hline $\begin{array}{l}\text { Suicídios e Lesōes Auto } \\
\text { Infligidas }\end{array}$ & E950-E959 & $\begin{array}{l}\text { Lesōes Autoprovocadas } \\
\text { Voluntariamente }\end{array}$ & $\times 60-\times 84$ \\
\hline Homicídios & $\begin{array}{l}\text { E960-E969, } \\
\text { E970-E978, } \\
\text { E990-E999 }\end{array}$ & Agressōes & $\begin{array}{l}X 85-Y 09 \\
Y 35-Y 36\end{array}$ \\
\hline Demais Causas Externas & E980-E989 & Todas as Outras Causas Externas & $\begin{array}{l}Y 10-Y 34 \\
Y 40-Y 89\end{array}$ \\
\hline
\end{tabular}

Fontes: CID-9 e CID-10.

Ainda que com pequenas diferenças, as séries utilizadas para o estudo das causas externas no período 1980-99 apresentam compatibilidade muito próxima, 
permitindo observar o seu comportamento para as diversas áreas do Estado de São Paulo e que serão utilizadas na análise estadual, regional e municipal.

As populações por sexo e idade para estas mesmas áreas foram estimadas pela Fundação Seade, com base nos Censos Demográficos e no Método dos Componentes, que leva em consideração o comportamento das variáveis demográficas (fecundidade, mortalidade e migração).

Foram considerados os seguintes grupos etários - menos de um ano; de 1 a 4 anos; 5 a 14 anos; 15 a 24 anos; 25 a 34 anos; 35 a 44 anos; 45 a 54 anos; 55 a 64 anos; 65 a 74 anos e 75 anos e mais, que é denominada "Classificação da OPS", no Sistema de Informações de Mortalidade do Ministério da Saúde. Esta divisão apresenta padrões de causas de morte mais homogêneos do que aquela de 10 a 19 anos, 20 a 29 anos, 30 a 39 anos e assim por diante, conforme constatado em estudo sobre a evolução da mortalidade para o Estado de São Paulo, na década de 80 (CAMARGO e MAIA 1994).

\section{Qualidade das Informações}

A cobertura dos dados de óbitos tem sido maior nas Regiões Sul e Sudeste do Brasil (VASCONCELOS 1996), sendo praticamente completa no Estado de São Paulo, já há várias décadas (ORTIZ 1983). Nos primeiros anos do século XX, as autoridades judiciais exigiam que os Oficiais de Cartórios de Registro Civil enviassem informações no prazo estabelecido, penalizando aqueles que não o fizessem inclusive com sua suspensão (RIBEIRO 1993).

Em relação à qualidade dos dados, observa-se que os percentuais de causas mal definidas mantêm-se em torno de $6 \%$ no Estado, situação que não é homogênea em suas regiões. Quanto às causas externas, destaca-se que o item relativo aos "eventos cuja intenção é indeterminada" apresentam valores em torno de 5\% para o Estado. Em determinados momentos, no entanto, como entre 1974 e 1976 e após 1999, observa-se aumento dos percentuais dessas causas para o Estado, que se aproximaram de $10 \%$. 
Os itens relativos aos acidentes de veículos a motor/de transportes e aos demais acidentes também apresentam aumentos ou reduções acentuados nesse período, o que se deve, em parte, à falta de melhores recursos de algumas unidades do Instituto Médico Legal para determinar com maior precisão as causas de morte. Em algumas áreas do oeste do Estado, a limitação de recursos faz com que os médicos do IML desloquem-se ao local do evento para atestar o óbito e, nesses casos, as condições permitem apenas classificar a causa como externa sem especificá-la. No entanto, o fato que tem comprometido e prejudicado em maior grau a classificação das causas externas refere-se às constantes alterações feitas nos modelos da Declaração de Óbito no Brasil. Quando os formulários disponiveis não prevêem a variável "tipo de acidente", as causas de morte, especialmente os acidentes, são classificados em itens mais abrangentes, em que não há especificação, ou naqueles denominados "demais causas externas". Assim, quando utilizaram-se modelos desse tipo, os dados relativos aos diferentes tipos de acidentes, tais como afogamentos, quedas, queimaduras e envenenamentos, aparecem muito comprometidos.

No caso das regiões de São Paulo, os dados referentes ao periodo 1998-99 não apresentam este tipo de problema, sendo que a classificação deficiente devese às falhas de preenchimento ou à impossibilidade de fazê-lo corretamente. Nesse periodo, para as 15 regiōes administrativas do Estado, os percentuais de causas externas sem identificação se a lesão havia sido intencional ou acidental ultrapassaram a $6 \%$ somente somente nas de Ribeirão Preto $(6,4 \%)$ e de São José dos Campos (8,7\%). Nas demais os valores situaram-se entre $2,3 \%$, na de Presidente Prudente, e 5,6\% na de Santos.

Em grande parte do periodo considerado no estudo, estes percentuais são relativamente baixos em todas as áreas do Estado. 


\section{Indicadores Utilizados}

Diversos indicadores podem descrever 0 comportamento da mortalidade em uma determinada área. Entre os considerados mais simples, destacam-se os coeficientes e as proporções, relacionando tanto a população total como a desagregada por categorias, como sexo, faixa etária, áreas geográficas, causas especificas ou agrupadas.

Quanto aos coeficientes, a relação é a seguinte:

$$
{ }_{n} M_{i}=\frac{{ }_{n} O_{i}}{{ }_{n} P_{i}}
$$

onde ${ }_{\mathrm{n}} \mathrm{O}_{\mathrm{i}}$ corresponde aos óbitos da categoria utilizada (sexo, causas, área) da idade $i, e{ }_{n} P_{i}$ compreende a população correspondente, com as mesmas caracteristicas destacadas.

No que se refere à proporção a relação é semelhante á anterior, tendo o total dos eventos no denominador, ou seja:

$$
{ }_{n} p_{x}=\frac{{ }_{n} O_{x}}{O}
$$

onde $\mathrm{O}$ é o total de eventos e ${ }_{n} \mathrm{O}_{i}$ constitui parte desse total, podendo corresponder a sexo, faixa etária e áreas, a exemplo do que se destacou para o coeficiente.

Os números absolutos, as proporções e os coeficientes de mortalidade, obtidos segundo sexo, faixa etária e causas de morte para diferentes momentos, embora sejam indicadores mais simples, constituem importante fonte de conhecimento, permitindo analisar sua tendência no decorrer do tempo e compará-la com outras áreas do país e do mundo. Sua principal vantagem reside 
justamente na simplicidade dos cálculos e na facilidade de compreensão, mas apresentam a desvantagem de não serem sintéticos, especialmente quando utilizam-se várias categorias, como os grupos etários, por exemplo, ou seja, não expressam o impacto da mortalidade em uma determinada área por meio de apenas um indicador.

Para que este procedimento fosse possivel, várias metodologias têm sido desenvolvidas, destacando-se a do Número de Anos Potenciais de Vida Perdidos, a dos Riscos Competitivos e também a que foi elaborada por Pollard.

A metodologia de Pollard tem sido muito utilizada para avaliar a contribuição das causas de morte sobre a esperança de vida ao nascer de determinada área e período de tempo. No caso de São Paulo destaca-se o estudo de YAZAKI (1990) onde avaliou-se esta situação para o Estado e suas regiões, para o período de 1975 a 1983.

A metodologia dos Riscos Competitivos também tem sido utilizada em vários estudos para avaliar os impactos de determinadas causas sobre os coeficientes de mortalidade. O instrumento para essa análise é a Tábua de Mortalidade de Múltiplo Decremento, sobre a qual ORTIZ (1998) faz as seguintes considerações :"Em termos competitivos, considera-se que um indivíduo qualquer durante sua vida está exposto ao risco de morrer por diversas causas, independente da causa que ocasionou sua morte. Nesse sentido, considera-se que houve uma certa "competição" entre os vários riscos. É importante, então, diferenciar os conceitos de risco e causa. Embora ambos são da mesma natureza, o termo risco refere-se ao fenômeno antes do óbito, a partir do qual se torna a causa. Através deste estudo pode-se determinar qual seria o efeito, na vida média da população, da eliminação e/ou redução da intensidade de uma determinada doença ou causa. Permite também conhecer a taxa de mortalidade devido a uma causa especifica, na presença de outras causas de morte" (ORTIZ, 1998:1790).

Nesse sentido, as Tábuas de Mortalidade disponiveis constituem importante fonte de conhecimento para este estudo, uma vez que seus indicadores são fundamentais para a observação do que tem ocorrido em determinada área. 
Entre os estudos que utilizaram esta metodologia, destaca-se, inicialmente, o de GOTLIEB (1977), em que é analisada a magnitude de alguns grupos de agravos à saúde (infecciosas, tumores malignos, incluindo neoplasias malignas do tecido linfático e dos órgãos hematopoéticos, doenças cardiovasculares), dos acidentes, dos envenenamentos e da violência, nas probabilidades de morte, de sobrevivência e nas esperanças de vida das pessoas residentes no município de São Paulo.

Os estudos de SANTOS, ORTIZ e YAZAKI (1985), para o Brasil, e de YAZAKI e ORTIZ (1985), para o Estado de São Paulo mostram a importância que os diversos grupos de causas tinham sobre a esperança de vida ao nascer e nos grupos etários na década de 80. CAMARANO et alii (1997) mostram o impacto das causas de morte sobre a esperança de vida aos dez anos e sobre a população economicamente ativa do país. BARBOSA e ANDRADE (1998) apresentam estudo para o Brasil e suas Regiōes, para 1991, e MAIA (1999) analisa quatro áreas do Município de São Paulo nos períodos 1979-81 e 1990-92. Em todos esses estudos, constata-se que os ganhos na esperança de vida seriam consideráveis se as causas externas fossem eliminadas de forma total ou até mesmo para algum de seus grupos de causas.

Com o aumento significativo dessas causas em várias regiões do Brasil e no Estado de São Paulo, torna-se muito importante avaliar seu impacto sobre os diversos grupos etários. Assim, utilizar-se-á a metodologia dos Riscos Competitivos para avaliar esta situação não apenas para o Estado de São Paulo, como também para as suas regiōes, nos períodos de 1980-81, 1990-91 e 199899.

Para que isso seja concretizado, o primeiro passo é dispor de tábuaspadrão que reflitam a situação real da mortalidade, ou seja, considerando todas as causas que ocorreram. Há dois tipos de tábuas que poderiam ser elaboradas para esta finalidade.

A primeira delas é a chamada Tábua de Mortalidade de Geração, que corresponde ao acompanhamento de uma certa coorte desde seu nascimento, observando as mudanças que ocorrem no decorrer do tempo, envolvendo não 
apenas as mortes, mas também as entradas e saídas de pessoas. Este procedimento é complexo, pois seria necessário acompanhar tal coorte por grande periodo de tempo, além de contar com informações de migração, o que é muito raro de ocorrer.

Para superar os obstáculos apresentados, utilizam-se, geralmente, as tábuas denominadas Abreviadas, elaboradas com informações de óbitos, de nascimentos $\mathrm{e}$ as populações correspondentes a certo período, resultando nas probabilidades de morte segundo os diversos grupos etários. O conjunto destas probabilidades reflete as condições de mortalidade a que uma população está exposta em determinado período.

Contando com as probabilidades de morte para os grupos etários, obtêm-se as Tábuas de Mortalidade Abreviadas, com as suas diversas funções. $O$ procedimento inicia-se com o cálculo dos coeficientes de mortalidade para os grupos etários, obtidos da seguinte forma:

$$
{ }_{n} M_{i}=\frac{{ }_{n} O_{i}}{{ }_{n} P_{i}}
$$

onde: ${ }_{n} \mathrm{O}_{i}$ é a média dos óbitos ocorridos em determinado período no grupo na idade $i$ e ${ }_{n} P_{i}$, corresponde à população média estimada para esse período no grupo de $x a x+n$ anos

A partir desses resultados, pode-se estimar a série de ${ }_{n} q_{x}$, que é a probabilidade de uma pessoa da idade $x$ a $x+n$ não sobreviver no periodo de $n$ anos. Para as pessoas acima de cinco anos, esta probabilidade é obtida por meio da equação:

$$
{ }_{n} q_{x}=\frac{2 \cdot n \cdot M_{i}}{2+n_{i} M_{i}}
$$


Para os menores de cinco anos, as probabilidades para o Estado de São Paulo serão obtidas relacionando diretamente os nascimentos e óbitos das idades individuais abaixo de 1 ano, 1, 2, 3, e 4 anos, utilizando-se os fatores de separação estimados para o Estado e cada região, por sexo (WALDVOGEL e CAPASSI 1994).

Dispondo das probabilidades de morte, as demais funções da tábua podem ser calculadas iniciando-se com $\circ I_{x}$ que é o número de pessoas sobreviventes às idades exatas $\mathrm{x} . \mathrm{O} \mathrm{I}_{\mathrm{x}}$ inicial, ou seja, o $\mathrm{l}_{0}$ denominado raiz da tábua, geralmente é colocado como sendo igual a $100 \mathrm{mil}$, embora pudesse ser utilizado qualquer valor. Para efeito de melhor visualização e entendimento, será utilizado esse valor de 100 mil nas tábuas a serem elaboradas.

Nas demais faixas etárias, os $I_{x+n}$ são obtidos utilizando:

$$
l_{x+n}=l_{x}-l_{x_{n}} q_{x}
$$

O número de mortos da tábua de mortalidade é obtido pela equação:

$$
{ }_{n} d_{x}=l_{x}-l_{x+n}
$$

O número de anos vividos entre $x$ e $x+n$ pelos sobreviventes de idade exata $x$ é definido como ${ }_{n} L_{x}$. Geralmente, utiliza-se uma relação aproximada para a obtenção desta função que é igual a:

$$
{ }_{n} L_{x}=n\left[f_{x} l_{x}+\left(1-f_{x}\right) l_{x+n}\right]
$$

onde $\mathrm{f}_{\mathrm{x}}$ é o fator de separação das mortes correspondentes à idade $\mathrm{x}$

A partir desses ${ }_{n} L_{x}$, podem ser obtidos os $T_{x}$, que correspondem ao total de anos de vida dos sobreviventes $I_{x}$, entre essa idade, e " $W$ " que corresponde à primeira idade em que já não existem sobreviventes, ou seja onde $\mathrm{I}_{\mathrm{x}} \dot{e}$ igual a zero. Os valores são calculados acumulando-se os números de anos vividos no intervalo $x$ a $x+n$ :

$$
T_{x}=\sum_{x}^{\infty}{ }_{n} L_{x}
$$


Finalmente, têm-se as esperanças de vida para as diferentes idades, definidas como $\left(e_{x}\right)$, que é o número médio de anos a serem vividos pelas pessoas na idade $x, x+n$. Esta compreende uma das funções de maior interesse prático da tábua de mortalidade e é estimada relacionando o número de anos de vida esperados $\left(T_{x}\right)$ com os sobreviventes até essa idade $\left(I_{x}\right)$, ou seja:

$$
e_{x}=\frac{T_{x}}{l_{x}}
$$

À medida que a idade aumenta, a esperança de vida decresce, com exceção da primeira idade $\left(e_{0}\right)$ devido à influência da mortalidade infantil. Assim, a esperança de vida observada no grupo seguinte $\left(e_{1}\right)$ é superior a $e_{0}$.

\section{A Tábua de Mortalidade de Múltiplo Decremento}

De posse da tábua de mortalidade que considera todas as causas, pode-se então obter a de múltiplo decremento, utilizando a técnica de Riscos Competitivos proposta por CHIANG (1968 e 1970), cujas considerações foram destacadas anteriormente por ORTIZ (1998) e também por PAES (1982) e WONG (1996).

Em termos simplificados, observa-se que a obtenção destas tábuas segue cálculos muito próximos aos destacados nas Tábuas Abreviadas. A única função que se diferencia da anterior é o $q_{x}$ - probabilidade de morte no intervalo etário $(x, x+n)$ - que, neste caso, passa a ser utilizada em sua forma líquida, ou seja, considera-se que a causa especifica de morte, ou grupos de causas, tenha sido eliminada da população. Esta probabilidade pode ser representada por:

- $q_{i j}=$ probabilidade de um indivíduo vivo no tempo $x_{i}$ vir a morrer no intervalo $\left(x_{i}, x_{i+n}\right)$ se a causa específica, ou grupos de causas, $R_{j}$ for o único fator de risco (ou grupos de risco) atuando sobre a população; 
- $\mathrm{q}_{\mathrm{i} . \mathrm{j}}=$ probabilidade de um indivíduo vivo no tempo $x_{i}$ vir a morrer no intervalo $\left(x_{i}, x_{i+n}\right)$ se a causa, ou grupos de causas, $R j$ for eliminada como fator de risco de morte.

Os estimadores dessas probabilidades são:

$$
\begin{gathered}
\hat{q}_{i j}=1-\hat{p}_{i}^{(D i j / D i)} \\
\hat{q}_{i \cdot j}=1-\hat{p}_{i}^{\left[(D i-D i)^{\prime} / D i\right]}
\end{gathered}
$$

onde; $i=0,1,2, \ldots$ (anos); $j=1,2, \ldots r$ (causas); $D_{i j}=$ número de óbitos ocorridos na idade $\mathrm{i}$ pela causa $\mathrm{j}$, ou grupos de causas; $D_{i}=$ número de óbitos ocorridos na idade $\mathrm{i}$.

- $p_{i}=$ estimador de probabilidade de um individuo sobreviver de $x_{i}$ a $x_{i+n}$ é igual a:

$$
\hat{p}_{i}=\frac{1-a_{i}^{\prime} N_{i} M_{i}}{1+\left(1-a_{i}^{\prime}\right) N_{i} M_{i}}
$$

Assim considerando-se que uma causa, ou um grupo delas, seja eliminada de uma determinada população, o $q_{x}$. passa a ser estimado da seguinte forma:

$$
q_{x .} \equiv \hat{q}_{i, j}=1-\hat{p}_{i}^{\left[\left(D_{i}-D_{i j}\right) / D_{i}\right]}
$$

Como ressaltou-se anteriormente neste estudo, será estimado o impacto das causas externas nas 15 regiões administrativas do Estado de São Paulo, para três momentos (1980-81, 1990-91 e 1998-99). Foram utilizadas médias de dois 
anos para minimizar as possíveis irregularidades que possam ocorrer com os dados das causas de morte. Além do total do Capítulo das causas externas utilizar-se-ão também os seguintes grupos de causas: os acidentes de veículos a motor/de transporte, os demais acidentes, os homicidios (agressões) e os suicídios (lesões autoprovocadas voluntariamente).

A mortalidade segundo as causas externas, para as regiões de governo e os municípios, será apresentada globalmente para o período de 1980 a 1999, ou seja, considerando os coeficientes para as suas populações totais. Isto permitirá destacar as áreas ou municípios que se encontram em situação mais crítica (ou mais favorável), ou ainda os que estão apresentando maiores alterações no decorrer do tempo. 
RESULTADOS E DISCUSSÃO 


\section{Contextualização Histórica}

O conhecimento da evolução demográfica no Brasil esbarra em algumas das mesmas limitações encontradas em outros países, especialmente no que diz respeito a periodos mais distantes. O primeiro Censo nacional realizou-se em 1872 e o Registro Civil foi criado em 1888, mas, desde seu início, apresentavam vários problemas (ALTMANN e FERREIRA, 1979 e 1982; MOREIRA 1982).

Para períodos anteriores, os registros coloniais e paroquiais, as contagens eclesiásticas e oficiais e os relatos da época são as principais fontes de conhecimento demográfico para o país (HENRY 1977).

A exemplo de outros paises, existem numerosos relatos sobre as condições de vida dessa época, no Brasil que chegam até a períodos próximos de seu descobrimento, inclusive quanto aos aspectos da saúde. Há descrições sobre as doenças que atingiam a população brasileira, as epidemias, as guerras e também a fome, fatos estes que ocorriam freqüentemente e provocavam elevado número de mortes desde os primeiros tempos da colonização. As doenças trazidas de outras áreas, como variola, peste, cólera e sarampo, entre outras, devastaram os povos nativos, chegando a provocar o desaparecimento de muitos de seus grupos. Já as pessoas que vinham de outras áreas eram afetadas não apenas por estas doenças, mas também por aquelas típicas dos trópicos. Além disso, expunham-se constantemente aos perigos de uma terra desconhecida, tais como os diversos tipos de acidentes: quedas, afogamentos, ataques de animais venenosos e selvagens, ingestão de água e alimentos contaminados, envenenados ou deteriorados, etc., além de confrontos com as populações nativas ou de outros países

Os conflitos ocorreram freqüentemente, desde o início ou até mesmo antes da ocupação do território, envolvendo brancos, negros e índios, provocando grande número de mortes. Recentes publicações descrevem certos episódios 
violentos, alguns dos quais antecedem a chegada de Cabral, como, por exemplo, o que ocorreu com a expedição comandada por Pinzón. Relata-se, entre outros fatos, que um dos seus integrantes foi trucidado pelos nativos ao desembarcar em algum local das atuais regiões Norte ou Nordeste do Brasil, no início de 1500. Seguiu-se uma batalha na qual morreram, além de vários nativos, oito integrantes da esquadra de Pinzón. Enfurecidos por esse fato, os nativos atacaram logo depois a expedição comandada por Diego de Lepe, que percorria o mesmo caminho de Pinzón, matando 11 de seus integrantes, quando estes desembarcaram para encher os barris com água (BUENO 1998).

As expedições que percorriam os mares, dirigindo-se ao continente americano, à África e à Índia, expunham-se a muitos perigos, como naufrágios, guerras, afogamentos, epidemias, tempestades, extravio da rota, falta de ventos que deixavam os navios paralisados em alto mar e podiam levar sua tripulação à morte, além de confrontos com expedições de outros paises. Das 13 embarcações que compunham a expedição de Cabral, somente seis retornaram a Lisboa, levando apenas 500 dos 1.500 homens que a formavam em seu início. Integrantes de grande prestígio, como Bartolomeu Dias, Aires Gomes, Simão de Pina e Luis Pires, sucumbiram em naufrágios perto do Cabo da Boa Esperança e mais de 50 pessoas, incluindo seis frades franciscanos e Pero Vaz de Caminha, foram mortos em conflitos na Índia.

Nos primeiros anos da colonização do Brasil também sucederam-se muitos confrontos com a população nativa, provocando elevado número de mortes em ambos os grupos. Do lado dos portugueses, expedições inteiras foram dizimadas nas incursões pela nova terra, enquanto a população indigena diminuiu consideravelmente, tendo muitos de seus grupos exterminados. Algumas vezes estes procuraram fortalecer-se formando confederações, como a dos Tamoios e a dos Cariris, mas acabaram sendo derrotados pelos portugueses. Conflitos com holandeses, franceses, espanhóis, ingleses e com paises vizinhos foram comuns nos períodos colonial e imperial, assim como rebeliōes e revoluções em várias áreas do país, como Pará, Pernambuco, Minas Gerais, São Paulo, Maranhão, Bahia e Rio Grande do Sul. Revoltas ou fugas de escravos também se 
multiplicaram nesse período e muitos refugiaram-se em quilombos, como 0 de Palmares. Registraram-se também disputas com Argentina, Uruguai e, principalmente, o Paraguai, onde estima-se que o Brasil perdeu cerca de $150 \mathrm{mil}$ pessoas, sendo que a população e a economia paraguaias foram destruídas (EDITORA ABRIL 1999).

Os indicadores de mortalidade estimados por Mortara e Arriaga e citados por MERRICK e GRAHAM (1981) para essa época, caracterizavam o Brasil como área situada no primeiro estágio da Transição Epidemiológica, com esperança de vida muito baixa, grande predominância de doenças infecciosas e parasitárias entre as causas de morte e quase inexistência de informações demográficas.

No início do século XX, a situação era semelhante à do final do século XIX $\mathrm{Na}$ maior parte do país, inclusive no Rio de Janeiro, as condições de saúde permaneciam muito precárias e as taxas de mortalidade diminuíram muito pouco nas primeiras décadas do século (MORTARA 1961; SINGER et alii 1978). Entre 1900 e 1920 a taxa de mortalidade reduziu-se para 26,4 óbitos por mil habitantes no Brasil, ou seja, pouco menos que os 27,8 estimados para o período de 1891 a 1900. Em relação à esperança de vida ao nascer estima-se que esta passou dos 29,4 anos, do início do século, para 30,6, em 1910, e para 32 anos em 1920 (MERRICK E GRAHAM 1981:63).

O Anuário Estatístico do Brasil, publicado em 1916, trazia as primeiras informações, provenientes do Registro Civil, referentes à causas de morte no período de 1908 a 1912, para as capitais brasileiras. Ainda que tivessem muitas limitações, estas informações oferecem um panorama das condições de saúde dessa época, confirmando a precariedade em que vivia a população brasileira. As doenças diarréicas - que na época eram classificadas no grupo das doenças digestivas - e as doenças infecciosas e parasitárias constituiam-se nas principais causas de morte, representando mais de $50 \%$ do total de óbitos na maior parte das capitais. A tuberculose e a disenteria apareciam com altos percentuais em todas as capitais, enquanto a febre amarela, a lepra, o beribéri e eventualmente a varíola, as febres e o sarampo destacavam-se em algumas. Devido à sua alta incidência, estas doenças denominadas infecto-contagiosas tinham grande 
destaque nos Anuários Demográficos e, principalmente, nos Anuários DemógrafoSanitários das primeiras décadas do século XX (BRASIL 1916).

Nesse panorama de alta mortalidade e com grande incidência das causas citadas anteriormente, outras doenças, como as dos aparelhos circulatório e respiratório, as neoplasias e também as causas externas, registravam percentuais bem menores. Algumas taxas de mortalidade, no entanto, eram relativamente elevadas. As causas externas representavam apenas de $2 \%$ a $4 \%$ do total dos óbitos, mas as taxas de mortalidade aproximavam-se de 70 óbitos por $100 \mathrm{mil}$ habitantes em várias capitais, semelhantes às observadas em algumas capitais brasileiras e no próprio país, na década de 80 , quando elas já começavam a ter maior destaque na imprensa nacional e nos estudos de mortalidade. Em São Paulo, os acidentes eram suas suas principais causas, seguidos pelos suicídios e pelos homicídios.

Nos anos seguintes, essas informações de causas de morte deixaram de ser publicadas, ficando restritas apenas ao então Distrito Federal (atual município do Rio de Janeiro) e a algumas capitais e Estados.

Os dados existentes para o Estado de São Paulo, onde desde 1892 a Divisão Demographo-Sanitaria os processava, mostram que os coeficientes de mortalidade geral tiveram poucas alterações no período de 1894 a 1940 , mantendo-se ao redor de 18 óbitos por mil habitantes. A mortalidade infantil permaneceu próxima de 170 por mil nascidos vivos e a de 1 a 4 anos também era muito elevada. Os óbitos dessas duas faixas etárias correspondiam a cerca de $50 \%$ do total ocorrido em São Paulo. A diarréia aparecia como a principal causa de mortalidade das crianças e tuberculose da população jovem.

Entre os fatos importantes ocorridos no pais, nas primeiras décadas do século XX, destacam-se, além das freqüentes revoltas militares, a questão do Contestado, em Santa Catarina, em 1915-16, que provocou cerca de 25 mil mortos.

Outro fato importante desse período foi o surgimento dos veículos a motor, cujo primeiro automóvel chegou ao país em 1893, trazido por Henrique Santos Dumont. Logo depois Olavo Bilac provocaria o primeiro acidente de veiculo, ao 
dirigir o carro de José do Patrocínio no Rio de Janeiro. A frota de veículos, no entanto, aumentou lentamente nas primeiras décadas do século. Em 1904 haviam apenas 83 veículos na capital paulista e, ao final da década de 20 , seu número ainda era relativamente pequeno no Brasil, quando comparado a outros países. Havia, então, cerca de 167 mil veículos no país, dos quais 105 mil eram automóveis, enquanto nos Estados Unidos esse número já aproximava-se de 11 milhões, nessa época.

A observação dos impactos desses fatos sobre a mortalidade, no entanto, continuou limitado a algumas capitais e Estados que possuíam sistemas próprios de informação, pois somente em 1944 os dados de causas de morte voltaram a ser publicados, por meio do Anuário Bioestatístico. Estas informações referem-se aos óbitos ocorridos nas capitais brasileiras entre 1929 e 1932, cujo processamento estava aos cuidados do Serviço Federal de Bioestatistica do Departamento Nacional de Saúde, do Ministério da Educação e Saúde. "Desde então, embora de forma incompleta, vêm sendo publicados dados de mortalidade por causa, nos municípios das capitais." (MINISTÉRIO DA SAÚDE 1987). Até o final da década de 70 , esta situação não teve grandes modificações.

\section{A Estrutura das Causas de Morte}

YUNES E RONCHEZEL (1974) utilizaram as informações publicadas nos Anuários Estatísticos do Brasil para analisar a evolução da mortalidade geral, infantil e proporcional, para o Brasil e suas regiões, no período de 1941 a 1970, bem como os fatores condicionantes.

Os autores observaram que as taxas de mortalidade geral diminuiram de forma mais acentuada no país a partir do final dos anos 40 , mas em algumas regiōes, como o Nordeste, a redução ocorreu somente na década seguinte. No Brasil, a taxa de mortalidade infantil reduziu-se praticamente à metade no período considerado, mas em 1970 ainda era muito elevada. As condições de saúde 
deterioraram-se a partir da metade dos anos 60 , refletindo-se em aumentos das taxas de mortalidade, especialmente entre as crianças.

Em 1974, esses mesmos autores, com a colaboração de SOMENSI utilizaram as informações sobre quatro causas de morte: doenças transmissiveis; tuberculose; neoplasias; e causas mal definidas, para o período 1959 a 1970, para avaliar as condições de saúde das cinco grandes regiões do país. Assim constatou-se que situação da região Nordeste era mais precária que a das demais regiões. No final do período analisado confirmava-se a deterioração das condições de saúde, com aumento das doenças infecciosas e parasitárias em todas as regiões do país.

Informações publicadas pela Fundação Oswaldo Cruz (1982) mostram que para o conjunto das capitais do Brasil, entre 1930 e 1940, os percentuais das principais causas de morte apresentaram poucas alterações, sugerindo que nesse periodo a mortalidade permaneceu quase inalterada. As doenças infecciosas e parasitárias eram as principais causas de morte, respondendo por $45,6 \%$, em 1930 e $43,5 \%$, em 1940 do total dos óbitos, seguidas pelas doenças do aparelho circulatório $(11,8 \%$ e $14,5 \%)$ e as doenças do aparelho respiratório (11,5\% e $12,1 \%)$. As neoplasias e as doenças do aparelho digestivo apareciam com cerca de $4 \%$ e as externas com menos de $3 \%$ (Gráfico 1 e Tabela 1 do Anexo).

Gráfico 1

Óbitos Segundo as Principais Causas

Capitais Brasileiras

Em\%

1930-75

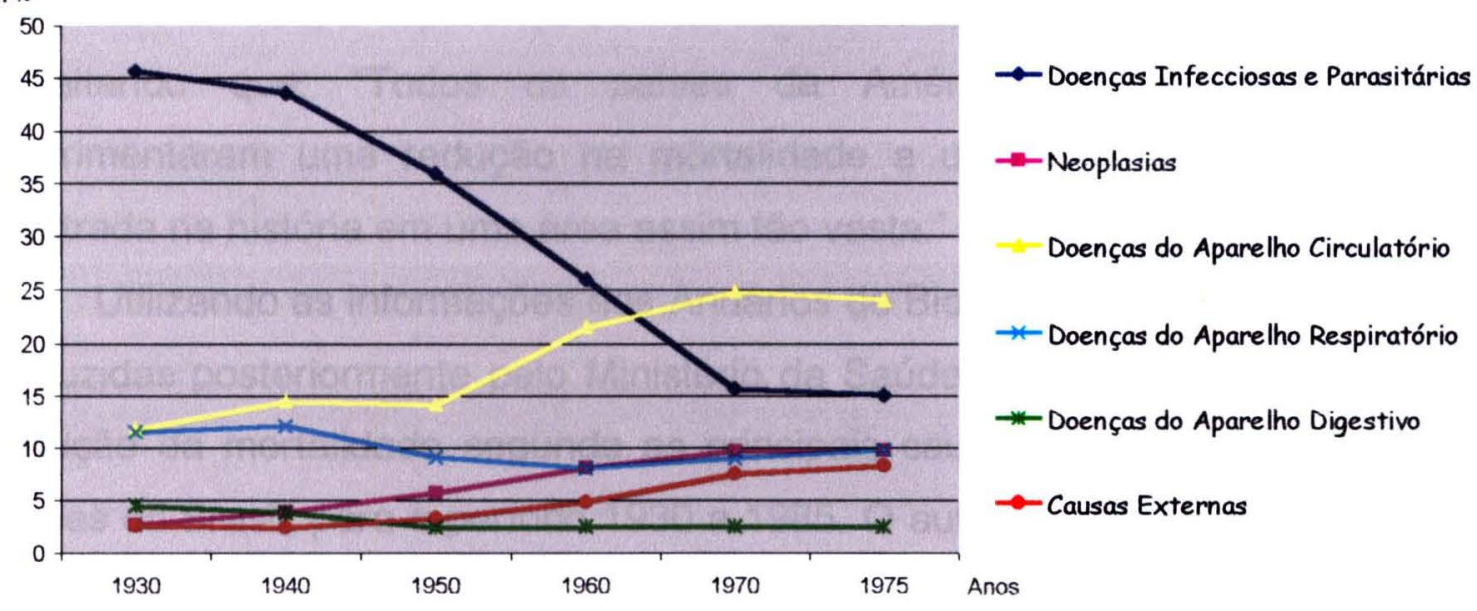

Fonte: Dados compilados por Mário Magalhães da Silveira a partir de Estatísticas de Saúde do Ministério da Saúde. 
Em 1950, as doenças infecciosas e parasitárias diminuiram para $35,9 \%$ do total de óbitos e para $25,9 \%$, em 1960 , permanecendo ainda como a principal causa de morte. Nesse último ano, as doenças do aparelho circulatório alcançaram $21,5 \%$, aproximando-se das infecciosas e parasitárias. As neoplasias respondiam por $8,1 \%$ do total, semelhante ao observado para as doenças do aparelho respiratório, enquanto as causas externas aumentaram para $4,8 \%$ e as do aparelho digestivo reduziram-se para $2,5 \%$.

Entre 1960 e 1970, inverteu-se a ordem das principais causas, com as doenças do aparelho circulatório passando a ser a principal, com quase $25 \%$ do total, superando as infecciosas e parasitárias, que diminuíram para $15,7 \%$, em 1970. Nesse ano, as doenças do aparelho respiratório mantiveram-se com $9 \%$, as neoplasias aumentaram para $9,7 \%$ e as causas externas passaram de $4,8 \%$, em 1960, para 7,5\%, em 1970.

Verifica-se que os coeficientes de mortalidade reduziram-se mais consideravelmente a partir da década de 40 , quando as doenças infecciosas e parasitárias começaram a diminuir nas capitais brasileiras.

As alterações nos niveis e na distribuição das causas de morte no Brasil, ocorreram em momentos semelhantes aos de outros países da América Latina, ainda que a ausência de informações mais completas do registro civil dificulte a observação em muitos deles (ARRIAGA 1995 e FRENK et alii 1994). Pode-se citar - caso do Chile, cujas taxas de mortalidade também reduziram-se acentuadamente após 1940 (MATTELART 1964). ARRIAGA (1970) destaca que, entre 1930 e 1960, a esperança de vida aumentou em 22 anos na América Latina, ressaltando que: "Todos os países da América Latina, sem exceção, experimentaram uma redução na mortalidade a uma velocidade nunca antes registrada na história em uma área assim tão vasta." (ARRIAGA, 1969:88)

Utilizando as informações dos Anuários de Bioestatística e também aquelas produzidas posteriormente pelo Ministério da Saúde, PRATA (1992) apresenta a evolução da mortalidade segundo as principais causas de morte para as cinco regiões do Brasil, para o período 1930 a 1985. O autor também ressalta aspectos da Transição Epidemiológica e constata que havia grandes diferenças na 
distribuição das principais causas de morte das regiões, desde o início do período estudado. Em 1930, as doenças infecciosas e parasitárias eram responsáveis por cerca de $60 \%$ dos óbitos gerais na Região Norte; por quase $50 \%$ no Nordeste, ficando ao redor de $40 \%$ nas outras três regiōes. As doenças circulatórias tinham percentuais de $9 \%$, no Nordeste, e de $13 \%$ no Sudeste, e as causas externas estavam entre $1 \%$ no Centro-Oeste e $3 \%$ no Sudeste.

Após 1940, as modificaçōes passaram a ser mais significativas em todas as regiōes, mantendo-se, porém, diferenças importantes. Em 1970, os percentuais das doenças infecciosas e parasitárias diminuíram para cerca de $25 \%$ do total dos óbitos nas capitais das regiōes Norte, Nordeste e Centro-Oeste, mas somente na primeira mantinha-se como principal causa de morte. No Sudeste, essas doenças participaram com pouco mais de $10 \%$ e, no Sul ficou abaixo desse percentual.

Por outro lado, as doenças circulatórias registraram significativos aumentos, principalmente nas regiōes Sudeste e Sul e de forma mais acentuada após 1950. Em 1970, os percentuais dessas causas aproximaram-se de $30 \%$ nessas duas regiões, de cerca de $20 \%$ no Norte e de $15 \%$ no Nordeste e Centro-Oeste. As neoplasias aumentaram lentamente, mas de forma contínua, em todas as regiōes e períodos, alcançando percentuais de $10 \%$ a $15 \%$. As causas externas apresentaram tendência de crescimento semelhante à das neoplasias, mas seus percentuais ficaram abaixo destas causas até 1970 .

Os resultados apresentados por PRATA (1992) mostram, portanto, que o processo de Transição Epidemiológica vem ocorrendo de forma muito heterogênea no país, onde as regiões Sul e Sudeste encontram-se em fase mais avançada, do que o Norte e o Nordeste.

Para o país, a evolução da mortalidade segundo as principais causas, para o período de 1979 a 1998, pode ser visualizada no Gráfico 2 e na Tabela 2 do Anexo, destacando especialmente a evolução das causas externas, objeto maior deste estudo. 
Gráf ico 2

Óbit os segundo as Principais Causas

Brasil

1977-98

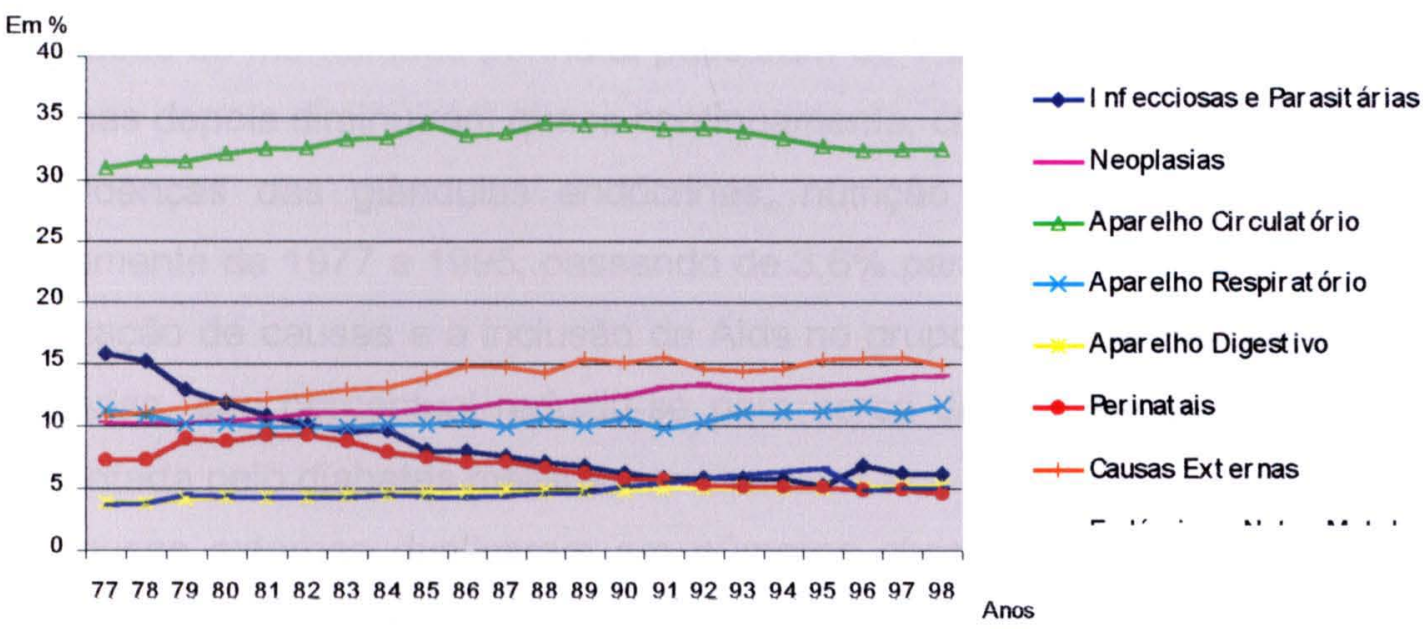

Font e: Minist ério da Saúde.

Os resultados apresentados mostram que algumas mudanças significativas ocorreram nesse período. Excluindo-se as causas mal definidas do total, observase o seguinte comportamento para as principais causas, no período de 1977-98:

- as doenças infecciosas e parasitárias, que respondiam por $15,8 \%$ dos óbitos do país em 1977, constituindo-se na segunda causa de morte, diminuíram para 5,2\%, em 1995, passando para a sétima posição, praticamente junto com as causas perinatais $e$ as doenças do aparelho digestivo. Com a adoção da CID-10, a partir de 1996, há um aumento do percentual deste grupo, devido à inclusão da Doença pelo Vírus da Imunodeficiência Humana [HIV] (Aids) nesse capítulo (SANTO 2000). Com a redução dessa causa, nos últimos anos seus percentuais diminuem novamente;

- as neoplasias aumentaram lentamente, passando de 10,2\% do total de óbitos, em 1977 para 14,0\%, em 1998 e saltaram da $5^{a}$ para a $3^{a}$ principal causa de morte;

- as doenças do aparelho circulatório permaneceram como a principal causa de morte no país, em todo o período, aumentando de $30,9 \%$ para $32,4 \%$; 
- as doenças do aparelho respiratório passaram de $3^{a}$ para $4^{a}$ principal causa de morte, expandindo-se de $11,2 \%$ para $11,6 \%$;

- as doenças do aparelho digestivo aumentaram de 3,9\% para 5,2\%;

- as causas de mortalidade perinatal passaram de 7,2\% em 1977, para 9,3\%, em 1982, mas depois diminuiram quase continuamente, chegando a 4,6\%, em 1998;

- as doenças das glândulas endócrinas, nutrição e metabolismo cresceram seguidamente de 1977 a 1995, passando de 3,6\% para 6,6\%. Com a mudança da classificação de causas e a inclusão da Aids no grupo das doenças infecciosas e parasitárias, seu percentual reduziu-se para cerca de $5 \%$, sendo a maior parte representada pelo diabetes mellitus;

- as causas externas duplicaram em números absolutos desde 1977 e o seu percentual elevou-se de 10,8, nesse ano, para 15,3\%, em 1995. O seu aumento é praticamente contínuo desde 1977 e, da $4^{a}$ colocação passaram para a $2^{a}$ causa de morte mais importante;.

- as causas mal definidas representavam cerca de 19,3\% dos óbitos, em 1977 , $16,2 \%$, em 1995 e 14,9\%, em 1998, refletindo uma certa melhoria na qualidade dos dados nesse periodo.

Observa-se, portanto, que as doenças do aparelho circulatório mantiveramse como as principais causas de morte em todo o periodo, mas as neoplasias e, principalmente, as causas externas elevaram-se de forma significativa. Por outro lado, as doenças infecciosas e parasitárias e as perinatais diminuíram consideravelmente. 


\section{As causas externas}

Em relação às causas externas, verifica-se que sua importância vem crescendo no Brasil desde 1930, quando representavam menos de $3 \%$ do total de óbitos, alcançando cerca de $15 \%$, em 1998. No entanto, somente no final da década de 70 , os demógrafos, epidemiologistas e pesquisadores da saúde passaram a estudá-las mais detalhadamente. Tal fato pode estar relacionado ao acúmulo de mais e melhores informaçōes, à maior presença de grupos técnicos envolvidos com o tema e também à importância que estas causas adquiriam.

Como se observou no Gráfico 2, os percentuais de causas de morte externas aumentaram significativamente desde 1977, quando representavam $10,8 \%$ dos óbitos totais, alcançando 15,3\%, em 1995 sendo que as diferenças tornam-se ainda mais acentuadas quando se considera a evolução dessas causas por sexo, como pode ser constatado no Gráfico 3 e na Tabela 3 do Anexo.

Entre os homens estas causas aparecem desde 1978 como a segunda mais importante e o percentual, que estava próximo de $15 \%$, aumentou seguidamente até 1987, chegando a 20,4\%. Entre 1995 e 1998, seus percentuais ficaram em torno de $21 \%$, ou seja, de cada cinco óbitos por causas definidas, um corresponde a esse grupo. Para as mulheres também observou-se um certo aumento, porém, muito menos significativo que entre os homens, passando de $5,5 \%$ para quase $7 \%$, em determinados anos.

Os óbitos provocados por causas externas e contabilizados no Sistema de Informações de Mortalidade aproximaram-se de 55 mil, em 1977, de $102 \mathrm{mil}$, em 1989, e de 120 mil em cada ano de 1996 a 1998. Portanto, o número de óbitos por causas externas mais que dobrou nesse periodo e seu total acumulado desde 1977 aproximou-se de 2 milhões de mortes. 


\section{Gráf ico 3}

Obit os, por Sexo, segundo Principais Causas

Brasil

1977-98
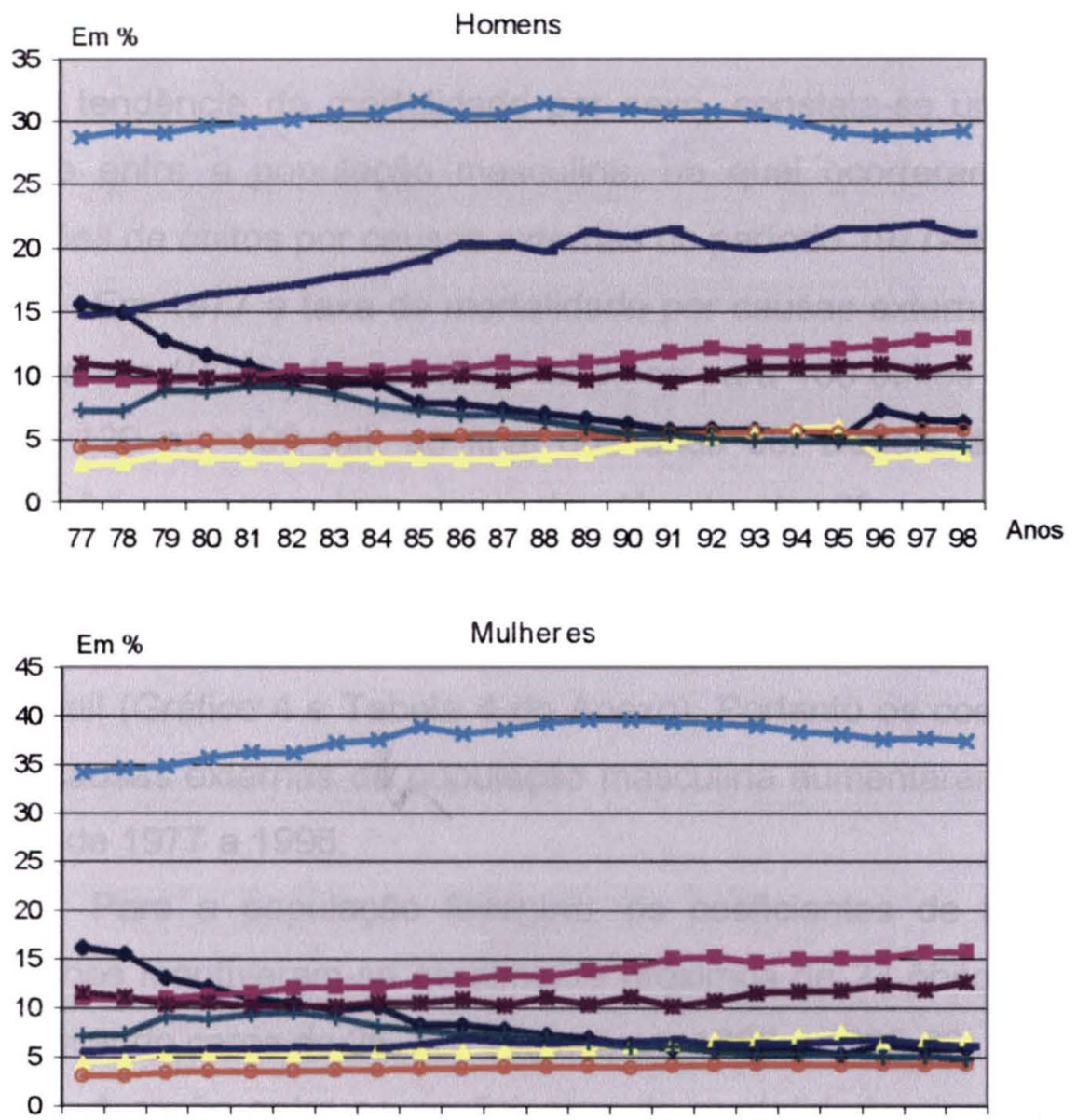

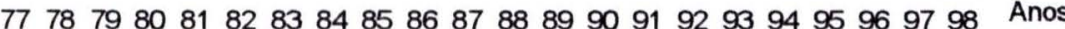

$\ldots$ I nf ecciosas e Par asit árias

$\rightarrow-$ Neoplasias

Endócrinas, Nut r., Met ab. e Transt. I munit .

$\rightarrow$ Apar elho Circulat ório

- Apar elho Respir at ório

$\longrightarrow$ Apar elho Digest ivo

$\ldots$ Perinat ais

_Causas Ext ernas

Font e: Minist ério da Saúde. 
Os coeficientes de mortalidade por causas externas aproximavam-se de 60 óbitos por 100 mil habitantes, no início dos anos 80 , alarmando os pesquisadores e governantes, que já os consideravam muito elevados. Em 1996, no entanto, este coeficiente tornou-se ainda maior, com um crescimento de cerca de $30 \%$, em relação ao início da década de 80 , alcançando 78 óbitos por 100 mil habitantes e permanecendo próximo de 75 por 100 mil, entre 1995 e 1998. Quando observase a tendência da mortalidade por sexo, constata-se um panorama ainda mais grave entre a população masculina, na qual ocorreram cerca de $82 \%$ dos 2 milhões de óbitos por causas externas no período 1977-98.

Em 1977 a taxa de mortalidade por causas externas estava próxima de 80 óbitos por 100 mil homens, elevando-se para 100 óbitos por 100 mil, em 1983, e para 120 por 100 mil, ao final dos anos 80 . Depois de apresentar uma certa redução nos primeiros anos da década de 90 , os coeficientes voltaram a aumentar, aproximando-se de 130 óbitos por 100 mil e mantendo-se nesse patamar até 1997. Em 1998, o coeficiente diminuiu para cerca de 123 mortes por 100 mil (Gráfico 4 e Tabela 4 do Anexo). Portanto os coeficientes de mortalidade por causas externas da população masculina aumentaram, no país, em cerca de 65\% de 1977 a 1998.

Para a população feminina, os coeficientes de mortalidade por causas externas mantiveram-se geralmente próximos de 23 óbitos por 100 mil mulheres, alcançando cerca de 26 por 100 mil, em 1986 e 1995-96.

A razão entre os coeficientes de mortalidade masculino/feminino, que era de 3,8 em 1979, passou para 4,5 em 1984-85 e a 5,2 em 1998.

Ao se observar a evolução da mortalidade segundo as causas que compõem este grupo e também as taxas por idade e sexo, compreende-se melhor o comportamento das causas violentas nesse período. 
Gráfico 4

Coeficientes de Mortalidade por Causas Externas, segundo Sexo

Brasil

1977-98

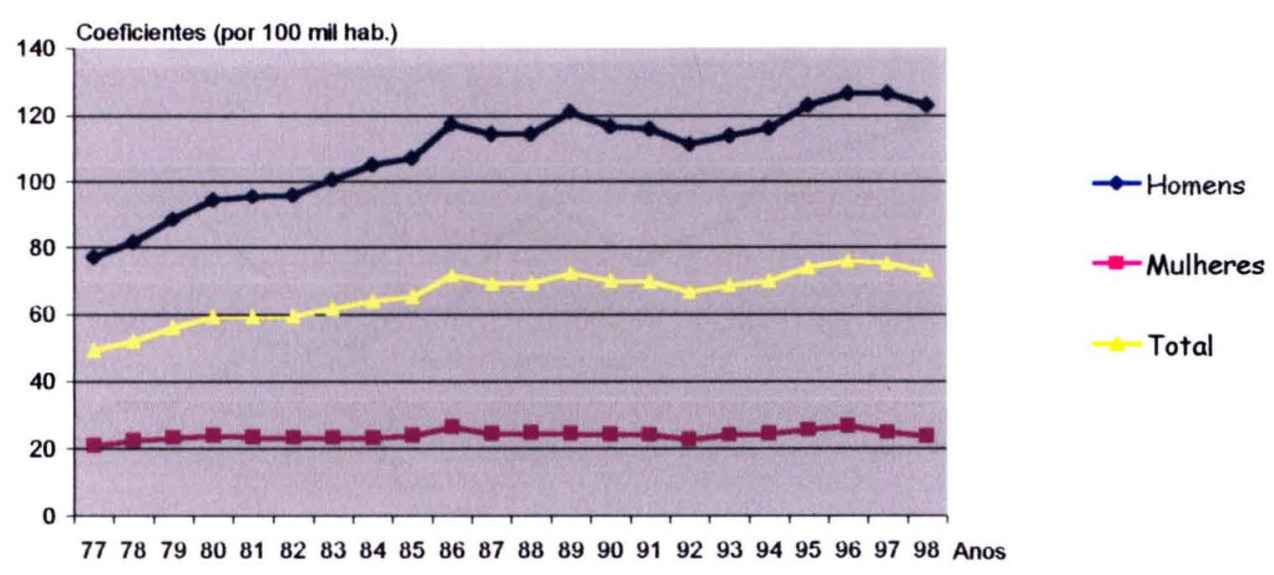

Fonte: Ministério da Saúde.

No Gráfico 5 e Tabela 5 do Anexo, observa-se a evolução dos coeficientes de mortalidade para os grupos de causas de morte violenta, entre 1979 e 1998, para a população total, em que se verifica a ocorrência de importantes alterações.

Os homicídios, que representavam a segunda causa de morte violenta no início do período analisado, com coeficientes próximos de 10 óbitos por $100 \mathrm{mil}$ habitantes - cerca de metade do observado para os acidentes de transporte aumentaram continuamente. Em 1989 os coeficientes desses dois grupos tornaram-se praticamente iguais, mas na década de 90 as mortes provocadas por homicídios ganharam cada vez mais destaque, distanciando-se das demais causas e aproximando-se de 27 óbitos por 100 mil habitantes, quase três vezes mais que o observado em 1979. Já os coeficientes relativos aos acidentes de transporte oscilaram entre 17 e 23 óbitos por 100 mil habitantes, sendo maiores em 1986 e 1996-97. Em 1998, o coeficiente diminuiu para cerca de 20 óbitos por 100 mil habitantes e a adoção de um novo Código de Trânsito, a partir do final de 1997, tem sido apontado como um dos principais responsáveis por tal fato (VASCONCELOS e LIMA 1998). Os coeficientes de mortalidade devido a esses acidentes mantêm-se, no entanto, elevados quando comparados a outros países. 
Gráfico 5

Coeficientes de Mortalidade por Causas Externas, por Tipos

Brasil

1979-98

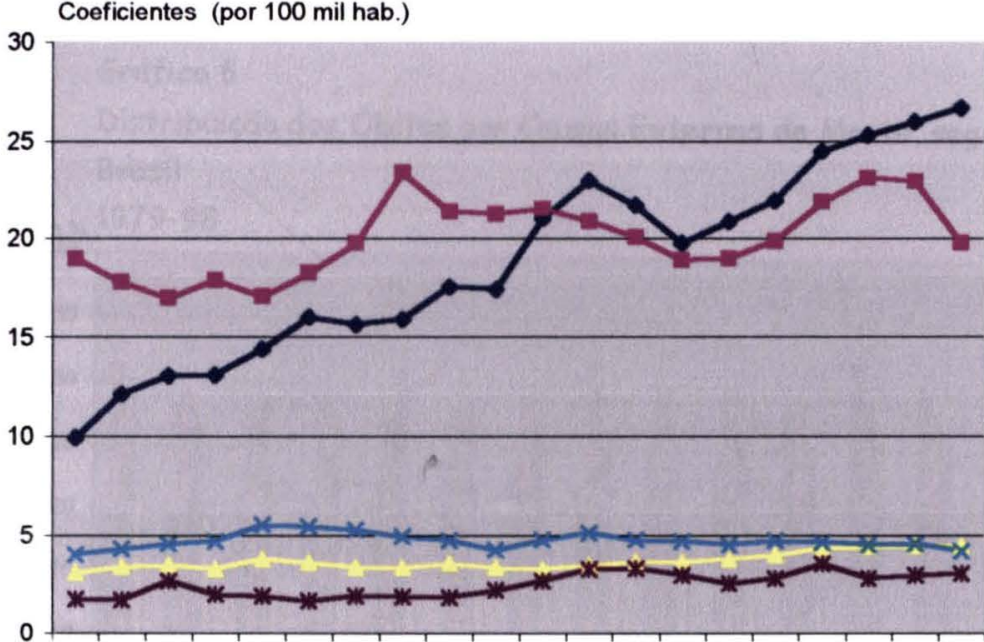

$\rightarrow$ Homicídios

$\rightarrow$-Acidentes de Transporte

Suicídios e Lesões AutoInfligidas

* Afogamento e Submersão Acidentais

$\because$ Quedas Acidentais

$\begin{array}{lllllllllllllllllllll}79 & 80 & 81 & 82 & 83 & 84 & 85 & 86 & 87 & 88 & 89 & 90 & 91 & 92 & 93 & 94 & 95 & 96 & 97 & 98 & \text { Anos }\end{array}$

Fonte: Ministério da Saúde.

Já os coeficientes provocados por suicídios são bem inferiores aos dos grupos anteriores, mas têm aumentado nos últimos anos. Até o início da década de 90 , os coeficientes ficaram abaixo de 4 óbitos por 100 mil habitantes, mas depois elevaram-se para 4,4 por 100 mil.

A mortalidade por afogamentos aumentou até a metade da década de 80 , passando de 4,0 para 5,5 óbitos por 100 mil habitantes, mas depois apresentou redução chegando a 4,2 por 100 mil no final dos anos 90 .

Em relação à mortalidade provocada pelas quedas, observa-se tendência de aumento, passando de cerca de 1,7 óbito por 100 mil, em 1979-80, para 3,0 por 100 mil, na metade dos anos 90 .

Em termos percentuais, os homicídios, que representavam $17,2 \%$ do total das causas externas em 1979, passaram para $35,6 \%$, em 1998 , enquanto a participação dos acidentes de transporte diminuiu de $32,8 \%$ para $26,4 \%$. Os percentuais dos demais acidentes decresceram de $24,0 \%$ para $20,9 \%$ e os de suicídios, aumentaram de $5,3 \%$ para $5,9 \%$. 
As demais causas externas respondiam por cerca de $21 \%$ da mortalidade do grupo em 1979, diminuindo para $7,7 \%$, em 1997 , mas aumentando para $11,2 \%$, em 1998 (Gráfico 6 e Tabela 6 do Anexo).

Gráfico 6

Distribuição dos Óbitos por Causas Externas de Morte, segundo Tipos

Brasil

1979-98

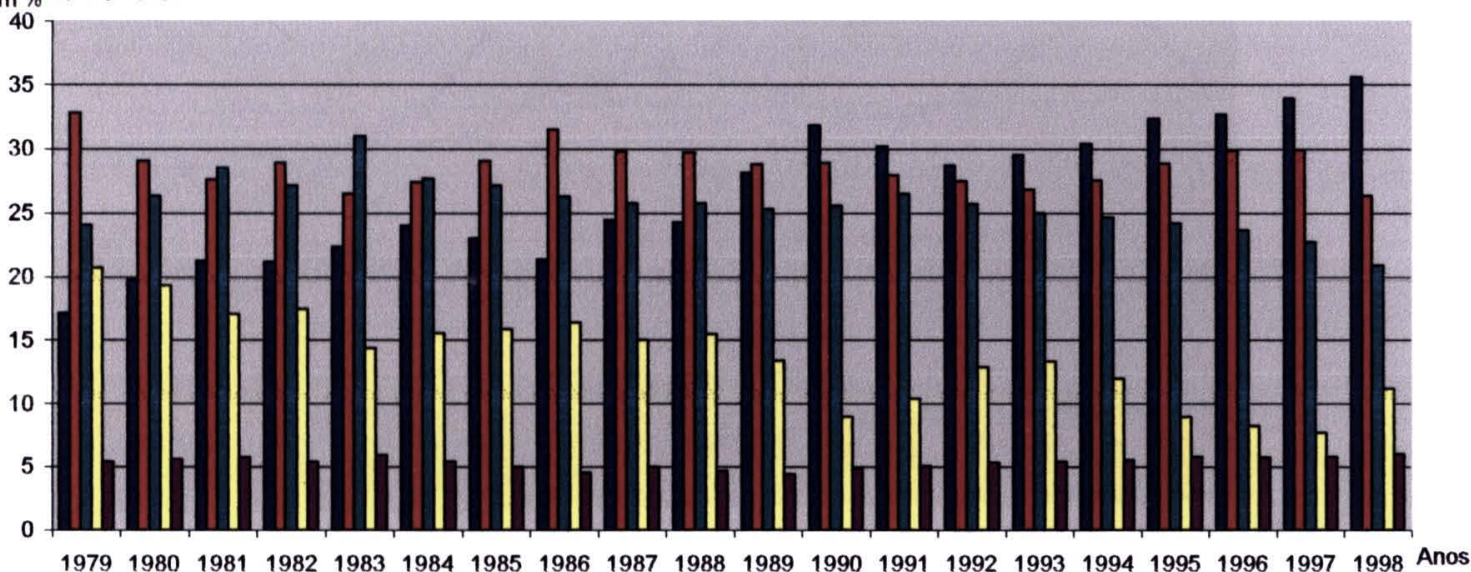

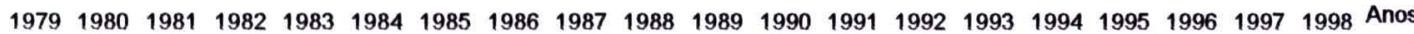

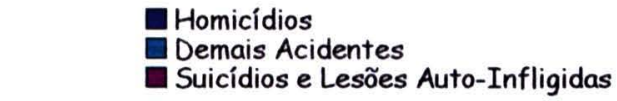

Acidentes de Transporte

Fonte: Ministério da Saúde.

Observando-se a evolução dessas causas, por sexo, constatam-se diferenças ainda mais nítidas.

O grande aumento das taxas de mortalidade por causas externas para os homens deveu-se, basicamente, ao aumento dos homicídios, que desde 1979, tornaram-se três vezes maiores, elevando-se de 17 óbitos por 100 mil habitantes para quase 50 por 100 mil. Para as mulheres, os coeficientes também aumentaram nesse período, mas ainda são muito menores que os registrados entre os homens, passando de 2,1 óbitos por 100 mil em 1979 para 3,0 em 1988, 4,7 em 1996 e 4,4 em 1998. Desde 1979, observa-se que este coeficiente duplicou entre a população feminina (Gráfico 7 e Tabela 7 do Anexo). 


\section{Gráfico 7}

Coeficientes de Mortalidade por Causas Externas por Sexo, segundo Tipos Brasil

1979-98
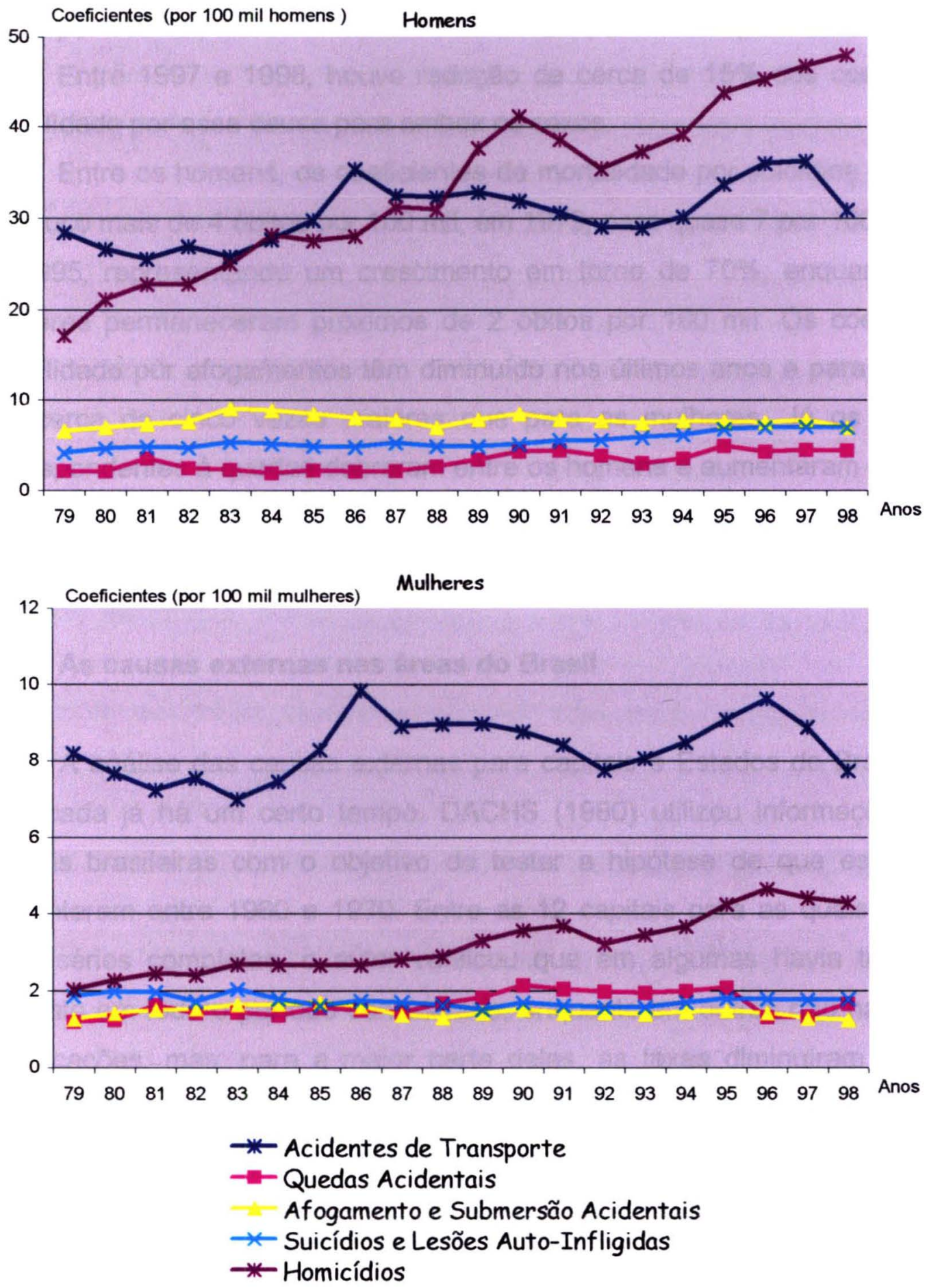

Fonte: Ministério da Saúde. 
Os maiores coeficientes de mortalidade por acidentes de transporte, para a população masculina, ocorreram em 1986 e em 1996-97, aproximando-se de 36 óbitos por 100 mil homens, enquanto para a população feminina registraram-se 10 óbitos por 100 mil mulheres. Nos demais anos as taxas ficaram entre 26 e 34 óbitos por 100 mil, entre os homens, e de 7 a 9 por 100 mil para as mulheres.

Entre 1997 e 1998, houve redução de cerca de 15\% dos coeficientes de mortalidade por essa causa para ambos os sexos.

Entre os homens, os coeficientes de mortalidade por suicidios aumentaram de pouco mais de 4 óbitos por 100 mil, em 1979, para quase 7 por 100 mil, a partir de 1995 , representando um crescimento em torno de $70 \%$, enquanto entre as mulheres permaneceram próximos de 2 óbitos por 100 mil. Os coeficientes de mortalidade por afogamentos têm diminuido nos últimos anos e para os homens, são cerca de cinco vezes maiores que para as mulheres. Já os coeficientes correspondentes à quedas dobraram entre os homens e aumentaram em cerca de $40 \%$ para as mulheres. Em 1998, os coeficientes de mortalidade deste grupo eram quase três vezes maiores entre a população masculina.

\section{As causas externas nas áreas do Brasil}

A análise das causas externas para capitais e Estados do Brasil tem sido destacada já há um certo tempo. DACHS (1980) utilizou informações para as capitais brasileiras com o objetivo de testar a hipótese de que estas causas aumentaram entre 1960 e 1970 . Entre as 12 capitais para as quais foi possivel obter séries completas, o autor verificou que em algumas havia tendência de aumento em todo o período considerado, enquanto em outras não havia grandes modificações, mas, para a maior parte delas, as taxas diminuíram na primeira metade dos anos 60 e aumentaram na segunda. Entre as 12 capitais analisadas, Vitória foi a que apresentou os maiores coeficientes de mortalidade, em todo 0 periodo, com exceção de 1961. Em determinados anos, como em 1965-66 os coeficientes superaram 200 óbitos por 100 mil habitantes e, nos demais, estiveram entre 90 e 200 por 100 mil. Outras capitais que registraram coeficientes elevados 
foram Goiânia, Niterói e Maceió, enquanto Manaus, Teresina, Natal e Aracaju apresentaram menos de 60 óbitos por 100 mil, na maior parte do período.

Em Maceió, João Pessoa, Salvador e Recife verificou-se clara tendência de aumento desses coeficientes nos últimos anos da década de 60 (DACHS 1980).

Entre as Unidades da Federação, constatava-se que os maiores coeficientes de mortalidade por causas externas, para 1980 foram encontrados em, Mato Grosso do Sul, Rio de Janeiro, Goiás e Rondônia, com mais de 90 óbitos por 100 mil habitantes. Mato Grosso, Espírito Santo, Distrito Federal e Roraima registraram entre 70 e 80 óbitos por 100 mil habitantes (FUNDAÇÃO OSWALDO CRUZ 1985). Os menores coeficientes referiram-se a Amapá, Rio Grande do Norte e Paraíba, com menos de 40 óbitos por 100 mil habitantes.

Entre as causas de morte, observou-se que somente em Rondônia, no Rio de Janeiro e em Pernambuco os homicidios constituiam-se na principal, pois nos demais Estados os acidentes de veículos a motor ocupavam tal posição.

Também havia grandes diferenças nas taxas de mortalidade por causas externas nas regiōes metropolitanas brasileiras, no período de 1977-87. "Entre as Capitais estudadas, o Rio de Janeiro é a que apresenta as maiores taxas de mortalidade por causas externas, tendo chegado a atingir 98 por cem mil habitantes em 1980. Na série 1977-87, São Paulo e Recife têm evolução nitidamente crescente. Belém, Fortaleza, Salvador, Rio de Janeiro e Porto Alegre apresentam primeiramente aclive (77-80), posterior decréscimo (81-83), para crescer novamente ou estabilizar-se nos últimos anos." (FUNDAÇÃO OSWALDO CRUZ 1990:12).

Em 1987, as maiores taxas de mortalidade por causas externas correspondiam ao Rio de Janeiro, mas também mostravam-se elevadas em Recife, Porto Alegre e São Paulo, estando entre 80 e 90 óbitos por 100 mil habitantes. As menores eram observadas em Belém, Fortaleza e Belo Horizonte, que situavam-se entre 50 e 60 por 100 mil, tendo diminuído em relação ao início do período analisado. Havia muitas dificuldades para analisar a mortalidade segundo os grupos de causas em várias capitais, especialmente Porto Alegre, Salvador e no Rio de Janeiro, devido aos altos percentuais de "outros acidentes". 
MINAYO e SOUZA (1993) E MINAYO (1995) também ressaltam a situação nas capitais das áreas metropolitanas, para o período de 1980-88, ficando o Rio de Janeiro, mais uma vez, com os maiores coeficientes de mortalidade por causas externas. Em 1988, a taxa chegou a 114 óbitos por 100 mil habitantes, nessa capital, enquanto em Goiânia aproximou-se de 100 e, em São Paulo, de 91 por 100 mil. Curitiba registrou cerca de 85 óbitos por 100 mil habitantes e Recife 90 por $100 \mathrm{mil}$ em 1987. Os menores coeficientes correspondiam a Belém e Fortaleza, com pouco mais de 60 óbitos por 100 mil habitantes, tendo diminuído em relação a 1980. Em Salvador e Belo Horizonte as taxas estavam entre 60 e 70 por 100 mil, com poucas alterações nesse período. Já em Recife, São Paulo e Porto Alegre houve tendência de aumento desde 1980.

MINAYO (1994) destacou novamente a importância das causas externas, ressaltando que "as Regiões Metropolitanas são as que concentram a maior proporção da mortalidade por violência em todas as causas específicas (homicidios, acidentes e suicidios) e em todas as faixas etárias. É neste espaço humano-social que se observam também as maiores proporções de crescimento de óbitos por causas externas, lideradas durante a década por Recife, Salvador e São Paulo. No Rio de Janeiro, a mortalidade por violência permanece com taxas elevadas durante todos os anos da década de 80 , apresentando a particularidade de ter os homicídios como a principal causa específica no conjunto dos óbitos também durante toda a década, passando de 33,4\%, em 1980 (em contraposição aos $30,4 \%$ dos acidentes), para $45,2 \%$ no final de 1988 (contra $31,2 \%$ dos acidentes)" (MINAYO 1994:11).

Os dados referentes ao periodo 1979-98 mostram que, no último ano, os coeficientes observados para alguns Estados como Roraima, Rio de Janeiro, Espírito Santo e Pernambuco, aproximaram-se ou ultrapassaram a 100 óbitos por 100 mil pessoas. Em Rondônia e em São Paulo, os coeficientes estavam entre 90 e 100 óbitos por 100 mil nesse ano, enquanto em Mato Grosso, Mato Grosso do Sul, Distrito Federal, Amapá e Goiás situavam-se entre 75 e 90 por 100 mil. Em Rondônia, os coeficientes de mortalidade eram muito elevados na segunda metade da década de 80 , chegando a cerca de 130 óbitos por 100 mil, mas 
diminuíram desde o início dos anos 90, alcançando 84 por 100 mil em 1997. No entanto, a taxa voltou a aumentar, em 1998, aproximando-se de 96 óbitos por 100 mil habitantes.

No Rio de Janeiro, o coeficiente chegou a cerca de 138 óbitos por 100 mil, em 1989, e a 134 por 100 mil, em 1990 e em 1994-95, mas diminuiu continuamente nos três anos seguintes, registrando 116 óbitos por $100 \mathrm{mil}$ pessoas, em 1998. No Espírito Santo há tendência de aumento dos coeficientes de mortalidade desde 1979, quando aproximaram-se de 67 óbitos por $100 \mathrm{mil}$, alcançando 109 por 100 mil em 1998. No Distrito Federal o aumento dos coeficientes foi praticamente contínuo até 1995, fato que ocorreu também em São Paulo até 1996. Em Pernambuco registrou-se grande aumento da mortalidade por causas externas após 1994, com o coeficiente passando de 72 óbitos por 100 mil habitantes para 99 por 100 mil, ou seja, um crescimento de $40 \%$.

Deve destacar-se ainda que a incidência das causas externas já vêm sendo estudada para áreas menores dos municípios, como bairros ou distritos, uma vez que existem grandes diferenças entre elas. Entre os estudos destacam-se os do CEDEC (1997), para as cidades de Salvador, Curitiba, Rio de Janeiro e São Paulo, o de GUEDES (1996) para o Distrito Federal, MACHADO e RIGOTTI (1996) para Belo Horizonte, PAIM (1980) para Salvador. Para o Rio de Janeiro, citam-se os SZWARCWALD e CASTILHO (1986), de SOUZA (1991), CRUZ (1986), MASSENA (1986) e MONTEIRO (1996). Para São Paulo, além dos publicados pelo Programa de Aprimoramento das Informaçōes de Mortalidade PRO-AIM, da Prefeitura de São Paulo, destacam-se os da FUNDAÇÃO SEADE (1988), de GAWRYSZEWSKI e DRUMOND (1992 e 1995), os de AKERMAN et alii (1994), AKERMAN (1996) e SPOSATI (1996).

Para os municípios paulistas destacam-se entre outros os de CAMPINAS (1996) e o de PAIVA (1998) para Santos, além de informativos como os referentes a São José dos Campos e São Bernardo do Campo. 


\section{As causas externas por sexo e grupos etários}

Quanto às principais características relacionadas às causas externas, além da distribuição segundo os grupos de causas, ressaltam-se aquelas por sexo e idade. Vários estudos apontaram a maior mortalidade por causas externas entre os homens, principalmente quando se trata dos homicídios (MINAYO 1990 e 1994; SOUZA 1993 e MELLO JORGE 1998). Em relação à distribuição dos óbitos por idade, os dados apontam que os maiores percentuais pertencem à população jovem, principalmente de 15 a 34 anos (PAES 1998; CASTRO 1993; CESAR e RODRIGUES 1994 e 1998; FUNDAÇÃO SEADE 1988; SOARES et alii 1995; YAZAKI e ORTIZ 1988; YUNES e PRIMO 1983 E YUNES e RAJV 1994)

Em 1979, 44\% dos óbitos por causas externas ocorreram nessa faixa etária, chegando a $47 \%$ entre os homens. Em 1998, esses percentuais passaram para $49 \%$ e $52 \%$ respectivamente para essas duas populações, mostrando que os óbitos por causas externas vêm ocorrendo em idades cada vez mais jovens Observando-se porém, os coeficientes de mortalidade por grupos etários, constata-se que, além dos grupos jovens, estes aparecem elevados também em outras faixas etárias.

Analisando-se informaçōes para quatro momentos (1979, 1986, 1992 e 1998), verifica-se que o padrão de mortalidade por causas externas, tanto para a população masculina como para a feminina, permaneceram semelhantes. Os niveis, entretanto, são diferentes em cada momento e distintos nas duas populações

Os dados de 1979 mostram que os coeficientes de mortalidade por causas externas aumentaram dos 15 aos 44 anos, diminuindo depois até a faixa de 55 a 64 anos. A partir dessa faixa etária aumentaram novamente, até atingir os maiores coeficientes entre todos os grupos de idade, na população de 75 anos e mais. Nos anos seguintes, o comportamento é semelhante, alterando-se apenas a faixa etária a partir da qual os coeficientes começam a diminuir, que passou a ser de 25 a 34 anos. Isto ocorre até o grupo de 55 a 64 anos, aumentando depois para 
atingir os coeficientes mais elevados entre as pessoas de mais de 75 anos, a exemplo do verificado em 1979. Na faixa de 15 a 34 anos, os coeficientes de mortalidade mais elevados são observados em 1998, enquanto nas demais faixas isto se dá em 1986 (Gráfico 8 e Tabela 8 do Anexo).

\section{Gráfico 8}

Coeficientes de Mortalidade por Causas Externas, segundo Sexo e Grupos de Idade Brasil

1979-1998
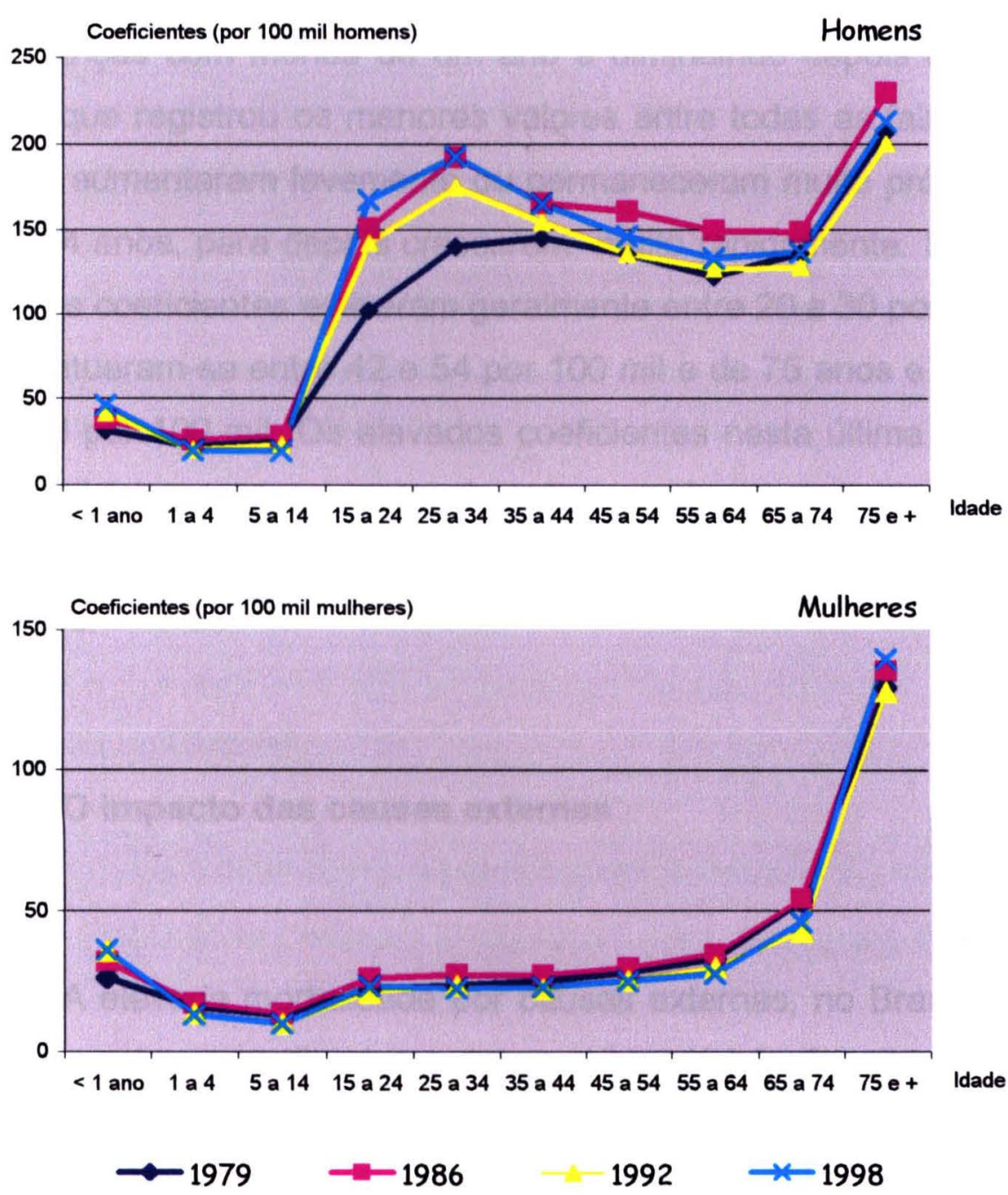

Fonte: Ministério da Saúde. 
Verifica-se que os coeficientes de mortalidade da população de 15 a 44 anos eram mais elevados em 1998, enquanto entre as pessoas de 45 anos e mais isto se dava em 1986.

Para as mulheres, as alterações säo menos significativas, com as taxas aproximando-se muito nos momentos considerados, sendo um pouco mais altos em 1986 e menores em 1992 ou em 1998, dependendo da faixa etária. O padrão, no entanto, permanece o mesmo, iniciando-se com coeficientes elevados no grupo de crianças com menos de um ano e diminuindo depois até o grupo de 5 a 14 anos, que registrou os menores valores entre todas as faixas etárias. A partir de então, aumentaram levemente ou permaneceram muito próximos até o grupo de 55 a 64 anos, para depois crescerem muito rapidamente. Se entre os 15 e os 64 anos os coeficientes estiveram geralmente entre 20 e 30 por 100 mil, entre 65 e 74 anos situaram-se entre 42 e 54 por 100 mil e de 75 anos e mais ficaram próximos de 130 por 100 mil. Os elevados coeficientes nesta última faixa etária devem-se, principalmente, aos acidentes de veículos e às quedas, enquanto nos grupos mais jovens relacionam-se especialmente aos homicídios e também aos acidentes de veículos.

\section{O impacto das causas externas}

A elevada mortalidade por causas externas, no Brasil, vem tendo grande impacto sobre os indicadores demográficos já há vários anos, mesmo quando os coeficientes eram menores do que os atuais. Estudo de SANTOS, ORTIZ e YAZAKI (1985) para o período 1979-80, mostra que uma diminuição mais significativa da mortalidade ocorreria com a eliminação das causas externas. Se tal fato acontecesse a esperança de vida ao nascer passaria de 55,9 anos para 59,5 anos, resultando em aumento de 3,6 anos. Para as mulheres o impacto seria menor, mas importante, resultando em acréscimo de 1,3 ano. 
Estudo de YAZAKI e ORTIZ (1985), também para 1979-80, mostra que as causas externas tinham grande impacto na esperança de vida ao nascer nas regiōes brasileiras. A eliminação dessas causas resultaria em ganho de 4,1 anos na esperança de vida ao nascer da população masculina na Região Centro-Oeste, cerca de 3,9 anos nas Regiōes Norte e Nordeste, e aproximadamente 3 anos no Sul e no Sudeste. Para as mulheres, os ganhos seriam de 1,0 ano para o Sul e Sudeste, 1,1 para o Norte e 1,2 para as outras duas regiões.

Para 1991, BARBOSA e ANDRADE (1998) mostram que haveria um ganho de 3,2 anos na esperança de vida ao nascer para a população masculina do Brasil, com a eliminação das causas externas, valor menor que o observado em 1979-80, devido a redução dos coeficientes de mortalidade por essas causas nas Regiões Norte e Nordeste. Para as mulheres, os ganhos também eram inferiores aos de 1979-80, estando entre 0,9 e 1,1 ano nas regiões .

CAMARANO et alii (1997) mostram que haveria um aumento de 2,2 anos na esperança de vida aos dez anos de idade e de 2,1 anos entre a população masculina economicamente ativa do país em 1991-92 com a eliminação das causas externas. Para as mulheres, esses ganhos seriam de, respectivamente, 0,8 ano e 0,3 ano, uma vez que sua participação no mercado de trabalho é menor que entre os homens.

Esses resultados indicam, portanto, o grande impacto que as causas externas vêm tendo sobre os indicadores demográficos desde o final da década de 70. Embora não existam estimativas para anos mais recentes, certamente 0 impacto será ainda maior, uma vez que os coeficientes de mortalidade por causas externas atingiram os maiores valores em 1996-97, além dos óbitos estarem concentrando-se cada vez mais em populações mais jovens.

A situação nas regiōes e em muitos Estados não é diferente. Como observado anteriormente, o Estado de São Paulo inclui-se entre os que apresentam, além de coeficientes elevados, tendência de aumento em grande parte das últimas duas décadas. A situação desse Estado será apresentada a seguir. 


\section{AS CAUSAS EXTERNAS NO ESTADO DE SÃO PAULO}

\section{As informaçס̋es para Săo Paulo}

Para o Estado de São Paulo dispõe-se de dados demográficos referentes a casamentos, nascimentos, óbitos gerais e as causas de morte, para todos os seus municípios desde o final do século XIX. As informações dos períodos mais antigos estão publicadas nos Anuários Estatístico e Demógrapho-Sanitário, cuja série inicia-se em 1892, permitindo acompanhar a evolução demográfica do Estado e as principais alteraçōes que vêm ocorrendo desde então.

No entanto, apesar da existência dessa longa série de informações, os estudos epidemiológicos e demográficos para o Estado de São Paulo tornaram-se mais freqüentes somente a partir do final da década de 70 , situação semelhante à observada para o Brasil.

Anteriormente, ressaltam-se apenas os comentários existentes nos Anuários de São Paulo e os estudos em que MORTARA (1961) utilizou as informações do Registro Civil do Estado, por ser praticamente a única fonte que possibilitava calcular indicadores demográficos de forma direta. No caso dos Anuários, os comentários enfocavam principalmente a situação da mortalidade infantil e a evolução das causas infecciosas e parasitárias, que constituíram-se nas principais causas de morte em grande parte do século $X X$.

A partir do final dos anos 70 , multiplicam-se os estudos que procuram avaliar e acompanhar a dinâmica demográfica do Estado de São Paulo e especialmente para sua capital, ressaltando-se os elaborados por pesquisadores da Faculdade de Saúde Pública da Universidade de São Paulo e da Fundação Seade.

Entre os estudos que mostram a evolução da mortalidade de uma forma mais global, destacam-se as Tábuas de Mortalidade, elaboradas inicialmente para o Estado de São Paulo e, posteriormente para as suas regiōes e para a capital. 
As primeiras Tábuas referentes ao Estado de São Paulo correspondem aos períodos de 1939-41, 1949-51, 1959-61 e 1969-71 e trazem vários indicadores, entre os quais os mais conhecidos são a esperança de vida ao nascer $e$ as probabilidades de morte, que também estão disponíveis por sexo e idade (FERREIRA 1980).

No primeiro período (1939-41), a esperança de vida ao nascer para a população total do Estado de São Paulo era de 45,4 anos, com pequena diferença por sexo: 44,3 anos para os homens e 46,7 anos para as mulheres. Duas décadas depois, a esperança de vida ao nascer aumentou quase 17 anos, alcançando 61,2 anos em 1960, sendo que entre as mulheres aproximava-se de 63,7 anos e, para os homens, de cerca de 59,3 anos, com a diferença aumentando portanto, de 2,4 anos para 4,6 anos (Tabela 1).

Tabela 1

Esperança de Vida ao Nascer, por Sexo

Estado de São Paulo

1940-1998

\begin{tabular}{|c|c|c|c|c|}
\hline & & & & Em anos) \\
\hline Anos & Total & Homens & Mulheres & Diferença \\
\hline 1940 & 45,4 & 44,3 & 46,7 & 2,4 \\
\hline 1950 & 54,2 & 52,8 & 55,9 & 3,1 \\
\hline 1960 & 61,2 & 59,0 & 63,7 & 4,6 \\
\hline 1970 & 62,6 & 59,3 & 65,5 & 6,2 \\
\hline 1980 & 66,7 & 63,3 & 70,0 & 6,7 \\
\hline 1991 & 68,9 & 64,9 & 73,2 & 8,4 \\
\hline 1998 & 70,2 & 65,9 & 74,5 & 8,6 \\
\hline
\end{tabular}

Fontes: Ferreira (1980), Ortiz e Yazaki (1984) e Ferreira e Castiñeiras (1996 e 2000)

Observa-se que, em 1970, a esperança de vida no Estado permaneceu praticamente igual à de 1960 , devido principalmente ao aumento da mortalidade infantil, registrada a partir da metade dos anos 60 .

Essas Tábuas foram elaboradas posteriormente para 1979-81, 1990-92 e 1997-98, constatando-se que a esperança de vida continuava a aumentar no 
Estado, aproximando-se, em anos recentes, de 66 anos para os homens e de 75 anos para as mulheres (ORTIZ e YAZAKI 1984; FERREIRA e CASTIÑEIRAS 1996 e 2000).

Essas informações mostram, portanto, que continuam a ocorrer alterações importantes na mortalidade no Estado de São Paulo, resultando inclusive em maior diferença por sexo. A disponibilidade de dados mais detalhados para as últimas décadas permite avaliar os grupos etários e as causas que proporcionaram o aumento da esperança de vida ao nascer. Embora o enfoque principal deste estudo refira-se às duas últimas décadas, para o Estado estenderse-á essa avaliação para um período maior.

\section{Evolução das Causas de Morte}

A disponibilidade de informações para o Estado de São Paulo tem permitido que muitos pesquisadores as utilizem para diagnosticar não apenas a situação recente, mas também para periodos mais remotos. RIBEIRO (1993), por exemplo, focaliza a história da saúde pública em São Paulo e as condições sanitárias entre o final do século $X I X$ e as primeiras décadas do século $X X$. Ressaltam-se aspectos relacionados aos órgãos responsáveis pela produção dessas informações desde seu inicio, a qualidade dos dados e, principalmente, a avaliação das condiçōes de saúde do Estado de São Paulo. A exemplo do que se observava para o Brasil, essas condições mostravam-se muito precárias, tanto no interior como na capital, com alta incidência de doenças infecciosas e parasitárias, especialmente a diarréia e a tuberculose. Estas causas provocavam altas taxas de mortalidade, principalmente entre as crianças e as mulheres jovens, sendo que estas também estavam expostas às complicações da gravidez (mortalidade materna), que igualmente eram muito elevadas. Ainda que tais causas tenham diminuído consideravelmente após a década de 30 , continuaram muito importantes até a década de 70, tanto no Brasil como no Estado de São Paulo.

A evolução da mortalidade segundo as principais causas, para o período de 1930 a 1970 é destacada em alguns estudos para o Brasil que utilizam as capitais 
como referência e onde se inclui São Paulo (YUNES et alii 1974 e 1979 e FUNDAÇÃO OSWALDO CRUZ 1982).

Em um estudo da década de 70 que enfocava a mortalidade na infância e a materna, para o Estado de São Paulo, constatava-se que os "acidentes, envenenamentos e violências" já constituiam-se nas principais causas de morte dos grupos de 1 a 4, 5 a 9 e 10 a 14 anos. No entanto, as recomendações para que a mortalidade diminuísse nos anos seguintes ainda contemplavam basicamente as causas infecciosas, como se pode observar na Carta de Punta del Este, elaborada em 1961. Entre as metas a serem alcançadas pelo país destacavam-se as seguintes:

- aumentar, no mínimo, em cinco anos a esperança de vida ao nascer;

- aumentar a capacidade do indivíduo para apreender e produzir;

- melhorar a saúde individual e coletiva.

As propostas apresentadas levaram em consideração o aumento da disponibilidade de água potável, o controle das doenças transmissiveis, a melhoria dos níveis de nutrição, a maior capacitação dos profissionais de saúde e a erradicação das doenças para as quais já se dispunha de técnicas eficazes (SECRETARIA DE ESTADO DA SAÚDE 1975).

No estudo em que ORTIZ e YAZAKI (1984) mostram a evolução da mortalidade para o Estado de São Paulo de 1930 a 1980, confirmam-se essas tendências não apenas para os grupos citados, mas também para outros. Informações detalhadas são apresentadas considerando a população por sexo e idade e entre os resultados mais significativos destacam-se os seguintes:

- a mortalidade infantil diminuiu de 175 por mil, em 1940, para 51 por mil, em 1980, observando-se redução tanto na mortalidade neonatal quanto na infantil tardia, mas de forma mais intensa entre 6 e 11 meses. As doenças infecciosas, que eram a principal causa de morte, com $40,5 \%$ do total dos óbitos infantis, passaram para a segunda posição com $23,7 \%$ nesse período, enquanto as perinatais passaram de $5,5 \%$ para $35,5 \%$;

- a mortalidade diminuiu consideravelmente nos grupos de 1 a 4, 5 a 9 e 10 a 14 anos devido, principalmente, à redução das doenças infecciosas e parasitárias, 
seguidas pelas doenças do aparelho respiratório. A partir da década de 70 , os "acidentes, envenenamentos e violência" tornaram-se a principal causa de morte das faixas de 5 a 9 e 10 a 14 anos, ainda que os seus coeficientes de mortalidade tenham apresentado pequenas alterações desde 1940;

- em 1940 e 1950 a tuberculose era a principal causa de morte das pessoas de 15 a 24 anos. Nos anos seguintes, essa causa apresentou acentuada redução e outras, como os acidentes de veículos a motor, passaram a se constituir nas principais, cujos coeficientes de mortalidade aumentaram consideravelmente, especialmente entre os homens, que registravam cerca de 4 óbitos por 100 mil pessoas, em 1940, passando para quase 50 por 100 mil em 1980, semelhante ao observado para os homicídios. Nesse último ano quatro grupos de causas externas - homicídios, acidentes de veículos a motor, suicídios e demais acidentes - apareciam entre as cinco principais causas de morte na população masculina de 15 a 24 anos. Fato semelhante observa-se entre as mulheres, porém, com coeficientes bem menores que entre os homens e em posições diferentes. Em conjunto, estas causas representavam $72 \%$ dos óbitos masculinos e $35 \%$ dos femininos desta faixa etária e apenas os coeficientes referentes aos suicidios apresentaram redução a partir de 1940;

- a situação para a população de 25 a 34 anos é semelhante à do grupo anterior, apenas com as doenças do aparelho circulatório aparecendo entre as principais causas de morte, juntamente com as causas violentas;

- na faixa de 35 a 44 anos, as causas externas já não eram as principais, mas ainda permaneciam importantes. Os acidentes em geral e os homicídios aumentaram consideravelmente entre os homens desde 1940, aproximando-se das doenças do aparelho circulatório. Os suicídios apareciam como a principal causa externa da população feminina e uma das três principais dessa faixa etária; - a partir dos 45 anos, as causas externas perdiam representatividade, mas os "demais acidentes" ainda permaneciam importantes.

Observa-se, portanto, que muitas alterações ocorreram no período analisado e já na década de 60 as causas externas passaram a ter importância significativa, especialmente entre a população jovem masculina. Os vários tipos de 
acidentes eram as principais causas de morte no início do período estudado, mas aqueles referentes aos veículos a motor aumentaram à medida que a frota de veículos tornou-se maior. Em 1960 estas causas já eram responsáveis por cerca de $10 \%$ dos óbitos masculinos na faixa de 15 a 24 anos e permaneceram como as mais importantes até os anos 70 .

A partir da metade da década de 60 as condições de saúde da população deterioraram-se em várias áreas do país, especialmente no Estado de São Paulo. As informaçōes apresentadas por ORTIZ e YAZAKI (1984) mostram que essas alterações refletiram-se especialmente entre as crianças com menos de um ano e também para aquelas de 1 a 4 anos. Depois de diminuírem acentuadamente e de forma contínua por algumas décadas, as doenças infecciosas e parasitárias aumentaram no Estado, permanecendo com elevados percentuais até a primeira metade dos anos 70 .

O Gráfico 9 e a Tabela 9 do Anexo mostra a situação da mortalidade geral em São Paulo nesse período e nos anos seguintes, ilustrando as grandes alteraçōes que ocorreram no Estado.

As doenças infecciosas e parasitárias permaneciam importantes no início da década de 70 , constituindo-se na segunda principal causa de morte, sendo responsáveis por cerca de $15 \%$ dos óbitos do Estado. Nesse período as doenças do aparelho circulatório eram as principais causas de morte, com $31 \%$ do total, e as doenças do aparelho respiratório ocupavam a terceira posição. Em seguida vinham as neoplasias, com cerca de $10 \%$ do total de óbitos e as causas externas, com $8 \%$ a $9 \%$. Até a metade dessa década as posições e os percentuais dessas causas tiveram poucas modificações e a taxa de mortalidade infantil permaneceu elevada, aproximando-se de 85 óbitos por mil nascidos vivos. As doenças infecciosas e parasitárias eram responsáveis por quase $40 \%$ dos óbitos dessas crianças e apareciam como sua principal causa de morte, seguidas pelas doenças do aparelho respiratório. 
Gráfico 9

Óbitos Gerais, segundo as Principais Causas de Morte

Estado de São Paulo

1971-99

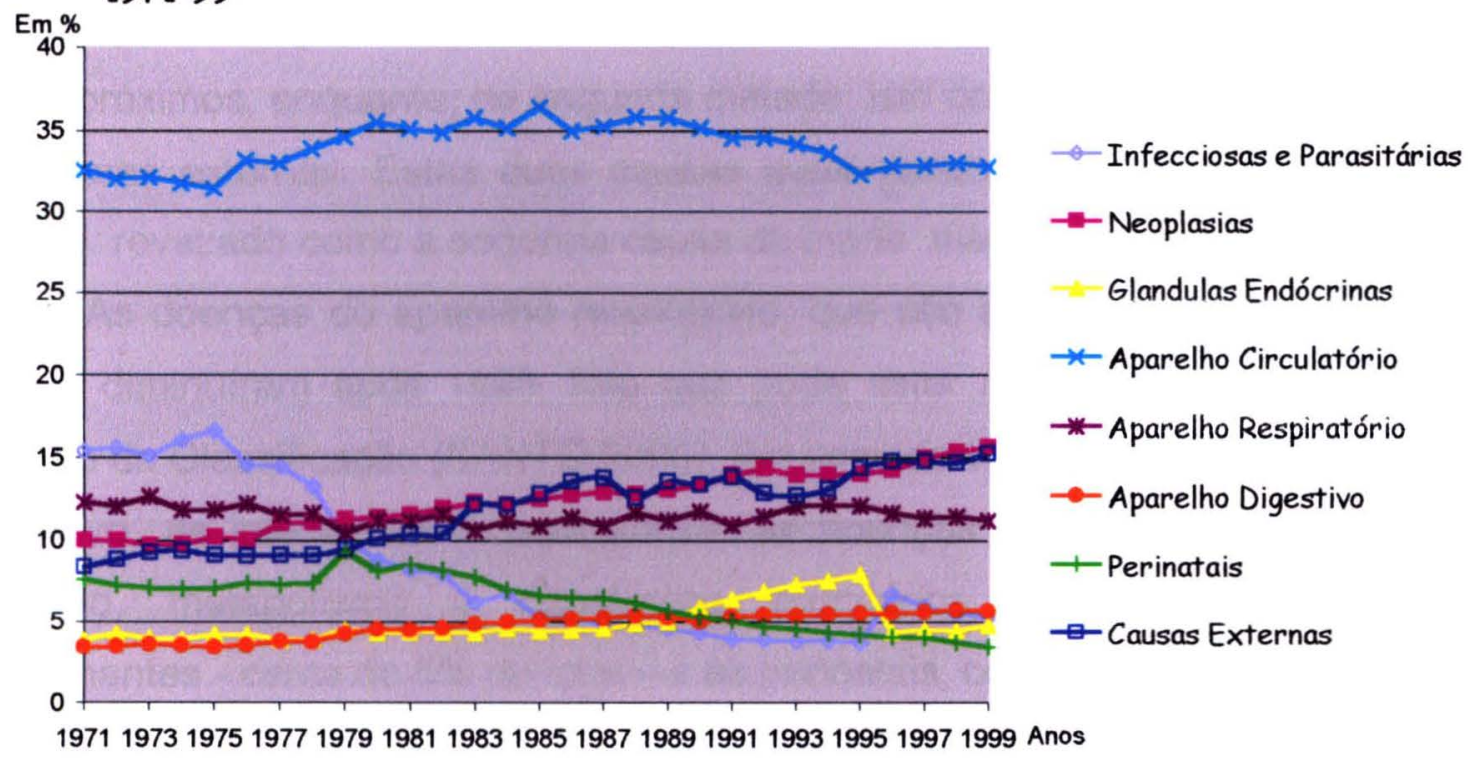

Fonte: Fundação Seade.

A partir de 1976 a situação modificou-se: as taxas de mortalidade infantil diminuíram continuamente e as causas infecciosas e parasitárias reduziram-se de forma significativa, sendo suplantadas por outra causas não apenas neste grupo etário, mas também na população geral. Nesta população, além das doenças do aparelho circulatório, as neoplasias e as causas externas também suplantaram as doenças infecciosas e parasitárias. Em 1980, as doenças do aparelho circulatório passaram a ser responsáveis por $36,9 \%$ do total das mortes com causas definidas, seguidas pelas neoplasias $(11,8 \%)$ e pelas doenças do aparelho respiratório $(11,7 \%)$. As causas externas apareciam como a quarta principal causa de morte, com $10,5 \%$ do total, enquanto as infecciosas e parasitárias passaram para $9,2 \%$, caindo portanto para a quinta posição, pouco acima das perinatais, que alcançaram, 8,4\%.

Nos anos 80 as mudanças continuaram significativas, observando-se que as doenças infecciosas e parasitárias diminuíram ainda mais, situando-se inclusive abaixo das perinatais e tendo a aproximação das doenças do aparelho digestivo. 
Ao final dessa década as doenças infecciosas e parasitárias ocupavam apenas a oitava posição, superadas por todas as causas citadas anteriormente (Gráfico 9).

Entre as demais causas de morte verifica-se que, na primeira metade dos anos 80 , as doenças do aparelho respiratório e as neoplasias tiveram percentuais muito próximos, enquanto, na segunda metade, isto ocorreu entre as neoplasias e as causas externas. Estas duas causas aumentaram em termos percentuais e têm-se revezado como a segunda causa de morte mais importante do Estado.

As doenças do aparelho respiratório, que são a quarta principal causa de morte, diminuíram após 1995, fato que pode estar relacionado à mudança da revisão da Classificação (SANTO 2000). Em seguida vêm as doenças do aparelho digestivo, as infecciosas e parasitárias, as doenças das glândulas endócrinas, nutrição, metabolismo e transtornos imunitários, com percentuais muito semelhantes - cerca de $5 \%$ do total -e as perinatais, com pouco mais de $3 \%$.

Os oito grupos de causas relacionados anteriormente têm sido responsáveis por cerca de $94 \%$ dos óbitos ocorridos no Estado de São Paulo, desde 0 início dos anos 70 . Entretanto cada causa tem apresentado muitas alterações, tanto em termos percentuais como nas posições ocupadas.

As causas externas eram superadas por várias outras até o final dos anos 70, quando aumentaram quase seguidamente, obtendo cada vez maior importância. Durante as últimas duas décadas, estas causas constituiram-se na segunda mais importante em vários anos, especialmente para a população masculina.

No Gráfico 10 e na Tabela 10 do Anexo, observa-se a evolução da mortalidade das principais causas de morte para os homens e, no Gráfico 11 e na Tabela 11 do Anexo, a correspondente para as mulheres, entre 1971 e 1999, para - Estado de São Paulo. Algumas causas apresentam evolução semelhante no decorrer do tempo, para as duas populações, ainda que os níveis mantenham-se diferentes. 
Gráfico 10

Coeficientes de Mortalidade da População Masculina, segundo Principais Causas

Estado de São Paulo

1971-99

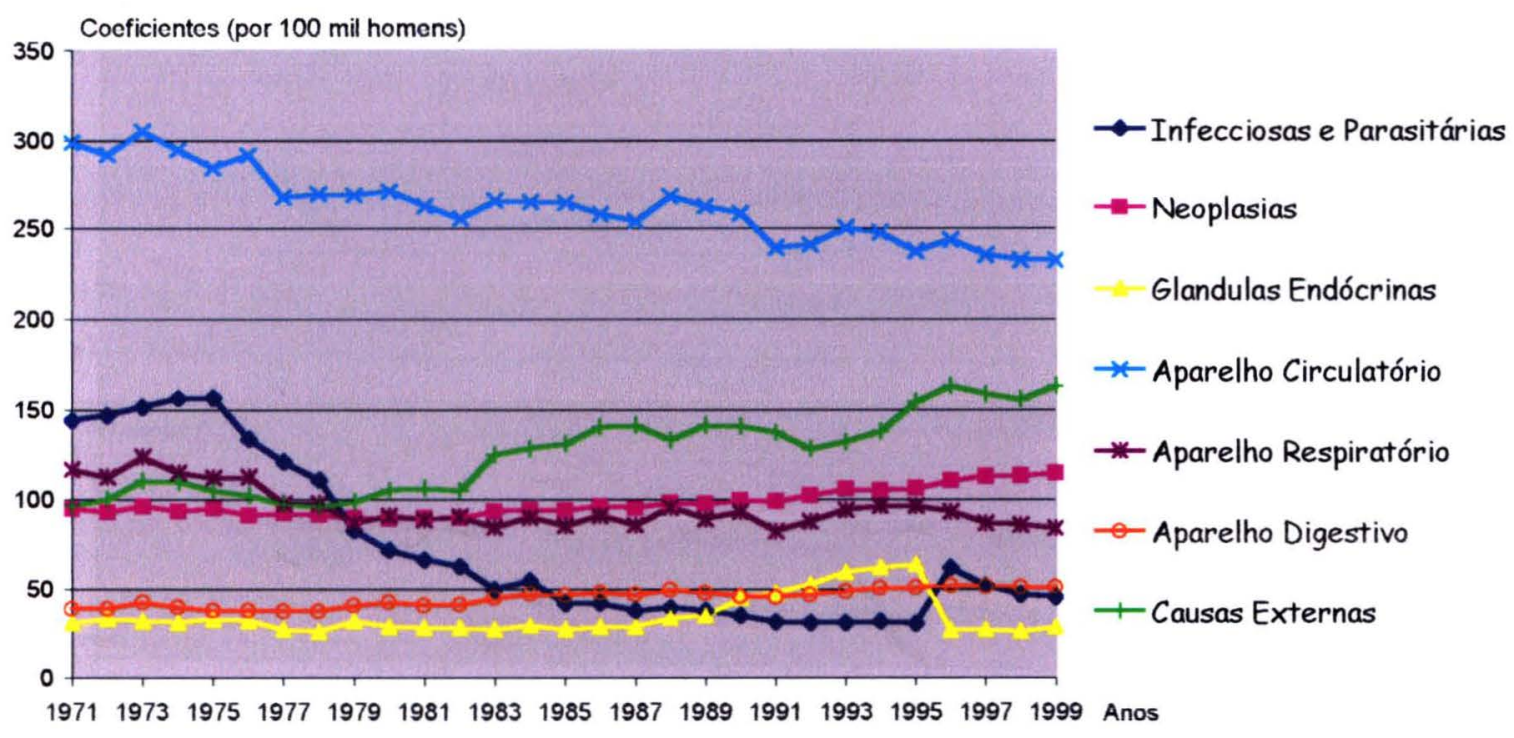

Fonte: Fundação Seade.

Em relação às doenças do aparelho circulatório, que são as principais causas de morte tanto para a população masculina como para a feminina, observa-se que as taxas de mortalidade diminuíram cerca de $20 \%$ em ambos os grupos. Esta tendência vem sendo verificada em outros países, como, por exemplo, os Estados Unidos, onde isso já ocorre desde os anos 50 , conforme ressalta LAURENTI (1990).

As doenças infecciosas e parasitárias foram as que apresentaram as maiores reduções entre as principais causas, diminuindo cerca de $70 \%$ para os homens e $80 \%$ para as mulheres, entre 1971 e 1999, destacando-se a grande redução da diarréia e do sarampo como causa de morte, especialmente entre as crianças. Em 1999 o coeficiente de mortalidade por doenças infecciosas e parasitárias era cerca de duas vezes maior para os homens, sendo atualmente a Aids a principal causa deste Capitulo. 
Gráfico 11

Coeficientes de Mortalidade da População Feminina, segundo Principais Causas

Estado de São Paulo

1971-99

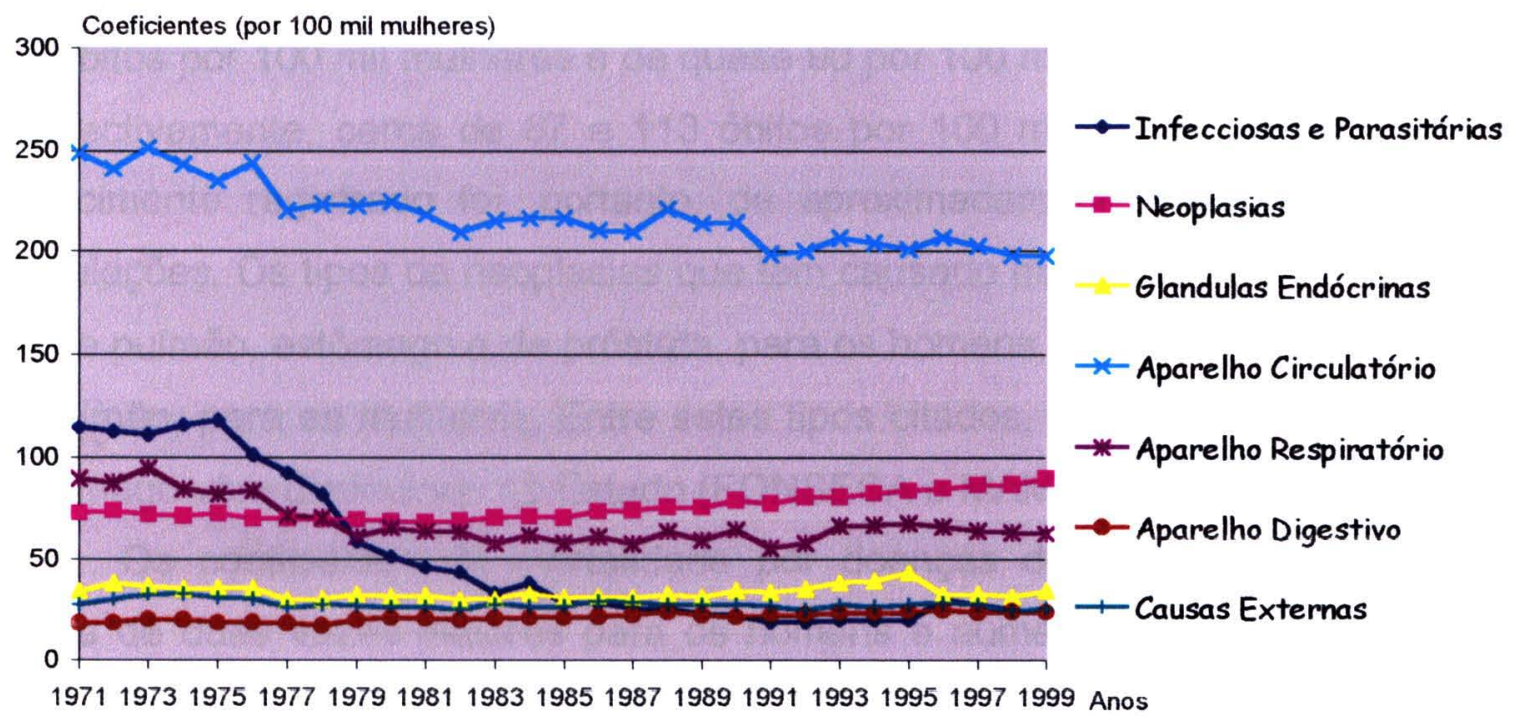

Fonte: Fundação Seade.

As doenças do aparelho respiratório também apresentaram importante redução: cerca de cerca de $30 \%$ em ambas as populações. Destaca-se que a pneumonia, que é a principal causa neste grupo contribuiu de forma importante para a redução da mortalidade infantil. Nos últimos anos, os coeficientes de mortalidade da população masculina eram cerca de $34 \%$ maiores que os femininos. Entretanto, a diferença vem diminuindo em relação ao final da década de 80 , quando o coeficiente da população masculina era superior em $50 \%$.

Comportamento diferente apresentou o grupo das doenças das glândulas endócrinas, nutrição, metabolismo e transtornos imunitários, no qual a principal causa é o diabetes mellitus. Enquanto entre os homens os coeficientes de mortalidade registraram redução de cerca de $8 \%$, entre as mulheres tiveram pequeno aumento, sendo um dos poucos grupos em que os coeficientes femininos superam os da população masculina. No período de 1996-98, esse coeficiente situava-se entre 32 e 34 óbitos por 100 mil mulheres, cerca de $20 \%$ maior que os dos homens (28 óbitos por cem mil). Neste grupo de causas ressalta-se que 
houve grande diminuição da mortalidade por desnutrição, que atingia principalmente as crianças.

As neoplasias apresentaram aumento nos coeficientes de mortalidade principalmente a partir de 1985. Entre 1971 e 1985, esse coeficiente era de 70 a 73 óbitos por 100 mil mulheres e de quase 90 por 100 mil homens, passando para respectivamente, cerca de 87 e 113 óbitos por 100 mil no período 1997-99. O crescimento registrado foi, portanto, de aproximadamente $30 \%$ para as duas populações. Os tipos de neoplasias que têm causado maior número de óbitos são os de pulmão, estômago e de próstata, para os homens, e os de mama, estômago e pulmão, para as mulheres. Entre estes tipos citados, somente os referentes ao estômago vêm diminuindo no Estado (FONSECA e MAMERI 1994).

Os coeficientes de mortalidade por doenças do aparelho digestivo são cerca de duas vezes maiores para os homens e aumentaram por volta de $30 \%$ para ambas as populações, desde 1971. Este coeficiente que era de 39 por 100 mil para os homens e de 19 por 100 mil para as mulheres, passou, respectivamente para cerca de 50 por e 24 por 100 mil. As principais causas de morte deste grupo são as doenças do fígado.

Ainda que muitas alterações tenham sido observadas entre as principais causas de morte desde o início dos anos 70 , poucas se comparam às das causas externas, especialmente quando se trata da população masculina. O coeficiente de mortalidade para essas causas, que no início dos anos 70 , estava pouco abaixo de 100 óbitos por 100 mil homens, alcançou 163 óbitos por $100 \mathrm{mil}$ em 1999, registrando um aumento de quase $70 \%$. Com o contínuo crescimento das causas externas e a redução das doenças do aparelho circulatório, verifica-se que a cada ano tem havido maior proximidade entre estas causas de morte na população masculina. Em 1971 ocorriam 3,1 óbitos por doenças do aparelho circulatório para um das causas externas, sendo que em 1999 essa razão passou para 1,4 , com o percentual destas últimas aumentando de $11 \%$ para $22 \%$ no período.

Para a população feminina, a configuração é bem distinta, pois os coeficientes de mortalidade das causas externas mantêm-se muito regulares, 
aproximando-se de 27 óbitos por 100 mil mulheres em todo o período, muito inferiores aos da população masculina. Torna-se assim interessante observar a evolução dos grupos dessas causas nesse período, pois, além de mostrar a contribuição de cada uma, permite verificar se essa constância não compreende compensações entre homicídios, suicídios e acidentes.

Para a população masculina, isso adquire ainda maior importância não apenas pelos elevados coeficientes que apresentam, mas também pela possibilidade de verificar os grupos que estão contribuindo mais intensamente para seu aumento, nesse periodo.

Dessa forma são apresentadas, a seguir considerações mais específicas sobre as causas externas, destacando-se não apenas sua evolução global, mas também algumas características importantes, como a distribuição por sexo, idade e grupos de causas.

\section{As Causas Externas}

A importância que as causas externas vêm adquirindo em áreas do Estado de São Paulo tem sido comprovada há vários anos nos estudos feitos, principalmente, a partir da década de 70.

No Estado, a capital e a Região Metropolitana de São Paulo têm sido as áreas mais estudadas porque, além de deterem significativa parcela da população estadual, tradicionalmente dispõem de melhores informações e registram altos coeficientes de mortalidade por essas causas.

Um dos primeiros estudos a tratar especificamente as causas externas foi o de RAMOS e BARBOSA (1965), no qual é ressaltada a significativa mortalidade por suicídios no Município de São Paulo, no período de 1948 a 1962. Este estudo foi atualizado posteriormente com dados de 1959 a 1968, verificando-se que os coeficientes de mortalidade por essas causas vinham diminuindo. Observou-se também, que os óbitos continuavam a ocorrer em maior proporção para os homens e que os percentuais de mortes provocadas por armas de fogo tornavamse maiores (BARBOSA 1974). 
Na década de 70, LAURENTI et alii (1972) analisaram a evolução da mortalidade por acidentes de trânsito no Município de São Paulo, constatando entre outros resultados, o grande aumento dos respectivos coeficientes a partir de 1960. Entre 1960 e 1967, os coeficientes de mortalidade duplicaram nesse Município passando de cerca de 14 para 25 óbitos por 100 mil habitantes.

SILVEIRA e GOTLIEB (1976) analisaram a evolução da mortalidade por acidentes e demais violências também para o Municipio de São Paulo, mostrando que estas causas vinham adquirindo grande importância. Entre 1970 e 1972 , as causas externas constituiam-se na terceira mais importante entre os homens, representando cerca de $12 \%$ dos óbitos, enquanto para as mulheres ainda não figuravam entre as cinco primeiras. Para a população masculina o coeficiente de mortalidade aproximava-se de 113,3 óbitos por 100 mil homens. As mortes por acidentes de veículos a motor representavam cerca de $43 \%$ das causas externas, seguindo-se os "outros acidentes" (27\%), os homicídios $(16 \%)$ e os suicídios $(9 \%)$. Os demais $4 \%$ ficavam na categoria na qual se ignorava se as violências haviam sido acidentais ou intencionalmente infligidas. Para as mulheres, o coeficiente total aproximava-se de 31 por 100 mil e os óbitos por acidentes de veículos a motor correspondiam a $48 \%$ do seu total, seguidos pelos "demais acidentes" ( $26 \%)$, os suicidios $(13 \%)$ e os homicídios $(9 \%)$. Os restantes $4 \%$ cabiam ao grupo em que se ignorava a sua intenção.

Os coeficientes de mortalidade por causas externas no período de 1970-72, eram muito superiores entre os homens, fato que se estendia a todos os grupos de causas. Os coeficientes de mortalidade por acidentes com veículos a motor correspondiam a 49,1 óbitos por 100 mil homens e a 15,0 por 100 mil mulheres, enquanto para os demais acidentes alcançavam, respectivamente, 31,1 e 8,0 óbitos por 100 mil. Os coeficientes de homicídios eram de 18 óbitos por 100 mil homens e de 2,7 por 100 mil para as mulheres, e os de suicídios alcançavam, respectivamente, 10,5 e 4,1 por 100 mil.

Observa-se também que os acidentes representavam a grande parcela das causas violentas, ainda que os homicídios viessem aumentando no período analisado, especialmente entre os homens. Estes, porém, não se constituíam nas 
principais causas em nenhuma das faixas etárias apresentadas, sendo que o maior coeficiente de mortalidade por essas causas era observado no grupo de 20 a 29 anos da população masculina, em que se aproximava-se de 40,2 óbitos por 100 mil habitantes. Na população feminina também era nessa faixa etária que os homicídios registravam o maior coeficiente de mortalidade, alcançando 5,7 óbitos por 100 mil mulheres. Ainda assim eram superados pelas demais causas externas, inclusive os suicídios, cujo coeficiente total de 7,9 por $100 \mathrm{mil}$ os deixavam como a segunda causa de morte externa mais importante.

Os estudos de MELLO JORGE (1979; 1980; 1981 e 1982) relativos ao Município de São Paulo mostram a importância que estas causas vinham adquirindo. Em um dos estudos elaborados em 1980, o autor apresenta a situação da mortalidade por várias causas externas, para o Município de São Paulo, entre 1960 e 1975, utilizando dados dos laudos do IML.

Verifica-se que, nesse período, houve grande aumento da mortalidade por causas externas, cujo coeficiente mínimo passou de 44,1 óbitos por 100 mil habitantes, em 1960, para 42,7 em 1965, 58,6 em 1970 e 59,2 em 1975. Constatase, portanto, que o maior crescimento dessa mortalidade ocorreu entre 1965 e 1970, devendo-se, em grande parte, ao aumento dos óbitos por acidentes de veículos a motor, cujo coeficiente praticamente duplicou. Os homicídios também apresentaram importante expansão, passando de 8,8 óbitos por $100 \mathrm{mil}$ habitantes, em 1960, para 15,5 por 100 mil em 1970, entre os homens, ou seja, quase duplicando, ainda que em um periodo maior. Por outro lado, os coeficientes de mortalidade por suicídios, mantiveram a tendência de redução, apontada anteriormente por BARBOSA (1974). Em 1960, os suicídios apresentavam coeficientes de mortalidade semelhantes aos dos acidentes de veículos a motor, que, por sua vez, estavam abaixo somente dos "demais acidentes". Para as mulheres, os suicídios constituiam-se na principal causa de mortalidade externa, igualando-se aos "demais acidentes".

Entre 1970 e 1975, os coeficientes de mortalidade por causas externas apresentaram poucas alteraçōes, especialmente para as mulheres. 
No segundo estudo de 1980, MELLO JORGE, especificou a mortalidade por acidentes, apresentando várias características relacionadas à sua ocorrência. Somente os óbitos por acidentes de trânsito aumentaram 455\%, entre 1960 e 1975, e o correspondente coeficiente de mortalidade duplicou entre 1965 e 1970. Os atropelamentos representavam cerca de $80 \%$ do total desse grupo, ressaltando-se ainda que as quedas e os afogamentos também apareciam como importante causa entre os acidentes. Os coeficientes de mortalidade por acidentes de trânsito cresciam continuamente à medida que aumentavam as faixas etárias entre os homens, enquanto para as mulheres elevavam-se somente a partir dos 40 anos de idade.

No estudo em que MELLO JORGE (1981) estudou as mortes intencionais, detalhou-se a mortalidade por suicídios e homicídios. Como ressaltado anteriormente, os suicídios diminuíram acentuadamente no período estudado no Município de São Paulo, enquanto os homicídios aumentaram. O coeficiente de mortalidade por suicídios, que era de 11,9 por 100 mil pessoas em 1960, passou para 8,2 por 100 mil em 1965, 7,4 em 1970 e 5,3 em 1975 (valores mínimos). Já aqueles referentes aos homicídios corresponderam a, respectivamente, 5,2; 6,4; 9,1 e 9,4 por 100 mil habitantes e, a exemplo do que se observou para os acidentes de veículos a motor, registrou grande aumento no período de 1965 a 1970.

No estudo de 1982, MELLO JORGE apresentou a situação da mortalidade por causas externas também para o Município de São Paulo para 1980. O coeficiente de mortalidade por causas externas, desse ano, era inferior ao de 1975, mas a redução observada entre os acidentes em geral foi compensada por um aumento de cerca de $80 \%$ entre os homicídios.

Os resultados obtidos por ORTIZ e YAZAKI (1984), mostram que para o Estado de São Paulo as causas externas vinham adquirindo grande importância desde 1940, especialmente entre a população jovem.

Em relação à população total as informaçōes referentes ao início dos anos 70 mostram que os coeficientes de mortalidade por causas externas aproximavam-se de 60 óbitos por 100 mil habitantes e já apresentavam 
significativa diferença por sexo, a exemplo do que se observou para a capital. Para os homens, o coeficiente era de cerca de 95 óbitos por 100 mil, enquanto para as mulheres correspondia a apenas 27 por 100 mil habitantes. No final da década de 90, estes coeficientes alcançaram 160 óbitos por 100 mil homens e para as mulheres, mantiveram-se em torno de 25 por 100 mil (Gráfico 12 e Tabela 12 do Anexo).

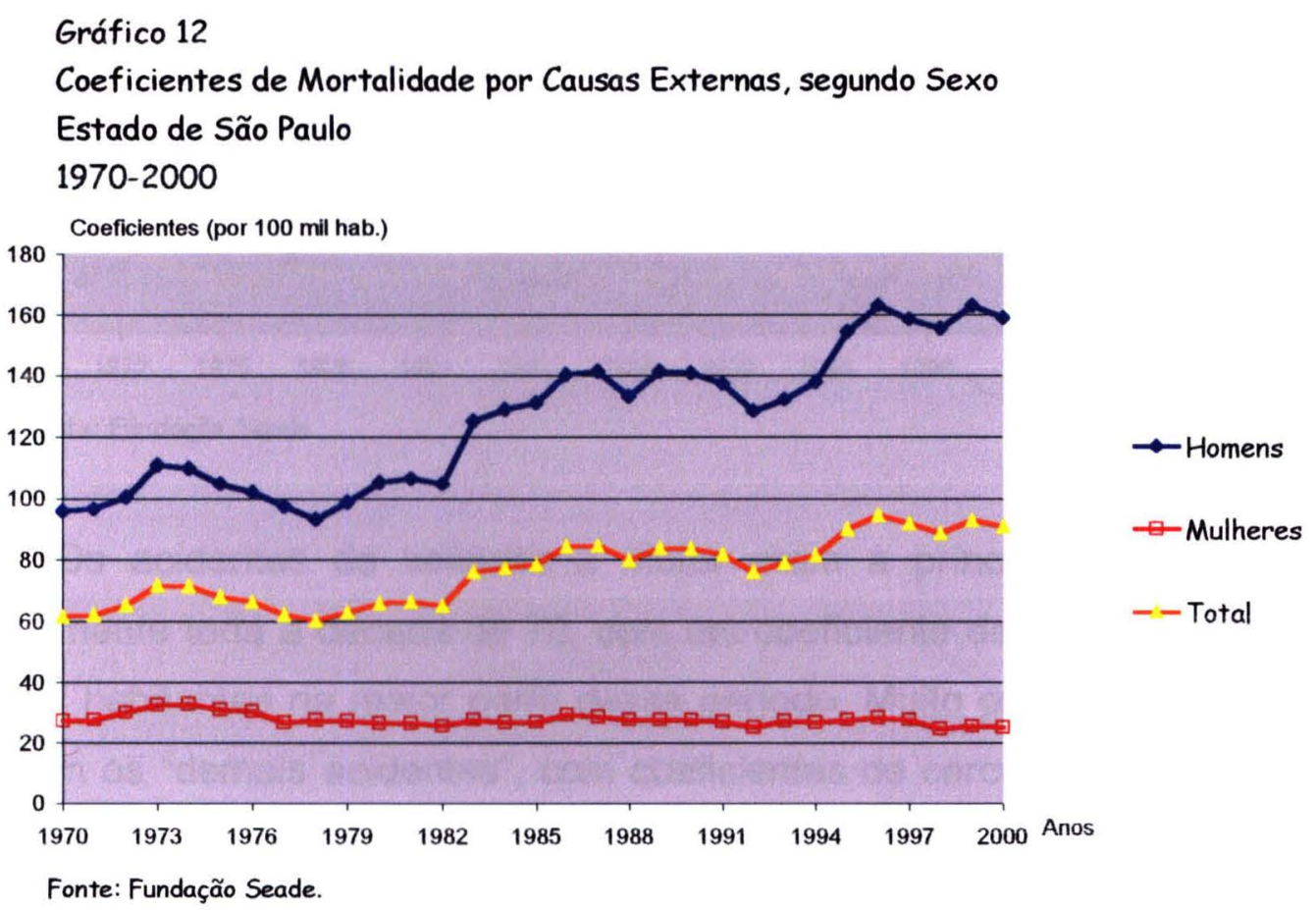

Quanto aos grupos de causas, os acidentes de veículos a motor representavam quase $40 \%$ do seu total, em 1970-71, seguidos depois pelos demais acidentes, com cerca de $35 \%$. Nesse período os valores relativos aos óbitos provocados por homicídios foram muito semelhantes aos dos suicídios, com percentuais próximos de $10 \%$ do total para cada um, enquanto os $7 \%$ restantes constituiam-se das demais causas externas.

Os homicídios permaneceram como a terceira causa externa mais importante até o final da década de 70 , ainda que seus coeficientes tenham quase duplicado, passando de cerca de 6,5 por 100 mil habitantes em 1969-71, para 9,4 em 1979 e para 12,8 por 100 mil em 1980 (Gráfico 13 e Tabela 13 do Anexo). 


\section{Gráfico 13}

Coeficientes de Mortalidade por Causas Externas, segundo Tipos

Estado de São Paulo

1969-99

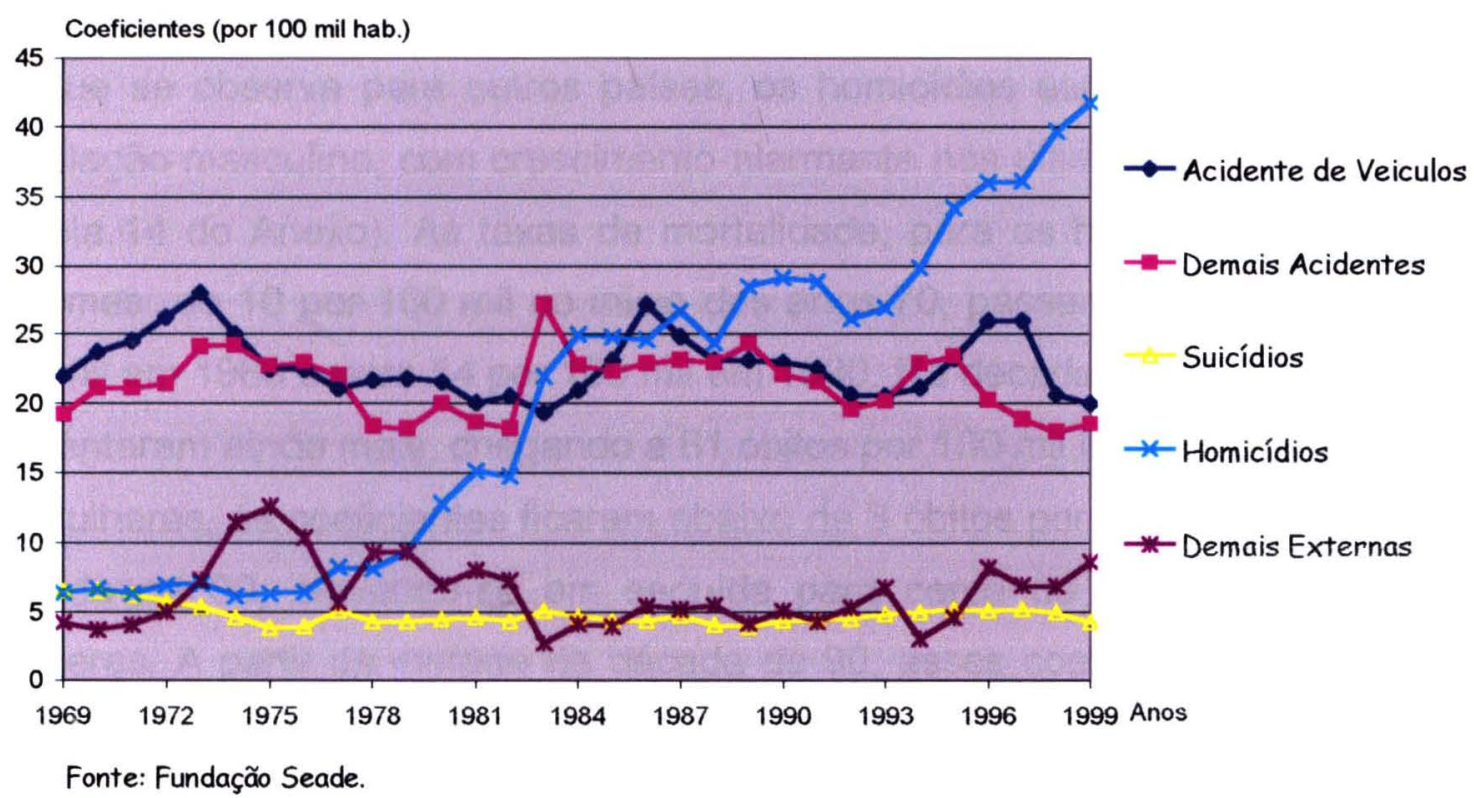

Os acidentes de veículos a motor eram a principal causa externa em praticamente toda a década de 70 , com um coeficiente de cerca de 22 óbitos por 100 mil habitantes na maior parte desse período. Muito próximos a estas causas estavam os "demais acidentes", com coeficientes de cerca de 20 óbitos por 100 mil e também apresentando poucas modificações no período.

A partir de 1984 os acidentes de veículos a motor e os demais acidentes, que eram as principais causas deste grupo, foram superados pelos homicídios, cujos coeficientes de mortalidade cresceram de forma significativa, dobrando em apenas quatro anos, ao passar de 12,8 óbitos por cem mil habitantes em 1980, para 24,9, em 1984. Nos anos seguintes, a tendência manteve-se crescente, ainda que em ritmo inferior ao dos anos anteriores. No final da década de 80 , o coeficiente de mortalidade era de cerca de 29 óbitos por 100 mil habitantes, ou $16 \%$ acima do observado em 1984. Este coeficiente voltou a aumentar a partir de 1994, quando passou para 30 óbitos por 100 mil, chegando a 43 por 100 mil, em 1999, ou seja, quase sete vezes superior àquele registrado em 1970.

As informações apresentadas mostram, portanto, que os homicídios vêm aumentando no Estado de São Paulo, principalmente a partir do final da década 
de 70 , fato que foi ainda mais agravado nos anos seguintes. Os coeficientes de mortalidade devido aos diferentes tipos de acidentes, especialmente de veículos a motor, também eram elevados, mas registravam variações menores. A exemplo do que se observa para outros países, os homicídios atingem especialmente a população masculina, com crescimento alarmante nos últimos anos (Gráfico $14 \mathrm{e}$ Tabela 14 do Anexo). As taxas de mortalidade, para os homens, que estavam próximas de 10 por 100 mil no início dos anos 70 , passaram para 23 óbitos por 100 mil em 1980 e para 54 por 100 mil em 1990. Na década de 90, os coeficientes aumentaram ainda mais, chegando a 81 óbitos por 100 mil homens em 1999. Para as mulheres, os coeficientes ficaram abaixo de 3 óbitos por 100 mil até o início da década de 80 , elevando-se em seguida para cerca de 4 óbitos por 100 mil mulheres. A partir da metade da década de 90 , esses coeficientes aproximaramse de 5 óbitos por 100 mil mulheres e, em 1999, alcançaram o maior valor: 6,1 óbitos por 100 mil mulheres, aproximando-se dos coeficientes registrados para os acidentes de transportes.

Gráfico 14

Coeficientes de Mortalidade por Causas Externas, por Tipos, segundo Sexo

Estado de São Paulo

1969-99
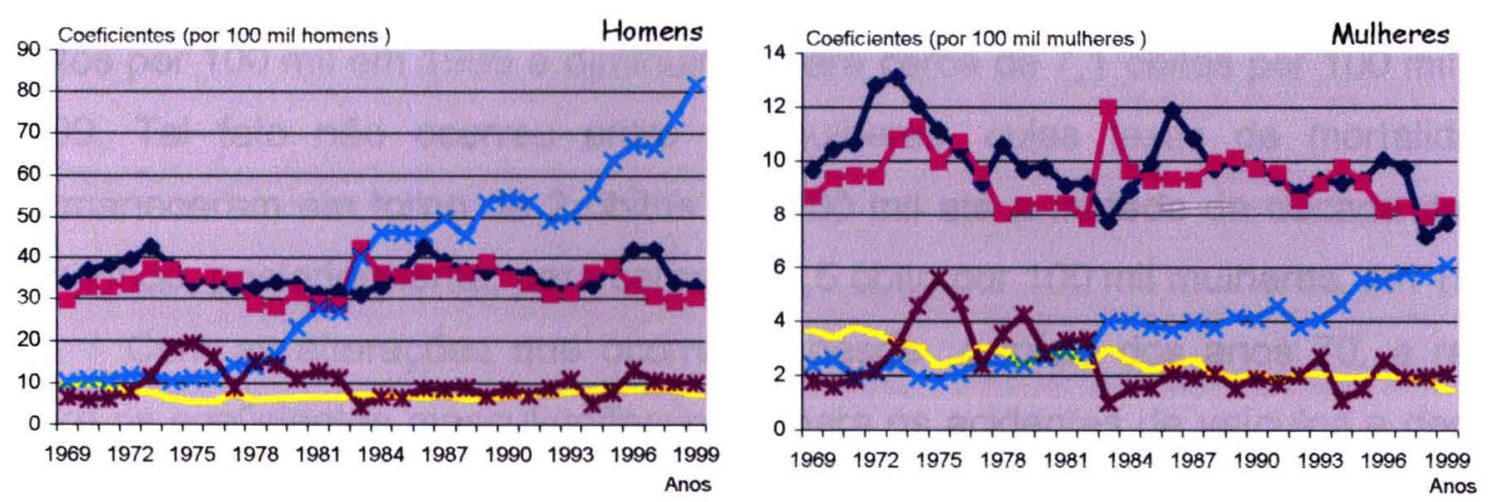

$\multimap$ Ac. Veículos $\rightarrow-$ Demais Acidentes

Suicídios $\rightarrow$ Homicídios $\rightarrow$ Demais Externas

Fonte: Fundação Seade.

Em relação aos acidentes de veículos, os coeficientes diminuíram entre 1973 e 1983, tanto para os homens como para as mulheres e aumentaram em 
seguida, até 1986, quando aproximaram-se de 43 óbitos por 100 mil homens e de 12 óbitos por 100 mil mulheres, voltando a diminuir posteriormente, tendência que se mantêm até 1993. Nesse ano, o coeficiente de mortalidade correspondia a 32 óbitos por 100 mil homens e a 9 por 100 mil mulheres. A partir dai registrou-se rápido crescimento e, em 1997, as taxas aproximaram-se de 42 e 10 óbitos por 100 mil, respectivamente, para homens e mulheres, mas, em seguida reduziramse consideravelmente, correspondendo, em 1999, a 33 e 7 óbitos por 100 mil para essas duas populações.

Os demais acidentes também apresentam oscilações nos coeficientes, no período estudado, tendo os maiores valores em 1983, quando aproximaram-se de 43 óbitos por 100 mil homens e de 12 por 100 mil mulheres. Em vários anos, essas taxas eqüivaleram a cerca de 37 e 11 óbitos por 100 mil, respectivamente, para as populações masculina e feminina. Nos últimos anos, estes coeficientes estão em torno de 30 por 100 mil homens e de 8 por 100 mil mulheres.

Em relação aos suicídios, os menores coeficientes foram registrados na metade da década de 70: cerca de 5 óbitos por 100 mil homens e de 2 por 100 mil mulheres. Até o final dos anos 80 , os coeficientes eram geralmente, inferiores a 7 óbitos por 100 mil homens e a 3 óbitos por 100 mil mulheres. A partir do início da década de 90 , estes coeficientes aumentaram entre os homens, chegando a 8,5 óbitos por 100 mil em 1995 e diminuíram para cerca de 7,1 óbitos por 100 mil, em 1999. Tal fato não ocorreu entre as mulheres, cujas taxas de mortalidade, permaneceram em torno de 2 óbitos por 100 mil até a metade da década de 90 , reduzindo, posteriormente, para cerca de 1,5 óbito por 100 mil mulheres, em 1999.

Com as alterações que ocorreram desde o início dos anos 70 , a razão entre os coeficientes masculino/feminino, para os acidentes de veiculos e demais acidentes, ficou próxima de 3,1 e, para os suicídios, entre 2 e 3,1. Já para os homicidios, a razão aumentou muito nesse periodo, passando de 4,1 para quase 9,1 , mostrando o grande crescimento registrado nessas taxas para os homens.

O panorama desse periodo, pode ser mais bem observado em alguns momentos, como por exemplo, 1971, 1979, 1986, 1992 e 1999, para o Estado de São Paulo, tanto para a população masculina como a feminina. Entre os homens, 
o crescimento da mortalidade por homicídios nesses últimos 30 anos, foi muito grande entre os jovens. O Gráfico 15 e a Tabela 15 do Anexo mostram os elevados coeficientes de mortalidade alcançados pela população masculina de 15 a 34 anos, aproximando-se de 180 óbitos por 100 mil homens. Ainda que em outras faixas os coeficientes sejam bem menores, observam-se aumentos em todas elas.

Gráfico 15

Coeficientes de Mortalidade por Homicídios, segundo Sexo e Grupos de Idade

Estado de São Paulo

1971-1999

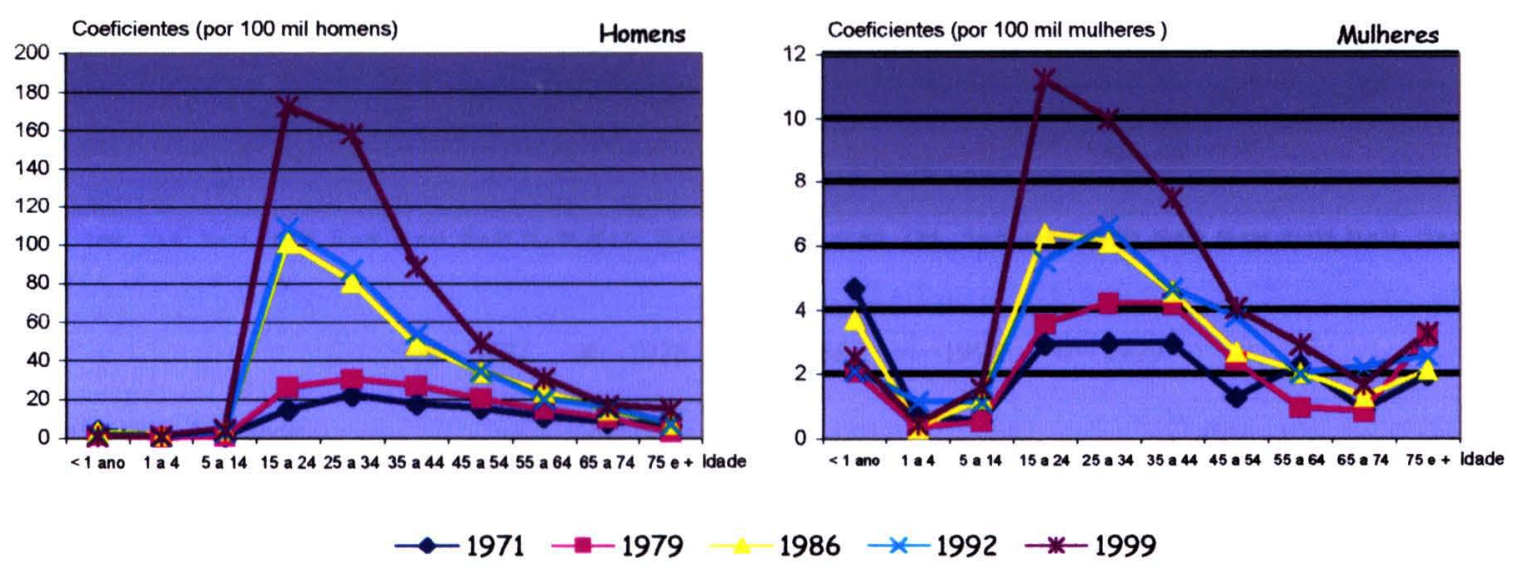

Fonte: Fundação Seade.

Tal fato ocorre também entre as mulheres, ainda que em níveis muito inferiores. As maiores taxas de mortalidade por homicídios também foram registradas entre 15 e 34 anos, chegando a se aproximar, em 1999, de 12 óbitos por 100 mil mulheres. Em 1971, o maior coeficiente para essa faixa etária era de 3 óbitos por 100 mil mulheres e, em 1979, estava pouco acima de 4 óbitos por 100 mil mulheres. Nesses anos, as taxas observadas nas faixas jovens da população masculina eram cerca de 10 vezes maiores que as observados entre as mulheres e aumentaram ainda mais nos anos seguintes.

A mortalidade por acidentes de veículos a motor mostra-se muito diferente. Em termos de evolução no tempo, observa-se que, embora seus níveis sejam relativamente elevados, tem havido significativa redução dos coeficientes respectivos, especialmente entre os homens com mais de 25 anos. Em alguns 
grupos etários, a redução entre 1971 e 1999 chegou a ser de 40\% (Gráfico 16 e Tabela 16 do Anexo).

Gráfico 16

Coeficientes de Mortalidade por Acidentes de Veículos a Motor, segundo Sexo e Grupos de Idade Estado de São Paulo

1971-1999
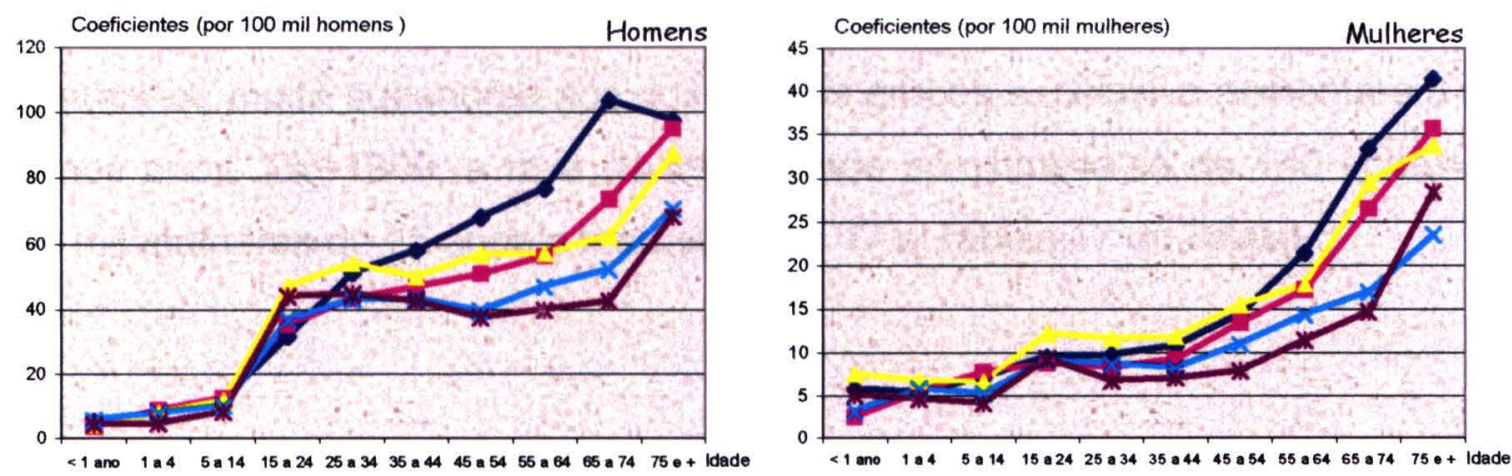

$\multimap 1971 \rightarrow-1979 \rightarrow 1986 * 1992 *-1999$

Fonte: Fundação Seade.

Já entre as mulheres foram registrados aumentos nos coeficientes de mortalidade por acidentes de veículos a motor de 1971 até 1986, em vários grupos etários. Em 1999, as taxas correspondentes às mulheres com menos de 45 anos eram semelhantes ás dos outros anos e, acima desta idade, eram menores que as observadas em 1971, 1979 e 1986. Observa-se, ainda, que os coeficientes de mortalidade feminina são menores que os da população masculina em todos os anos e faixas etárias apresentadas.

O comportamento da mortalidade assemelha-se nas duas populações, aumentando da infância até o grupo de 15 a 24 anos e permanecendo semelhante nos grupos seguintes. A partir dos 45 anos, os coeficientes de mortalidade voltam a aumentar até o grupo de pessoas de 75 anos e mais, no qual atinge os maiores valores. Isto mostra que, embora essas causas apareçam com percentuais inferiores aos de outras causas de morte nesta faixa etária, são muito importantes em termos de coeficientes, merecendo assim maior atenção por parte dos planejadores, especialmente no que se refere aos atropelamentos. 
Entre os denominados "demais acidentes", as principais causas relacionavam-se às quedas, aos afogamentos e à aspiração/ingestão de alimentos.

Se no caso dos acidentes de veículos a motor a situação mostrava-se grave em vários grupos etários, em relação aos demais acidentes isto aparece ainda mais preocupante quando se trata das pessoas mais idosas, especialmente entre as mulheres. Na população feminina, os coeficientes para as pessoas idosas mostram-se muito superiores aos dos demais grupos e inclusive aumentaram nos últimos anos. Em 1999, a taxa de mortalidade aproximava-se de 140 óbitos por 100 mil mulheres de 75 anos e mais (Gráfico 17 e Tabela 17 do Anexo).

Gráfico 17

Coeficientes de Mortalidade por "Demais Acidentes", segundo Sexo e Grupos de Idade

Estado de São Paulo

1971-1999

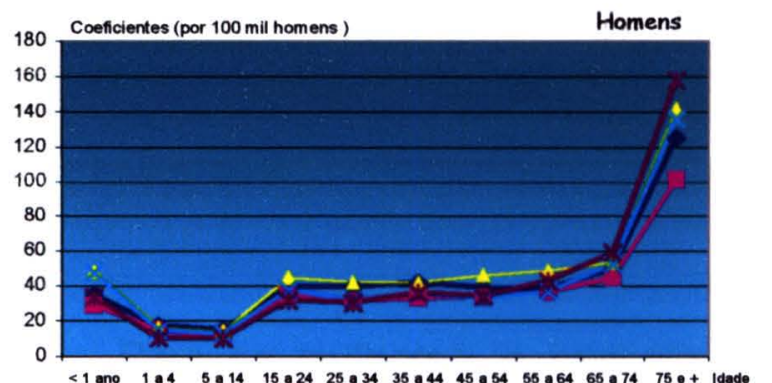

$\multimap 1971$

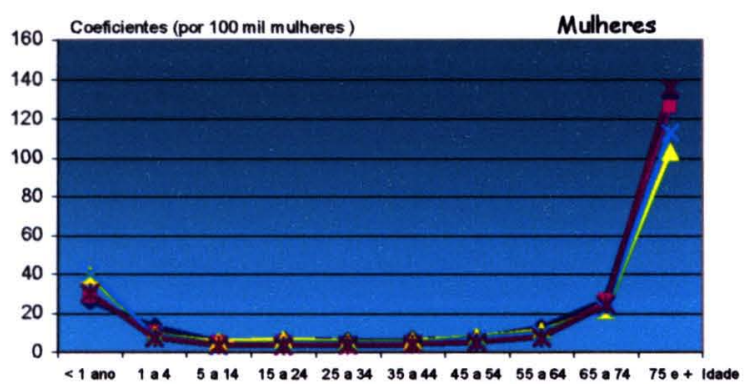

1986 $\rightarrow-1999$

Fonte: Fundação Seade.

Para os homens, o panorama é semelhante, registrando-se também coeficientes importantes entre as pessoas de 15 a 55 anos, o que pode estar relacionado com os acidentes de trabalho.

Já em relação aos suicídios, a configuração é mais complexa. O Brasil não se encontra entre as áreas que apresentam elevados coeficientes de mortalidade por suicídios, como destacam CASSORLA (1991) e CASSORLA e SMEKE (1994) e a desagregação das informações por sexo e faixas etárias torna-os mais 
suscetíveis a irregularidade. Observa-se uma tendência de aumento dos coeficientes à medida que se avança a idade, especialmente entre os homens, que registram os maiores valores entre as pessoas de mais de 65 anos, ainda que haja tendência de diminuição no decorrer do tempo, a exemplo do que ocorreu com as demais faixas etárias (Gráfico 18 e Tabela 18 do Anexo).

\section{Gráfico 18}

Coeficientes de Mortalidade por Suicidios, segundo Sexo e Grupos de Idade

Estado de São Paulo

1971-1999
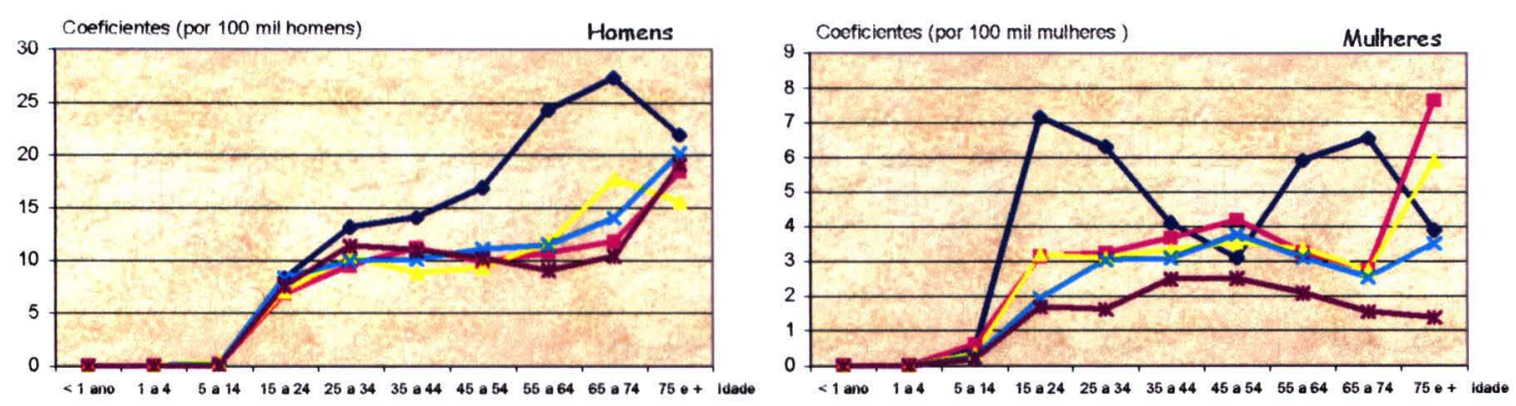

$\multimap 1971$

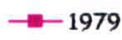

1986

$\rightarrow-1992$

$\rightarrow-1999$

Fonte: Fundação Seade.

Para as mulheres, o panorama é ainda mais complexo, ainda que nos últimos anos a tendência seja de crescimento dos coeficientes a medida que aumenta a idade na faixa compreendida entre 25 e 55 anos. Este fato reflete alterações em relação ao padrão observado em 1971, quando foram registrados coeficientes mais elevados em duas faixas etárias (de 15 a 34 anos e de 55 a 74 anos), bem como ao de 1979, com as maiores taxas observadas para as pessoas mais idosas.

O panorama apresentado mostra que algumas causas, como os acidentes e também os suicídios, reduziram-se em muitos grupos etários. Entretanto, os homicídios vêm constituindo-se em motivo de grande preocupação em todos os segmentos analisados. Entre os homens, o crescimento dos homicídios foi muito maior que o decréscimo das demais causas, especialmente entre os jovens. Em 
alguns grupos etários, como os situados entre 15 e 24 anos, as taxas de mortalidade por homicídios mais que duplicaram desde 1971, passando de cerca de 100 a 140 óbitos por 100 mil homens para 260 a 270 . Após os 45 anos de idade, os coeficientes aparecem próximos dos observados em outros anos, especialmente os de 1986 e 1992. Entre os homens de 75 anos e mais, os coeficientes mantêm-se como os mais elevados, ainda que nos últimos anos aqueles correspondentes aos grupos jovens venham se aproximando (Gráfico 19 e Tabela 19 do Anexo). Entre os denominados "demais acidentes", as principais causas relacionavam-se às quedas, aos afogamentos e à inalação/ingestão de alimentos e objetos.

Gráfico 19

Coeficientes de Mortalidade por Causas Externas, segundo Sexo e Grupos de Idade Estado de São Paulo

1971-1999

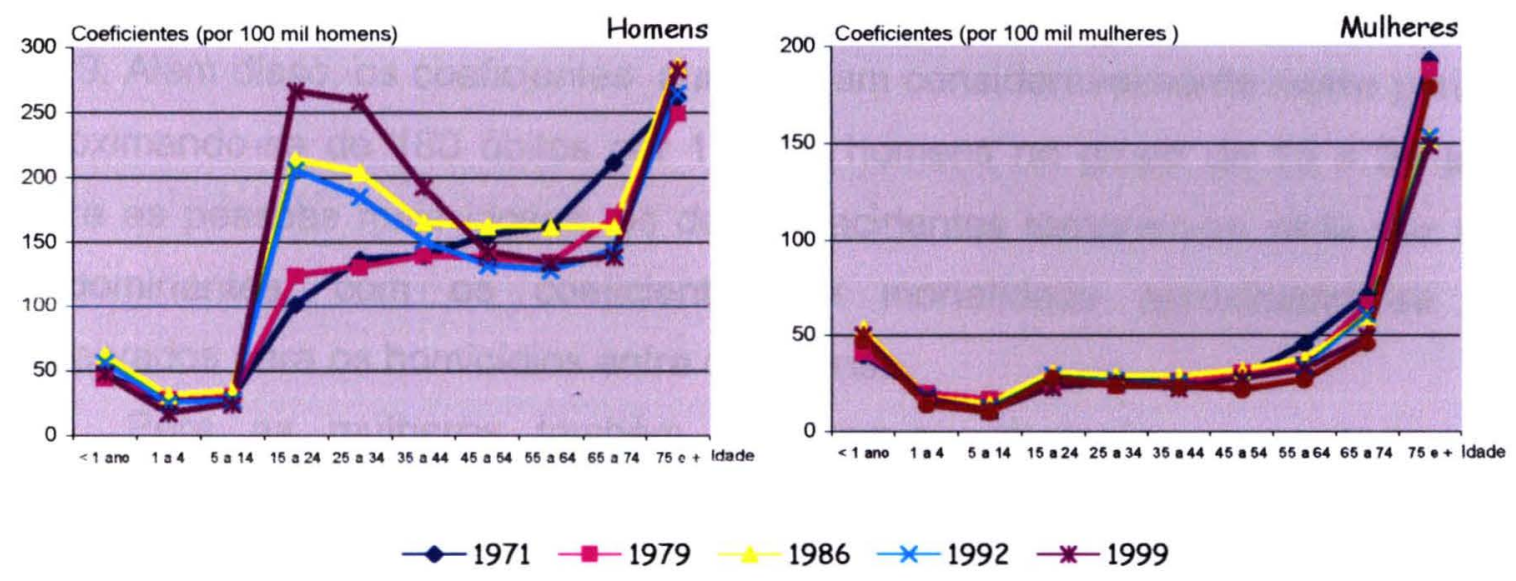

Fonte: Fundação Seade.

Para as mulheres, não há alterações significativas no padrão de mortalidade por causas externas. Os coeficientes iniciam-se mais elevados entre as crianças de menos de um ano, depois decrescem até os 5 a 14 anos e mantêm-se próximos na faixa de 15 a 45 anos, chegando mesmo a diminuir em certos anos. A partir dessa faixa etária, os coeficientes aumentam, inicialmente de forma mais lenta, mas crescem abruptamente na faixa de 75 anos e mais, atingindo as maiores taxas entre todos os grupos etários. A importância de cada grupo das causas externas nos momentos destacados pode ser visualizada 
também conjuntamente. $\mathrm{O}$ Gráfico 20 e a Tabela 20 do Anexo mostram essa situação para os homens e o Gráfico 21 e a Tabela 21 do Anexo, para as mulheres, entre 1971 e 1999.

Para os homens observa-se que os coeficientes de mortalidade por homicídios, em 1971, estavam bem abaixo daquele referente aos acidentes de transporte e aos demais acidentes. Em vários grupos etários, os homicidios eram superadas pelas taxas de mortalidade por suicídios. Em 1979, o panorama era bem diferente, com os coeficientes de mortalidade por homicídios aproximando-se para os jovens, daqueles correspondentes aos acidentes de transporte e superando-os em 1986. Daí em diante, as taxas aumentaram ainda mais, distanciando-se dos demais grupos de causas e ampliando a faixa etária na qual aparece como a principal causa de morte. Em 1986, os homicidios representavam a principal causa externa de morte para a população masculina de 15 a 34 anos, estendendo-se tal faixa para 15 a 44 anos, em 1992, e para 15 a 54 anos, em 1999. Além disso, os coeficientes aumentaram consideravelmente nesse período, aproximando-se de 180 óbitos por 100 mil homens no grupo de 15 a 24 anos. Entre as pessoas mais idosas, os demais acidentes tornaram-se cada vez mais predominantes, com os coeficientes de mortalidade aproximando-se dos observados para os homicídios entre os jovens.

Para as mulheres também registram-se alteraçōes na estrutura de mortalidade por causas externas. Os óbitos por homicídios, que no início apareciam até abaixo dos suicídios, aumentaram no decorrer do tempo e, em 1999, já constituiam-se na principal causa entre as jovens, especialmente de 15 a 34 anos. Anteriormente, esta posição era ocupada pelos acidentes de veículos a motor, que eram a principal causa desde os 5 até os 64 anos, enquanto os demais acidentes predominavam entre as crianças e os idosos. Entre as crianças, a asfixia por alimentos ou por objetos e alguns outros tipos de acidentes, incluiamse entre as principais causas de morte. Para os idosos, as quedas têm sido mais importantes e os coeficientes de mortalidade são sempre maiores que todos os outros. Os demais acidentes e os acidentes de veículos a motor aparecem como as principais causas das pessoas mais idosas. 


\section{Gráfico 20}

Coeficientes de Mortalidade da População Masculina por Causas Externas, segundo Tipos e Grupos de Idade Estado de São Paulo

1971-1999
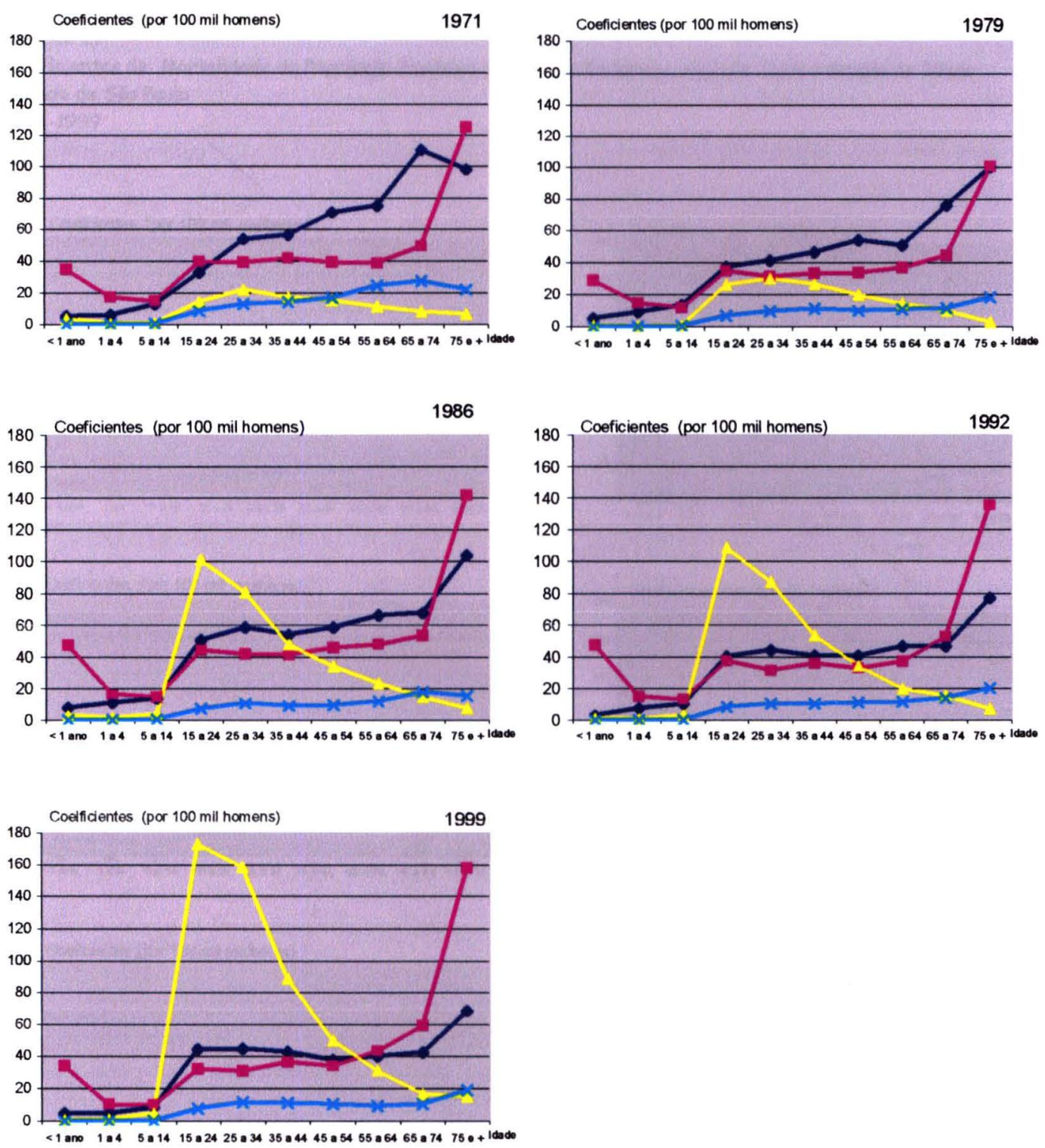

$\rightarrow$ Acidente de Transporte $\rightarrow$-Demais Acidentes $\rightarrow$ Homicidios $*$ Suicidios

Fonte: Fundação Seade.

Como ressaltado anteriormente, os homicídios têm aumentado de forma considerável nos últimos anos entre as mulheres, mas ainda permanecem muito inferiores aos observados para os homens. 
Quando consideradas na totalidade, as causas externas de morte registraram poucas alterações, em seus coeficientes, fato que não ocorreu com seus grupos, ou seja, as reduções referentes aos demais acidentes foram compensadas pelo aumento dos homicídios.

Gráfico 21

Coeficientes de Mortalidade da População Feminina por Causas Externas, segundo Tipos e Grupos de Idade

Estado de São Paulo

1971-1999
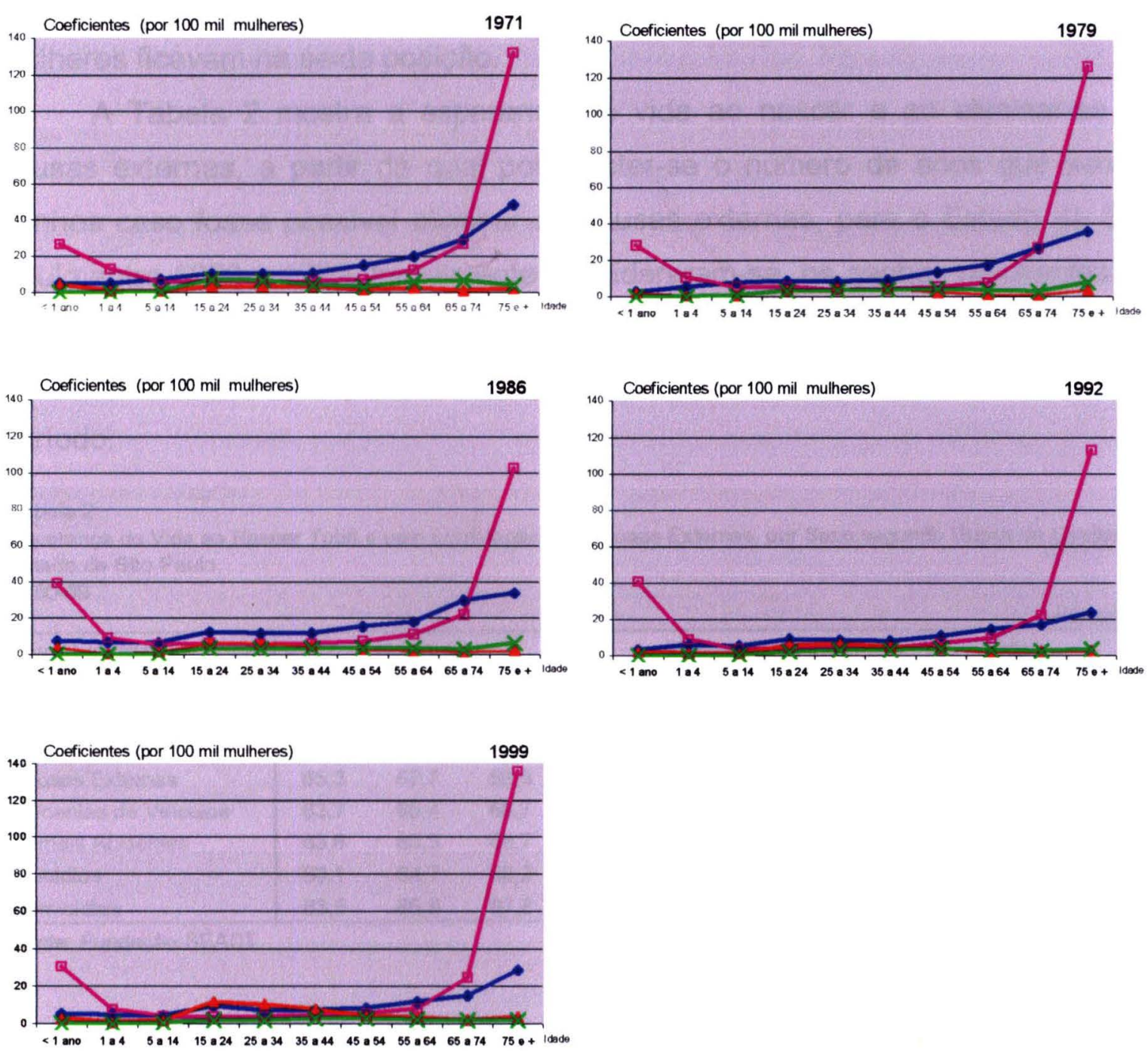

$\rightarrow$ Acidente de Transporte $\rightarrow$-Demais Acidentes $\rightarrow$ Homicidios $\quad *$ Suicidios

Fonte: Fundação Seade. 


\section{O impacto das causas externas}

A exemplo do que fizeram para o Brasil, ORTIZ e YAZAKI (1985) estimaram os ganhos na esperança de vida ao nascer do Estado de São Paulo para 1979/80, caso as causas externas fossem eliminadas. Se tal fato ocorresse, a esperança de vida ao nascer aumentaria em 2,3 anos para os homens e 0,7 ano para as mulheres. Para a população masculina as causas externas correspondiam ao grupo com maior impacto na esperança de vida ao nascer, enquanto para as mulheres ficavam na sexta posição.

A Tabela 2 mostra a esperança de vida ao nascer e ao eliminar-se as causas externas, a partir da qual pode obter-se o número de anos que seriam ganhos caso fosse possivel eliminar as causas externas, para o Estado de São Paulo entre 1980 e 1999. Inicialmente consideraram-se os ganhos resultantes da eliminação integral das causas externas e, em seguida, para os grupos de causas individualmente, o que permite observar a importância de cada uma, em cada período.

\begin{tabular}{|c|c|c|c|c|c|c|c|c|c|}
\hline & & & & & & & & & Em anos \\
\hline \multirow[t]{2}{*}{ Causas de Morte } & \multicolumn{3}{|c|}{ Homens } & \multicolumn{3}{|c|}{ Mulheres } & \multicolumn{3}{|c|}{ Total } \\
\hline & $1980-81$ & $1990-91$ & $1998-99$ & $1980-81$ & $1990-91$ & $1998-99$ & $1980-81$ & $1990-91$ & $1998-99$ \\
\hline Total & 62,9 & 64,6 & 66,0 & 69,8 & 72,9 & 74,1 & 66,2 & 68,5 & 69,9 \\
\hline \multicolumn{10}{|l|}{ Com a Exclusão de } \\
\hline Causas Externas & 65,3 & 67,7 & 69,6 & 70,6 & 73,6 & 74,8 & 67,8 & 70,6 & 72,2 \\
\hline Acidentes de Veículos & 63,7 & 65,4 & 66,7 & 70,1 & 73,1 & 74,3 & 66,7 & 69,1 & 70,4 \\
\hline Demais Acidentes & 63,6 & 65,3 & 66,7 & 70,1 & 73,1 & 74,3 & 66,7 & 69,0 & 70,3 \\
\hline Suicidios & 63,1 & 64,7 & 66,2 & 69,9 & 72,9 & 74.1 & 66,3 & 68,6 & 70,0 \\
\hline Homicídios & 63,5 & 65,8 & 67,8 & 69,9 & 73,0 & 74,3 & 66,6 & 69,2 & 70,9 \\
\hline
\end{tabular}

Fonte: Fundação SEADE.

Constata-se mais uma vez a importância das causas externas em São Paulo, tornando-se crescente com o decorrer do tempo. Para a população masculina, com a eliminação das causas externas haveria ganho de 2,4 anos em 1980-81, de 3,2 anos, em 1990-91, e de 3,6 anos, em 1998-99. Para as mulheres, esses ganhos, além de muito menores que os observados entre os homens, 
apresentam pouca alteração, tendo até apresentado uma pequena redução, de 0,8 ano, em 1990-91, para 0,7 ano, em 1998-99 (Tabela 3).

Considerando-se inicialmente a situação das causas externas entre a população masculina, constata-se que os anos de vida que seriam ganhos com a eliminação das mortes por acidentes de veículos, por "demais acidentes" e por suicídios apresentam poucas alterações nos três momentos considerados. Para os homicídios a situação é diferente, observando-se grande aumento nesse número de anos e passando a ter grande importância no Estado de São Paulo. Em 1980-81 o ganho correspondente à eliminação dos homicídios seria de 0,6 anos, inferior ao que seria obtido com a extinção dos dois grupos de acidentes. Em 1990-91 o ganho de anos resultante da eliminação dos homicídios alcançaria a 1,2 anos, ultrapassando o dos acidentes e, em 1998-99 chegaria a 1,8 ano de vida. Neste último período, o ganho relativo aos homicídios representava quase a metade do ganho total das causas externas.

\begin{tabular}{|c|c|c|c|c|c|c|c|c|c|}
\hline \multirow{2}{*}{\multicolumn{4}{|c|}{$\begin{array}{l}\text { Ganho de Anos na Esperança de Vida ao Nascer com a } \\
\text { Grupos de Causas } \\
\text { Estado de São Paulo } \\
1980-1999\end{array}$}} & limina & las & $s \in$ & \multirow{2}{*}{\multicolumn{3}{|c|}{ Em anos }} \\
\hline & & & & & & & & & \\
\hline \multirow[t]{2}{*}{ Causas de Morte } & \multicolumn{3}{|c|}{ Homens } & \multicolumn{3}{|c|}{ Mulheres } & \multicolumn{3}{|c|}{ Total } \\
\hline & 1980-81 & $1990-91$ & $1998-99$ & $1980-81$ & $1990-91$ & $1998-99$ & $1980-81$ & $1990-91$ & 1998-99 \\
\hline Externas & 2,4 & 3,2 & 3,6 & 0,7 & 0,8 & 0,7 & 1,6 & 2,1 & 2,3 \\
\hline Acidentes de Veículos & 0,7 & 0,8 & 0,7 & 0,3 & 0,3 & 0,2 & 0,5 & 0,6 & 0,5 \\
\hline Demais Acidentes & 0,7 & 0,8 & 0,7 & 0,2 & 0,3 & 0,2 & 0,5 & 0,5 & 0,5 \\
\hline Suicídios & 0,2 & 0,1 & 0,2 & 0,1 & 0,1 & 0,0 & 0,1 & 0,1 & 0,1 \\
\hline Homicidios & 0,6 & 1,2 & 1,8 & 0,1 & 0,1 & 0,2 & 0,4 & 0,7 & 1,1 \\
\hline
\end{tabular}

Fonte: Fundação SEADE.

Para as mulheres as alterações são bem menores, ainda que se constate aumento na perda de anos devido aos homicidios, que passa de 0,10 ano para 0,2 e que vem aproximando-se dos resultantes para os dois grupos de acidentes.

Entre os resultados proporcionados pelo Método dos Riscos Competitivos, observam-se além dos ganhos de anos de vida, as probabilidades de morte resultantes da eliminação de determinadas causas de morte. Para o Estado de São Paulo, informações referentes às principais causas de morte para 1998-99 
foram usadas para verificar como seria seu comportamento caso fossem totalmente eliminadas.

O Gráfico 22 e a Tabela 22 do Anexo, mostram essa situação para homens e mulheres, considerando as doenças do aparelho circulatório, as neoplasias, as doenças do aparelho respiratório, as doenças infecciosas e parasitárias e as causas externas. Constata-se que os coeficientes de mortalidade têm grande impacto em determinadas idades, alterando inclusive o seu padrão, especialmente entre os jovens. A eliminação de tais causas modificaria totalmente o padrão etário observado da população masculina, que ficaria semelhante ao da população feminina.

A eliminação das doenças infecciosas e parasitárias também teria um certo impacto para os jovens, devido à mortalidade por Aids que se concentra nesta faixa etária, tanto para os homens como para as mulheres.

Para as demais causas, especialmente as doenças do aparelho circulatório, os reflexos seriam mais importantes nas idades mais avançadas.

Os resultados apresentados mostram a importância que as causas externas de morte têm no Estado de São Paulo, especialmente entre sua população masculina, com crescimento nos últimos anos. FERREIRA (1980) e FERREIRA e CASTIÑEIRAS (1998) mostram que os coeficientes de mortalidade observados para o Estado de São Paulo, em 1995-97, para a população masculina entre 15 e 39 anos, eram semelhantes aos de 1949-51, quando as doenças infecciosas eram importantes. Os coeficientes de 1995-97 superavam em cerca de $50 \%$ os observados em 1969-71, quando as taxas de mortalidade por causas externas apareciam menores que as dos anos seguintes.

A situação verificada para o Estado, porém, é uma média do que ocorre entre as suas regiões e seus municípios, sendo importante estudar a situação da mortalidade por causas externas para essas áreas menores, cujo panorama apresenta-se a seguir. 
Gráfico 22

Comparação entre as Probabilidades de Morte Observadas $\left(q_{x}\right)$ e Líquida $\left(q_{x_{0}}\right)$ Eliminando-se os Grupos de Causas como Fator de Risco de Morte, por Sexo Estado de São Paulo

1998-1999
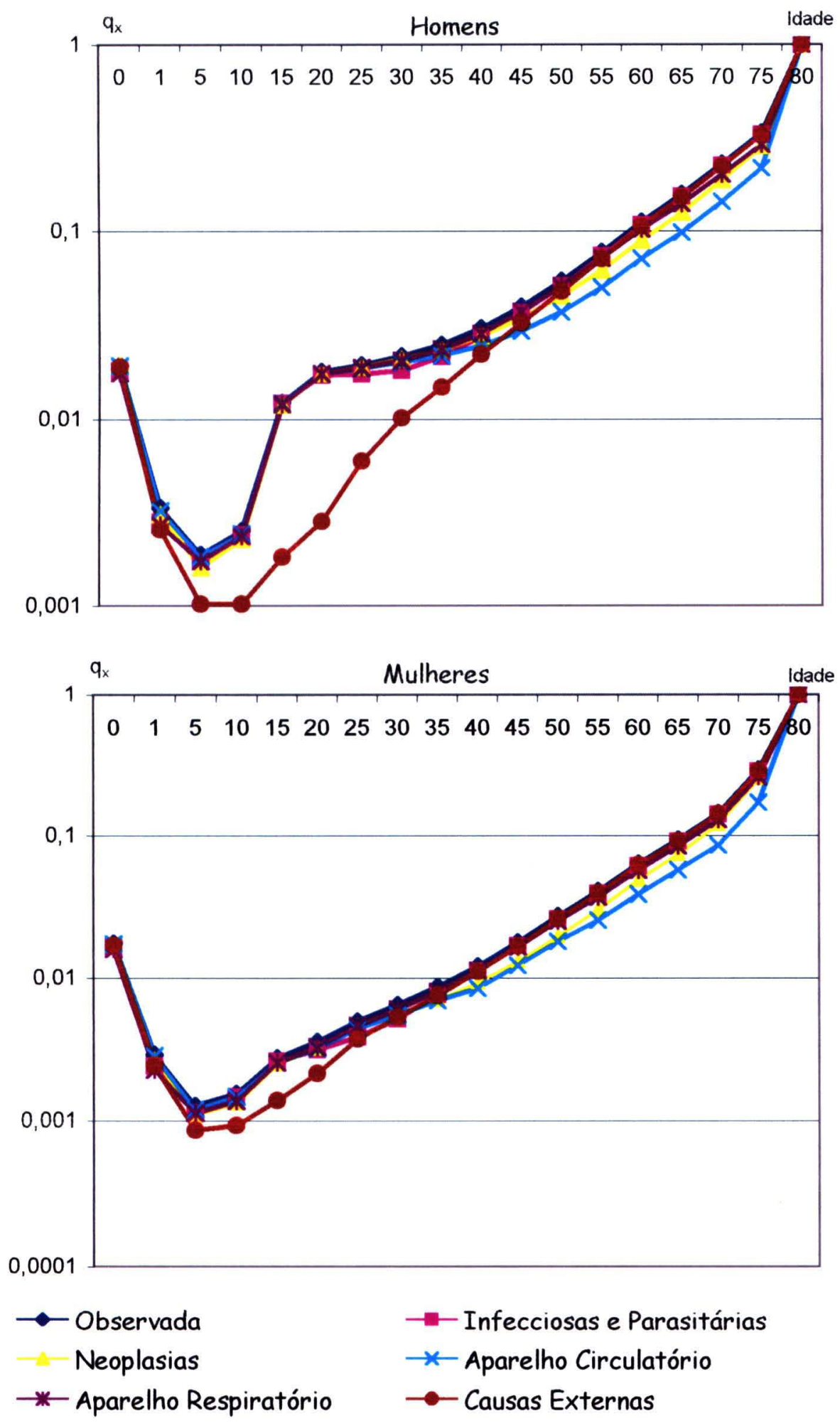

Fonte: Fundação Seade. 


\section{AS CAUSAS EXTERNAS NAS REGIÕES DE SÃO PAULO}

\section{Caracterização das regiões}

A partir do final dos anos 60, o Estado de São Paulo foi dividido em regiões administrativas, com o objetivo de descentralizar a administração e melhorar o planejamento e as condições de vida de sua população. Na primeira divisão feita no Estado, havia 11 regiões administrativas, que, por sua vez, subdividiam-se em 48 áreas menores, denominadas sub-regiōes (FUNDAP 1983) .

Esta divisão administrativa foi alterada na metade da década de 80 , quando - Estado passou a ter 14 regiões administrativas, além da Região Metropolitana de São Paulo, e 42 Regiões de Governo, que congregam os atuais 645 municípios (Mapa 1).

As sedes dessas regiōes, tanto administrativas como de governo, geralmente são municípios de grande importância demográfica, econômica e no atendimento à saúde e estendem sua influência sobre determinada área do Estado ou até mesmo para outras Unidades da Federação. No caso da área da saúde, significa a possibilidade de atender pacientes de várias cidades. Isto ocorre especialmente naqueles municípios denominados "pólos", cuja influência atinge áreas que chegam a ultrapassar os limites do Estado, como são os casos de Bauru, da capital, Campinas, São José do Rio Preto e Ribeirão Preto. Esta situação repete-se em vários outros municípios, dando uma certa autonomia local e regional para este atendimento, ainda que em casos mais graves e especializados ainda se recorra aos hospitais da capital.

Não existem estudos que mostrem as condições de saúde nas regiões de São Paulo, anteriormente a 1960, mas, ao se considerarem indicadores mais globais - como os coeficientes de mortalidade geral e infantil verifica-se que a capital apresentava melhor situação que o interior. $O$ cálculo das primeiras Tábuas de Mortalidade para as regiões do Estado referentes a 1960-61, confirmava as 
melhores condições de saúde na área que atualmente constitui a Região Metropolitana de São Paulo - RMSP.

Mapa 1

Regiões Administrativas e de Governo

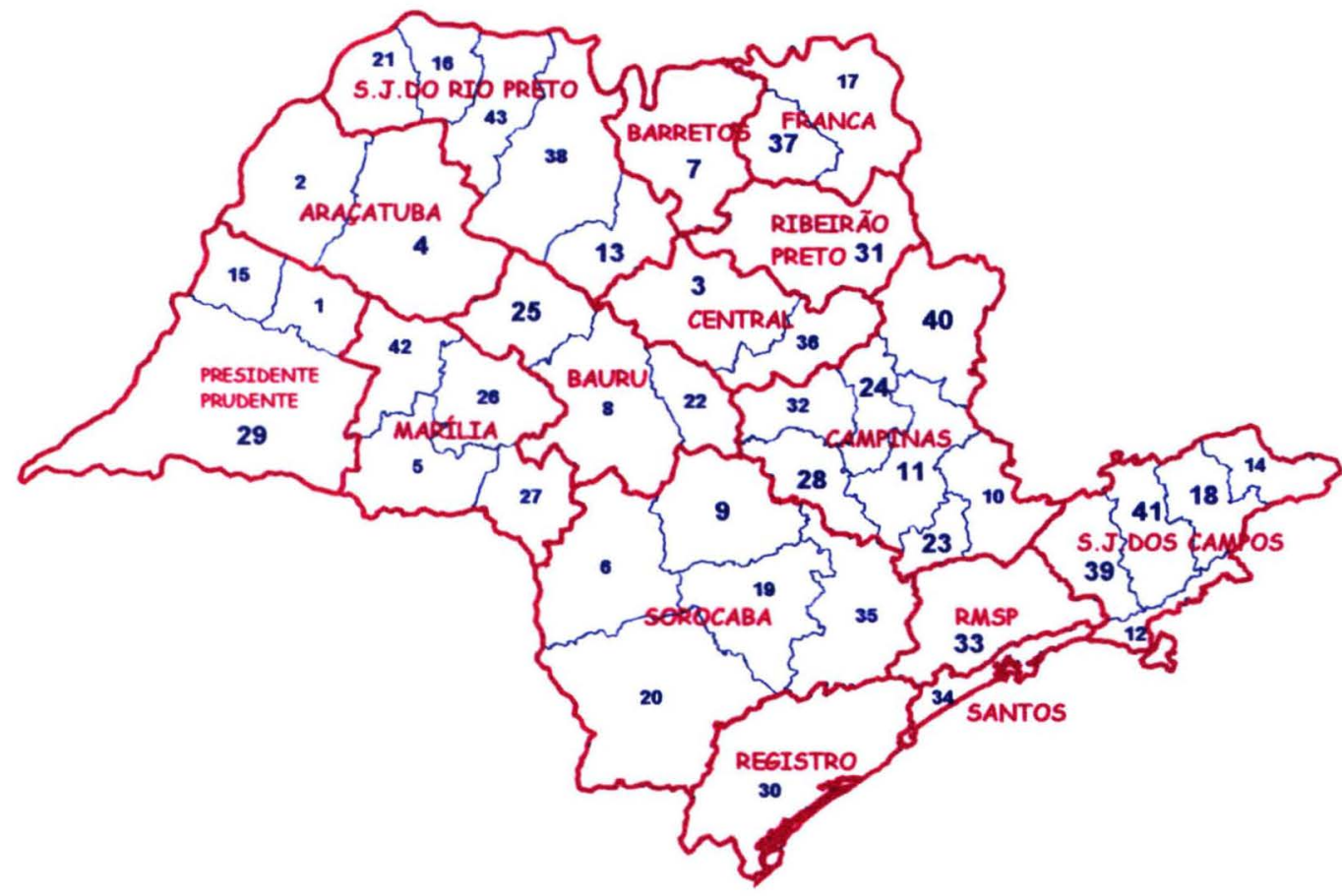

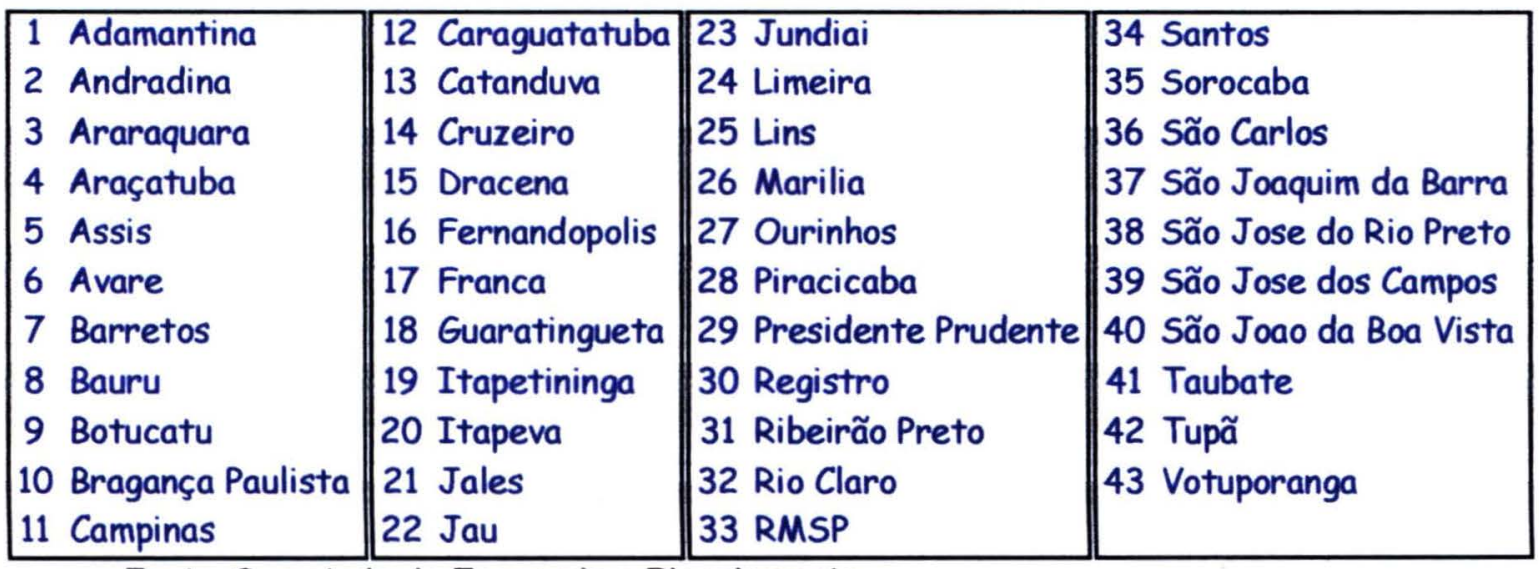

Fonte: Secretaria de Economia e Planejamento.

Naquele período a esperança de vida da população feminina da RMSP era a maior do Estado de São Paulo e a dos homens era inferior apenas à da Região Administrativa de São José do Rio Preto. 
Em 1970 esta situação já se apresentava muito diferente, pois a esperança de vida das mulheres dessa área era inferior a de outras três Regiōes, enquanto para os homens passou a se situar entre as menores. Nesse período, várias regiōes obtiveram melhorias consideráveis, refletindo-se nos respectivos indicadores, como a esperança de vida ao nascer, sendo que algumas delas apresentaram ganhos de até sete anos. Por outro lado, na Região Metropolitana de São Paulo e também na Região Administrativa de Santos a esperança de vida estacionou, observando-se inclusive deterioração das condições de vida. Os coeficientes de mortalidade infantil aumentaram, fato que se repetiu também com as causas externas, especialmente acidentes de trânsito e homicídios, como mostra MELLO JORGE (1980) em estudo referente à capital. Foi somente a partir da metade da década de 70 que os coeficientes de mortalidade infantil voltaram a diminuir no Estado de São Paulo e em várias regiões, o que não ocorreu com as causas externas. A esperança de vida elevou-se novamente no Estado, chegando a 70 anos, em 1980, e a 73 anos, em 1996. O aumento da esperança de vida ao nascer, no entanto, ocorreu de forma muito diferenciada, tanto por sexo como por regiōes. $O$ desenvolvimento econômico, a disponibilidade de recursos médicos e hospitalares, a melhoria das condições de nutrição, habitação, saneamento básico e infra-estrutura urbana e as condiçōes de segurança, de transportes e de lazer geram situações muito diferentes entre as regiōes.

A Tabela 4 mostra que o número de habitantes é bastante heterogêneo entre as regiōes, variando em $\mathbf{2 0 0 0}$ de pouco mais de $\mathbf{2 6 0}$ mil, da Região Administrativa de Registro, até quase 18 milhões, da RMSP. As taxas de crescimento populacional por sua vez, já não apresentam diferenças tão acentuadas como aquelas observadas até recentemente, quando chegaram a ultrapassar $5 \%$ ao ano em algumas regiōes, enquanto em outras eram negativas, mas ainda são importantes. Na Região de Presidente Prudente, por exemplo, a taxa corresponde a 0,8\% ao ano, entre 1991 e 2000, enquanto nas de Santos, Sorocaba, Campinas e São José dos Campos, ficou próxima de 2,2\% ao ano. O mesmo pode-se dizer em relação ao percentual de população urbana, que ultrapassa a $90 \%$ na maior parte das regiões, enquanto em Registro alcança apenas $66 \%$. Quanto à 
densidade demográfica, registram-se também grandes diferenças no Estado de São Paulo: Registro possui apenas 22 habitantes por $\mathrm{km}^{2}$ e Presidente Prudente tem 33 hab $/ \mathrm{km}^{2}$, enquanto na região de Santos são 621 habitantes por $\mathrm{km}^{2} \mathrm{e}$, na Área Metropolitana de São Paulo, 2.215 habitantes por $\mathrm{km}^{2}$.

\begin{tabular}{|c|c|c|c|c|c|}
\hline \multirow{2}{*}{ Regiōes Administrativas } & \multicolumn{3}{|c|}{ Populaçăo } & \multirow{2}{*}{$\begin{array}{c}\text { Grau de } \\
\text { Urbanização } \\
(2000)(\%)\end{array}$} & \multirow{2}{*}{$\begin{array}{c}\text { Densidade } \\
\text { Demográfica } \\
(2000)\left(\mathrm{hab} / \mathrm{km}^{2}\right)\end{array}$} \\
\hline & 1991 & $2000(1)$ & $\begin{array}{l}\text { Taxa de Crescimento } \\
\text { Anual }(1991-2000)(\%)\end{array}$ & & \\
\hline Estado & 31.588 .925 & 36.966 .527 & 1,8 & 93,4 & 149,7 \\
\hline Região Metropolitana de São Paulo & 15.444 .941 & 17.833 .511 & 1,6 & 95,7 & 2215,1 \\
\hline RA de Registro & 226.413 & 264.519 & 1,8 & 66,2 & 21,8 \\
\hline RA de Santos & 1.220 .249 & 1.474 .665 & 2,1 & 99,6 & 621,4 \\
\hline RA de São José dos Campos & 1.651 .594 & 1.989 .692 & 2,1 & 93,0 & 122,3 \\
\hline RA de Sorocaba & 2.016 .555 & 2.467 .674 & 2,3 & 83,5 & 60,1 \\
\hline RA de Campinas & 4.409 .363 & 5.385 .489 & 2,3 & 92,8 & 198,9 \\
\hline RA de Ribeirão Preto & 897.889 & 1.060 .209 & 1,9 & 96,3 & 113,4 \\
\hline RA de Bauru & 824.249 & 955.581 & 1,7 & 93,4 & 59,3 \\
\hline RA de São José do Rio Preto & 1.130 .282 & 1.300 .164 & 1,6 & 89,1 & 50,9 \\
\hline RA de Araçatuba & 614.818 & 672.994 & 1,0 & 90,9 & 36,2 \\
\hline RA de Presidente Prudente & 734.312 & 787.824 & 0,8 & 85,4 & 32,9 \\
\hline RA de Marilia & 789.503 & 887.164 & 1,3 & 89,5 & 48,1 \\
\hline RA Central & 728.940 & 853.137 & 1,8 & 92,3 & 77,6 \\
\hline RA de Barretos & 358.306 & 393.923 & 1,1 & 91,9 & 47,6 \\
\hline RA de Franca & 541.511 & 639.981 & 1,9 & 93,9 & 61,7 \\
\hline
\end{tabular}

Fonte: Fundaçăo IBGE.

(1) Dados Preliminares.

Tais características não estão vinculadas apenas ao comportamento da fecundidade e da mortalidade, mas também à migração. $O$ desenvolvimento econômico de algumas áreas tem atraído elevados contingentes de migrantes, enquanto em outras as perdas populacionais foram consideráveis por não oferecerem as mesmas possibilidades, especialmente emprego. Assim, regiões como a Metropolitana de São Paulo, Campinas, São José dos Campos e Sorocaba, que aparecem como as mais industrializadas do Estado, detêm a quase totalidade das instalaçōes industriais, do pessoal ocupado e a maior parte do valor da transformação industrial do Estado. Outras regiões, especialmente as 
localizadas no oeste do Estado, foram por muito tempo dependentes basicamente da agropecuária, situação que se mantém em muitas delas até os dias atuais. Nos últimos anos, algumas delas têm atraído unidades industriais e apresentado importante desenvolvimento no setor de serviços, no comércio, nas atividades sociais e de turismo, fato que se repete largamente na região de Santos. Nas últimas décadas, várias regiōes têm apresentado maior desenvolvimento, exigindo vias de comunicação mais adequadas, melhorando a renda de suas populações e também demandando novos serviços, como o do atendimento à saúde. Por outro lado, surgem também problemas, tais como favelização, periferização, déficit de habitações, subemprego, poluição ambiental, deterioração das condições de vida e violência, muitos dos quais eram caracteristicos ou mais restritos às áreas de maior população ou mais adensadas, como as áreas metropolitanas ou de conurbação.

Essas vantagens e desvantagens apresentadas pelas regiōes nos mais variados aspectos refletem-se, evidentemente, nas condições de saúde de seus habitantes, com maior ou menor incidência de determinados agravos à saúde e também sobre os níveis de mortalidade. Como destaca PRATA (1992:168) os niveis e a estrutura da mortalidade são determinados por fatores históricos, sócioeconômicos, demográficos e ambientais. Vários indicadores mostram a heterogeneidade existente no Estado, tais como os coeficientes de mortalidade infantil, mortalidade por causas, sexo e grupos etários e também a esperança de vida ao nascer para vários períodos, esta última apresentada, por sexo, na Tabela 5 . 
Esperança de Vida ao Nascer, por Sexo

Regiōes Administrativas do Estado de Săo Paulo $1979-1997$

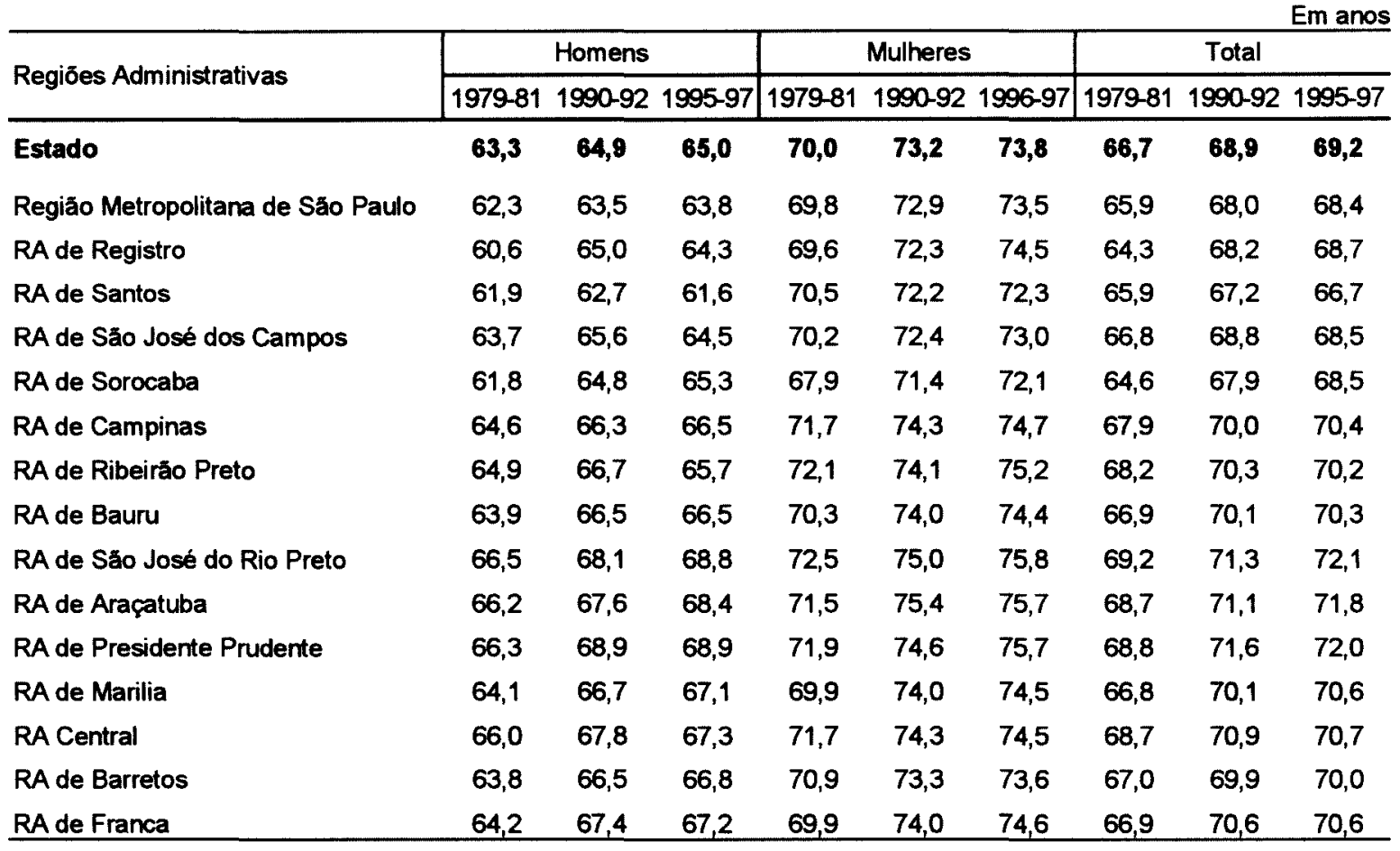

Fonte: Ferreira (1980), Ortiz e Yazaki (1984) e Ferreira e Castifieiras (1996 e 2000 ).

A Região Metropolitana - e mais especificamente a capital, que por muitos anos apresentou indicadores de saúde mais favoráveis, vinha perdendo posições dentro do Estado desde os anos 60 . No período 1979-81, a esperança de vida ao nascer da população masculina da RMSP era superior somente à de três regiōes do Estado (Registro, Santos e Sorocaba), enquanto em 1990-92 e 1996-97, ultrapassava apenas a da região de Santos. Para a população feminina, a situação era semelhante: em 1979-81 somente as regiōes de Registro e de Sorocaba tinham esperança de vida ao nascer inferior à da RMSP, enquanto em 1996-97, superava três regiões: Santos, São José dos Campos e Sorocaba. Enquanto a esperança de vida ao nascer da população masculina da Região Metropolitana aproximava-se de 64 anos, no período de 1995-97, nas regiões de São José do Rio Preto e de Presidente Prudente chegava a quase 69 anos, portanto, com diferença de cerca de cinco anos. Para as mulheres, a esperança de vida ao nascer da RMSP era de cerca de 74 anos, enquanto em São José do Rio Preto, Araçatuba e Presidente Prudente, alcançava quase 76 anos, no mesmo 
período, apresentando diferença de cerca de 2 anos. Essa situação, observada tanto para os homens, como para as mulheres pode ser considerada importante, dentro de um mesmo Estado, onde a esperança de vida já aparece relativamente elevada e as regiōes não apresentam diferenças demográficas tão acentuadas.

\section{As Causas de Morte}

Um fato que chama a atenção em relação à estrutura das causas de morte nas regiões do Estado de São Paulo são os elevados percentuais registrados para as causas externas, especialmente entre a população masculina de São José dos Campos, Registro, Santos e a Metropolitana (Tabelas 6 e 7). Nestas áreas, em cada 4 ou 5 óbitos, um correspondia a uma morte violenta, nível esse considerado muito alto quando comparado com outras áreas do Brasil ou do exterior. Estas regiões estavam entre as que possuiam as menores esperanças de vida do Estado, podendo ser reflexo do alto nível de mortes violentas observado. Analisando a situação nas regiões do Estado de São Paulo, entre 1975 e 1983, YAZAKI (1990) constatou que algumas causas externas, tais como determinados tipos de acidentes, haviam diminuído, contribuindo assim para o aumento da esperança de vida ao nascer, o que já não ocorria com os homicídios. Para esta última causa, o efeito tinha sido muito negativo, especialmente na Região Metropolitana de São Paulo, seguida pelas regiōes de Santos, São José dos Campos e Campinas. Nas demais áreas, ainda que o efeito também tenha sido negativo, a proporção era muito menor. Considerando-se o total das causas externas, o efeito permanecia negativo na Região Metropolitana de São Paulo, vindo em seguida a Região de Sorocaba, porém com níveis muito inferiores.

Os resultados apresentados mostram que, nos últimos anos a proporção de causas violentas aumentou consideravelmente em várias regiōes, especialmente entre os homens, o que certamente afetou a esperança de vida ao nascer e ampliou a diferença da mortalidade por sexo. 
Tabela 6

Distribuiçáo dos Óbltos da Populaçáo Masculina, por Principais Causas

Regibes Administrativas do Estado de Sao Paulo

1980-1999

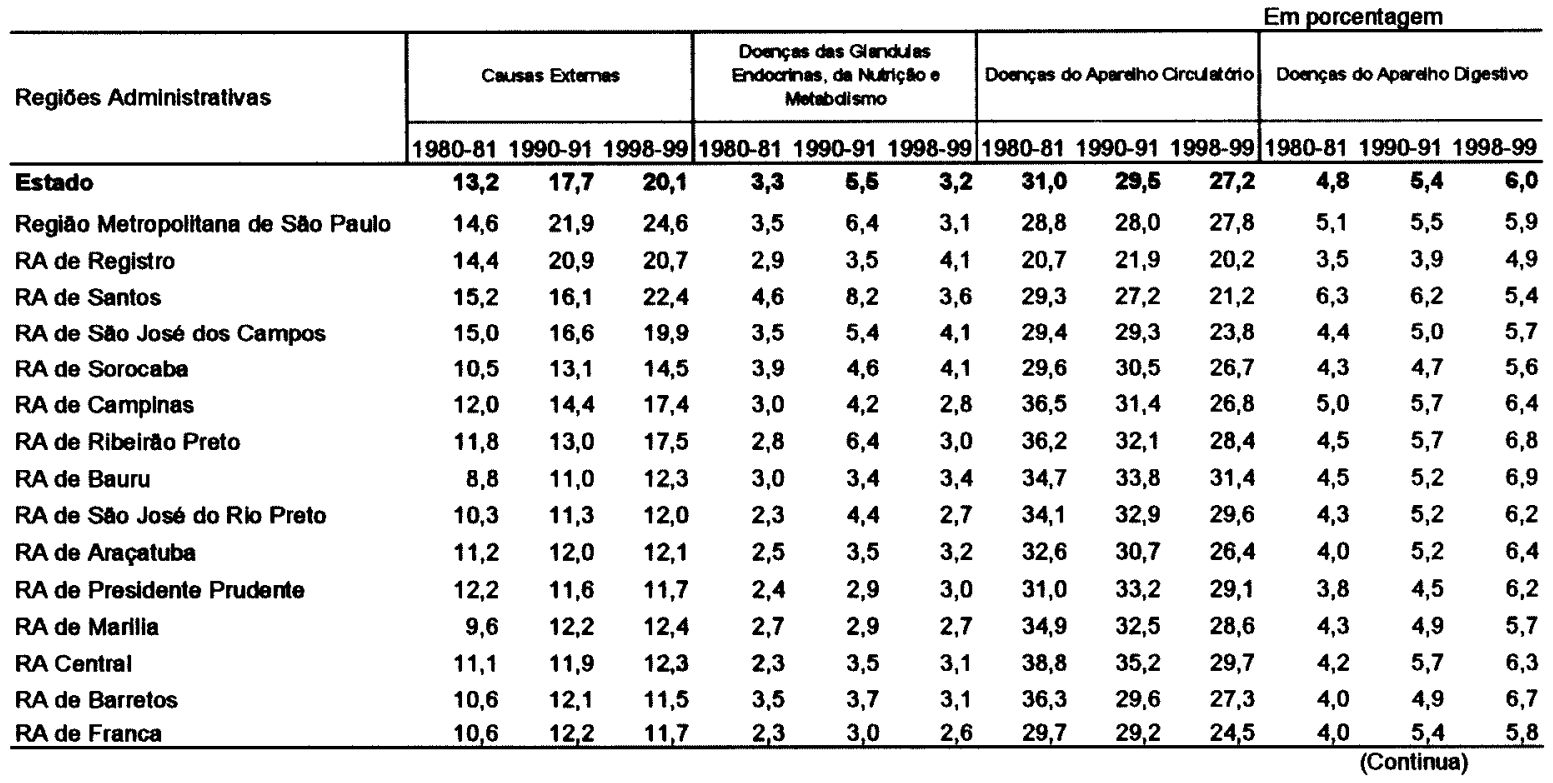

\begin{tabular}{|c|c|c|c|c|c|c|c|c|c|c|c|c|}
\hline & & & & & & & & & & Em porce & entagem & \\
\hline Regioes Administratwas & Doençus dx & OAperedho R & Rospiratorio & Doench & $\begin{array}{l}\text { Ges Infeccios } \\
\text { Parestiterias }\end{array}$ & sesse & & Necpiasias & & Sintomas, & $\begin{array}{l}\text { Sineis e Afe } \\
\text { Defiridas }\end{array}$ & ocçbes Mal \\
\hline & 1980-81 & $1990-91$ & 1998-99 & $1980-81$ & $1990-91$ & $1998-99$ & $1980-81$ & $1990-91$ & $1998-99$ & $1980-81$ & $1990-91$ & $1998-99$ \\
\hline Estado & 10,4 & 10,4 & 10,0 & $\mathbf{8 , 0}$ & 3,9 & 6,4 & 10,4 & 11,8 & 13,4 & 5,8 & 6,9 & 6,7 \\
\hline Regiāo Metropolitana de Sáo Paulo & 12,6 & 10,8 & 9,6 & 8,9 & 4,0 & 5,6 & 10,4 & 11,4 & 13,3 & 2,2 & 2,0 & 1,8 \\
\hline RA de Registro & 8,4 & 7,6 & 7,0 & 9,4 & 4,0 & 4,4 & 5,6 & 9,2 & 10,4 & 21,8 & 19,6 & 18,4 \\
\hline RA de Santos & 11,6 & 10,2 & 8,1 & 8,1 & 4,4 & 6,2 & 11,6 & 12,5 & 11,3 & 1,3 & 6,3 & 14,5 \\
\hline RA de Sao José dos Campos & 8,1 & 8,6 & 8,9 & 6,1 & 3,4 & 5,5 & 9,2 & 10,1 & 11,4 & 9,5 & 10,4 & 11,4 \\
\hline RA de Sorocaba & 9,3 & 10,5 & 10,2 & 8,2 & 4,6 & 4,6 & 8,6 & 10,7 & 12,6 & 13,3 & 10,4 & 12,6 \\
\hline RA de Campinas & 9,0 & 11,1 & 11,0 & 6,2 & 3,0 & 4,8 & 11,1 & 12,7 & 14,0 & 4,9 & 8,1 & 8,9 \\
\hline RA de Ribeirbo Preto & 7,7 & 10,3 & 11,2 & 7,1 & 5,2 & 7,2 & 12,3 & 13,3 & 14,8 & 5,0 & 4,2 & 3,3 \\
\hline RA de Bauru & 8,6 & 10,0 & 10,9 & 6,8 & 3,2 & 4,4 & 10,7 & 13,6 & 14,8 & 11,1 & 11,3 & 8,0 \\
\hline RA de Săo José do Rio Preto & 6,6 & 10,0 & 12,0 & 8,3 & 4,4 & 5,6 & 11,8 & 13,4 & 16,1 & 12,3 & 10,5 & 9,6 \\
\hline RA de Araçatuba & 5,7 & 9,2 & 10,7 & 7,4 & 3,3 & 5,7 & 10,8 & 13,4 & 14,2 & 15,1 & 13,8 & 13,8 \\
\hline RA de Presidente Prudente & 6,7 & 8,2 & 10,0 & 6,1 & 3,9 & 4,3 & 10,2 & 13,0 & 14,2 & 15,7 & 13,2 & 14,7 \\
\hline RA de Marilia & 6,9 & 9,0 & 8,9 & 8,2 & 4,5 & 4,4 & 9,9 & 11,4 & 12,8 & 13,0 & 14,1 & 17,3 \\
\hline RA Central & 7,3 & 10,2 & 12,0 & 5,8 & 3,6 & 5,1 & 12,7 & 13,4 & 14,6 & 6,7 & 7,9 & 9,0 \\
\hline $\begin{array}{l}\text { RA de Barretos } \\
\text { RA de Franca }\end{array}$ & $\begin{array}{l}6,4 \\
6,1\end{array}$ & $\begin{array}{r}10,4 \\
9,5\end{array}$ & $\begin{array}{l}10,1 \\
10,4\end{array}$ & $\begin{array}{l}6,2 \\
9,6\end{array}$ & $\begin{array}{l}6,0 \\
6,1\end{array}$ & $\begin{array}{l}7,7 \\
5,8 \\
\end{array}$ & $\begin{array}{r}11,4 \\
8,9 \\
\end{array}$ & $\begin{array}{l}12,9 \\
11,0\end{array}$ & $\begin{array}{l}15,0 \\
13,2 \\
\end{array}$ & $\begin{array}{r}9,8 \\
17,4\end{array}$ & $\begin{array}{l}11,2 \\
13,1\end{array}$ & $\begin{array}{l}10,3 \\
17,3 \\
\end{array}$ \\
\hline
\end{tabular}


Tabcla 7

Distribuiçáo dos Óbitos da Populaçao Feminina, por Principals Causas

Regioes Administrativas do Estado de Sáo Paulo

1980-1999

\begin{tabular}{|c|c|c|c|c|c|c|c|c|c|c|c|c|}
\hline \multicolumn{13}{|c|}{ Em porcentagem } \\
\hline \multirow[t]{2}{*}{ Regloes Administrativas } & \multicolumn{3}{|c|}{ Cunsas Externas } & \multicolumn{3}{|c|}{ 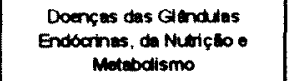 } & \multicolumn{3}{|c|}{ Doençes do Aper tho Crculatcrio } & \multicolumn{3}{|c|}{ Doences do Apretho Digestivo } \\
\hline & $1980-81$ & $1990-91$ & $1998-99$ & $1980-81$ & $1990-91$ & $1998-99$ & $1980-81$ & $1990-91$ & $1998-99$ & $1980-81$ & $1990-91$ & 1998-99 \\
\hline Estado & 4,7 & 5,3 & 4,9 & 5,2 & 6,2 & 6,0 & 36,5 & 37,7 & 36,0 & 3,5 & 4,0 & 4,4 \\
\hline Regiéo Metropolitana de Sáo Paulo & 4,9 & 6,0 & 5,2 & 5,5 & 6,7 & 5,9 & 35,1 & 37,9 & 37,9 & 3,5 & 4,1 & 4,3 \\
\hline RA de Registro & 5,4 & 8,5 & 6,3 & 3,1 & 7,1 & 8,3 & 24,4 & 23,8 & 27,4 & 2,7 & 1,9 & 4,0 \\
\hline RA de Santos & 5,4 & 4,8 & 5.4 & 7.0 & 8,2 & 5,8 & 34,9 & 35,2 & 28.7 & 4,1 & 3,8 & 3,8 \\
\hline RA de Săo José dos Campos & 4,6 & 5,0 & 5,0 & 5,9 & 6,3 & 7,7 & 37,2 & 35,9 & 31,7 & 3,1 & 3,6 & 4,1 \\
\hline RA de Sorocaba & 3,7 & 4,1 & 4,4 & 5,6 & 6,2 & 7,1 & 33,5 & 36,4 & 33,0 & 2,9 & 3,6 & 4,2 \\
\hline RA de Campinas & 4,4 & 4,8 & 4,6 & 5,1 & 6,0 & 5,8 & 41,3 & 38,0 & 35,6 & 3,7 & 4,1 & 4,4 \\
\hline RA de Ribeirao Preto & 4,6 & 5,0 & 5,0 & 4,5 & 5,4 & 5,9 & 42,1 & 39,7 & 37,0 & 3,7 & 4,2 & 5,1 \\
\hline RA de Bauru & 3,9 & 4,5 & 3,9 & 4,4 & 4,8 & 6,1 & 38,8 & 41,6 & 40,0 & 3,8 & 3,8 & 5,1 \\
\hline RA de Sao José do Rlo Preto & 4,8 & 4,7 & 4,5 & 4,4 & 5,1 & 4,3 & 38,6 & 39,7 & 37,4 & 3,2 & 5,1 & 4,3 \\
\hline RA de Araçatuba & 4,8 & 4,7 & 5,0 & 3,8 & 5,4 & 5,6 & 37,1 & 34,3 & 32,4 & 3,2 & 4,0 & 5,0 \\
\hline RA de Presidente Prudente & 4,8 & 4,0 & 4,5 & 3,8 & 5,5 & 6,3 & 33,1 & 37,7 & 34,5 & 3,8 & 4,0 & 4,8 \\
\hline RA de Marilia & 4,2 & 5,5 & 4,3 & 4,6 & 4,5 & 5,4 & 38,0 & 38,2 & 34,3 & 2,8 & 3,9 & 4,1 \\
\hline RA Central & 3,8 & 3,8 & 3,9 & 4,5 & 4,4 & 6,5 & 44,0 & 42,2 & 38,8 & 3,9 & 4,0 & 4,6 \\
\hline RA de Barretos & 4,6 & 4,2 & 5,1 & 4,0 & 4,5 & 6,1 & 43,1 & 37,7 & 34,0 & 3,4 & 5,2 & 4,8 \\
\hline RA de Franca & 4,7 & 4,2 & 4,3 & 3,2 & 4,4 & 4,1 & 36,3 & 37,7 & 32,1 & 4,2 & 3,5 & 4,9 \\
\hline
\end{tabular}

\begin{tabular}{|c|c|c|c|c|c|c|c|c|c|c|c|c|}
\hline & & & & & & & & & & Em porce & entagem & \\
\hline \multirow{2}{*}{ Regloes Administrativas } & \multicolumn{3}{|c|}{ Doences do Apw tho Respiraterio } & \multicolumn{3}{|c|}{$\begin{array}{c}\text { Doenças Infecdiosas o } \\
\text { Paresittrias }\end{array}$} & \multicolumn{3}{|c|}{ Necplasies } & \multicolumn{3}{|c|}{$\begin{array}{c}\text { Sintomes, Snais e Alecçoes Mat } \\
\text { Delinidas }\end{array}$} \\
\hline & $1980-81$ & $1990-91$ & $1998-99$ & $1980-81$ & $1990-91$ & $1998-99$ & $1980-81$ & $1990-91$ & 1998-99 & $1980-81$ & $1990-91$ & $1998-99$ \\
\hline Estado & 10,7 & 11,0 & 11,5 & 8,0 & 3,8 & 4,5 & 11,4 & 14,4 & 16,1 & 5,6 & 6,0 & 6,5 \\
\hline Regiáo Metropolitana de Sao Paulo & 12,6 & 11,8 & 11.7 & 8,9 & 3,7 & 4,6 & 12,0 & 15,5 & 17,6 & 2,2 & 2,4 & 1,7 \\
\hline RA de Registro & 10,5 & 11,2 & 9,5 & 11,9 & 4,2 & 4,1 & 6,4 & 7,5 & 12,5 & 23,0 & 20,3 & 18,3 \\
\hline RA de Santos & 12,0 & 11,0 & 10,3 & 8,4 & 3,7 & 5,4 & 12,7 & 14,7 & 14,7 & 1,7 & 7,2 & 16,3 \\
\hline RA de Sao José dos Campos & 8,0 & 10,7 & 11,8 & 6,8 & 3,0 & 4,2 & 10,0 & 13,0 & 14,9 & 9,5 & 9,3 & 10,1 \\
\hline RA de Sorocaba & 9,9 & 10,8 & 11,6 & 8,3 & 4,5 & 3,7 & 8,5 & 11,9 & 14,1 & 14,1 & 10,7 & 12,0 \\
\hline RA de Campinas & 9,6 & 10,6 & 12,2 & 5,9 & 3,1 & 3,7 & 11,8 & 14,3 & 15,5 & 5,0 & 7,6 & 9,0 \\
\hline RA de Ribeirao Preto & 7,5 & 10,7 & 11,9 & 8,0 & 5,4 & 6,0 & 12,0 & 14,7 & 16,6 & 4,7 & 3,6 & 3,2 \\
\hline RA de Bauru & 9,5 & 10,0 & 10,7 & 6,4 & 3,2 & 3,6 & 10,2 & 12,8 & 14,5 & 10,5 & 10,2 & 7,9 \\
\hline RA de Sao José do Rlo Preto & 6,5 & 9,3 & 11,6 & 7,5 & 4,3 & 6,0 & 10,7 & 12,8 & 14,8 & 11,9 & 10,8 & 9,5 \\
\hline RA de Araçatuba & 5,8 & 9,9 & 11,4 & 7,0 & 3,6 & 5,0 & 11,2 & 13,8 & 14,5 & 14,1 & 14,4 & 13,0 \\
\hline RA de Presidente Prudente & 7,0 & 7,6 & 9,4 & 7,0 & 4,0 & 3,7 & 10,5 & 13,0 & 13,5 & 17,1 & 14,2 & 14,8 \\
\hline RA de Marilia & 7,4 & 9,9 & 10,4 & 8,7 & 3,8 & 4,0 & 9,7 & 12,3 & 13,7 & 11,8 & 12,6 & 15,3 \\
\hline RA Central & 7,0 & 10,3 & 10,4 & 5,1 & 3,6 & 3,9 & 11,6 & 14,0 & 14,8 & 6.0 & 7,5 & 8,6 \\
\hline RA de Barretos & 6,2 & 9,0 & 11,8 & 6,9 & 5,3 & 6,1 & 10,6 & 14,5 & 14,0 & 9,1 & 9,3 & 9,7 \\
\hline RA de Franca & 7,1 & 9,9 & 9,8 & 8,8 & 6,6 & 6,8 & 10,0 & 12,6 & 12,5 & 13,0 & 10,6 & 15,8 \\
\hline
\end{tabular}

As Tabelas 8 e 9 apresentam as taxas de mortalidade de algumas das principais causas de morte para as 15 regiões administrativas de São Paulo, por sexo, referentes aos períodos 1980-81, 1990-91 e 1998-99. 
Tabela 8

Coeficientes de Mortalidade da Populaçăo Masculina, por Principais Causas

Regioes Administrativas do Estado de Sao Paulo

1980-1999

\begin{tabular}{|c|c|c|c|c|c|c|c|c|c|c|c|c|}
\hline \multirow[t]{2}{*}{ Regloes Administratwas } & \multicolumn{3}{|c|}{ Causas Extenas } & \multicolumn{3}{|c|}{$\begin{array}{c}\text { Doenças das Gitndilas } \\
\text { Endocrinus, de Nutriçlo e } \\
\text { Motubolismo }\end{array}$} & \multicolumn{3}{|c|}{ Doenças do Aperetho Circulatcrio } & \multicolumn{3}{|c|}{ Doenças do Aperdho Digestivo } \\
\hline & $1980-81$ & $990-91$ & $998-99$ & $1980-81$ & $90-91$ & 98-99 & $1980-81$ & $990-91$ & 998-99 & $1980-81$ & 1990-91 & $1998-99$ \\
\hline Regiao Metropolitana de Sao Paulo & 116,6 & 174,5 & 195,4 & 28,4 & 52,7 & 25,5 & 236,6 & 228,9 & 226,7 & 41,6 & 45,1 & 47,7 \\
\hline RA de Registro & 135,9 & 166.7 & 165,2 & 37,3 & 37,5 & 42,6 & 262,8 & 231,1 & 210,5 & 44,3 & 41,5 & 51,0 \\
\hline RA de Santos & 136,0 & 149,8 & 221,1 & 41,6 & 82,7 & 43,5 & 265,5 & 274,1 & 256,9 & 57,5 & 62,4 & 65,6 \\
\hline RA de Sao José dos Campos & 117,0 & 117,5 & 149,1 & 30,5 & 43,8 & 36,1 & 258,7 & 237,2 & 207,7 & 38,7 & 40,4 & 50,0 \\
\hline RA de Sorocabe & 97,4 & 106,5 & 114,1 & 42,8 & 43,0 & 37,3 & 321,9 & 282,6 & 246,1 & 47,2 & 43,6 & 51,3 \\
\hline RA de Campinas & 92,3 & 107,0 & 133,1 & 24,2 & 34,0 & 24,2 & 298,1 & 257,1 & 230,2 & 40,8 & 46,5 & 54,7 \\
\hline RA de Ribeirăo Preto & 88,4 & 96,3 & 134,1 & 22,0 & 49,6 & 23,9 & 287,7 & 250,5 & 227,0 & 35,5 & 44,4 & 54,3 \\
\hline RA de Bauru & 76,7 & 88,3 & 101,8 & 29,5 & 31,7 & 30,6 & 344,1 & 311,4 & 284,9 & 44,4 & 48,4 & 62,4 \\
\hline RA de Sao José do Rlo Preto & 76,6 & 87,1 & 93,3 & 19,7 & 38,1 & 23,2 & 293,5 & 287,7 & 258,8 & 37,4 & 45,5 & 54,5 \\
\hline RA de Araçaluba & 79,9 & 85,9 & 94,0 & 21,7 & 30,0 & 29.5 & 278,8 & 260,1 & 243,3 & 34,2 & 44,5 & 58,6 \\
\hline RA de Presidente Prudente & 86,8 & 81,5 & 92,4 & 20,8 & 24,1 & 28,5 & 267,9 & 274,1 & 275,1 & 32,6 & 37,3 & 58,9 \\
\hline RA de Marilia & 83,4 & 100,2 & 103,7 & 27,9 & 28,3 & 28,2 & 354,3 & 319,0 & 298,3 & 43,4 & 48,0 & 59,4 \\
\hline RA Central & 85,9 & 86,3 & 96,4 & 19,3 & 27,9 & 27,4 & 324,9 & 280,6 & 258,3 & 35,2 & 45,3 & 54,5 \\
\hline RA de Barretos & 93,1 & 94,2 & 93,5 & 34,0 & 33,0 & 28,9 & 356,5 & 263,3 & 250,1 & 39,3 & 43,7 & 61,8 \\
\hline RA de Franca & 80,4 & 83,1 & 81,2 & 21,9 & 24,0 & 22,5 & 279,9 & 233,0 & 212,5 & 37,7 & 43,3 & 50,1 \\
\hline
\end{tabular}

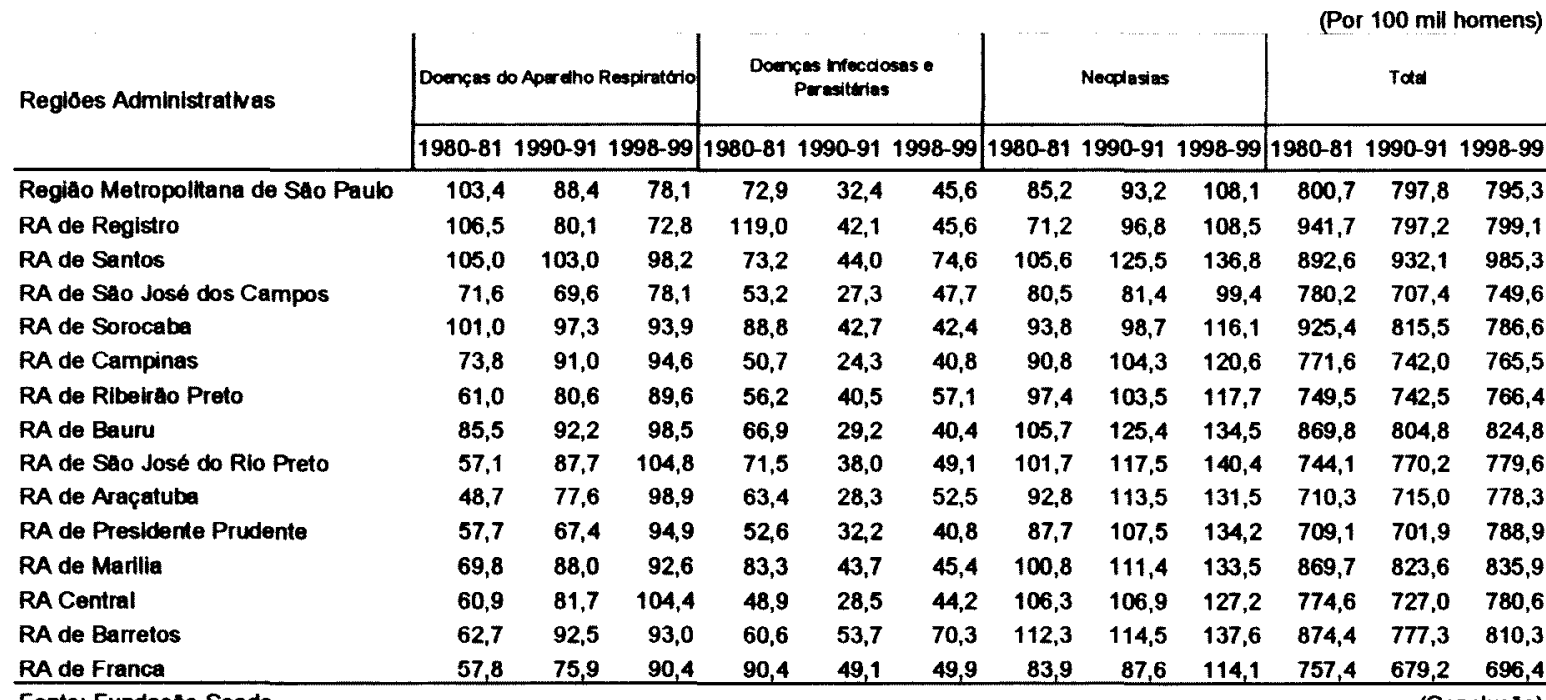

Fonte: Fundaçao Seade.

(Conclusáo)

No período 1980/81, os menores coeficientes de mortalidade por causas externas para os homens, foram registrados nas regiões de Bauru, São José do Rio Preto e Araçatuba, com pouco menos de 80 óbitos por 100 mil pessoas, enquanto os maiores correspondiam a Santos e Registro, com 136 por 100 mil, havendo portanto uma diferença em torno de 56 óbitos por 100 mil homens. Em 1990-91 a menor taxa foi observada em Presidente Prudente com 81 óbitos por 
cem mil homens, e a maior na Região Metropolitana de São Paulo, com 175 por 100 mil, e a diferença passou para 94 óbitos por 100 mil. As regiōes de Registro e de Santos continuaram a apresentar coeficientes de mortalidade muito elevados, alcançando, respectivamente, 167 e 150 óbitos por cem mil homens.

Tabela 9

Coeficientes de Mortalidade da Populaçăo Feminina, por Principais Causas

Regiōes Administrativas do Estado de Săo Paulo 1980-1999

\begin{tabular}{|c|c|c|c|c|c|c|c|c|c|c|c|c|}
\hline \multirow{3}{*}{ Regiơes Administrativas } & \multirow{2}{*}{\multicolumn{3}{|c|}{ Externas }} & \multirow{2}{*}{\multicolumn{3}{|c|}{ GI. Endócrinas }} & & & & \multirow{2}{*}{\multicolumn{3}{|c|}{$\begin{array}{c}\text { (Por } 100 \text { mil mulheres) } \\
\text { Ap. Digestivo }\end{array}$}} \\
\hline & & & & & & & \multicolumn{3}{|c|}{ Ap. Circulatório } & & & \\
\hline & $80-81$ & $90-91$ & $98-99$ & $80-81$ & $90-91$ & 98-99 & $80-81$ & $90-91$ & $98-99$ & $80-81$ & 90.91 & $98-99$ \\
\hline Regiăo Metropolitana de São Paulo & 27,7 & 29,9 & 25,5 & 31,8 & 34,1 & 29,4 & 203,8 & 193,7 & 189,3 & 20,4 & 20,8 & 21,7 \\
\hline RA de Registro & 31,8 & 43,4 & 32,1 & 24,3 & 46,4 & 52,7 & 190,7 & 156,1 & 173,3 & 21,4 & 12,3 & 25,1 \\
\hline RA de Santos & 33,1 & 28,1 & 32,4 & 43,6 & 51,9 & 42,0 & 218,6 & 223,1 & 207,2 & 25,5 & 24,2 & 27,7 \\
\hline RA de São José dos Campos & 26,3 & 25,6 & 24,8 & 37,1 & 35,6 & 42,7 & 234,4 & 203,0 & 175,3 & 19,3 & 20,3 & 22,5 \\
\hline RA de Sorocaba & 25,6 & 23,5 & 23,9 & 45,3 & 40,1 & 44,3 & 270,0 & 235,7 & 205,8 & 23,1 & 23,4 & 26,3 \\
\hline RA de Campinas & 23,7 & 24,5 & 23,3 & 29,0 & 33,2 & 32,3 & 236,5 & 208,8 & 200,0 & 21,2 & 22,4 & 24,9 \\
\hline RA de Ribeirāo Preto & 25,0 & 24,8 & 24,4 & 25,5 & 27,8 & 29,8 & 240,2 & 205,7 & 185,9 & 20,9 & 21,6 & 25,7 \\
\hline RA de Bauru & 23,1 & 24,4 & 22,7 & 29,7 & 29,7 & 39,2 & 260,9 & 254,9 & 255,4 & 25,5 & 23,1 & 32,3 \\
\hline RA de São José do Rio Preto & 24,9 & 24,3 & 24,0 & 26,3 & 29,4 & 25,6 & 230,9 & 229,8 & 221,4 & 19,4 & 29,3 & 25,4 \\
\hline RA de Araçatuba & 23,7 & 22,6 & 26,5 & 22,2 & 30,3 & 34,7 & 214,6 & 193,7 & 199,6 & 18,6 & 22,4 & 30,6 \\
\hline RA de Presidente Prudente & 22,9 & 19,2 & 23,7 & 22,3 & 30,8 & 39,5 & 192,8 & 210,6 & 214,9 & 22,1 & 22,4 & 30,0 \\
\hline RA de Marilia & 24,4 & 30,3 & 23,9 & 30,8 & 28,7 & 35,3 & 252,8 & 242,6 & 224,7 & 18,7 & 24,9 & 26,7 \\
\hline RA Contral & 21,8 & 19,4 & 21,2 & 27,4 & 24,7 & 39,1 & 268,1 & 235,0 & 231,8 & 23,8 & 22,2 & 27,5 \\
\hline RA de Barretos & 27,6 & 22,8 & 29,0 & 26,3 & 26,9 & 39,2 & 285,9 & 225,2 & 216,9 & 22,6 & 31,3 & 30,3 \\
\hline RA de Franca & 25,8 & 20,0 & 20,8 & 20,3 & 23,7 & 23,8 & 231,7 & 203,5 & 187,0 & 27,1 & 19,1 & 28,6 \\
\hline
\end{tabular}

Fonte: Fundação Seade.

(Continua)

\begin{tabular}{|c|c|c|c|c|c|c|c|c|c|c|c|c|}
\hline \multirow{3}{*}{ Regióes Administrativas } & \multirow{2}{*}{\multicolumn{3}{|c|}{ Ap. Respiratório }} & \multirow{2}{*}{\multicolumn{3}{|c|}{ Infec. e Parasitárias }} & \multirow{2}{*}{\multicolumn{3}{|c|}{ Nooplasmas }} & \multicolumn{3}{|c|}{ (Por 100 mil mulheres) } \\
\hline & & & & & & & & & & & Total & \\
\hline & $80-81$ & $90-91$ & $98-99$ & $80-81$ & $90-91$ & $98-99$ & $80-81$ & $90-91$ & $98-99$ & $80-81$ & $90-91$ & 98-99 \\
\hline Regiảo Metropolitana de Sảo Paulo & 73,1 & 60,2 & 58,4 & 50,3 & 18,9 & 22,5 & 69,7 & 79,2 & 88,1 & 567,0 & 497,9 & 490,5 \\
\hline RA de Registro & 82,5 & 73,4 & 60,1 & 70,3 & 27,6 & 21,0 & 50,1 & 49,3 & 79,3 & 592,8 & 509,9 & 509,2 \\
\hline RA de Santos & 74,9 & 69,8 & 74,5 & 51,3 &, 6 & 32,3 & 79,2 & 93,3 & 106,2 & 614,4 & 586,3 & 597,8 \\
\hline RA de Săo José dos Campos & 50,3 & 60,3 & 65,3 & 38,7 & 16,9 & 20,7 & 62,9 & 73,3 & 82,4 & 567,2 & 510,1 & 494,8 \\
\hline RA de Sorocaba & 80,1 & 69,8 & 72,3 & 57,0 & 28,8 & 20,4 & 68,3 & 77,3 & 88,2 & 687,3 & 574,9 & 545,1 \\
\hline RA de Campinas & 55,3 & 58,3 & 68,6 & 32,0 & 17,3 & 19,0 & 67,5 & 78,7 & 87,3 & 542,7 & 504,8 & 508,8 \\
\hline RA de Ribeirăo Preto & 42,6 & 55,3 & 59,7 & 43,2 & 28,2 & 29,3 & 68,7 & 76,2 & 83,6 & 542,8 & 498,7 & 485,5 \\
\hline RA de Bauru & 64,2 & 61,3 & 68,2 & 38,4 & 19,8 & 20,9 & 68,4 & 78,6 & 93,0 & 600,1 & 547,2 & 586,9 \\
\hline RA de Sáo José do & 39,1 & 54,2 & 68,7 & 39,2 & 24,9 & 32,2 & 63,7 & 74,0 & 87,6 & 523,1 & 514,0 & 533,0 \\
\hline RA de Araçatuba & 33,4 & 55,9 & 70,2 & 34,4 & 20,1 & 26,7 & 65,1 & 77,9 & 89,5 & 493,0 & 479,6 & 531,8 \\
\hline RA de Presidente Prudente & 40,9 & 42,7 & 58,3 & 33,4 & 22,2 & 19,4 & 61,0 & 72,5 & 83,8 & 478,7 & 476,3 & 526,3 \\
\hline RA de Marilia & 49,3 & 62,9 & 68,0 & 50,8 & 24,1 & 22,1 & 64,8 & 77,9 & 90,0 & 584,0 & 550,1 & 550,5 \\
\hline RA Contral & 42,3 & 57,3 & 62,0 & 29,0 & 20,0 & 21,2 & 70,3 & 78,2 & 88,3 & 570.7 & 513,4 & 543,6 \\
\hline RA de Barret & 41,1 & 54,1 & 75,2 & 41,3 & 31,9 & 34,7 & 70,3 & 87,0 & 89,5 & 600,6 & 540,0 & 572,0 \\
\hline RA de Franca & 45,7 & 53,6 & 57,2 & 48,4 & 35,4 & 33,2 & 64,0 & 67,8 & 72,8 & 551,5 & 480,4 & 485,4 \\
\hline
\end{tabular}

Fonte: Fundação Seade.

(Conclusão)

Em 1998-99 esses coeficientes aumentaram ainda mais nestas três regiōes: Santos voltou à primeira posição, com 221 óbitos por 100 mil homens, a Região Metropolitana registrou 195 por 100 mil e Registro obteve uma taxa 
semelhante à do período anterior, com 165 por 100 mil. Em Franca registrou-se o menor coeficiente, com 81 óbitos por 100 mil homens, ou seja, uma diferença de 140 óbitos por 100 mil em relação à região de Santos. Verifica-se que, em 198081 apenas quatro regiões possuiam coeficientes superiores a 100 óbitos por 100 mil homens, mas em 1998-99 nove superavam essa taxa, mostrando a importância que as causas externas adquiriram em todo o Estado. Apenas as regiōes de Franca e Barretos apresentaram coeficientes semelhantes nos três períodos e, juntamente com Presidente Prudente, Araçatuba, Central e São José do Rio Preto, formam o grupo em que os coeficientes mantêm-se abaixo de 100 óbitos por 100 mil homens. Nestas quatro regiōes os coeficientes de mortalidade aumentaram desde 1980-81. Nos casos de Santos e da Região Metropolitana de São Paulo, as causas externas têm se aproximado inclusive dos coeficientes de mortalidade devido às doenças do aparelho circulatório, o que mostra sua importância nessas áreas e certamente com reflexos muito negativos na esperança de vida ao nascer. A violência, que se espalha por várias regiões, é responsável por significativa parte da diferença existente na esperança de vida entre as regiões administrativas de São Paulo.

Para a população feminina as diferenças entre os coeficientes de mortalidade das causas externas não são tão importantes, pois as taxas situamse entre 21 óbitos por 100 mil mulheres na região Central, e 32 óbitos em Registro e em Santos, no período 1998-99. A diferença, portanto, é de apenas 10 óbitos por cem mil mulheres, inferior à observada em 1980-81 e 1990-91. Em 1980-81 o coeficiente aproximava-se de 32 óbitos por 100 mil mulheres nas regiões de Registro e de Santos, enquanto em 1990-91, chegou a 43 por 100 mil mulheres em Registro.

Os resultados apresentados mostram portanto que a mortalidade masculina por causas externas tem sido muito superior à da população feminina, em todas as regiōes do Estado de São Paulo, inclusive aumentando a diferença entre as duas populações no período mais recente. 


\section{A Mortalidade por Causas Externas}

As taxas de mortalidade por causas externas são resultantes da soma dos vários tipos de acidentes, dos homicídios, dos suicídios e também daqueles óbitos cuja intenção é indeterminada e das complicações de assistência médica e cirúrgica. Estes coeficientes podem alcançar altos valores, principalmente se uma ou várias destas causas também apresentarem coeficientes elevados. Para as regiōes de São Paulo será apresentado um panorama para os principais grupos de causas e um resumo para o total, mostrando como elas influenciam em seu coeficiente geral.

\section{Mortalidade por Homicídios}

O Gráfico 23 e a Tabela 23 do Anexo mostram a tendência da mortalidade por homicídios, nas regiōes administrativas entre 1980 e 1999, que tem considerável participação no total das causas externas de várias áreas do Estado. A Região Metropolitana de São Paulo apresenta, em todo o período considerado, os maiores coeficientes do Estado. Desde o início dos anos 90 , as taxas de mortalidade por homicídios da Região de Santos têm aumentado consideravelmente e vêm se aproximando dos observados na RMSP.

O coeficiente de mortalidade da Região de Santos, que era de 25 óbitos por 100 mil habitantes no início dos anos 90, chega a 55 em 1999, enquanto na Região Metropolitana de São Paulo passou de 46 para 65 óbitos por 100 mil habitantes. Em seguida vêm a Região de São José dos Campos, com 31 óbitos por 100 mil habitantes, em 1999, registrando um crescimento de 65\% em relação à taxa de 1990 (19 óbitos por 100 mil) e a de Ribeirão Preto, onde o coeficiente passou de 11 para 30 óbitos por 100 mil habitantes, o que eqüivale a um aumento superior a $160 \%$. Na região de Campinas os coeficientes mais que duplicaram, passando de 12 para 27 óbitos por 100 mil, entre 1990 e 1999. 
Gráfico 23

Coeficientes de Mortalidade por Homicídios

Regiões Administrativas do Estado de São Paulo

1980-99

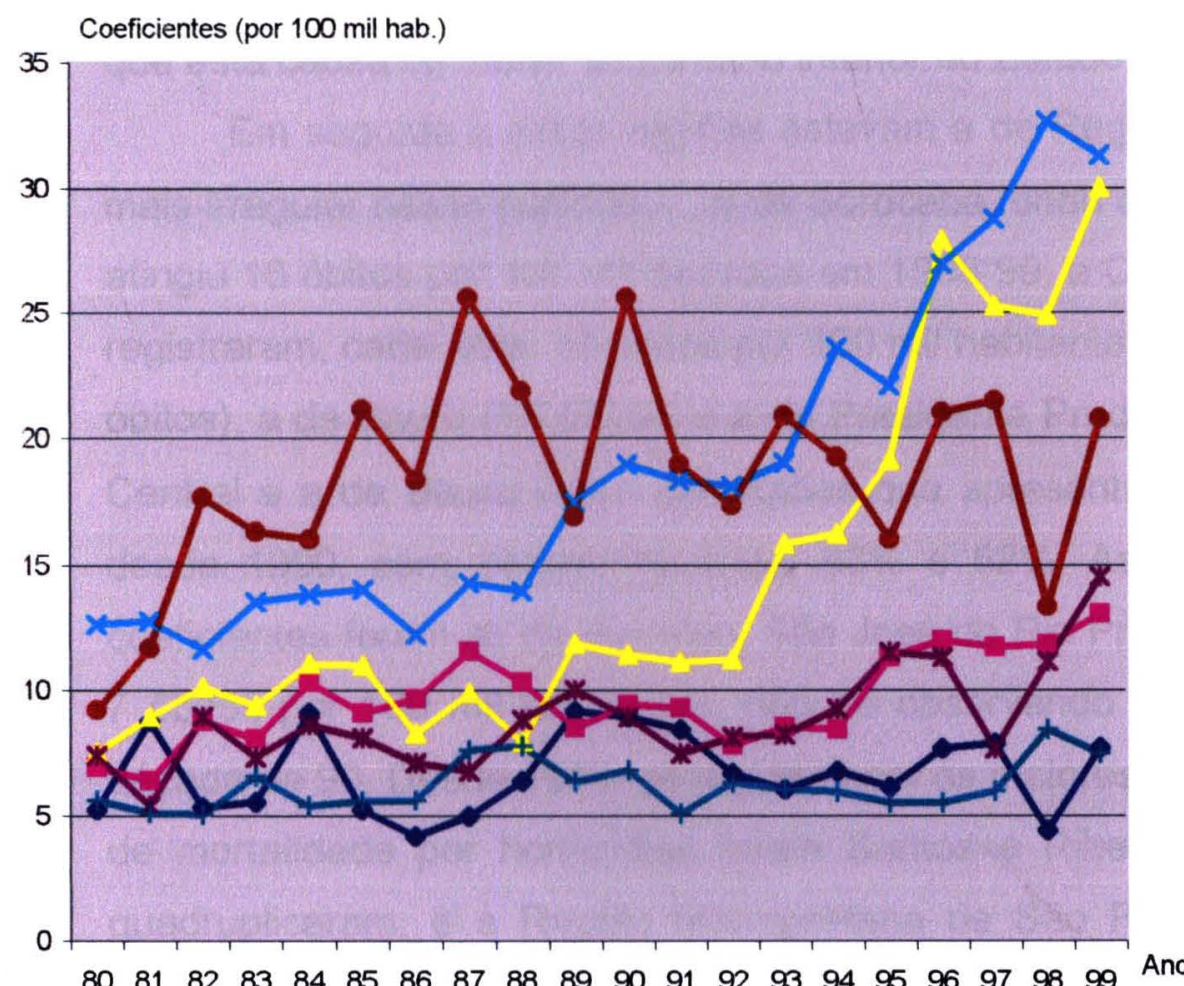

$\rightarrow$ Barretos

$\rightarrow-$ Marília

Ribeirão Preto

$\rightarrow$ São José dos Campos

$\rightarrow$ - Central

$\rightarrow$ Registro

+ São José do Rio Preto

$\begin{array}{lllllllllllllllllllll}80 & 81 & 82 & 83 & 84 & 85 & 86 & 87 & 88 & 89 & 90 & 91 & 92 & 93 & 94 & 95 & 96 & 97 & 98 & 99 & \text { Ano }\end{array}$

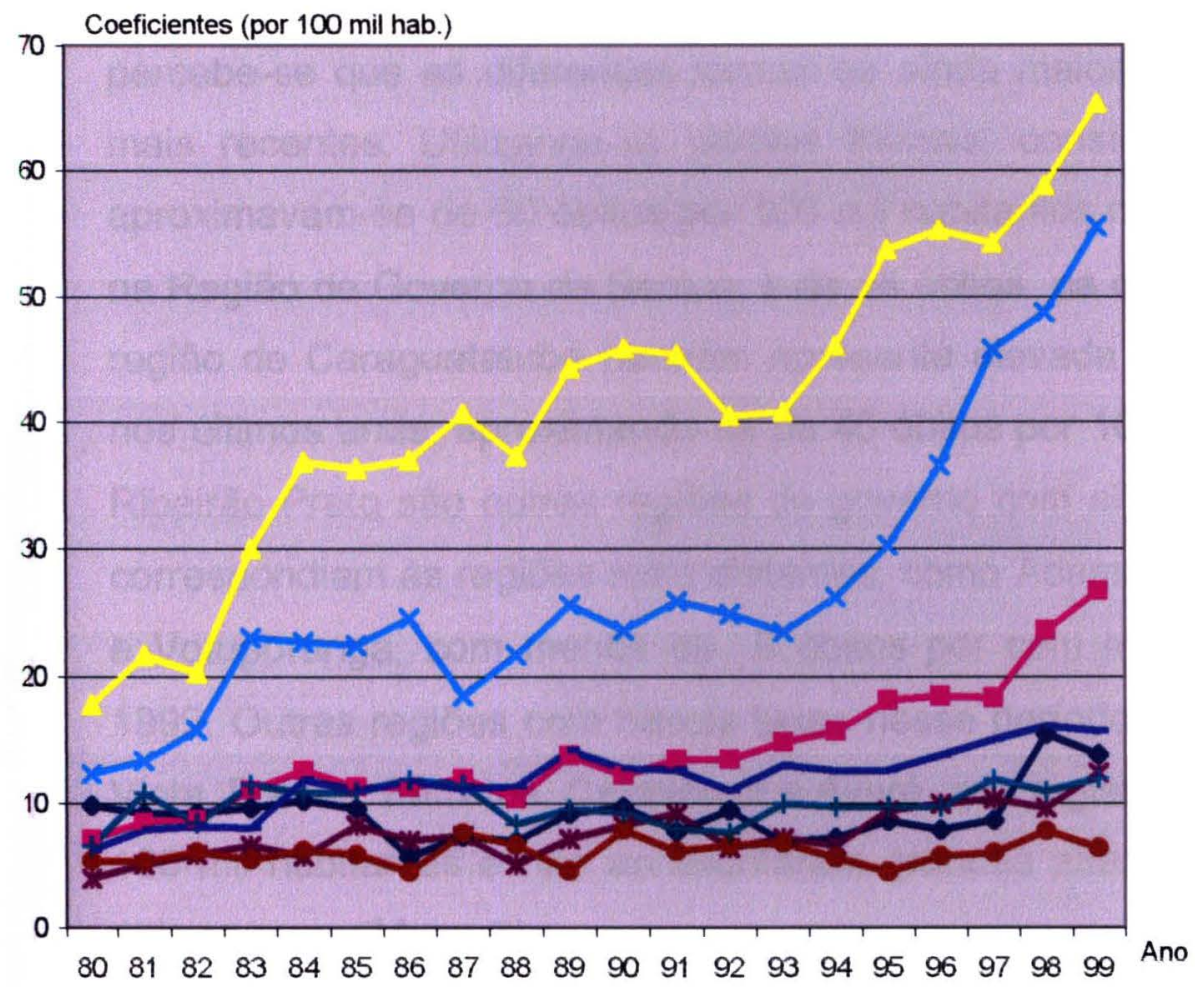
$\rightarrow$ Araçatuba
$\rightarrow-$ Campinas
RMSP
$\rightarrow$ Santos
*-Bauru
$\rightarrow$ Franca
1 Presidente Prudente
- Sorocaba

Fonte: Fundação Seade. 
Portanto, as taxas de mortalidade por homicídios registradas nas Regiões de São José dos Campos, Ribeirão Preto e Campinas, que oscilavam entre $27 \mathrm{e}$ 31 óbitos por 100 mil habitantes no período 1998-99, evidenciam a importância que esta causa de morte adquiriu no interior do Estado, na última década

Em seguida a essas regiões estavam a de Registro - com comportamento mais irregular nesse período - , a de Sorocaba, onde o coeficiente de mortalidade atingiu 16 óbitos por 100 mil pessoas em 1998-99, a Central, a de Araçatuba, que registraram, cada uma, 14 óbitos por 100 mil habitantes em 1999, a de Marilia (13 óbitos), a de Bauru (12 óbitos) e a de Presidente Prudente (12 óbitos). Destas, a Central e a de Bauru foram as regiões que apresentaram os maiores aumentos desde 1990 , com, respectivamente, $63 \%$ e $52 \%$. As regiões com os menores coeficientes foram as de Barretos, São José do Rio Preto e Franca, com cerca de 7 óbitos por 100 mil habitantes, não se observando tendência de aumento na década de 90 . Desde 1980, as regiões com os maiores aumentos nos coeficientes de mortalidade por homicídios foram Santos e Ribeirão Preto, onde mais que quadruplicaram, e a Região Metropolitana de São Paulo, Campinas e Bauru, cujas taxas mais que triplicaram.

Quando se consideram áreas menores, como as regiões de governo, percebe-se que as diferenças tornam-se ainda maiores, especialmente em anos mais recentes. Utilizando-se médias trienais, constata-se que os coeficientes aproximavam-se de 60 óbitos por 100 mil habitantes na RMSP, de 50 por 100 mil na Região de Governo de Santos, e de 46 óbitos na de São José dos Campos. A região de Caraguatatuba também apresenta elevada mortalidade por homicidios nos últimos anos, aproximando-se de 40 óbitos por 100 mil pessoas. Campinas e Ribeirão Preto são outras regiões de governo com alta mortalidade. Os menores correspondiam às regiōes mais distantes, como Adamantina, Fernandópolis, Jales e Votuporanga, com menos de 6 óbitos por cem mil habitantes, entre 1997 e 1999. Outras regiões com baixas taxas nesse periodo são Jaú, São João da Boa Vista, Franca, Barretos, Catanduva e Avaré, que registraram entre 6 e 7 óbitos por 100 mil habitantes e não apresentaram grandes alteraçōes dos coeficientes nos últimos anos (Mapa 2). 


\section{Mapa 2}

Coeficientes de Mortalidade por Homicídios

Regiões de Governo do Estado de São Paulo

1980-1999
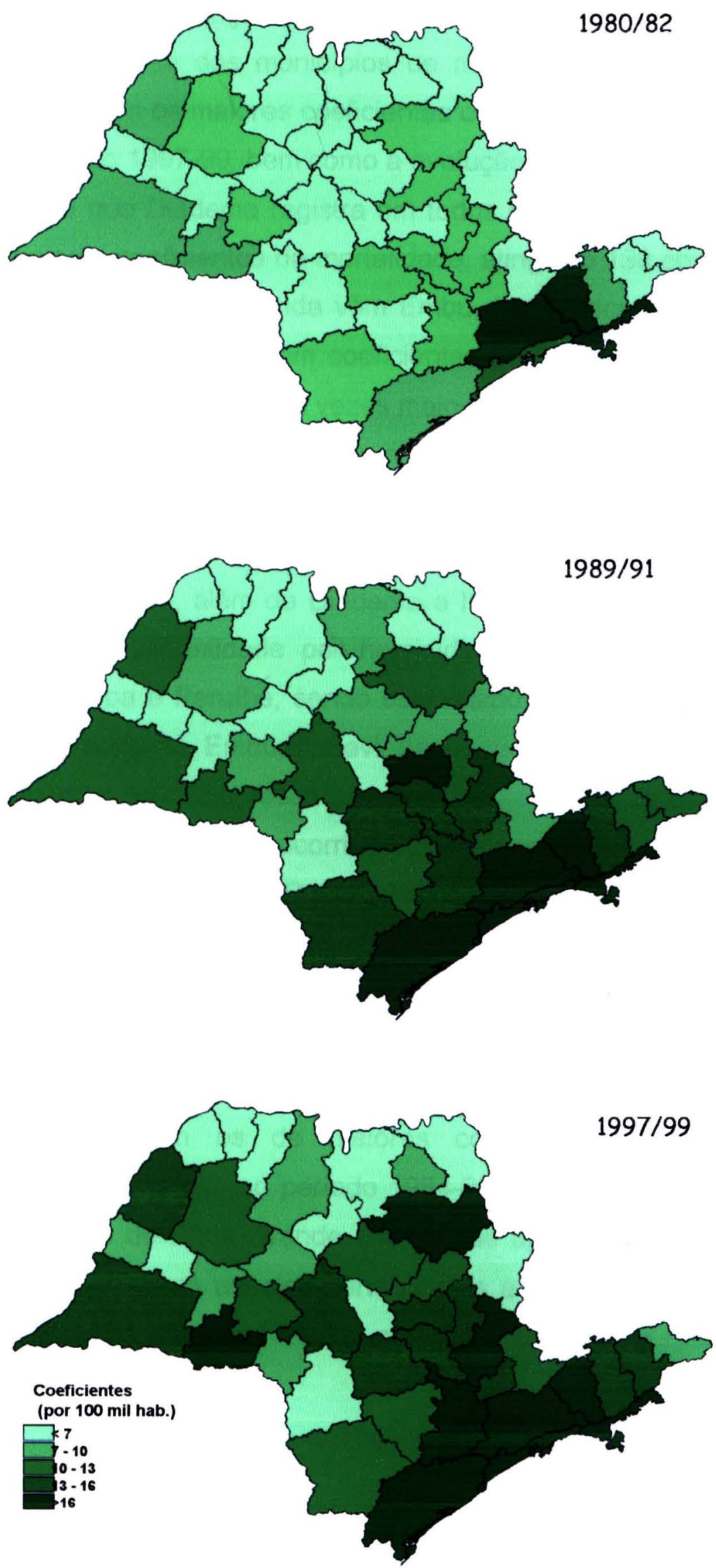

Fonte: Fundação Seade. 
Considerando-se os municipios paulistas, as diferenças aumentam ainda mais, mesmo quando se restringe a um determinado número de habitantes. A Tabela 10 traz uma relação dos municípios de mais de 20 mil habitantes do Estado, que apresentaram os maiores coeficientes de mortalidade por homicídios, ordenada para o periodo 1997-99, bem como a evolução dessas taxas a partir dos anos 80. Observa-se que Diadema registra em todos os periodos, com exceção de 1993-95, os maiores coeficientes de mortalidade, atingindo 138 óbitos por cem mil habitantes em 1997-99. Em seguida vêm Embu, Itapecerica da Serra, Embu Guaçu, Itaquaquecetuba e Itapevi, com coeficientes de 75 a 100 por óbitos por 100 mil habitantes, cerca de duas a três vezes maiores que os observados no total do estado. Todas essas localidades situam-se na Região Metropolitana de São Paulo, que tem vários de seus municípios incluídos entre os de maior mortalidade por homicidios em todos os periodos considerados.

No início dos anos 80 , além de Diadema e Itapevi, os municípios com os maiores coeficientes de mortalidade por homicídios eram Osasco, Ferraz de Vasconcelos, Carapicuiba e Peruibe, sendo este último da região de Santos. Já no período 1989-91, Diadema, Embu, Itapevi, Itaquaquecetuba, Taboão da Serra e Francisco Morato eram os que apresentavam as maiores taxas no Estado.

Percebe-se, portanto, que tem ocorrido deslocamento dos coeficientes mais altos para áreas mais periféricas da Região Metropolitana de São Paulo, sendo que os municípios que antes apresentavam maiores taxas de mortalidade por homicídios são superados por outros. Incluem-se neste caso Osasco, Carapicuiba e Ferraz de Vasconcelos, que embora continuem elevados não tiveram crescimento tão significativo. Peruíbe também não se encontra nessa relação de municipios com os de maiores coeficientes, inclusive tendo apresentado redução em relação ao período 1984-86. Na região de Santos, os municipios de Guarujá e de Praia Grande são os que apresentam recentemente as maiores taxas. Excluindo-se aqueles pertencentes à Região Metropolitana de São Paulo, esses dois municipios são os de maior mortalidade por homicídios do Estado de São Paulo. 
Tabela 10

Coeficientes de mortalidade por homicidios

Estado de Săo Paulo e Municípios

1980-1999

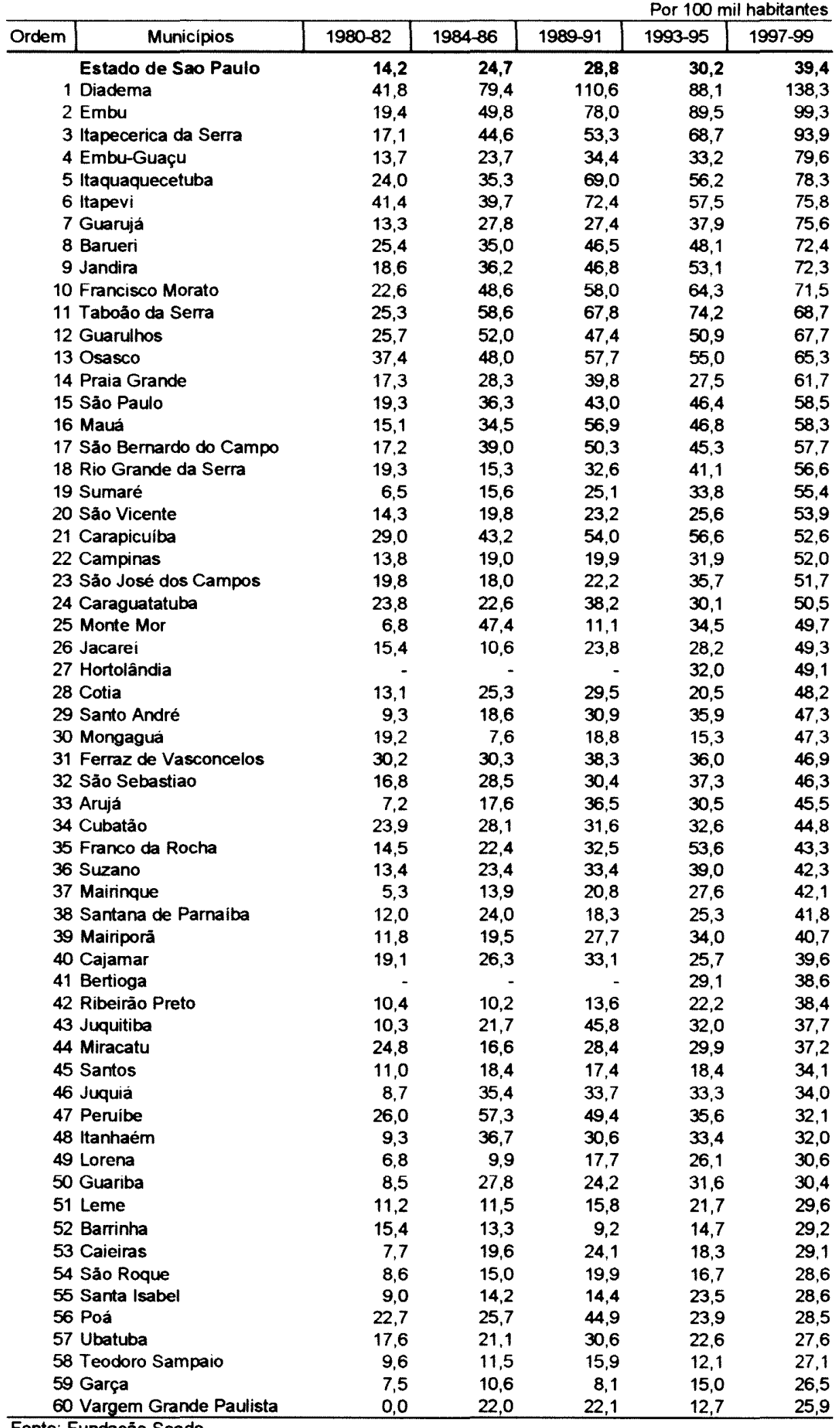


Entre os 20 municipios que registravam os maiores coeficientes de mortalidade em 1997-99, somente quatro municípios não se localizam na RMSP: Guarujá, Praia Grande, Sumaré e São Vicente. Entre a $21^{\text {a }}$ e a $30^{\mathrm{a}}$ posições, sete municípios são de outras regiōes: Campinas, Monte Mor e Hortolândia, da Região de Campinas, Mongaguá, da Região de Santos e São José dos Campos, Jacareí e Caraguatatuba, da Região de São José dos Campos. Entre os municípios mais distantes da Região Metropolitana de São Paulo, os maiores coeficientes correspondiam a São Sebastião, com 46 óbitos por 100 mil pessoas, Ribeirão Preto, com 38, e Miracatu, Juquiá, Lorena, Guariba, Leme e Barrinha, com 29 a 37 óbitos por 100 mil habitantes.

Comparando-se os coeficientes de 1997-99 com os de 1980-82, constatase que a expansão mais intensa ocorreu em Sumaré, com mais de $700 \%$. Nos municipios de Mairinque, Monte Mor e Arujá, os aumentos foram superiores a $500 \%$, enquanto em Embu Guaçu, Guarujá, Itapecerica da Serra, Embu e Santo André ultrapassaram a $400 \%$. Alguns municípios mais distantes, como Lorena, Sertãozinho e Juquiá, também apresentaram crescimento elevado. Deve-se destacar ainda que, mesmo em municipios de maior população (mais de 100 mil habitantes), observam-se coeficientes de mortalidade por homicídios relativamente baixos, quando comparados aos que foram citados anteriormente. Encontram-se nesta situação, Franca, Barretos, com menos de 6 óbitos por 100 mil habitantes, e Jaú, com cerca de 8 por 100 mil em 1997-99.

No Mapa 3 que apresenta as taxas de mortalidade por homicídios para os municípios paulistas, é possível verificar as áreas mais críticas e aquelas que se encontram em situação mais favorável, para três momentos: 1980-82, 1990-92 e 1997-99.

No período 1980-1982, 64 municipios do Estado possuiam coeficientes de mortalidade superiores a 15 óbitos por 100 mil habitantes, sendo que 20 pertenciam à Região Metropolitana de São Paulo. Outros municípios, também com taxas acima desse patamar localizam-se nas regiões de Santos e São José dos Campos. 


\section{Mapa 3}

Coeficientes de Mortalidade por Homicídios

Municípios do Estado de São Paulo

1980-1999
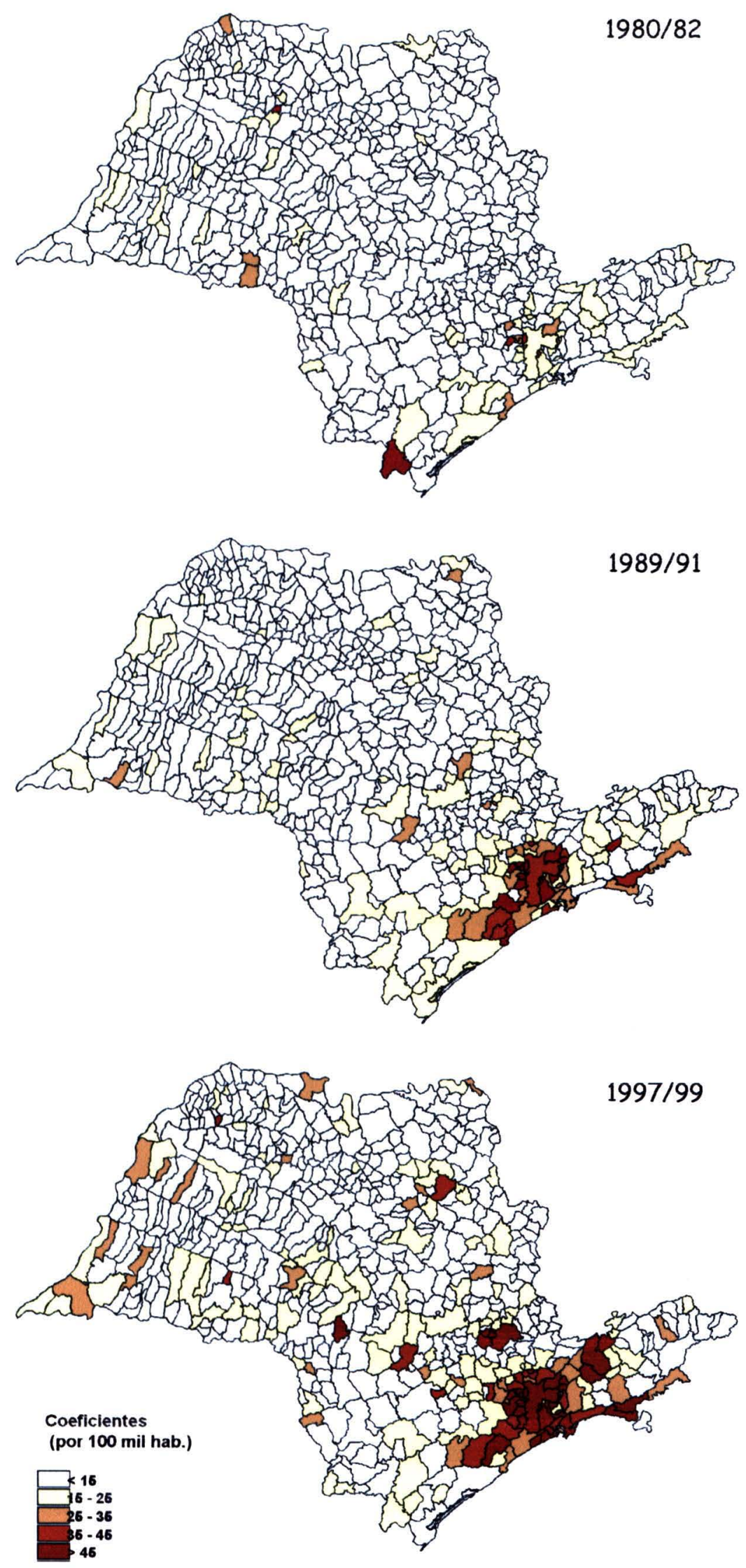

Fonte: Fundação Seade. 
Em apenas dois municipios o coeficiente ultrapassou 45 óbitos por 100 mil pessoas, sendo ambos de população muito reduzida: União Paulista e Barra do Turvo.

Quando se comparam os períodos 1980-82 e 1989-91, verificam-se acentuadas diferenças. Mais uma vez, grande parte dos municipios da Região Metropolitana de São Paulo possuía coeficientes de mortalidade mais elevados. 0 número de municípios cuja taxa ultrapassou 15 óbitos por 100 mil habitantes passou para 119, dos quais 18 registravam mais de 45 óbitos por $100 \mathrm{mil}$ habitantes, a maioria pertencente à Região Metropolitana de São Paulo.

Em 1998-99 o número de municípios com coeficientes de mortalidade por homicídios superiores a 15 óbitos por 100 mil chegou a 190, sendo que destes, 36 ultrapassaram 45 por 100 mil. Grande parte deles corresponde novamente à Região Metropolitana, inclusive os seis primeiros. Áreas com elevada mortalidade formaram-se ao redor de Santos, Campinas, São José dos Campos e em partes das regiões de Ribeirão Preto e de Sorocaba. Coeficientes de 15 a 25 óbitos por 100 mil habitantes já foram registrados em outras áreas do Estado, em 1998-99, especialmente nas regiões de Marília, Bauru e Presidente Prudente, fato raro nos períodos anteriores.

Portanto, constata-se que, nas duas últimas décadas além de ter aumentado consideravelmente o número de municípios com coeficientes mais elevados, as áreas nessa situação expandiram-se, mostrando a gravidade alcançada, especialmente nos últimos anos. Coeficientes mais altos, como por exemplo os superiores a 45 óbitos por 100 mil habitantes, foram encontrados em várias regiões do Estado em 1998-99, o que praticamente não ocorria em 198082.

\section{Acidentes de veiculos a motor/acidentes de transporte}

O panorama da mortalidade por acidentes de veículos a motor nas regiões do Estado de São Paulo não é tão claro como aquele observado para os homicídios. Várias regiões administrativas apresentam coeficientes semelhantes e somente a de Registro destaca-se das demais, apresentando, desde 1980, os 
maiores coeficientes de mortalidade, que se aproximavam de 44 óbitos por 100 mil habitantes, em 1998-99, inferior ao registrado em 1997, quando a taxa foi de 56 óbitos por 100 mil pessoas (Gráfico 24 e Tabela 24 do Anexo).

\section{Gráf ico 24}

Coef icient e de Mortalidade por Acident es de Transporte Regiões Administ r ativas do Est ado de São Paulo 1980-99

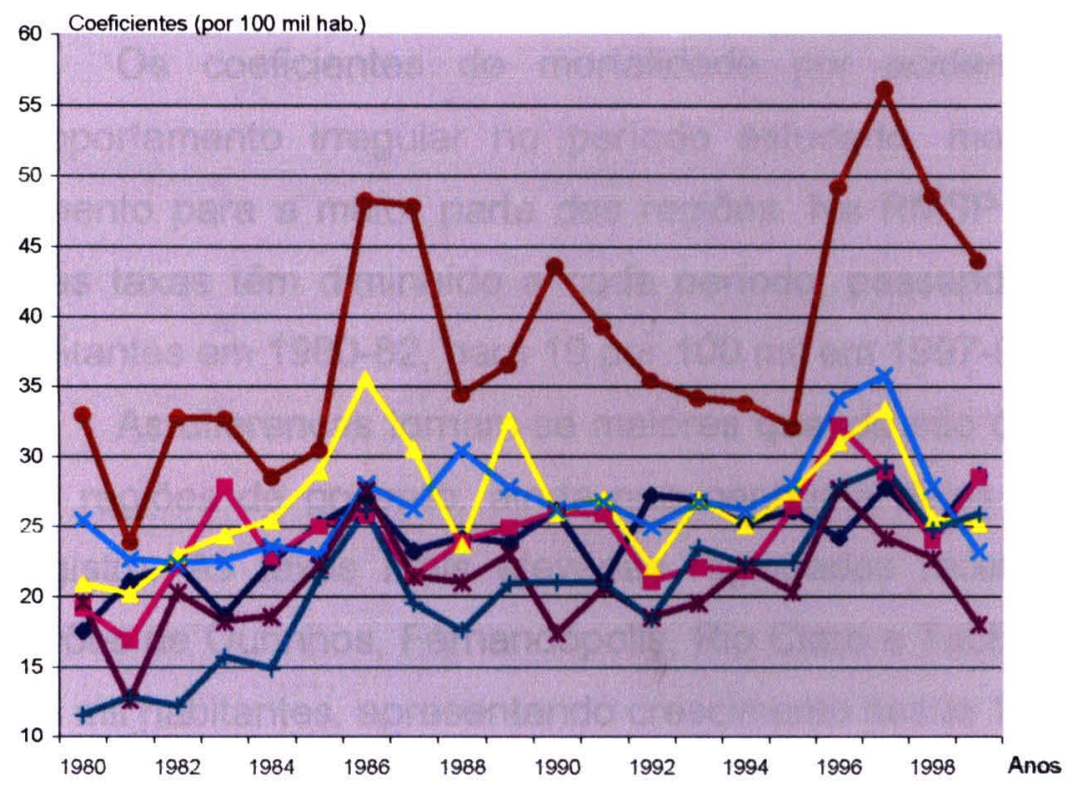

$\rightarrow$ Barret os

$\rightarrow-$ Marília

Ribeirão Preto

* São J osé dos Campos

$\rightarrow$ Central

$\multimap$ Regist ro

—— São J osé do Rio Preto

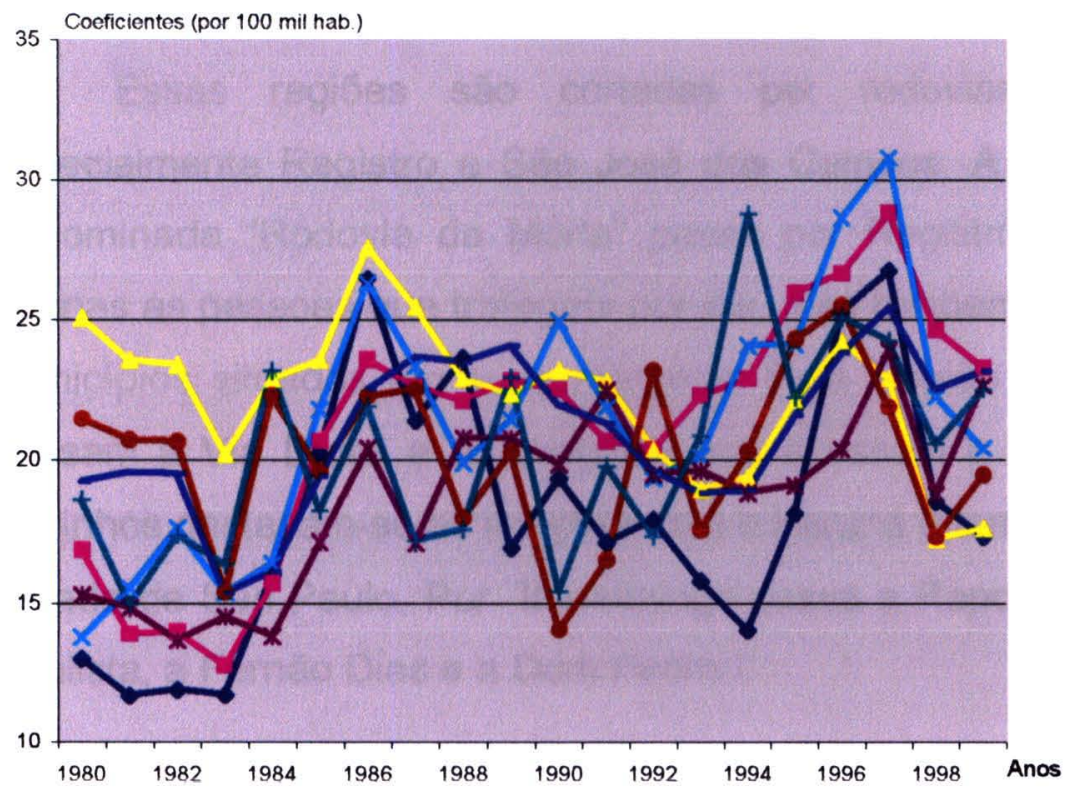

$\rightarrow$ Araçat uba

$\rightarrow-$ Campinas

RMSP

$\rightarrow$ Sant os

$\rightarrow$ Bauru

$\longrightarrow$ Franca

- President e Prudent e

Sor ocaba

Fonte: Fundação Seade 
Considerando-se médias trienais, observa-se que há aumento dos coeficientes por acidentes de veículos, entre 1980-82 e 1984-86, em todas as regiões. Um grupo formado pelas regiōes Central, Bauru, RMSP, Araçatuba, Franca, Presidente Prudente, Sorocaba e Santos apresentou coeficientes entre 20 e 22 óbitos por cem mil pessoas nesses dois períodos. Um outro grupo, constituído pelas regiões de Barretos, Campinas, Marília, Ribeirão Preto, São José do Rio Preto e São José dos Campos, registrou taxas um pouco maiores, aproximando-se de 26 óbitos por 100 mil habitantes.

Os coeficientes de mortalidade por acidentes de veículos possuem comportamento irregular no período estudado, mas a tendência geral é de aumento para a maior parte das regiões. Na RMSP a tendência é oposta, pois estas taxas têm diminuído a cada período, passando de 24 óbitos por 100 mil habitantes em 1980-82, para 19 por 100 mil em 1997-99.

As diferenças tornam-se maiores quando são considerados os coeficientes das regiões de governo, ainda que nenhuma delas aproxime-se da Região de Registro. As taxas mais elevadas registradas recentemente correspondem às regiões de Ourinhos, Fernandópolis, Rio Claro e Taubaté, com 31 a 34 óbitos por 100 mil habitantes, apresentando crescimento desde 1980-82. Em seguida vêm as regiões de São José dos Campos, Itapetininga, Catanduva, Bragança Paulista e Barretos, com cerca de 28 óbitos por 100 mil habitantes (Mapa 4).

Essas regiōes são cortadas por rodovias de grande movimento, especialmente Registro e São José dos Campos. A Rodovia Régis Bittencourt, denominada "Rodovia da Morte" passa por Registro, colocando em risco não apenas as pessoas que trafegam por ela, mas também a população residente nos municípios situados em suas margens. Pela Região de São José dos Campos passam a Via Dutra e as rodovias que acessam o litoral norte. Na Região de Ourinhos destacam-se as ligações com o Paraná e também com outras regiões do Estado de São Paulo. Por Itapetininga passa a Raposo Tavares e por Bragança Paulista, a Fernão Dias e a Dom Pedro I. 


\section{Mapa 4}

Coeficientes de Mortalidade por Acidentes de Transporte Regiões de Governo do Estado de São Paulo

1980-1999
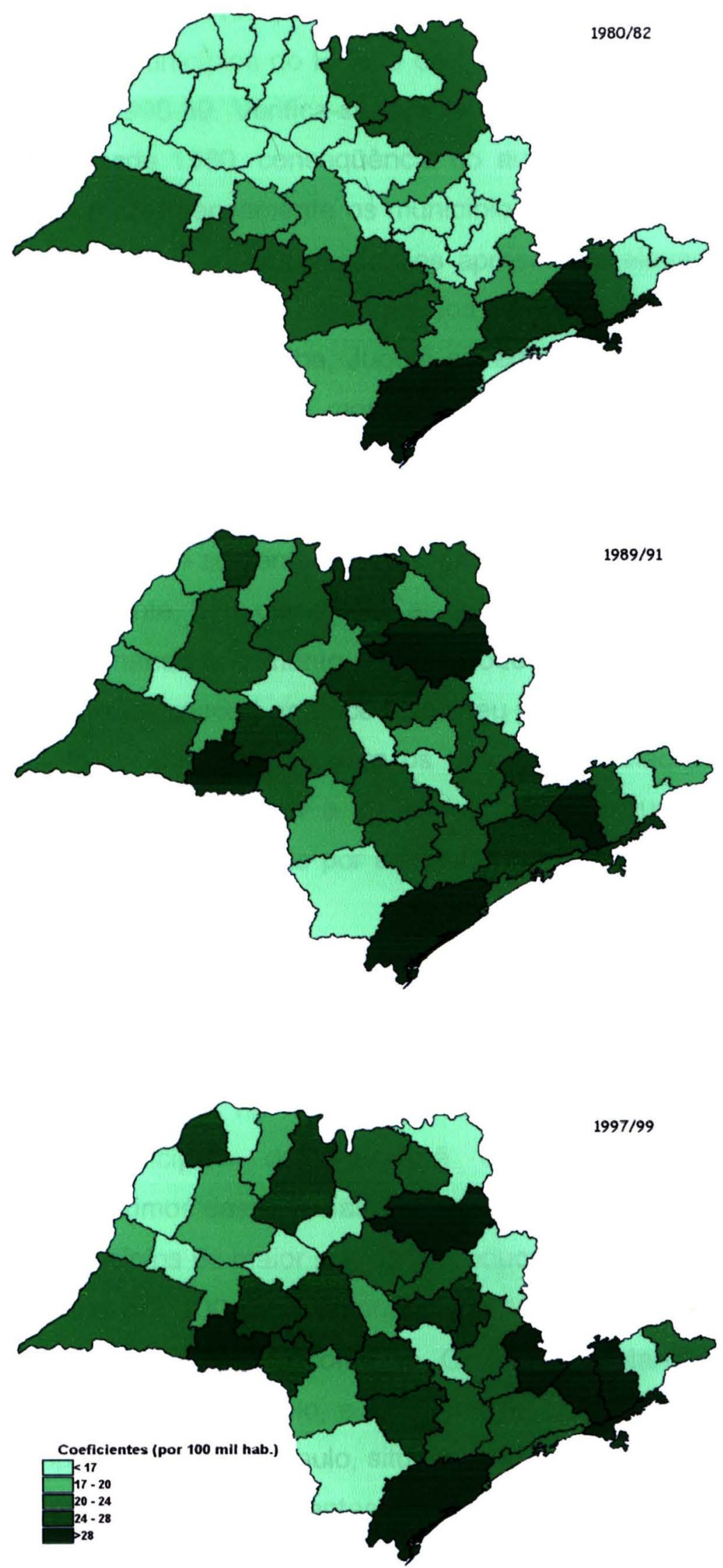

Fonte: Fundação Seade. 
O Mapa 5 mostra a evolução das taxas de mortalidade por acidentes de veículos a motor nos municípios do Estado de São Paulo para os períodos entre 1980-82, 1990-92 e 1998-99. Verifica-se que os coeficientes têm aumentado em vários municípios desde 1980, conseqüência do aumento de tráfego em várias áreas, o que afeta mais intensamente os municípios localizados às margens das rodovias mais importantes. Alguns municípios apresentam elevados coeficientes de mortalidade, destacando-se aqueles situados às margens da Rodovia Régis Bittencourt, como Miracatu, Juquitiba, Juquiá e Registro, que apresentaram em 1997-99 os maiores coeficientes de mortalidade por acidentes de transporte do Estado. Em Miracatu, a taxa tem sido superior a 80 óbitos por 100 mil habitantes desde 1989-91, fato que havia ocorrido também com Juquitiba em 1980-82. Os coeficientes de mortalidade aumentaram consideravelmente nos quatro municípios destacados anteriormente, bem como em Cajati, também localizado nessa região, certamente acompanhando o aumento de fluxo rodoviário Norte-Sul do Brasil, no qual a Rodovia Régis Bittencourt aparece como seu principal eixo.

A exemplo do que foi feito para os homicídios, relacionam-se aqui os municipios com população superior a 20 mil habitantes e que apresentaram os maiores coeficientes de mortalidade por acidentes de veículos a motor em 199799 (Tabela 11).

Além dos municipios citados e pertencentes à Região de Registro, destacam-se, com elevadas taxas, Guararema, próximo à Via Dutra, Mongaguá e Bertioga, na Região de Santos, Aguaí, Casa Branca e São Pedro, da Região de Campinas e São Sebastião, na Região de São José dos Campos. Na RMSP sobressaem os municipios de Mairiporã e Arujá, que se localizam, respectivamente, próximos das rodovias Fernão Dias e Dutra.

Entre os municípios de maior população, poucos apresentaram coeficientes abaixo de 20 óbitos por 100 mil habitantes, em 1997-99, destacando-se, entre estes, Carapicuiba, Ferraz de Vasconcelos, Osasco e Santana de Parnaiba, na Região Metropolitana de São Paulo, e Lins, no interior. Vários outros municípios da Região Metropolitana de São Paulo, situam-se entre aqueles com os menores coeficientes de mortalidade por acidentes de veículos a motor. 


\section{Mapa 5}

Coeficientes de Mortalidade por Acidentes de Transporte Municípios do Estado de São Paulo

1980-1999
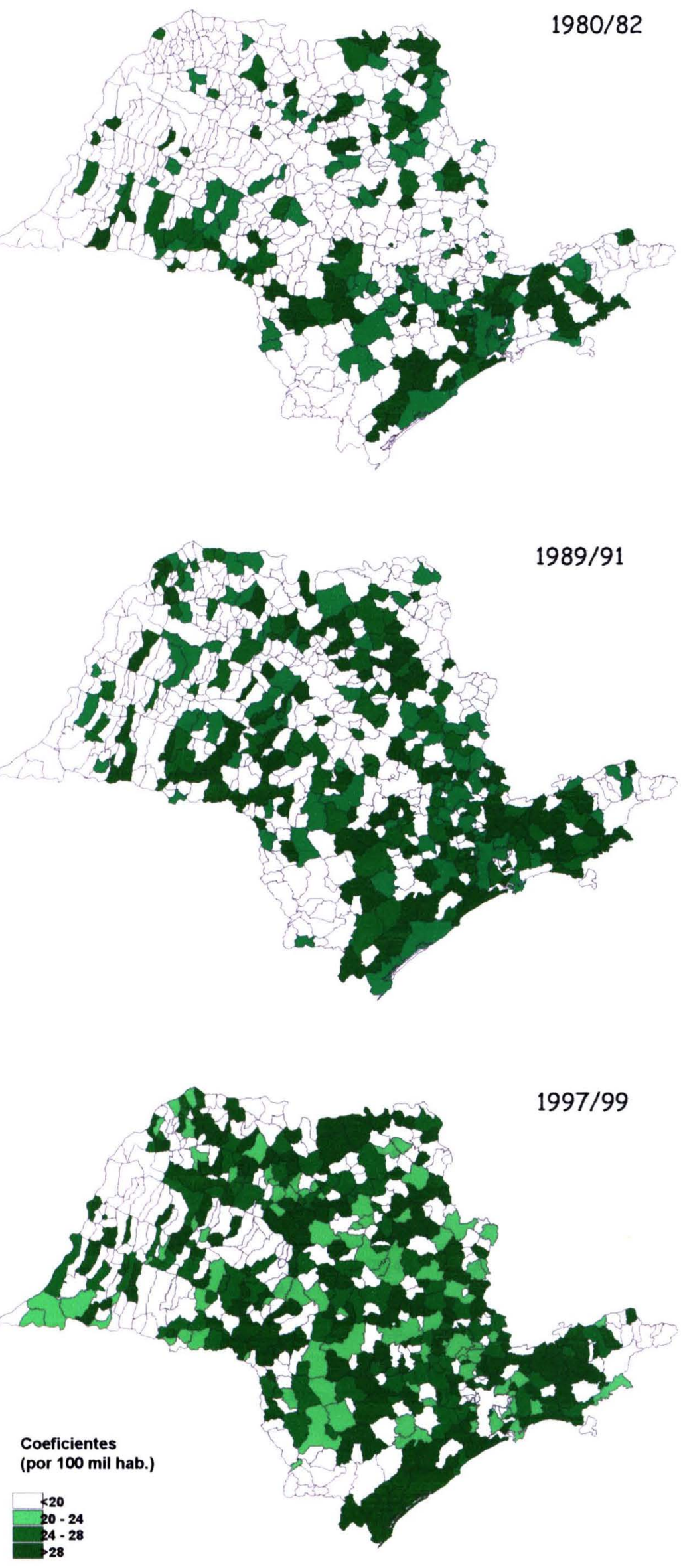
Tabela 11

Coeficientes de Mortalidade por Acidentes de Transporte

Estado de São Paulo e Municípios

1980-1999

\begin{tabular}{|c|c|c|c|c|c|c|}
\hline \multirow{2}{*}{ Ordem } & \multicolumn{6}{|c|}{ Por 100 mil habitantes } \\
\hline & Municipios & $1980-82$ & $1984-86$ & $1989-91$ & 1993-95 & $1997-99$ \\
\hline \multicolumn{2}{|r|}{ Estado de São Paulo } & 20,7 & 23,8 & 22,9 & 21,5 & 22,0 \\
\hline \multicolumn{2}{|c|}{1 Miracatu } & 30,5 & 42,3 & 93,9 & 83,2 & 96,1 \\
\hline \multicolumn{2}{|c|}{2 Juquitiba } & 100,4 & 60,7 & 77,5 & 62,5 & 72,7 \\
\hline \multicolumn{2}{|c|}{3 Juquiá } & 28,3 & 31,3 & 33,7 & 44,3 & 61,2 \\
\hline \multicolumn{2}{|c|}{4 Registro } & 37,7 & 33,9 & 52,2 & 29,8 & 54,2 \\
\hline \multicolumn{2}{|r|}{5 Guararema } & 39,2 & 14,3 & 28,3 & 43,3 & 52,6 \\
\hline \multicolumn{2}{|c|}{6 Mongaguá } & 47,9 & 45,3 & 63,9 & 51,6 & 48,4 \\
\hline \multicolumn{2}{|r|}{7 Casa Branca } & 33,3 & 28,6 & 17,4 & 25,8 & 45,2 \\
\hline \multicolumn{2}{|c|}{8 Cajati } & - & - & - & 20,8 & 44,4 \\
\hline \multicolumn{2}{|c|}{9 Bertioga } & - & - & - & 52,3 & 43,8 \\
\hline \multicolumn{2}{|c|}{10 Sāo Pedro } & 0,0 & 21,0 & 19,1 & 19,2 & 42,3 \\
\hline \multicolumn{2}{|c|}{11 Sảo Sebastiao } & 23,5 & 20,4 & 29,4 & 27,6 & 41,2 \\
\hline 12 & Aguai & 19,1 & 15,3 & 22,1 & 30,8 & 40,7 \\
\hline 13 & Femandópolis & 10,5 & 28.8 & 13,9 & 24,1 & 40,2 \\
\hline 14 & Mairiporã & 40,0 & 49,2 & 43,4 & 34,0 & 39,4 \\
\hline 15 & Cerquilho & 39,0 & 17,4 & 27,9 & 31,9 & 38,0 \\
\hline 16 & Arujá & 48,5 & 46,2 & 25,0 & 30,5 & 36,8 \\
\hline 17 & Iguape & 22,5 & 28,9 & 23,1 & 14,0 & 35,9 \\
\hline 18 & Serrana & 24,6 & 33,8 & 25,7 & 19,2 & 35,3 \\
\hline 19 & Louveira & 15,6 & 52,7 & 34,4 & 34,0 & 34,8 \\
\hline 20 & Pindamonhangaba & 22,8 & 24,2 & 31,6 & 19,5 & 34,8 \\
\hline & Atibaia & 27,9 & 33,3 & 34,7 & 31,2 & 34,3 \\
\hline 22 & Rio Claro & 7,1 & 17,5 & 24,3 & 30,1 & 34,0 \\
\hline 23 & Artur Nogueira & 16,0 & 16,3 & 31,5 & 39,2 & 33,6 \\
\hline 24 & Guaira & 25,6 & 34,6 & 14,3 & 30,1 & 33,5 \\
\hline 25 & Jaguariúna & 33,7 & 22,8 & 25,3 & 23,8 & 33,4 \\
\hline 26 & Piracaia & 35,4 & 18,8 & 25,3 & 28,0 & 33,2 \\
\hline 27 & Vargem Grande Paulista & 0,0 & 30,2 & 31,0 & 41,2 & 32,9 \\
\hline 28 & Ourinhos & 31,7 & 21,9 & 33,3 & 32,0 & 32,7 \\
\hline 29 & Cubatäo & 20,5 & 24,6 & 37,5 & 34,7 & 32,2 \\
\hline 30 & Săo Manuel & 29,7 & 34,6 & 28,0 & 29,8 & 31,9 \\
\hline 31 & Santa Cruz do Rio Pardo & 27,4 & 25,8 & 28,3 & 19,3 & 31,8 \\
\hline 32 & Taubaté & 24,2 & 20,0 & 27,8 & 36,9 & 31,8 \\
\hline 33 & Salto de Pirapora & 15,2 & 16,0 & 16,7 & 21,2 & 31,6 \\
\hline 34 & Capäo Bonito & 23,9 & 27,4 & 28,9 & 15,8 & 31,4 \\
\hline 35 & Caçapava & 15,3 & 20,9 & 32,7 & 28,5 & 31,3 \\
\hline 36 & Monte Mor & 15,9 & 20,0 & 25,0 & 31,0 & 31,2 \\
\hline 37 & Espirito Santo do Pinhal & 16,8 & 11.4 & 10,9 & 15.7 & 31,1 \\
\hline 38 & Itapira & 12,4 & 19,3 & 21,0 & 27,7 & 31,1 \\
\hline 39 & Paulinia & 20,0 & 23,7 & 20,3 & 26,0 & 30,8 \\
\hline 40 & Dracena & 9,2 & 29,2 & 27,2 & 26,7 & 30,5 \\
\hline 41 & Itapecerica da Serra & 34,1 & 27,8 & 31,5 & 20,9 & 30,2 \\
\hline 42 & Americana & 5,1 & 10,6 & 21,3 & 25,1 & 29,9 \\
\hline 43 & Aparecida & 19,1 & 31,1 & 19,2 & 17,7 & 29,9 \\
\hline 44 & Santa Cruz das Palmeiras & 20,2 & 10,9 & 23,7 & 31,9 & 29,7 \\
\hline 45 & Presidente Venceslau & 26,1 & 26,5 & 23,5 & 19,1 & 29,6 \\
\hline 46 & Cajamar & 23,5 & 28,8 & 38,2 & 25,7 & 29,5 \\
\hline 47 & Itanhaém & 25,7 & 31,8 & 29,8 & 30,3 & 29,5 \\
\hline 48 & Sumaré & 16,0 & 15,9 & 23,4 & 33,3 & 29,4 \\
\hline & Ribeirāo Preto & 25,9 & 34,6 & 31,6 & 25,8 & 29,3 \\
\hline 50 & Birigui & 9,5 & 23,7 & 17,1 & 18,8 & 29,3 \\
\hline & Bariri & 8,2 & 13,7 & 18,0 & 26,0 & 29,2 \\
\hline 52 & Conchal & 24,8 & 12,9 & 23,4 & 31,2 & 29,1 \\
\hline 53 & Praia Grande & 32,2 & 39,7 & 28,5 & 25,0 & 29,0 \\
\hline & Monte Alto & 15,7 & 31,6 & 32,7 & 41,4 & 28,9 \\
\hline & Itapetininga & 22,5 & 29,3 & 25,6 & 23,8 & 28,8 \\
\hline & Santa Rosa do Viterbo & 9,0 & 16,2 & 19,7 & 20,1 & 28,6 \\
\hline & Lorena & 10,3 & 12,0 & 17,3 & 26,5 & 28,4 \\
\hline 58 & Sāo Jose dos Campos & 30,2 & 35,9 & 31,2 & 28,7 & 28,4 \\
\hline 59 & Campos do Jordão & 13,7 & 22,9 & 21,4 & 22,1 & 28,3 \\
\hline 60 & Cabreúva & 22,0 & 16,1 & 28,0 & 27,3 & 28,2 \\
\hline
\end{tabular}

Fonte:Fundaçāo Seade. 


\section{Mortalidade por suicídio nas Regióes de São Paulo}

Como destacado anteriormente, o Brasil e o Estado de São Paulo não se caracterizam por elevados coeficientes de mortalidade por suicídio. $\mathrm{O}$ estudo da evolução desta mortalidade em áreas menores pode ser complexo, devido aos reduzidos coeficientes, bem como à sua grande irregularidade no comportamento dos mesmos, que apresentaram, para as regiōes do Estado de São Paulo, aumentos seguidos de reduções. Por isso, ao contrário dos dois grupos anteriores, não foram utilizadas informações para cada ano, mas sim médias de quatro anos (Gráfico 25).

Ainda assim, a tendência não se mostra muito evidente, pois as irregularidades permaneceram em determinados casos. Em relação às áreas com os menores coeficientes, pôde-se distinguir algumas que, em todos os momentos estudados permaneceram nessa situação. Entre estas, destaca-se a de São José dos Campos, que, nos cinco períodos quadrienais considerados, esteve na última ou na penúltima posição. Em seguida vêm a Região de Campinas, sempre situada entre as cinco últimas, e a Região de Santos. A RMSP registrou coeficientes um pouco acima das regiōes destacadas anteriormente, estando sempre entre as seis que apresentaram menores coeficientes, situação semelhante à de Ribeirão Preto. As regiões de Araçatuba e Sorocaba permaneceram em posições intermediárias, entre as regiões de maiores e menores coeficientes.

Considerando os periodos estudados, Presidente Prudente aparecia como a região que esteve à frente das demais em maior número de vezes, seguida por Central, Marília, Barretos, Registro, São José do Rio Preto, Franca e Bauru. 


\section{Gráfico 25}

Coeficientes de Mortalidade por Suicídios

Regiões Administrativas do Estado de Săo Paulo

1980-1999
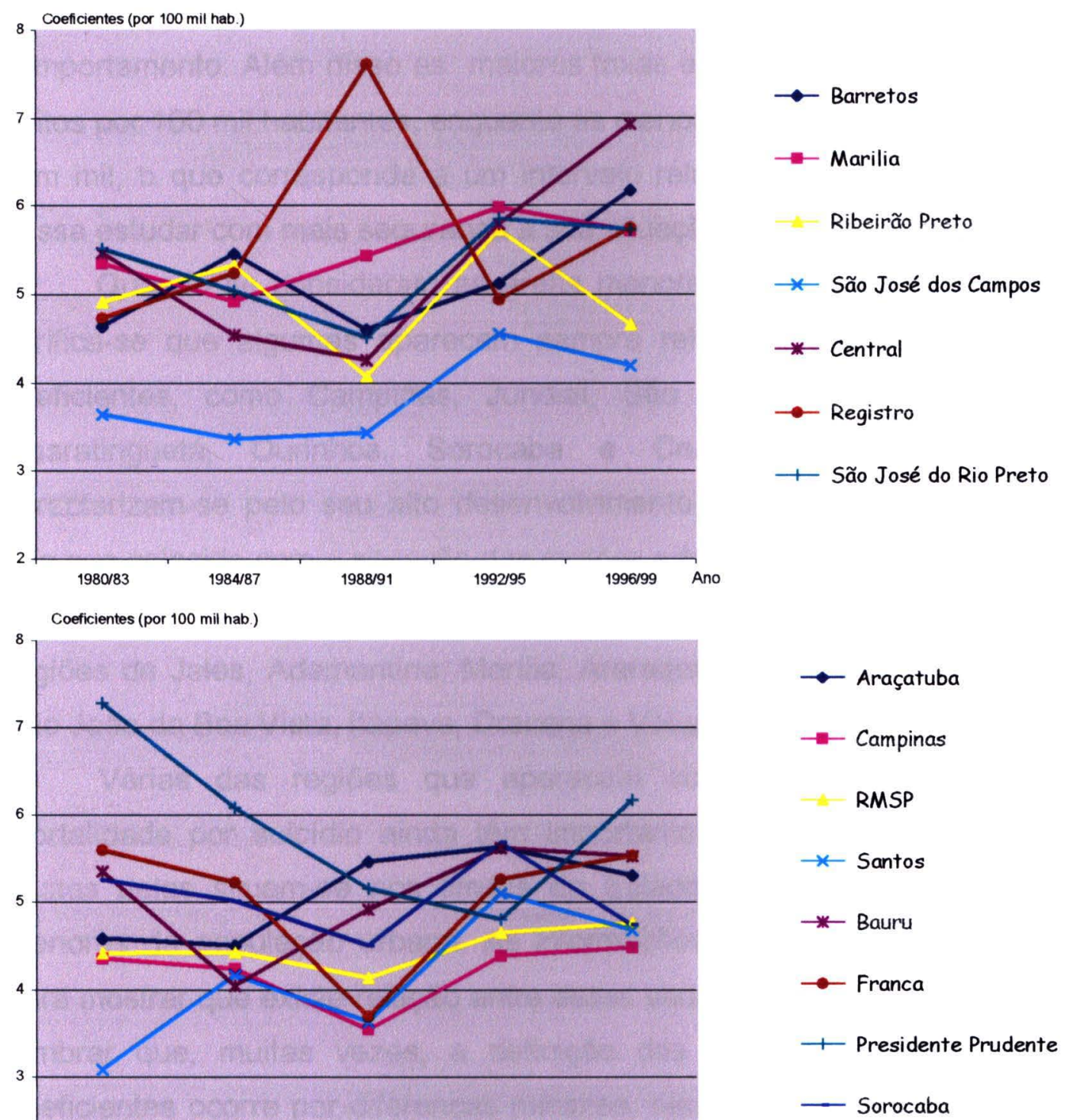

$\rightarrow$ Araçatuba
$\rightarrow$ Campinas
RMSP
$\rightarrow$ Santos
$\rightarrow$ Bauru
$\rightarrow$ Franca
+ Presidente Prudente
- Sorocaba

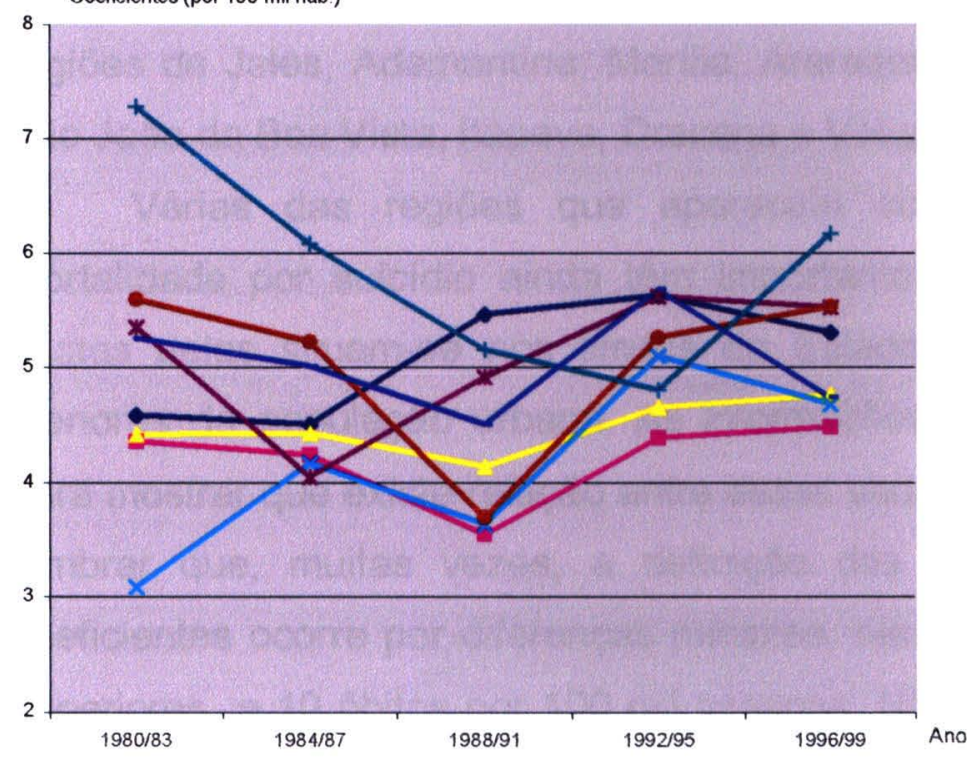

Fonte: Fundação Seade. 
Em várias regiões os coeficientes de mortalidade por suicídio apresentaram reduções, seguidas por aumentos, como Presidente Prudente, Central, Bauru, Campinas e Franca. Não se pode afirmar que esta tendência seja definitiva, sendo necessário observar os coeficientes dos próximos anos para avaliar seu comportamento. Além disso as maiores taxas encontravam-se pouco acima de 7 óbitos por 100 mil habitantes, enquanto as menores estavam entre 3 e 4 óbitos por cem mil, o que corresponde a um intervalo relativamente pequeno para que se possa estudar com mais segurança a sua situação.

Quando se consideram as áreas menores, como as regiões de governo, verifica-se que algumas aparecem sempre relacionadas entre as de menores coeficientes, como Campinas, Jundiai, São José dos Campos, Piracicaba, Guaratinguetá, Ourinhos, Sorocaba e Cruzeiro. Várias destas regiões caracterizam-se pelo seu alto desenvolvimento industrial e grande urbanização, fato que coincide com a situação das regiōes administrativas (Mapa 6). Em sentido oposto, sempre incluídas entre aquelas com as maiores taxas, aparecem as regiōes de Jales, Adamantina, Marilia, Araraquara, Botucatu, Bragança Paulista, São João da Boa Vista, Itapeva, Dracena e Votuporanga.

Várias das regiões que aparecem com os maiores coeficientes de mortalidade por suicídio ainda têm importante ligação com o setor primário e muitas delas situam-se nos limites do Estado, com percentuais relativamente menores de população urbana. As informaçōes disponiveis não são suficientes para mostrar que existe relação entre essas variáveis e, além disso, é necessário lembrar que, muitas vezes, a definição das posições regionais segundo os coeficientes ocorre por diferenças mínimas, não se observando casos com taxas superiores a 10 óbitos por 100 mil pessoas. Não deixa de ser sugestivo, porém, que regiões como Jales, Adamantina e Presidente Prudente apareçam com coeficientes de mortalidade por suicídio superiores a 6 óbitos por $100 \mathrm{mil}$ habitantes. No caso de Jales, deve-se ressaltar que, na maior parte das vezes, a taxa esteve acima de 7,5 por 100 mil, quase o dobro da média estadual. 


\section{Mapa 6}

Coeficientes de Mortalidade por Suicídios

Regiões de Governo do Estado de São Paulo 1980-1999
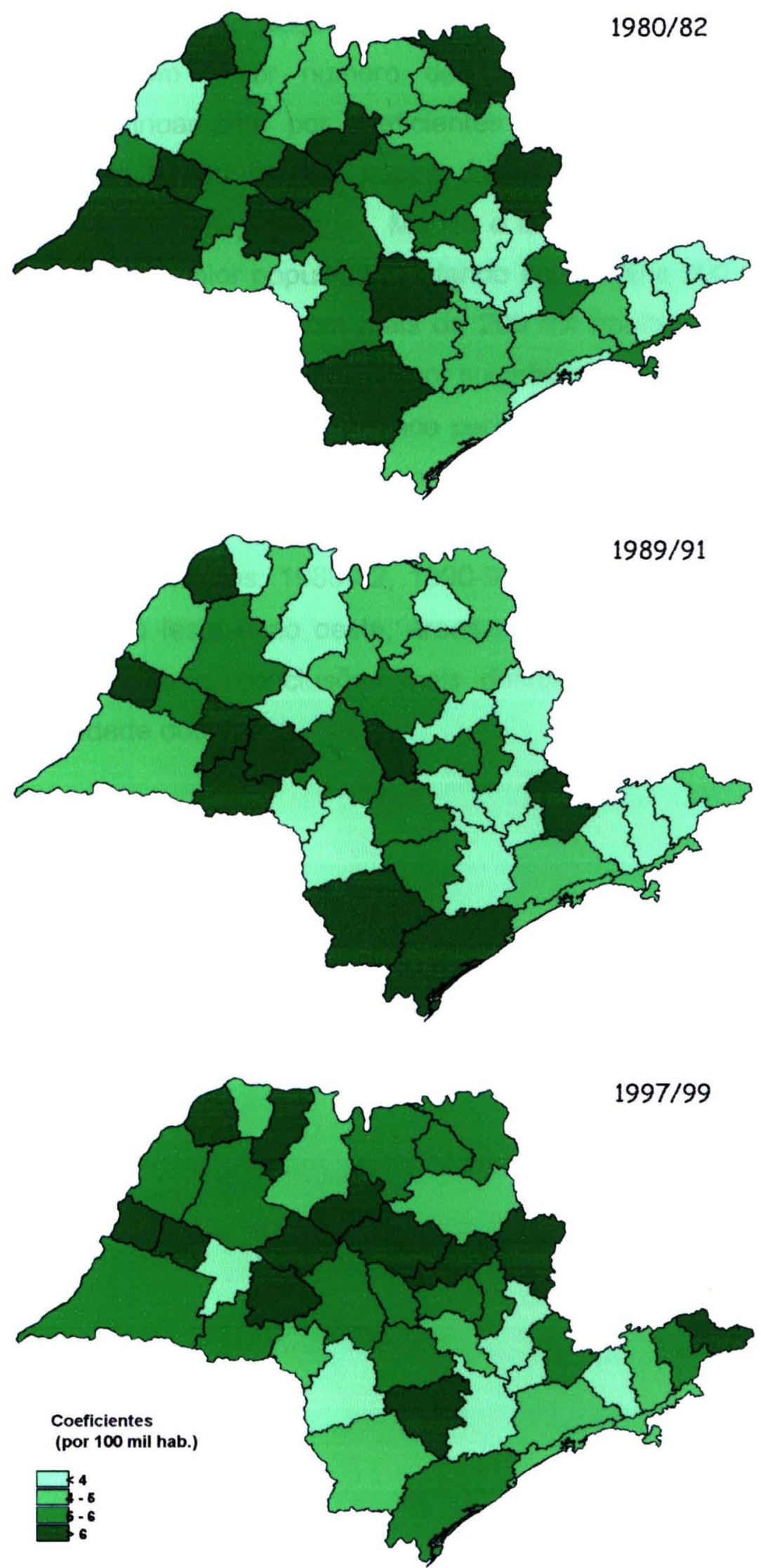

Fonte: Fundação Seade. 
O estudo da mortalidade por suicidios nos municípios apresenta ainda maior dificuldade em face do pequeno número de óbitos. Restringindo-se mais uma vez àqueles com maior número de habitantes, nota-se que alguns caracterizam-se continuamente por coeficientes mais elevados, como são os casos de Campos do Jordão, Ibitinga, Itapira, Jales, Itararé, Mairiporã, Araçatuba, Matão, Vinhedo, Mococa, Itapetininga, Marilia e Botucatu. Entre estes, os três últimos são os que têm maior população, estando entre 100 e 200 mil habitantes. Ressalte-se que nos municipios com mais de 200 mil habitantes, poucas vezes encontram-se coeficientes de mortalidade por suicídio acima de 5,5 óbitos por 100 mil habitantes: Marilia, em quatro dos cinco períodos estudados, Limeira e Mogi das Cruzes, com três e São Carlos, em dois (Tabela 12)

O Mapa 7 mostra os coeficientes de mortalidade por suicídio no Estado de São Paulo em três momentos: 1980-82, 1990-92 e 1997-99. Observam-se, nas parte central, extremo leste e no oeste, áreas com coeficientes de mortalidade mais elevados. Entretanto, conclusões mais definitivas não podem ser feitas devido à irregularidade dos casos. 
Tabela 12

Coeficientes de Mortalidade por Suicidios

Estado de São Paulo e Municipios 1980-1999

\begin{tabular}{|c|c|c|c|c|c|}
\hline \multirow{2}{*}{ Ordem } & \multirow[b]{2}{*}{$1980-82$} & \multirow{2}{*}{$1984-86$} & \multirow{2}{*}{$1989-91$} & \multicolumn{2}{|c|}{ Por 100 mil habitantes } \\
\hline & & & & $1993-95$ & $1997-99$ \\
\hline Estado de Sao Paulo & 4,5 & 4,5 & 4,2 & 5,0 & 4,7 \\
\hline 1 Campos do Jordão & 14,9 & 10,9 & 4,7 & 6,8 & 10,2 \\
\hline 2 Itanhaém & 3,5 & 2,9 & 8,4 & 4,9 & 9,2 \\
\hline 3 São Joaquim da Barra & 3,4 & 11,4 & 1,9 & 3,5 & 9,1 \\
\hline 4 lbitinga & 12,3 & 13,2 & 10,8 & 7,3 & 9,0 \\
\hline 5 Franco da Rocha & 4,4 & 9,4 & 2,9 & 4,7 & 8,8 \\
\hline 6 Jaboticabal & 4,9 & 7,0 & 6,3 & 6,5 & 8,7 \\
\hline 7 Itapira & 5,5 & 7,7 & 5,4 & 8,5 & 8,6 \\
\hline 8 Araraquara & 3,6 & 3,9 & 5,5 & 6,8 & 8,5 \\
\hline 9 Jales & 1,7 & 8,8 & 8,1 & 10,1 & 8,1 \\
\hline 10 Batatais & 1,8 & 8,3 & 3,1 & 0,7 & 8,1 \\
\hline 11 Itararé & 8,7 & 5,7 & 4,6 & 9,9 & 8,1 \\
\hline 12 Mairiporã & 3,5 & 4,1 & 6,9 & 7,2 & 7,9 \\
\hline 13 Araçatuba & 4,1 & 4.2 & 5,8 & 6.1 & 7,9 \\
\hline 14 Matão & 3,4 & 2,1 & 7,7 & 7,1 & 7,6 \\
\hline 15 Vinhedo & 6,0 & 6,3 & 2,1 & 7,1 & 7,6 \\
\hline 16 Mococa & 5,5 & 7,7 & 3,5 & 7,7 & 7,3 \\
\hline 17 Itapetininga & 5,4 & 5,4 & 6,8 & 7,9 & 7,3 \\
\hline 18 Tatui & 1,2 & 4,2 & 5,8 & 4,1 & 7,1 \\
\hline 19 Garça & 2,5 & 4,9 & 9,7 & 8,7 & 7,0 \\
\hline 20 Lorena & 0,6 & 2,6 & 4,2 & 5,9 & 7,0 \\
\hline 21 Mogi-Mirim & 4,5 & 2,9 & 2,6 & 6,2 & 6.9 \\
\hline 22 Aruja & 12,6 & 5,4 & 3,8 & 0,8 & 6,9 \\
\hline 23 Itapecerica da Serra & 3,7 & 5,5 & 3,8 & 7,2 & 6,8 \\
\hline 24 Bebedouro & 3,5 & 6,1 & 4,6 & 5,2 & 6,8 \\
\hline 25 Dracena & 4,6 & 0,9 & 7,6 & 5,8 & 6,6 \\
\hline 26 Presidente Prudente & 6,0 & 6,3 & 4,7 & 3,8 & 6,5 \\
\hline 27 Catanduva & 6,7 & 4,5 & 3,7 & 7,3 & 6,5 \\
\hline 28 Embu-Guaçu & 1,5 & 6,2 & 4,9 & 4,7 & 6,5 \\
\hline 29 Mogi-Guaçu & 6,2 & 4,2 & 3,9 & 4,6 & 6,5 \\
\hline 30 Marilia & 8,0 & 4,6 & 6,4 & 7,2 & 6,4 \\
\hline 31 Cosmópolis & 2,8 & 7,0 & 3,8 & 3,5 & 6,4 \\
\hline 32 Mogi das Cnuzes & 5,3 & 5,2 & 7,4 & 5,5 & 6,3 \\
\hline 33 Assis & 5,3 & 4,9 & 8,0 & 3.8 & 6,3 \\
\hline 34 São Carios & 4,6 & 4,2 & 2,6 & 5,7 & 6,1 \\
\hline 35 São Jose do Rio Pardo & 12,7 & 7,5 & 2,3 & 6,4 & 6,1 \\
\hline 36 Cruzeiro & 1,1 & 4,3 & 5,4 & 2,8 & 6,0 \\
\hline 37 Caraguatatuba & 4,8 & 1,6 & 3.3 & 5.5 & 6,0 \\
\hline 38 Taquaritinga & 4,5 & 4,1 & 2,2 & 6,9 & 5,9 \\
\hline 39 Porto Ferreira & 7,0 & 2,1 & 2,7 & 2,4 & 5,9 \\
\hline 40 Nova Odessa & 4,4 & 1,2 & 4,1 & 3,6 & 5,8 \\
\hline 41 Rio Claro & 5,1 & 4,9 & 6,2 & 6.1 & 5,8 \\
\hline 42 São Sebastião & 6,7 & 4,1 & 5,2 & 3,2 & 5,8 \\
\hline 43 São João da Boa Vista & 7,0 & 3,2 & 2,5 & 6,0 & 5,7 \\
\hline 44 Amparo & 6,3 & 7,3 & 8,1 & 10,5 & 5,7 \\
\hline 45 Limeira & 4,1 & 2,7 & 6,1 & 6,5 & 5,7 \\
\hline $46 \mathrm{ltu}$ & 3,1 & 2,3 & 1,9 & 4,3 & 5,7 \\
\hline 47 Guaratinguetá & 1,5 & 2,5 & 3,0 & 2,8 & 5,6 \\
\hline 48 Leme & 4,9 & 6,1 & 5,6 & 4,6 & 5,6 \\
\hline 49 Barretos & 2,7 & 4,1 & 3,9 & 5,8 & 5,6 \\
\hline 50 Fernandópolis & 3,5 & 1,3 & 3,6 & 5,7 & 5,5 \\
\hline 51 Andradina & 3,5 & 6,7 & 3,2 & 6,9 & 5,5 \\
\hline 52 Votuporanga & 2,5 & 5,2 & 2,1 & 7,3 & 5,5 \\
\hline 53 Bauru & 5.6 & 5,2 & 5,4 & 5,9 & 5,4 \\
\hline 54 Bragança Paulista & 6,6 & 7,1 & 4,4 & 8,1 & 5,3 \\
\hline 55 Diadema & 2,7 & 4,4 & 3,3 & 4,8 & 5,3 \\
\hline 56 Pirassununga & 1,5 & 4,7 & 5,4 & 6,7 & 5,3 \\
\hline 57 Salto & 3,8 & 6,2 & 4,4 & 3,0 & 5,3 \\
\hline 58 Birigui & 0,6 & 5,5 & 3,7 & 4,5 & 5,2 \\
\hline 59 Praia Grande & 1,9 & 4,6 & 4,0 & 5,1 & 5,2 \\
\hline 60 Botucatu & 10,6 & 7,1 & 6,5 & 7,3 & 5,1 \\
\hline
\end{tabular}




\section{Mapa 7}

Coeficientes de Mortalidade por Suicídios Municípios do Estado de São Paulo
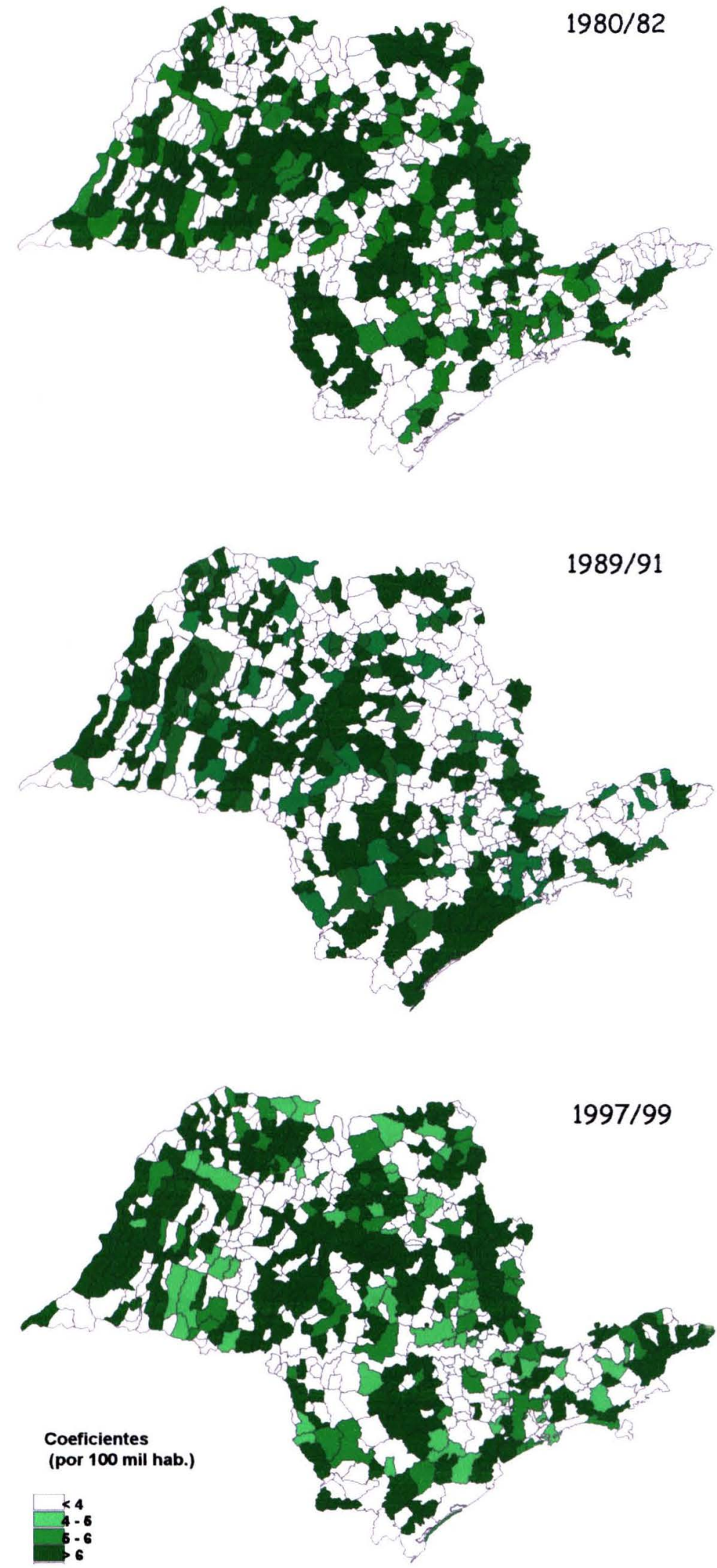

Fonte: Fundação Seade. 


\section{Demais Acidentes}

No Estado de São Paulo, a mortalidade por acidentes de transportes e aquela causada por outros tipos de acidentes apresentaram comportamento e evolução muito próximos na maior parte do período estudado, com os respectivos coeficientes situados entre 20 e 25 óbitos por 100 mil habitantes. Quando consideradas conjuntamente os "demais acidentes", constituiam-se na segunda ou terceira causa externa mais importante. Até 0 início dos anos 80 , quando a mortalidade por homicídios ainda era menor, os óbitos correspondentes aos "demais acidentes" aparecem muito próximos aos dos acidentes de veículos a motor. Com o aumento dos homicidios, os demais acidentes passaram para a terceira posição que se mantém até o final dos anos 90 .

A situação também é semelhante na maior parte das regiōes do Estado, com os coeficientes de mortalidade por demais acidentes mantendo-se próximos de 20 óbitos por 100 mil habitantes (Gráfico 26 e Tabela 26 do Anexo). Somente nas regiōes de Santos e de Registro o panorama é diferente, ultrapassando em muito os coeficientes médios do Estado. Nessas duas regiōes as respectivas taxas aproximaram-se de 40 óbitos por 100 mil habitantes na metade dos anos 90 . Os afogamentos correspondem a uma das principais causas de mortalidade deste grupo, por isso os elevados coeficientes observados nestas duas regiões, que, juntamente com São José dos Campos (litoral norte), são as que possuem municípios litorâneos no Estado.

Nesse período observa-se também certo aumento da mortalidade por demais acidentes nas regiões de Bauru, Presidente Prudente e Sorocaba, porém sem alcançar os niveis observados em Santos e em Registro. As regiões de Campinas, Sorocaba e São José dos Campos aparecem, em grande parte do período, com coeficientes um pouco superiores aos das demais regiões do Estado, enquanto as menores taxas correspondem, geralmente às regiões Central e Ribeirão Preto.

Os coeficientes de mortalidade por demais acidentes apresentaram comportamento irregular nas regiōes, com aumentos $e$ diminuições em determinados anos ou períodos. Em 1980, a Região de Franca, aparecia entre as 
de menor mortalidade por demais acidentes, passando a ocupar a quarta posição em 1994.

\section{Gáfico 26}

Coef icient es de Mort alidade por " Demais Acident es" Regiōes Administ rativas do Est ado de São Paulo

1980-95
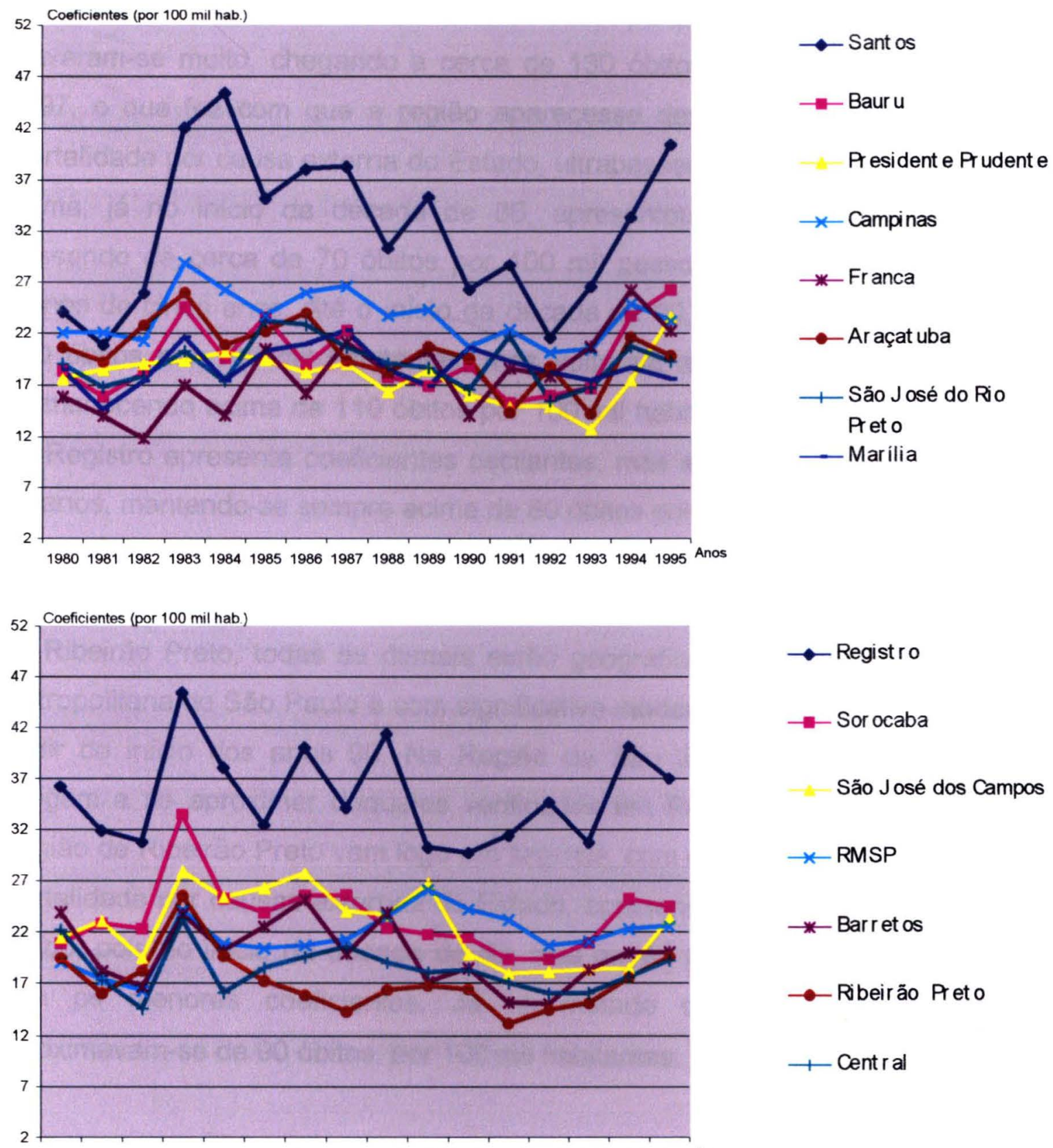

$\rightarrow$ Registro

- Sor ocaba

São J osé dos Campos

$x$ RMSP

* Bar r et os

$\longrightarrow$ Ribeirão Preto

+ Cent r al

Fonte: Fundação Seade 


\section{A mortalidade por causas externas}

Os maiores coeficientes de mortalidade por causas externas foram registrados, entre 1980 e 1999, para as regiōes de Registro, Santos e RMSP (Gráfico 27 e Tabela 27 do Anexo). No início dos anos 80, a Região de Santos possuia coeficientes próximos de 80 óbitos por 100 mil habitantes, apresentando poucas alterações até o início dos anos 90. A partir de 1992, esses coeficientes elevaram-se muito, chegando a cerca de 130 óbitos por 100 mil habitantes em 1997, o que fez com que a região aparecesse desde 1996, como a de maior mortalidade por causa externa do Estado, ultrapassando Registro e a RMSP. Esta última, já no início da década de 80 , apresentou aumento dos coeficientes, passando de cerca de 70 óbitos por 100 mil pessoas para 90 por $100 \mathrm{mil}$, em menos de cinco anos. Até o início da década de 90, as taxas ficaram entre 90 e 100 óbitos por 100 mil habitantes, mas voltaram a aumentar depois de 1994, permanecendo acima de 110 óbitos por 100 mil habitantes, desde 1996. A região de Registro apresenta coeficientes oscilantes, mas sempre elevados nos últimos 20 anos, mantendo-se sempre acima de 80 óbitos por 100 mil pessoas.

Entre as demais regiões, destaca-se o importante crescimento observado em São José dos Campos, Campinas, Ribeirão Preto e Sorocaba. Com exceção de Ribeirão Preto, todas as demais estão geograficamente próximas da Região Metropolitana de São Paulo e com significativa mortalidade por causas externas a partir do início dos anos 90. Na Região de São José dos Campos, as taxas chegam a se aproximar daqueles verificados em Registro nos últimos anos. A Região de Ribeirão Preto vem logo em seguida, com o quinto maior coeficiente de mortalidade por causas externas do Estado, apresentando um crescimento muito rápido, pois no início da década de 80 , esta região encontrava-se entre aquelas com os menores coeficientes. Já na metade dos anos 90 , suas taxas aproximavam-se de 90 óbitos por 100 mil habitantes. 
Gáf ico 27

Coeficient es de Mortalidade por Causas Externas

Regiões Administ rativas do Est ado de São Paulo

1980-99
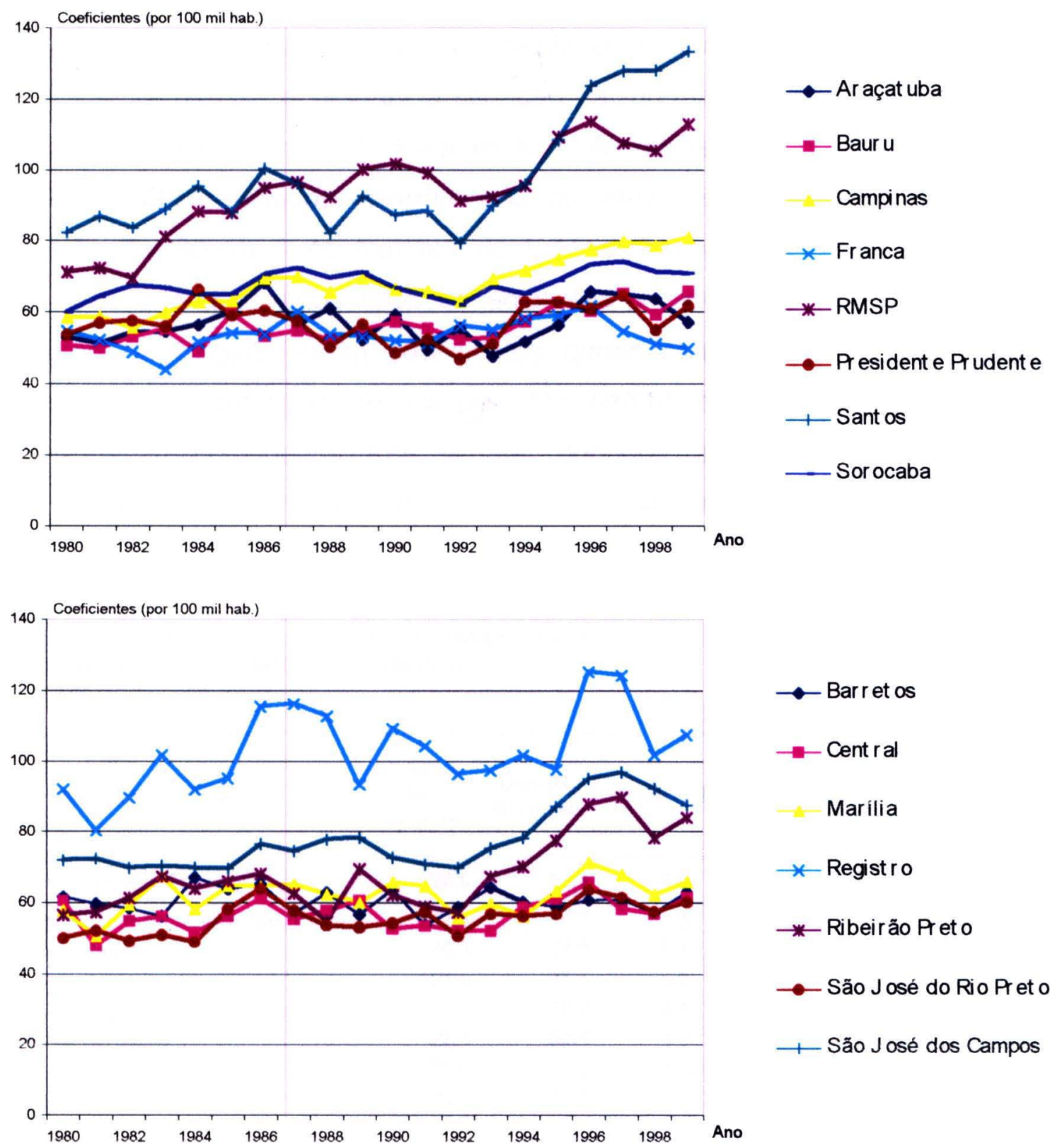

$\multimap$ Barr et os

$\rightarrow-$ Cent ral

Marilia

$*$ Registro

* Ribeirão Preto

$\longrightarrow$ São J osé do Rio Preto

— São J osé dos Campos

Fonte: Fundação Seade.

Em Campinas e Sorocaba também houve aumentos importantes, ainda que em ritmos inferiores aos observados em São José dos Campos e Ribeirão Preto. Entre as demais áreas não há um panorama muito claro, ainda que Marilia pareça estar desprendendo-se aos poucos desse grupo, com seus coeficientes 
aproximando-se de 70 óbitos por 100 mil habitantes, enquanto antes estavam geralmente entre 50 e 60 por 100 mil. As regiōes com os menores coeficientes localizam-se no centro e no oeste do Estado, onde aparentemente ainda estão mais imunes aos altos índices de mortalidade violenta.

A Tabela 13 apresenta a situação da mortalidade segundo os grupos de causas externas, para as 15 Regiōes Administrativas de São Paulo, no período de 1998-99. Os resultados mostram que os altos coeficientes de mortalidade da Região de Santos - os maiores do Estado - devem-se à alta ocorrência de homicídios e dos vários tipos de acidentes. A seguir aparecem a RMSP e a Região de Registro, com coeficientes gerais semelhantes, mas distintos em termos de distribuição de causas. Na RMSP os homicídios têm a maior participação, com quase $60 \%$ do total, enquanto em Registro os acidentes em geral, mas principalmente os de transporte, constituem-se nas principais causas.

Tabela 13

Coeficientes de Mortalidade por Causas Externas, segundo Grupos

Regiōes Administrativas do Estado de São Paulo

1998-99

Por 100 mil habitantes

\begin{tabular}{|c|c|c|c|c|c|c|c|}
\hline Regiōes Administrativas & $\begin{array}{l}\text { Acidentes } \\
\text { de } \\
\text { Transporte }\end{array}$ & $\begin{array}{l}\text { Demais } \\
\text { Acidentes }\end{array}$ & Suicidios & Homicidios & $\begin{array}{l}\text { Demais } \\
\text { Externas }\end{array}$ & Total & $\begin{array}{c}\text { Percentual } \\
\text { das } \\
\text { Externas } \\
\text { no Total }\end{array}$ \\
\hline Estado de Sāo Paulo & 20,6 & 18,3 & 4,6 & 42,0 & 7,0 & 92,4 & 14,0 \\
\hline Região Metropolitana de São Paulo & 17,4 & 16,7 & 4,5 & 62,9 & 7,6 & 109,1 & 16,9 \\
\hline RA de Registro & 46,3 & 27,8 & 6,1 & 17,9 & 6,5 & 104,6 & 15,2 \\
\hline RA de Santos & 21,3 & 37,7 & 4,3 & 54,9 & 12,4 & 130,6 & 15,8 \\
\hline RA de São José dos Campos & 25,5 & 19,3 & 4,1 & 33,1 & 7,8 & 89,7 & 13,9 \\
\hline RA de Sorocaba & 22,8 & 20,4 & 4,0 & 16,4 & 7,2 & 70,8 & 10,4 \\
\hline RA de Campinas & 24,0 & 19,1 & 4,3 & 25,6 & 6,5 & 79,5 & 12,2 \\
\hline RA de Ribeirão Preto & 25,4 & 17,1 & 4,2 & 28,3 & 6,1 & 81,1 & 12,6 \\
\hline RA de Bauru & 20,7 & 20,0 & 5,4 & 11,1 & 5,1 & 62,4 & 8,8 \\
\hline RA de São José do Rio Preto & 25,4 & 15,8 & 5,2 & 8,0 & 4,4 & 58,8 & 8,9 \\
\hline RA de Araçatuba & 17,9 & 17,5 & 5,7 & 14,8 & 4,2 & 60,3 & 9,2 \\
\hline RA de Presidente Prudente & 21,5 & 15,6 & 6,5 & 11,7 & 2,9 & 58,2 & 8,7 \\
\hline RA de Marilia & 26,3 & 14,7 & 4,9 & 12,5 & 5,6 & 64,0 & 9,2 \\
\hline RA Central & 20,4 & 14,3 & 7,8 & 13,0 & 3,8 & 59,2 & 8,9 \\
\hline RA de Barretos & 26,7 & 18,2 & 4,6 & 5,9 & 4,8 & 60,2 & 8,9 \\
\hline RA de Franca & 18,4 & 15,9 & 5,5 & 7.0 & 3,5 & 50,3 & 8,6 \\
\hline
\end{tabular}


Em seguida vêm as regiōes de São José dos Campos, Ribeirão Preto e Campinas, com coeficientes de mortalidade muito próximos para os acidentes de transporte, mas para os homicídios são maiores na primeira. Ressalta-se ainda que, nessas três regiões, os coeficientes por homicídios superam os de acidentes de transporte, constituindo-se nas principais causas externas.

Entre as demais regiões, Sorocaba foi a que apresentou o maior coeficiente de mortalidade para o total das causas externas e também por homicídios, entre 1998 e 1999, embora estes fossem superados pelos acidentes de transporte, fato verificado também nas outras oito regiōes. Na maior parte delas, os coeficientes totais estavam próximos de 60 óbitos por 100 mil habitantes, dos quais cerca de $35 \%$ a $45 \%$ correspondiam aos acidentes de transporte. Neste grupo de regiōes, Barretos, Marília e São José do Rio Preto apresentaram altos coeficientes de mortalidade por tais causas - entre 25 e 27 óbitos por 100 mil habitantes - . inferiores apenas ao da Região de Registro.

A Região de Franca, que apresentou o menor coeficiente de mortalidade por causas externas, com cerca de 50 óbitos por cem mil habitantes, registrou também a segunda menor taxa por homicídios - superior apenas à de Barretos - e um dos menores coeficientes por acidentes de transporte e por demais acidentes. A taxa de mortalidade por homicídios desta região, bem como de Barretos e de São José do Rio Preto, era de nove a dez vezes menor que a da RMSP.

Verifica-se, portanto, que os coeficientes de mortalidade eram muito elevados em algumas regiōes de São Paulo, especialmente Santos, RMSP e Registro, sendo que na primeira aproximavam-se recentemente de 130 óbitos por 100 mil habitantes e ultrapassavam a 100 por 100 mil mortes nas outras duas.

As regiōes que estão em torno da RMSP como São José dos Campos, Campinas e até Sorocaba, além de Ribeirão Preto, que está mais distante, também apresentaram elevada mortalidade por causas externas e, geralmente, com significativa participação dos homicídios.

Constata-se ainda que, mesmo nas regiōes do Estado que registraram os menores coeficientes de mortalidade por causas externas, algumas causas 
apresentavam-se relativamente elevadas, como os acidentes de transporte, cujos menores índices, aproximavam-se de 18 óbitos por 100 mil habitantes.

Em relação à mortalidade por causas externas nos municípios do Estado, apresenta-se a situação para aqueles que possuíam os maiores coeficientes e populações mais numerosas nos períodos 1980-82, 1984-86, 1989-91, 1993-95 e 1997-99 (Tabela 14).

Os resultados mostram a grande participação dos municípios da Região Metropolitana de São Paulo, em todos os períodos estudados. Dos 30 municípios com maiores coeficientes de mortalidade, por causas externas, entre 1997 e 1999 , 19 pertenciam a esta região, seguida por Santos, com seis municípios, entre os quais Mongaguá ocupava a primeira posição, com cerca de 200 óbitos por 100 mil habitantes. Na RMSP destacam-se Diadema e Itapecerica da Serra, com mais de 180 óbitos por 100 mil habitantes, Embu, Juquitiba, Embu Guaçu e Mairiporã, com coeficientes de 135 a 163 por 100 mil. Na Região de Santos, apareciam ainda Praia Grande e Guarujá. O município de Miracatu na região de Registro, completava a relação dos dez municípios com maiores coeficientes de mortalidade do Estado.

Além da grande presença de municipios da RMSP e da Região de Santos, entre aquelas com os maiores coeficientes de mortalidade por causas externas, nota-se a participação de outros das regiões de São José dos Campos, Registro e Campinas. Estendendo-se a relação para 60 municípios, somente Ribeirão Preto não pertence às regiões relacionadas acima. Não constavam municipios das regiões do Oeste do Estado, de Barretos, Central e Franca, que ainda continuam a apresentar coeficientes de mortalidade menores que as demais. Entre os municípios com maior população, os menores coeficientes de mortalidade estavam entre 50 e 60 óbitos por 100 mil habitantes, como Franca, São José do Rio Preto e São Caetano do Sul. 
Tabela 14

Coeficientes de Mortalidade por Causas Externas

Estado de Săo Paulo e Municípios 1980-1999

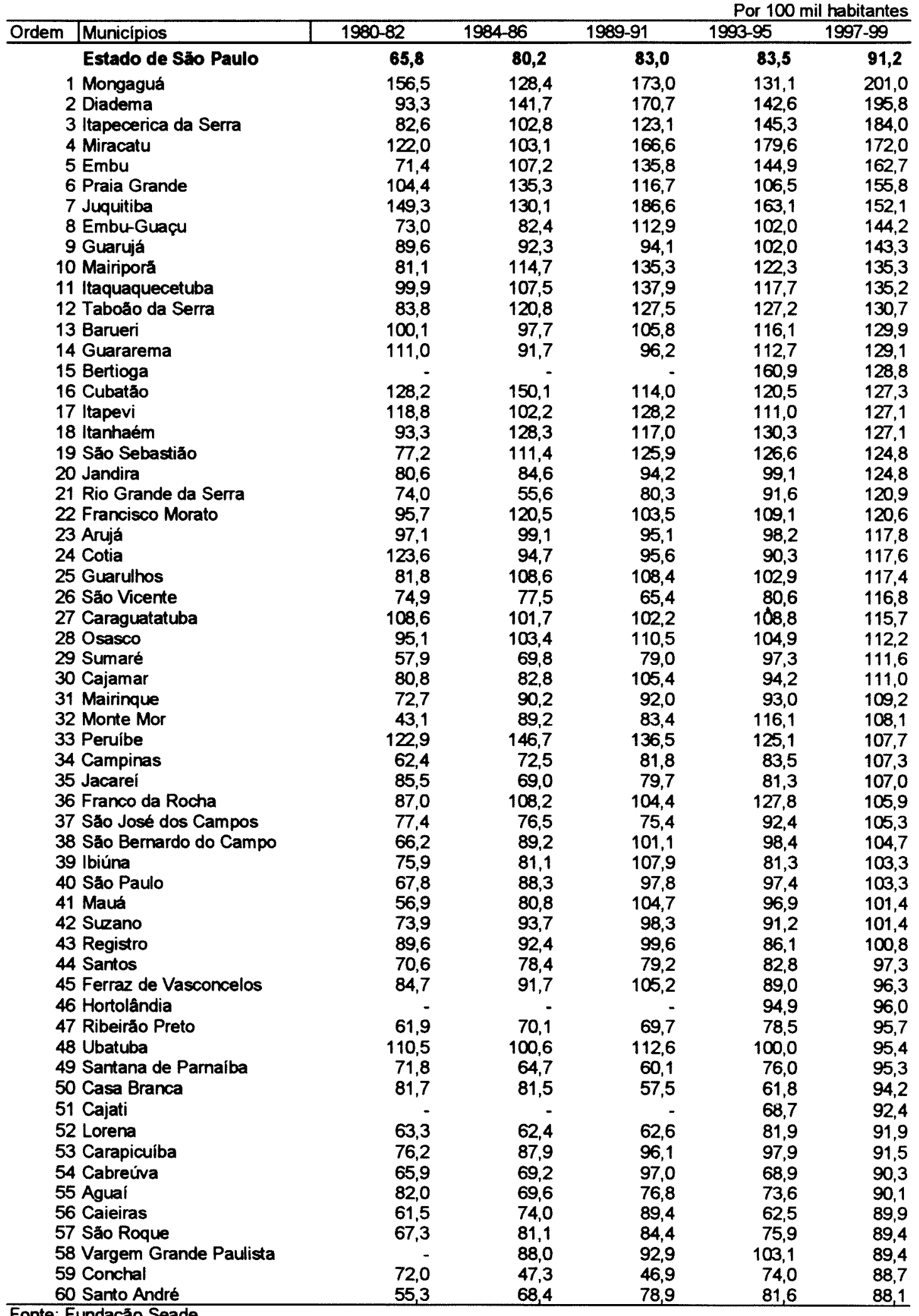


Nos periodos considerados, os municípios da RMSP, os litorâneos e os situados próximos de rodovias importantes, como as Vias Dutra e a Régis Bittencourt, aparecem constantemente entre os de maiores coeficientes de mortalidade por causas externas. Nos últimos anos, alguns municípios das regiōes de Campinas e Sorocaba, além de Ribeirão Preto, estão na relação daqueles com maiores taxas, mas ainda acima da $29^{\mathrm{a}}$ posição.

Os municípios cujos coeficientes ultrapassaram 85 óbitos por $100 \mathrm{mil}$ habitantes, que em 1980-81, eram 52, passaram para 73, em 1990-91, e para 139 em 1998-99.

Verifica-se a formação de uma área com altos coeficientes de mortalidade por causas externas a partir da divisa com o Estado do Paraná até a divisa com o Rio de Janeiro, passando pela Região Metropolitana de São Paulo e abrangendo toda a área litorânea. Além dos altos coeficientes de mortalidade por homicídios em muitos desses municípios, há elevada ocorrência de acidentes em geral. Por estas localidades passam importantes rodovias brasileiras, que fazem a ligação norte/sul do país, com intenso movimento e alto número de acidentes. No último período, nota-se também a expansão da área, com elevados coeficientes para as regiōes de Campinas, Sorocaba e Ribeirāo Preto.

As áreas com coeficientes de mortalidade inferiores a 55 óbitos por $100 \mathrm{mil}$ habitantes vêm diminuindo e restringem-se principalmente, às regiões de Araçatuba, Presidente Prudente e Franca e a pequenas partes do centro e do sul do Estado (Mapa 8).

O crescimento da mortalidade por causas externas tem sido muito importante em várias regiões, provocando grande impacto sobre os seus indicadores de mortalidade, como a esperança de vida ao nascer e as probabilidades de morte, aspectos que serão abordados a seguir. 


\section{Mapa 8}

Coeficientes de Mortalidade por Causas Externas

Municípios do Estado de São Paulo

1980-1999
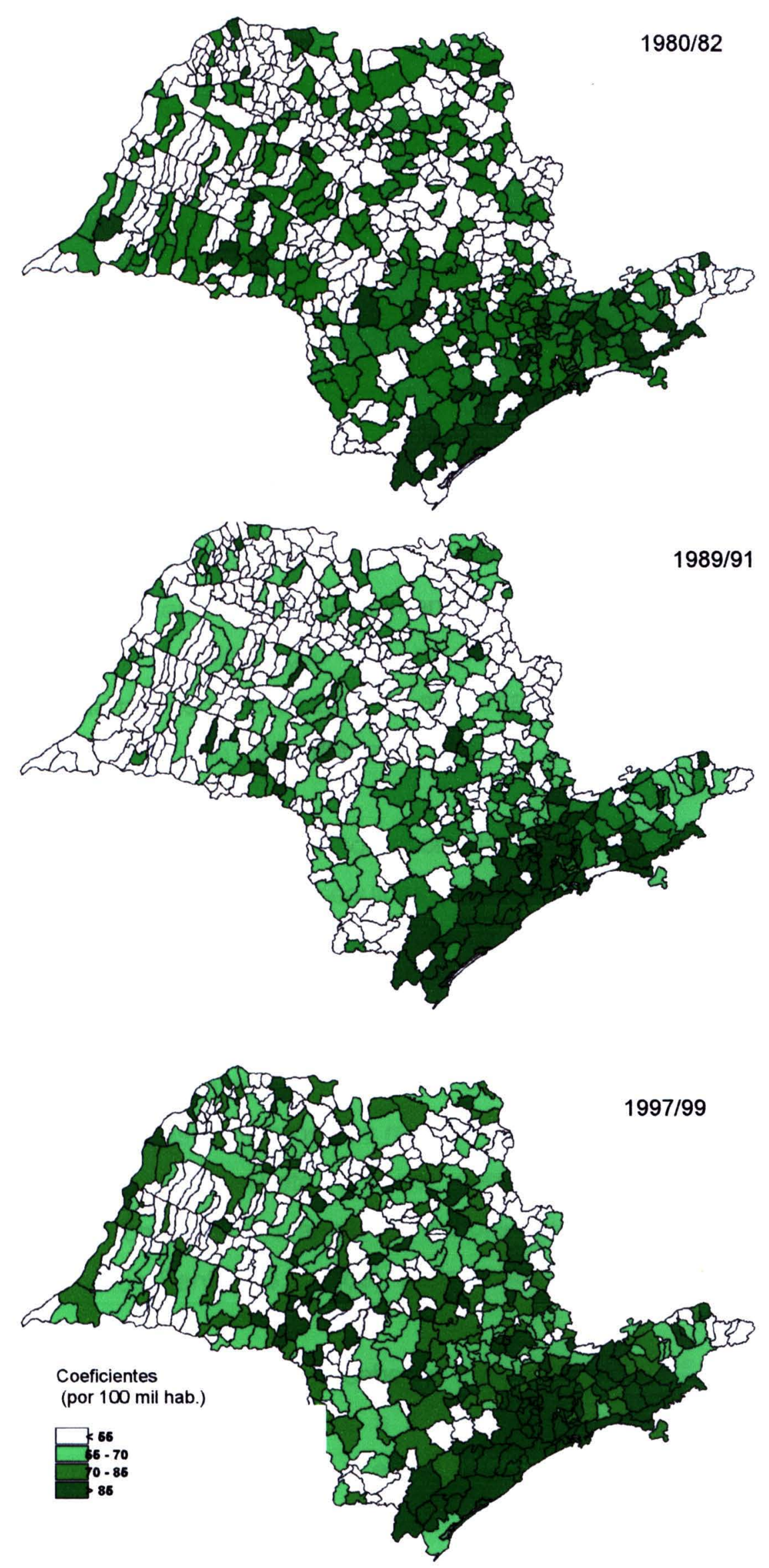

Fonte: Fundação Seade. 


\section{O Impacto das Causas Externas de Morte sobre os Indicadores de Mortalidade}

Várias regiões do Estado têm apresentado elevados coeficientes de mortalidade por causas externas, o que se reflete distintamente nos grupos etários e também nas populações masculina e feminina.

Assim, para avaliar o impacto que as causas externas vêm tendo sobre a esperança de vida ao nascer das regiões de São Paulo, utilizou-se a metodologia dos Riscos Competitivos. Os períodos relacionados foram 1980-81, 1990-91 e 1998-99, sendo que os resultados destacam, inicialmente, os efeitos que teriam caso fosse possivel eliminar totalmente a ocorrência das causas externas (Tabela 15).

Constatou-se que essas causas têm grande impacto em todas as regiōes do Estado, especialmente entre os homens, fato que se torna crescente no decorrer do tempo. A eliminação das causas externas possibilitaria que a esperança de vida nas regiões do Estado, aumentasse de 1,8 a 3,2 anos para os homens, em 1980-81. Esse valor aumenta para 1,8 a 4,1 anos, em 1990-91 e a 1,9 a 4,7 anos, em 1998-99.

Em 1980-81 os menores ganhos ocorreriam nas regiōes de Franca e São José do Rio Preto, com 1,8 ano, seguidas por Araçatuba, Bauru e Marília, com cerca de 1,9 ano, Central e Ribeirão Preto, com 2 anos. Os maiores ganhos seriam registrados para a Região Metropolitana de São Paulo, com 2,6 anos, a de Santos, com 2,9 e a de Registro, com 3,2 anos.

Em 1990-91, a eliminação das causas externas faria com que a esperança de vida tivesse menores aumentos nas regiões de Presidente Prudente $(1,8 \mathrm{ano})$, Franca e São José do Rio Preto (2 anos), seguidas pela Central, Araçatuba e Bauru, todas com cerca de 2,1 anos. Os maiores ganhos ocorreriam, mais uma vez, nas regiões de Santos (3,2 anos), Metropolitana de São Paulo (3,9 anos) e Registro (4,1 anos).

Finalmente, em 1998-99, percebe-se que somente em Franca o aumento na esperança de vida seria inferior a 2 anos, com a eliminação das causas externas. Em Araçatuba, Barretos, Central, Presidente Prudente e São José do 
Rio Preto, a esperança de vida aumentaria de 2,1 a 2,2 anos. Em situação intermediária encontravam-se as regiōes de São José dos Campos, Ribeirão Preto e Campinas, que teriam ganhos de 3,1 a 3,4 anos, e em Sorocaba com 2,6 anos. Os maiores aumentos de esperança de vida foram observados nas mesmas regiões, ou seja, Registro (4,0 anos), Região Metropolitana de São Paulo (4,4 anos) e Santos ( 4,7 anos).

Verifica-se portanto, que as regiōes do oeste do Estado, bem como Franca, Barretos e Central, teriam os menores aumentos de esperança de vida com a eliminação das causas externas, nos três periodos analisados, enquanto em outras regiões, o ganho seria considerável. Incluem-se, neste último caso, as regiōes de Campinas, onde o aumento passaria de 2,1 anos, em 1980-81, para 3,1 anos, em 1998-99; Ribeirão Preto, de 2,0 para 3,2 anos, em São José dos Campos, de 2,7 para 3,4 anos, e Sorocaba, de 2,2 para 2,6 anos. No oeste do Estado, o maior aumento de anos de vida ocorreria na Região de Marilia, passando de 1,9 anos em 1980-81 para 2,4 anos em 1998-99. A eliminação das causas externas traria maiores ganhos na Região de Santos, com 2,9 anos, em 1980-81, e 4,7 anos em 1998-99, na RMSP, com respectivamente 2,6 e 4,4 anos e Registro, com 3,2 e 4,0 anos.

O estudo da mortalidade segundo os grupos das causas externas contribui para o melhor entendimento do comportamento apresentado pelas regiōes nesse período e das diferenças existentes entre elas. Constata-se que, no caso de Santos, há importante e crescente contribuição dos homicídios, cuja eliminação faria com que a esperança de vida ao nascer aumentasse 0,5 ano em 1980-81, passando para 2,2 anos em 1998-99. Também observa-se alta mortalidade por demais acidentes, cuja eliminação desta causa aumentaria a esperança de vida ao nascer em 1,2 ano, em 1998-99. Tal fato também é verificado em Registro, porém com a presença dos acidentes de veículos/transporte substituindo os homicídios. O ganho resultante da eliminação de tais causas seria de 1,7 ano, em 1998-99, enquanto aos demais acidentes corresponderia 1,1 ano. Na Região Metropolitana de São Paulo, a eliminação dos homicídios traria maiores ganhos à esperança de vida: 0,8 ano, em 1980-81, e 2,6 anos em 1998-99. 


\begin{tabular}{|c|c|c|c|c|c|c|c|c|c|c|c|c|c|c|c|}
\hline \multirow{3}{*}{ Sexo e Regiöes Administrativas } & & & & & & & & & & & & & & & Em anos \\
\hline & \multicolumn{3}{|c|}{ Externas } & \multicolumn{3}{|c|}{ Acid. de Veiculos } & \multicolumn{3}{|c|}{ Demais Acidentes } & \multicolumn{3}{|c|}{ Homicidios } & \multicolumn{3}{|c|}{ Suicidios } \\
\hline & $80-81$ & $90-91$ & 98-99 & $80-81$ & $90-91$ & 98-99 & 8081 & $90-91$ & 98-99 & $80-81$ & $90-91$ & $98-99$ & $80-81$ & 9091 & 98-99 \\
\hline \multicolumn{16}{|l|}{ Homens: } \\
\hline Regiăo Metropolitana de Sảo Paulo & 2,6 & 3,9 & 4,4 & 0,8 & 0,8 & 0,6 & 0,7 & 0,8 & 0,6 & 0,8 & 1,9 & 2,6 & 0,1 & 0,1 & 0,2 \\
\hline RA de Registro & 3,2 & 4.1 & 4,0 & 1.0 & 1.5 & 1.7 & 1,2 & 1,0 & 1.1 & 0,5 & 0,9 & 0,7 & 0.2 & 0,3 & 0,3 \\
\hline RA de Santos & 2,9 & 3,2 & 4,7 & 0,5 & 0,8 & 0,7 & 0,8 & 1,0 & 1,2 & 0.5 & 1,0 & 2,2 & 0,1 & 0,1 & 0,1 \\
\hline RA de Säo José dos Campos & 2,7 & 2,7 & 3,4 & 0,9 & 0,9 & 0,9 & 0,8 & 0,7 & 0,7 & 0,5 & 0,8 & 1,3 & 0,1 & 0,1 & 0,1 \\
\hline RA de Sorocaba & 2,2 & 2,5 & 2,6 & 0,7 & 0,8 & 0,8 & 0,8 & 0.7 & 0,7 & 0,3 & 0,5 & 0,6 & 0,2 & 0,1 & 0,1 \\
\hline RA de Campinas & 2,1 & 2,5 & 3,1 & 0.6 & 0,8 & 0.9 & 0,8 & 0,8 & 0,7 & 0,3 & 0,5 & 1,1 & 0,1 & 0,1 & 0,2 \\
\hline RA de Ribeiräo Preto & 2,0 & 2,2 & 3,2 & 0.7 & 1,0 & 0,9 & 0,6 & 0.5 & 0,6 & 0,3 & 0,5 & 1,2 & 0,1 & 0,1 & 0.2 \\
\hline RA de Bauru & 1,9 & 2,1 & 2,3 & 0,5 & 0,8 & 0,8 & 0,6 & 0.6 & 0,7 & 0,3 & 0.4 & 0,5 & 0,2 & 0,2 & 0,2 \\
\hline RA de São Jasó do Rio Preto & 1,8 & 2,0 & 2,2 & 0,5 & 0,8 & 1,0 & 0,6 & 0.7 & 0,6 & 0,2 & 0,2 & 0,3 & 0,2 & 0.1 & 0,2 \\
\hline RA de Araçatuba & 1,9 & 2,1 & 2,2 & 0,5 & 0,7 & 0,6 & 0,7 & 0,6 & 0,6 & 0,4 & 0,4 & 0,6 & 0,1 & 0,2 & 0,2 \\
\hline RA de Presidente Prudente & 2,2 & 1,8 & 2,2 & 0,7 & 0,6 & 0,8 & 0,7 & 0,5 & 0,5 & 0,4 & 0,3 & 0,5 & 0,2 & 0,2 & 0.2 \\
\hline RA de Marilia & 1,9 & 2,3 & 2,4 & 0,7 & 0,9 & 1,0 & 0,5 & 0,7 & 0,5 & 0,3 & 0,4 & 0,5 & 0,2 & 0,2 & 0,2 \\
\hline RA Central & 2,0 & 2,1 & 2,1 & 0,6 & 0,7 & 0,7 & 0,8 & 0.7 & 0,5 & 0,3 & 0,3 & 0,5 & 0,2 & 0,2 & 0,3 \\
\hline RA de Barretos & 2,1 & 2,2 & 2,2 & 0,7 & 0,9 & 1,0 & 0,7 & 0,6 & 0,6 & 0,2 & 0,3 & 0,2 & 0,1 & 0,1 & 0,1 \\
\hline RA de Franca & 1,8 & 2,0 & 1,9 & 0,7 & 0,6 & 0,7 & 0,5 & 0,6 & 0,5 & 0,2 & 0,3 & 0,3 & 0,2 & 0,2 & 0,2 \\
\hline \multicolumn{16}{|l|}{ Mulheres } \\
\hline Regiäo Metropolitana de Säo Paulo & 0,8 & 0,8 & 0,7 & 0,4 & 0,3 & 0,2 & 0,3 & 0,3 & 0,2 & 0,1 & 0,2 & 0,2 & 0,1 & 0,0 & 0,0 \\
\hline RA de Registro & 1,0 & 1,2 & 0,9 & 0,4 & 0,6 & 0,5 & 0,4 & 0,4 & 0,3 & 0,1 & 0,2 & 0,1 & 0,0 & 0,0 & 0,0 \\
\hline RA de Santos & 0,9 & 0,8 & 0,9 & 0,3 & 0,3 & 0,2 & 0,3 & 0,3 & 0,4 & 0,1 & 0,1 & 0,2 & 0,0 & 0,0 & 0,0 \\
\hline RA de Säo José dos Campos & 0,8 & 0,7 & 0,7 & 0,3 & 0,3 & 0,3 & 0,3 & 0,2 & 0,2 & 0,1 & 0,1 & 0,1 & 0,1 & 0,0 & 0,0 \\
\hline RA de Sorocaba & 0,7 & 0,6 & 0,6 & 0,3 & 0,2 & 0,2 & 0,3 & 0,2 & 0,2 & 0,1 & 0,1 & 0,1 & 0,0 & 0,1 & 0,0 \\
\hline RA de Campinas & 0,7 & 0,7 & 0,6 & 0,2 & 0,3 & 0,2 & 0,3 & 0,2 & 0,2 & 0,1 & 0,1 & 0,1 & 0,1 & 0,0 & 0,0 \\
\hline RA de Ribeiräo Preto & 0.7 & 0,7 & 0,7 & 0,3 & 0,3 & 0,3 & 0,2 & 0.1 & 0,2 & 0,1 & 0,1 & 0,1 & 0,1 & 0,1 & 0,0 \\
\hline RA de Bauru & 0,7 & 0,7 & 0,6 & 0,3 & 0,3 & 0,2 & 0,2 & 0,2 & 0,2 & 0,1 & 0,1 & 0,0 & 0,1 & 0,0 & 0,0 \\
\hline RA de São José do Rio Preto & 0.7 & 0,7 & 0.6 & 0,1 & 0,3 & 0,3 & 0,3 & 0,2 & 0,2 & 0,1 & 0,1 & 0,1 & 0,1 & 0,1 & 0,0 \\
\hline RA de Araçatuba & 0,7 & 0,6 & 0,7 & 0,2 & 0,2 & 0,3 & 0,3 & 0,2 & 0,2 & 0,1 & 0,1 & 0,1 & 0,1 & 0,1 & 0,0 \\
\hline RA de Presidente Prudente & 0,7 & 0,5 & 0,6 & 0,2 & 0,2 & 0,3 & 0,3 & 0,2 & 0,2 & 0,1 & 0,1 & 0,1 & 0,1 & 0,1 & 0,1 \\
\hline RA de Marilia & 0,7 & 0,8 & 0,6 & 0,2 & 0,3 & 0,3 & 0,3 & 0,3 & 0,2 & 0,1 & 0,1 & 0,1 & 0,1 & 0.1 & 0,1 \\
\hline RA Central & 0,7 & 0,5 & 0,6 & 0,2 & 0,2 & 0,2 & 0,2 & 0,2 & 0.1 & 0,1 & 0,1 & 0,1 & 0,1 & 0,1 & 0,1 \\
\hline RA de Barretos & 0,7 & 0,6 & 0,7 & 0,2 & 0,2 & 0,3 & 0,2 & 0,2 & 0,2 & 0,1 & 0,1 & 0,1 & 0,0 & 0,1 & 0,1 \\
\hline RA de Franca & 0,8 & 0,6 & 0,5 & 0,3 & 0,2 & 0,1 & 0,2 & 0,2 & 0,1 & 0,1 & 0,1 & 0,1 & 0,1 & 0.0 & 0,0 \\
\hline
\end{tabular}

Em relação às demais regiões, constata-se a importância dos homicídios também em São José dos Campos, cuja eliminação aumentaria a esperança de vida ao nascer em 0,5 ano, em 1980-81, e 1,3 ano em 1998-99. Em Ribeirão Preto, os ganhos seriam de, respectivamente, 0,3 e 1,2 ano e, em Campinas, de 0,3 e 1,1 ano. Nas demais regiōes, inclusive em Registro, os aumentos médios da esperança de vida seriam inferiores a 0,7 ano, sendo que em Barretos, Franca e São José do Rio Preto estariam entre 0,2 e 0,3 ano. Ainda que os ganhos sejam muito inferiores aos de outras regiões já citadas, deve-se destacar o crescimento registrado em Sorocaba (de 0,3 para 0,6 ano), na Central e em Marília (de 0,3 para 0,5 ano em ambas). Os resultados mostram que, mesmo com níveis 
diferentes, os homicidios já aparecem muito importantes em várias regiões do Estado, para a população masculina.

Entretanto, ainda são os acidentes de veículos a motor as causas externas de morte mais importantes na maior parte das regiöes e somente na de Santos não ocupavam a primeira ou a segunda posição. Em 1998-99 os maiores ganhos resultantes da eliminação das mortes por acidentes de veículos a motor corresponderiam à Região de Registro, com 1,7 ano, bem à frente das regiões de Barretos, São José do Rio Preto e Marília, com 1,0 ano. Em seguida vêm Ribeirão Preto, São José dos Campos e Campinas, que teriam a esperança de vida ao nascer aumentada de 0,9 a 1,0 ano com a eliminação das mortes por acidentes de veículos. Os menores aumentos ocorreriam na Região Metropolitana de São Paulo e em Araçatuba, com cerca de 0,6 ano, e nas de Santos, Central e Franca, com cerca de 0,7 ano em 1998/99.

Em relação aos acidentes de veículos a motor, observa-se que o número de anos de vida ganhos com sua eliminação tem aumentado na maior parte das regiōes do Estado, destacando-se Barretos, onde a esperança de vida ao nascer aumentaria 0,7 ano, em 1980-81 e 1,0 ano, em 1998-99, Araçatuba, com respectivamente 0,5 e 0,6 ano, Campinas, (0,6 e 0,9 ano), Marília (0,7 e 1,0 ano), São José do Rio Preto ( 0,5 e 1,0 ano) e principalmente Registro, com 1,0 e 1,7 ano. Na Região Metropolitana de São Paulo, observa-se o inverso, ou seja, a eliminação das mortes por acidentes de veículos a motor traria aumento de 0,8 ano na esperança de vida ao nascer, em 1980-81 e de 0,6 ano em 1998-99. Na Região de Santos, a redução desse número de anos ocorre após 1990-91, quando alcançava 0,8 ano, passando para 0,7 ano em 1998-99.

Os ganhos proporcionados pela eliminação dos demais acidentes seriam mais importantes nas regiões de Santos e Registro, resultando em aumento de pouco mais de um ano na esperança de vida em 1998-99. As Regiões de Bauru, São José dos Campos, Sorocaba e Campinas vem a seguir, com 0,7 ano, em cada uma. Os menores aumentos de esperança de vida corresponderam às regiões Central, Presidente Prudente, Franca e Marilia, com cerca de 0,5 ano. Em termos de tendência, observam-se diminuições importantes dos ganhos de anos 
ao serem eliminados esses acidentes nas regiões de Araçatuba, Central, São José dos Campos e Registro. Já em Santos e Bauru, ocorre o oposto, pois na primeira região, a eliminação dessas causas proporcionaria aumento de 0,8 ano na esperança de vida ao nascer em 1980-81 e 1,2 ano em 1998-99 e na de Bauru, 0,6 e 0,7 ano, respectivamente.

Em relação aos suicídios, a eliminação, dessa causa de morte não traria ganhos superiores a 0,3 ano na esperança de vida ao nascer em qualquer das. Regiōes do Estado. Apenas em Araçatuba, RMSP, Central, Campinas e Ribeirão Preto sua contribuição aumentaria desde 1980-81, permanecendo, porém, muito inferior às demais causas.

Observa-se, portanto, que a mortalidade por causas externas tem grande responsabilidade pelas diferenças observadas na esperança de vida ao nascer das regiões do Estado de São Paulo. Caso fosse possivel eliminar totalmente estas causas, a esperança de vida da população masculina estaria, na maior parte das regiōes, próxima dos 70 anos, enquanto atualmente situa-se entre 65 e 67 anos. Se isto parece quase impossivel a curto prazo, poder-se-ia esperar que ao menos os coeficientes de mortalidade por tais causas fossem semelhantes, por exemplo, aos registrados para a população feminina. Os coeficientes observados para as mulheres, para o Estado de São Paulo, não estão no patamar mais baixo quando comparados com outras áreas do mundo, mas se fossem alcançados pela população masculina, haveria aumentos significativos na esperança de vida ao nascer.

Os resultados obtidos por meio da metodologia dos Riscos Competitivos, para a população feminina, mostram que somente na Região de Registro a esperança de vida ao nascer aumentaria em mais de um ano de vida com a eliminação das causas externas e, assim mesmo apenas em 1990-91. Assim caso os coeficientes de mortalidade masculina fossem semelhantes aos da população feminina, a esperança de vida ao nascer aumentaria em mais de 3 anos nas regiōes de Santos, da RMSP e Registro, enquanto nas demais, estariam entre 1,0 e 2,4 anos, resultados estes muito significativos, dado que a esperança de vida ao nascer, no Estado de São Paulo, está relativamente elevada. 
Ainda em relação às mulheres, pode-se destacar também que, na maior parte das regiōes, os ganhos com a eliminação das causas externas estariam próximos de 0,7 ano para a maior parte das regiōes. Além de Registro, somente em Santos este aumento seria de 0,9 ano, observado em 1998-99, enquanto na Região Metropolitana de São Paulo corresponderia a 0,8 ano nos períodos de 1980-81 e 1990-91, e diminuindo para 0,7 ano em 1998/99. Nas regiōes de Sorocaba, Presidente Prudente, Campinas, Bauru, São José do Rio Preto, Marília e Central os ganhos estariam atualmente próximos de 0,6 ano e em Franca de 0,5 ano. Nas demais os aumentos seriam de cerca de 0,7 ano.

Entre as mulheres, observa-se que o ganho proporcionado pela eliminação das causas externas tem diminuído em várias regiōes, com destaque para Bauru, Campinas, Central, Franca, RMSP e Sorocaba, devido principalmente, aos "demais acidentes", seguidos pelos acidentes de veículos a motor. Este último grupo tem maior importância em Franca e, especialmente, na Região Metropolitana de São Paulo, sendo que nesta última compensou inclusive o aumento registrado para os homicídios. Os ganhos resultantes da eliminação dos homicídios passou de 0,1 ano em 1980-81, para 0,2 em 1998-99. Este aumento foi observado também nas regiões de Registro e Santos, mas ainda com menores reflexos sobre os coeficientes totais, uma vez que sua ocorrência ainda é relativamente pequena tanto no total das causas externas como quando comparada às demais causas.

Os ganhos resultantes da eliminação dos suicídios para a população feminina seriam ainda menores que os observados entre os homens. Considerando-se os três períodos estudados, os aumentos não ultrapassam a 0,1 ano, tendo inclusive diminuído desde 1980-81 em várias regiões.

A exemplo do que foi feito para o Estado, o impacto das causas externas nas regiōes, pode ser observado por meio das probabilidades de morte nos grupos etários, inicialmente considerando-se os resultados encontrados e depois sem a influência das causas externas. Como existem muitas regiōes no Estado e o padrão repete-se em várias, selecionaram-se quatro delas para ilustrar esse 
comportamento, em 1998/99 e que poderiam representar .a totalidade. As regiōes foram as seguintes:

- Região Metropolitana de São Paulo, com elevados coeficientes por causas externas;

- Campinas, com coeficientes intermediários entre as regiōes de maior e de menor mortalidade, mas com maior aproximação com a RMSP;

- Bauru, com coeficientes menores que os de Campinas, mas maiores que os de outras regiões;

- Franca, com a menor mortalidade por causas externas entre as 15 regiões do Estado de São Paulo.

Os resultados para a população masculina encontram-se no Gráfico 28 e na Tabela 28 do Anexo e os da população feminina no Gráfico 29 e na Tabela 29 do Anexo, em que se constatam comportamentos muito diferentes entre as regiōes selecionadas.

Para a população masculina, o primeiro fato que chama a atenção é a grande diferença existente entre as probabilidades de morte observadas e as que resultam da eliminação das causas externas entre a população jovem, principalmente na RMSP e em Campinas.

Outro aspecto importante refere-se à alta presença dos homicídios nessa mortalidade da Região Metropolitana de São Paulo. Em Campinas isto também ocorre, mas em niveis menores, enquanto em Franca são os acidentes que têm maior participação. 


\section{Gráfico 28}

Probabilidades de Morte Observadas ( $q x$ ) e Líquida ( $q \times 0$ ) Eliminando-se os Grupos de Causas Externas como Fator de Risco de Morte, da População Masculina, segundo a Idade Região Metropolitana de São Paulo, Bauru, Campinas e Franca 1998-1999
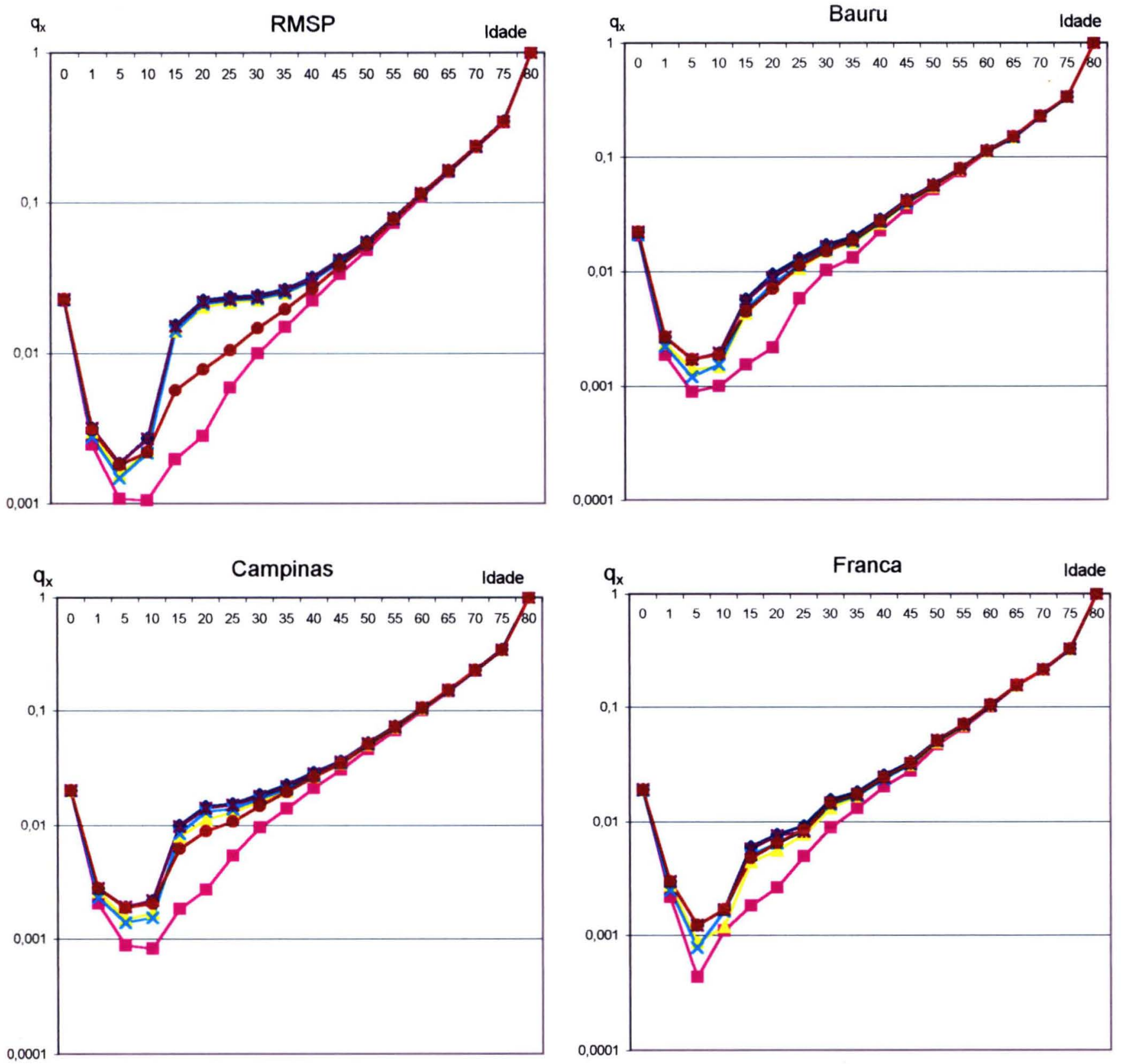

$\multimap$ Obs $\rightarrow$ Ac. V. $\rightarrow$ Ext $\rightarrow$ Dac $\rightarrow$ Suic $\rightarrow$ Hom

Fonte: Fundação Seade. 


\section{Gráfico 29}

Probabilidades de Morte Observadas ( $q x$ ) e Líquida ( $q \times 0$ ) Eliminando-se os Grupos de Causas Externas como Fator de Risco de Morte, da População Feminina, segundo a Idade Região Metropolitana de São Paulo, Bauru, Campinas e Franca 1998-1999
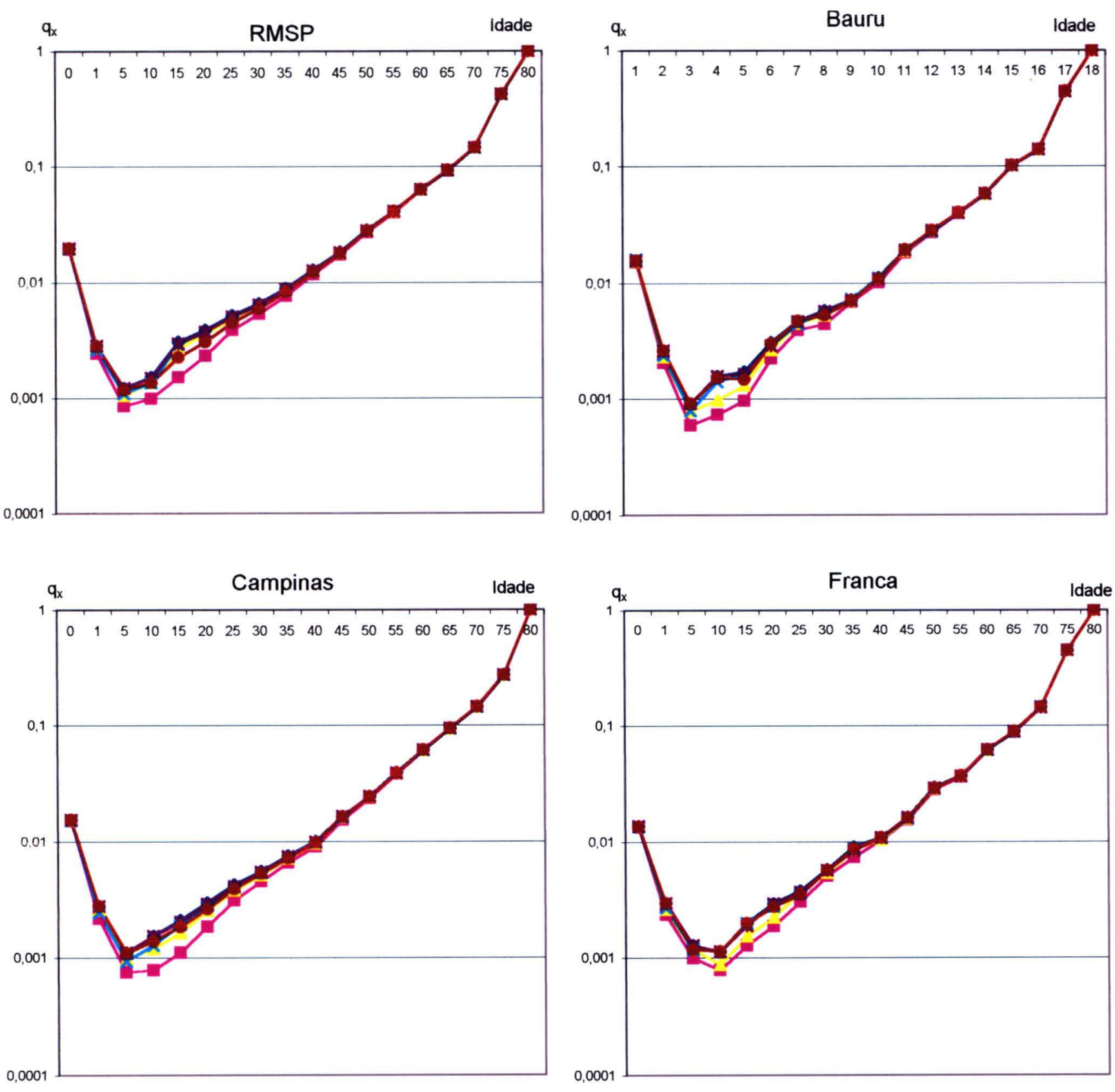

$\multimap$ Obs $\rightarrow$ Ext $\rightarrow$ Ac. V. $\rightarrow$ Dac $\rightarrow$ Suic $\rightarrow$ Hom

Fonte: Fundação Seade. 
Verifica-se que há grandes diferenças nos niveis de mortalidade masculina observados para essas regiões. A partir dos 15 anos de idade, os coeficientes de mortalidade são superiores a 100 óbitos por 100 mil habitantes em todos os grupos etários da RMSP, enquanto em Campinas isso ocorre a partir dos 20 anos, em Bauru depois dos os 25 anos e em Franca somente a partir dos 30 anos.

A configuração etária também mostra-se muito diferente entre as regiões e isto deve-se, em grande parte, às causas externas. Ao serem eliminadas estas causas, a configuração e os niveis seriam semelhantes nas regiões, como pode ser observado no Gráfico 30 e na Tabela 30 do Anexo, para os homens.

Entre as mulheres, ainda que os coeficientes de mortalidade também sejam maiores na RMSP, as diferenças mostram-se bem menores que entre os homens, sendo que as taxas ultrapassam a 100 óbitos por 100 mil habitantes somente após os 40 anos, nas quatro Regiões. Constata-se ainda que a eliminação das causas externas não acabaria com a diferença existente entre as pessoas jovens, o que significa que outras causas, como a Aids, que são importantes entre essas pessoas, mantêm as diferenças entre as regiōes, como pode se verificar no Gráfico 31 e na Tabela 31 do Anexo. 


\section{Gráfico 30}

Probabilidades de Morte Observadas $\left(q_{x}\right)$ e Liquida $\left(q_{x o}\right)$ Eliminando-se as

Causas Externas como Fator de Risco de Morte, da População Masculina, segundo a Idade Região Metropolitana de São Paulo, Bauru, Campinas e Franca 1998-1999
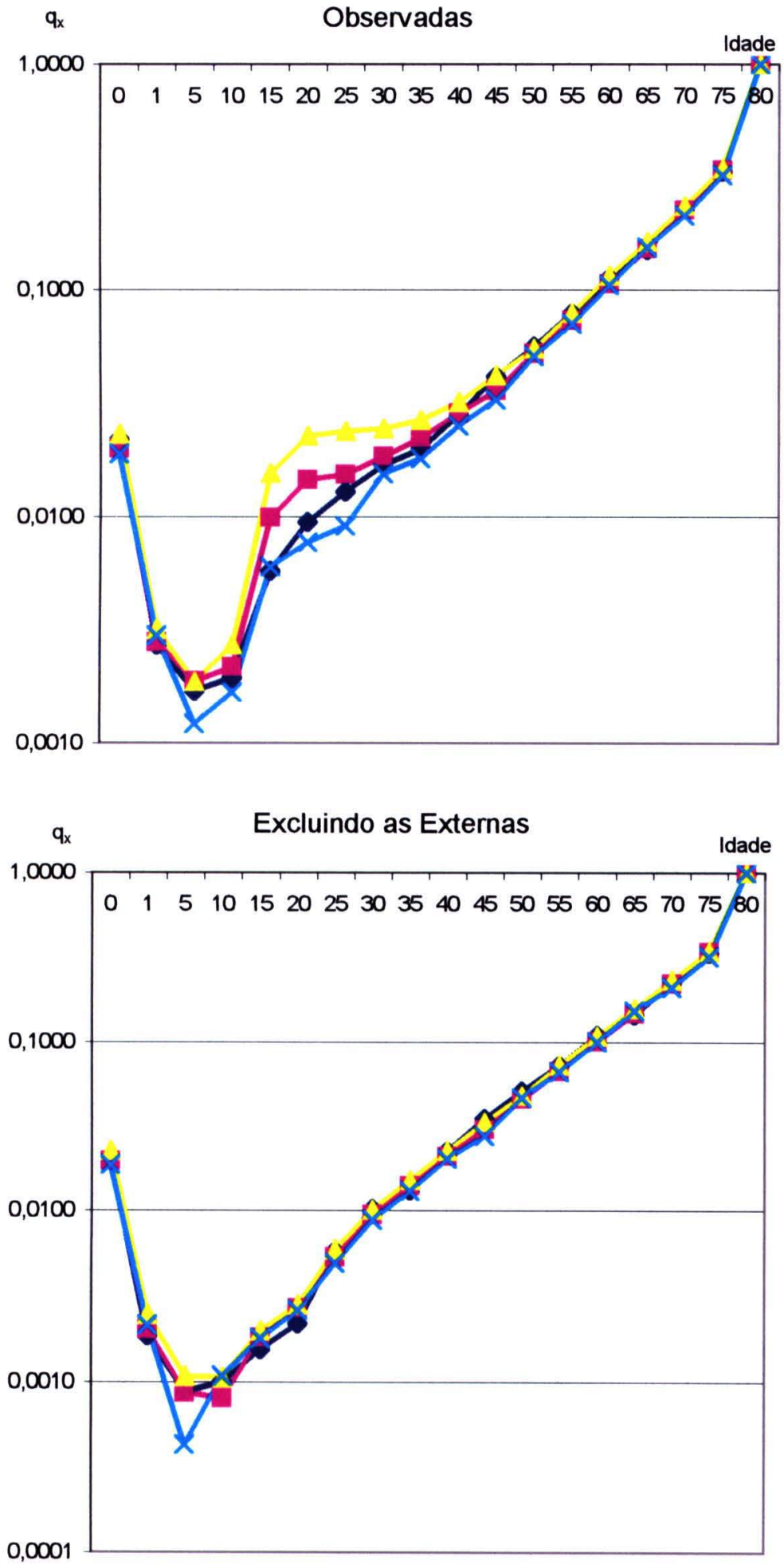

$$
\multimap \text { Bauru } \rightarrow \text { Campinas } \rightarrow \text { RMSP } \rightarrow \text { Franca }
$$

Fonte: Fundação Seade. 


\section{Gráfico 31}

Probabilidades de Morte Observadas $\left(q_{x}\right)$ e Líquida $\left(q_{x_{0}}\right)$ Eliminando-se as

Causas Externas como Fator de Risco de Morte, da População Feminina, segundo a Idade Região Metropolitana de São Paulo, Bauru, Campinas e Franca

1998-1999
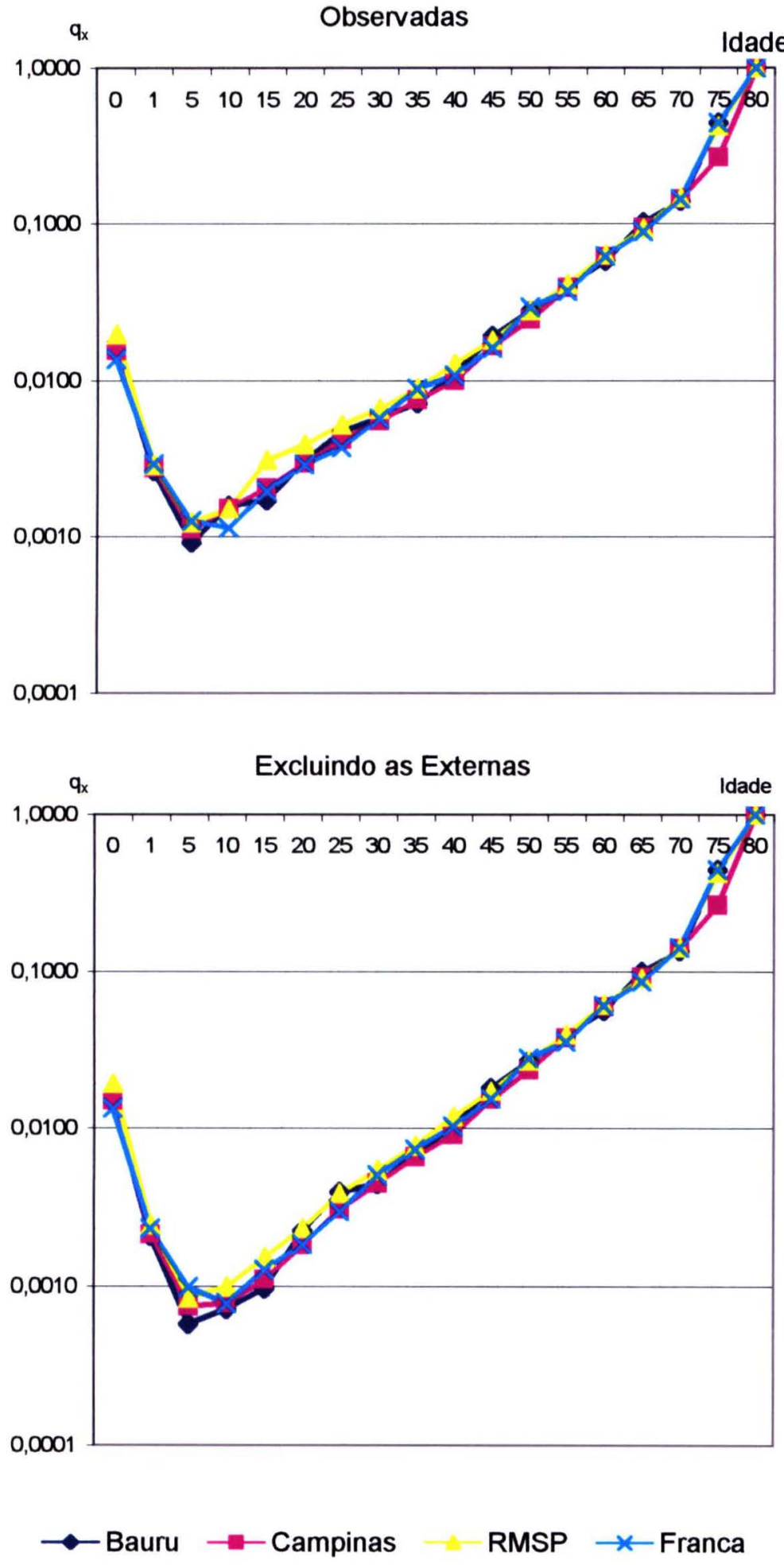

Fonte: Fundação Seade. 
O CONTEXTO DAS CAUSAS EXTERNAS NO ÂMBITO MUNDIAL 


\section{Contextualização Histórica da Violência}

Os dados apresentados mostraram a importância que as causas externas vêm tendo em várias áreas do mundo nos mais diferentes periodos. Estas causas ganham maior destaque à medida que outras, especialmente as infecciosas, diminuem consideravelmente, como mostra OMRAN $(1971,1972,1974$ e 1983) ao descrever a Teoria da Transição Epidemiológica. O autor ressalta que esse processo começou a ocorrer em alguns países a partir do século XVIII. Antes disso não se conhecem casos em que a mortalidade tenha diminuído de forma contínua e considerável, embora desde 1650 as flutuações de seus niveis tinham se tornado mais raras. Tal fato pode ser observado em países como a França, a Inglaterra e a Suécia, onde a população passou a crescer mais rapidamente a partir do século XIX. Os coeficientes de mortalidade, no entanto, permaneceram elevados e as doenças infecciosas representavam, em alguns casos, até $75 \%$ do total das causas de morte. Na França, o coeficiente de mortalidade, que era de 35 óbitos por mil habitantes em 1750, passou para 27 por mil, em 1800, 23 por mil, em 1850 e 21 por mil em 1900, antecedendo portanto o período do grande desenvolvimento médico e científico (MATTELART 1964).

A queda dos coeficientes de mortalidade deveu-se, principalmente, à redução das doenças infecciosas, proporcionando aumento considerável da esperança de vida ao nascer, em muitos paises. Já no início do século $X X$ esta aproximava-se de 52 anos para os homens, e de 56 anos, para as mulheres, na Suécia, Austrália, Dinamarca e Noruega, níveis estes que ainda não foram alcançados por vários paises africanos e também alguns asiáticos (SAWYER 1980).

$\mathrm{Na}$ maior parte dos paises, no entanto, o processo de Transição Demográfica e Epidemiológica iniciou-se somente depois de 1940, a partir do desenvolvimento médico e tecnológico. Além da utilização de medicamentos e vacinas, observaram-se também melhorias nas condiçōes gerais de vida, trabalho, nutrição, habitação e saneamento em muitas partes do mundo, levando à redução 
considerável das taxas de mortalidade, inclusive nos paises mais desenvolvidos. $\mathrm{Na}$ década de 50, a esperança de vida ao nascer de alguns países mais desenvolvidos alcançou cerca de 70 anos, para os homens, e 73 anos, para as mulheres.

No período 1975-80, a esperança de vida já ultrapassava 60 anos em muitos países e em alguns chegava a 70 anos, para os homens, e a 75 anos, para as mulheres. Atualmente, em países como a Grécia, o Japão e a Suécia, a esperança de vida ao nascer supera os 75 anos para os homens e os 80 anos para as mulheres (Tabela 16).

Esses dados mostram que, mesmo entre os paises mais desenvolvidos, continuam a ocorrer alterações nos níveis de mortalidade e das causas de morte, o que tem proporcionado aumento da esperança de vida ao nascer.

\section{A estrutura das Causas de Morte}

As informaçōes apresentadas mostram que, na maior parte do tempo, a humanidade esteve inserida no primeiro estágio da Transição Demográfica e Epidemiológica, que se caracterizava por altas taxas de mortalidade, freqüente ocorrência de epidemias e grande predominância de doenças infecciosas e parasitárias. Com a diminuição destas causas de morte, outras, que até então estavam em plano secundário, começam a ganhar maior destaque, o que ocorre não apenas proporcionalmente, mas, também em termos absolutos e das próprias taxas de mortalidade. Entre estas causas, destacam-se as doenças do aparelho circulatório, as neoplasias, o diabetes e também as causas externas, que certamente já tinham muita importância no passado, mas, a exemplo das demais, eram largamente superadas pelas doenças infecciosas e parasitárias. 
Tabela 16

Esperança de Vida ao Nascer, por Sexo

Países Selecionados

1950-1995

Em anos

\begin{tabular}{|c|c|c|c|c|c|c|c|c|c|c|c|}
\hline \multirow[t]{2}{*}{ Países } & \multicolumn{2}{|c|}{$1950-55$} & \multicolumn{2}{|c|}{$1975-80$} & \multicolumn{2}{|c|}{$1990-95$} & \multicolumn{3}{|c|}{$\begin{array}{c}\text { Diferença } \\
\text { Homens - Mulheres }\end{array}$} & \multicolumn{2}{|c|}{$\begin{array}{l}\text { Incremento } \\
90-95 / 50-55 \\
\end{array}$} \\
\hline & $\mathrm{H}$ & M & $\mathrm{H}$ & $M$ & $\mathrm{H}$ & $M$ & $1950-55$ & $1970-75$ & $1990-95$ & $\mathrm{H}$ & $M$ \\
\hline Mundo & 45,1 & 47,8 & 56,4 & 59,4 & 62,4 & 66,5 & 2,7 & 3,0 & 4,1 & 17,3 & 18,7 \\
\hline Afeganistăo & 31,3 & 31,8 & 38,0 & 38,0 & 43,0 & 44,0 & 0,5 & 0,0 & 1,0 & 11,7 & 12,2 \\
\hline Alemanha & 65,3 & 69,6 & 67,9 & 73,8 & 72,7 & 79,0 & 4,3 & 5,9 & 6,3 & 7,4 & 9,4 \\
\hline Angola & 28,6 & 31,5 & 36,5 & 39,6 & 44,9 & 48,1 & 2,9 & 3,1 & 3,2 & 16,3 & 16,6 \\
\hline Argélia & 42,1 & 44,2 & 53,5 & 55,5 & 66,0 & 68,3 & 2,1 & 2,0 & 2,3 & 23,9 & 24,1 \\
\hline Argentina & 60,4 & 65,1 & 64,1 & 70,7 & 68,6 & 75,7 & 4,7 & 6,6 & 7,1 & 8,2 & 10,6 \\
\hline Áustria & 63,2 & 68,4 & 67,0 & 74,3 & 73,0 & 79,2 & 5,2 & 7,3 & 6,2 & 9,8 & 10,8 \\
\hline Bolívia & 38,5 & 42,5 & 44,6 & 49,0 & 57,7 & 61,0 & 4,0 & 4,4 & 3,3 & 19,2 & 18,5 \\
\hline Brasil & 49,3 & 52,8 & 57,6 & 62,2 & 64,0 & 68,7 & 3,5 & 4,6 & 4,7 & 14,7 & 15,9 \\
\hline Bulgária & 62,2 & 66,1 & 68,7 & 73,9 & 67,8 & 74,9 & 3,9 & 5,2 & 7,1 & 5,6 & 8,8 \\
\hline Chile & 52,9 & 56,8 & 60,5 & 66,8 & 70,4 & 77,4 & 3,9 & 6,3 & 7,0 & 17,5 & 20,6 \\
\hline China & 39,3 & 42,3 & 62,5 & 63,9 & 66,7 & 70,4 & 3,0 & 1,4 & 3,7 & 27,4 & 28,1 \\
\hline Comores & 39,5 & 40,5 & 47,0 & 48,0 & 55,5 & 56,5 & 1,0 & 1,0 & 1,0 & 16,0 & 16,0 \\
\hline Costa do Marfim & 34,5 & 37,5 & 43,9 & 47,1 & 49,7 & 52,4 & 3,0 & 3,2 & 2,7 & 15,2 & 14,9 \\
\hline Cuba & 57,8 & 61,3 & 69,4 & 72,7 & 73,5 & 77,3 & 3,5 & 3,3 & 3,8 & 15,7 & 16,0 \\
\hline Egito & 41,2 & 43,6 & 50,8 & 53,4 & 62,4 & 64,8 & 2,4 & 2,6 & 2,4 & 21,2 & 21,2 \\
\hline Espanha & 61,6 & 66,3 & 70,2 & 75,7 & 74,6 & 80,5 & 4,7 & 5,5 & 5,9 & 13,0 & 14,2 \\
\hline Estados Unidos & 66,2 & 72,0 & 67.5 & 75,3 & 72,5 & 79,3 & 5,8 & 7,8 & 6,8 & 6,3 & 7,3 \\
\hline Estônia & 61,7 & 68,3 & 65,7 & 74,7 & 63,8 & 74,8 & 6,6 & 9,0 & 11,0 & 2,1 & 6,5 \\
\hline França & 63,7 & 69,5 & 68,6 & 76,3 & 73,0 & 80,8 & 5,8 & 7,7 & 7,8 & 9,3 & 11,3 \\
\hline Gâmbia & 28,6 & 31,5 & 35,5 & 38,6 & 43,4 & 46,6 & 2,9 & 3,1 & 3,2 & 14,8 & 15,1 \\
\hline Grécia & 64,3 & 67,5 & 70,6 & 74,2 & 75,0 & 80,1 & 3,2 & 3,6 & 5,1 & 10,7 & 12,6 \\
\hline Hungria & 61,5 & 65,8 & 66,5 & 72,4 & 64,5 & 73,8 & 4,3 & 5,9 & 9,3 & 3,0 & 8,0 \\
\hline lêmen & 32,0 & 32,3 & 41,9 & 42,4 & 49,9 & 50,4 & 0,3 & 0,5 & 0,5 & 17,9 & 18,1 \\
\hline Índia & 39,4 & 38,0 & 51,2 & 49,3 & 60,3 & 60,4 & $-1,4$ & $-1,9$ & 0,1 & 20,9 & 22,4 \\
\hline Indonésia & 36,9 & 38,1 & 48,0 & 50,5 & 61,0 & 64,5 & 1,2 & 2,5 & 3,5 & 24,1 & 26,4 \\
\hline Itália & 64,3 & 67,8 & 69,2 & 75,2 & 74,2 & 80,6 & 3,5 & 6,0 & 6,4 & 9,9 & 12,8 \\
\hline Japão & 62,1 & 65,9 & 70,6 & 76,2 & 76,4 & 82,5 & 3,8 & 5,6 & 6,1 & 14,3 & 16,6 \\
\hline Letônia & 62,5 & 69,0 & 65,3 & 74,5 & 63,3 & 74,9 & 6,5 & 9,2 & 11,6 & 0,8 & 5,9 \\
\hline Libéria & 36,0 & 38,9 & 46,0 & 49,0 & 54,0 & 57,0 & 2,9 & 3,0 & 3,0 & 18,0 & 18,1 \\
\hline Líbia & 41,9 & 43,9 & 51,4 & 54,5 & 61,6 & 65,0 & 2,0 & 3,1 & 3,4 & 19,7 & 21,1 \\
\hline Malawi & 35,8 & 36,7 & 40,3 & 41,7 & 45,0 & 46,2 & 0,9 & 1,4 & 1,2 & 9,2 & 9,5 \\
\hline México & 49,2 & 52,4 & 60,6 & 65,3 & 67,8 & 73,9 & 3,2 & 4,7 & 6,1 & 18,6 & 21,5 \\
\hline Nicarágua & 40,9 & 43,7 & 53,7 & 56,8 & 64,8 & 68,5 & 2,8 & 3,1 & 3,7 & 23,9 & 24,8 \\
\hline Niger & 31,5 & 34,5 & 37,5 & 40,6 & 44,9 & 48,1 & 3,0 & 3,1 & 3,2 & 13,4 & 13,6 \\
\hline Omã & 35,8 & 37,0 & 47,8 & 50,2 & 67,7 & 71,8 & 1,2 & 2,4 & 4,1 & 31,9 & 34,8 \\
\hline Paquistão & 40,1 & 37,6 & 50,6 & 50,5 & 60,6 & 62,6 & $-2,5$ & $-0,1$ & 2,0 & 20,5 & 25,0 \\
\hline Portugal & 56,9 & 61,9 & 64,9 & 71,3 & 71,1 & 78,0 & 5,0 & 6,4 & 6,9 & 14,2 & 16,1 \\
\hline Quênia & 39,0 & 43,0 & 49,0 & 53,0 & 54,2 & 57,3 & 4,0 & 4,0 & 3,1 & 15,2 & 14,3 \\
\hline Reino Unido & 66,7 & 71,8 & 69,0 & 75,2 & 73,6 & 78,7 & 5,1 & 6,2 & 5,1 & 6,9 & 6,9 \\
\hline Romênia & 59,4 & 62,8 & 66,8 & 71,3 & 66,6 & 73,3 & 3,4 & 4,5 & 6,7 & 7,2 & 10,5 \\
\hline Rússia & 62,5 & 70,5 & 63,1 & 73,5 & 61,7 & 73,6 & 8,0 & 10,4 & 11,9 & $-0,8$ & 3,1 \\
\hline Síria & 44,8 & 47,2 & 55,4 & 58,7 & 65,2 & 69,2 & 2,4 & 3,3 & 4,0 & 20,4 & 22,0 \\
\hline Suécia & 70,4 & 73,3 & 72,1 & 77,5 & 75,4 & 81,1 & 2,9 & 5,4 & 5,7 & 5,0 & 7,8 \\
\hline Uganda & 38,5 & 41,6 & 44,9 & 48,1 & 43,6 & 46,2 & 3,1 & 3,2 & 2,6 & 5,1 & 4,6 \\
\hline Uruguai & 63,3 & 69,4 & 65,6 & 72,2 & 69,3 & 75,7 & 6,1 & 6,6 & 6,4 & 6,0 & 6,3 \\
\hline
\end{tabular}

Fonte: Nações Unidas, 1995. 
No caso específico das causas externas o aumento de sua importância nos coeficientes de mortalidade pode ser constatado para aquelas áreas que dispõem de dados mais contínuos, como a França. Nesse país, as informaçōes estão disponiveis desde 1827, mas alguns grupos de causas passaram a ser relacionados posteriormente, como os acidentes de veículos a motor registrados a partir de 1903 (quando começaram a ocorrer com maior freqüência) e dos homicídios a partir de 1929, uma vez que até então eram incluidos entre os acidentes. CHESNAIS (1981) apresenta um panorama da evolução das causas violentas para a França para o período de 1827 a 1970, destacando especialmente os suicídios e os acidentes, pois, além das séries estarem mais completas, representavam a maior parcela desse grupo.

No início do período analisado, as taxas de mortalidade devido às causas externas já eram significativas, com os suicídios alcançando 5,6 óbitos por 100 mil habitantes, enquanto os coeficientes relativos aos acidentes aproximavam-se de cerca de 13 óbitos por 100 mil habitantes. Em 1840, os suicídios e os acidentes provocaram quase 10 mil óbitos, em uma população estimada em 34 milhões de pessoas, resultando uma taxa de cerca de 25 óbitos por 100 mil habitantes. Nos anos seguintes, os coeficientes devidos a tais causas aumentaram de forma significativa e aqueles correspondentes aos suicídios chegaram a 25 por $100 \mathrm{mil}$ habitantes, no final do século XIX, mantendo-se nesse patamar até a metade do século XX. Nesse momento, as taxas devidas aos acidentes aproximavam-se de 50 por 100 mil habitantes, enquanto aquelas referentes aos homicidios estavam bem abaixo. Em todo o período analisado raramente os coeficientes desta última causa ultrapassaram a dois óbitos por 100 mil pessoas. Observa-se ainda que, no decorrer do tempo, alguns tipos de acidentes, como os afogamentos e os provocados por envenenamentos e desmoronamentos, diminuiram consideravelmente, enquanto outros, como as quedas e os acidentes de veículos, aumentaram. Os coeficientes de mortalidade destes últimos passaram de 0,3 por 100 mil, no período de 1901 a 1905, para quase 20 por 100 mil, entre 1931 e 1935, e para mais de 35 por 100 mil após 1960, estando relacionadas ao grande crescimento da frota de veículos ocorrido nesse período. 
Ao se considerarem todas as causas externas de morte, CHESNAIS constatou que as taxas de mortalidade estavam próximas de 67 óbitos por 100 mil habitantes nos primeiros anos do século $X X$, sendo assim semelhantes ou até maiores que as registradas atualmente em muitos paises e um pouco menores que as da própria França, na metade da década passada.

Os fatos observados para a França repetiram-se em outras partes do mundo. As mudanças no perfil epidemiológico fizeram com que, além das causas externas, outras também tivessem maior destaque. Se doenças como tuberculose, diarréias, sarampo e a varíola desapareceram ou diminuíram acentuadamente, outras adquiriram grande importância. Entre estas, destacam-se as doenças do aparelho circulatório, as neoplasias, o diabetes, os transtornos mentais e ainda as perinatais $e$ as anomalias congênitas, entre as crianças. Esses fatos são ressaltados na Teoria da Transição Epidemiológica, especialmente no que se refere às doenças do aparelho circulatório e às neoplasias, que constituiam-se, à época de sua elaboração, nas principais causas de morte na maioria dos países.

Especificamente em relação às causas externas, OMRAN (1972) não as trata com grande ênfase, incluindo-as em um grupo que denomina de "causas provocadas pelo homem", esperando que se mantivessem em certo patamar ou que seus aumentos ocorressem em função do desenvolvimento. Segundo os padrões apresentados, em países com esperança de vida próxima de 75 anos, estas causas não ultrapassariam a $10 \%$ do total dos óbitos, enquanto as doenças do aparelho circulatório deveriam aproximar-se de $50 \%$. Além disso, vários países já vinham adotando medidas no sentido de reduzir as causas violentas e esperava-se que seu impacto fosse maior sobre a morbidade, devido à ocorrência "de acidentes, riscos de radiação e outros tipos de contaminação cada vez mais predominantes" (OMRAN 1972:66). Deve se ressaltar também que, na época da elaboração desta Teoria, a grande preocupação dos paises em desenvolvimento e subdesenvolvidos ainda voltava-se para outras doenças, especialmente as infecciosas e parasitárias e a desnutrição, que, em conjunto estavam muito à frente das demais causas, inclusive das externas. 
Nos últimos anos, no entanto, algumas considerações e reavaliações têm sido feitas a respeito da Transição Epidemiológica, devido a importantes alterações ocorridas na evolução e na distribuição das causas de morte em várias partes do mundo, envolvendo inclusive as causas violentas.

LAURENTI (1990) destaca as mudanças ocorridas na evolução das causas de morte desde a elaboração desta Teoria, destacando que, no futuro as doenças do aparelho circulatório e as neoplasias podem ter suas posições invertidas como principais causas de morte. Em vários países, observa-se, há alguns anos que as doenças do aparelho circulatório vêm diminuindo, enquanto as neoplasias aumentam continuamente. $O$ autor ressalta também que algumas causas tidas como controladas podem aumentar novamente, como é o caso da tuberculose, e que novas doenças podem aparecer, fatos estes que não haviam sido considerados na Teoria da Transiçăo Epidemiológica. A Aids - surgida no início dos anos 80 - é a mais conhecida delas, mas várias outras têm sido descobertas nas últimas décadas.

\section{As causas externas}

Um panorama recente da mortalidade por causas externas pode ser observado na Tabela 17 para vários países, destacando-se as taxas totais e os principais grupos de causas, além de sua participação na mortalidade geral.

Entre os países relacionados e com populações mais significativas, observa-se que as causas externas tinham menor participação na Romênia, Holanda, Espanha, Irlanda, Grécia, Suécia, Alemanha, Noruega e no Reino Unido, aproximando-se de $5 \%$ do total dos óbitos. Em vários outros, entre os quais incluem-se Itália, Estados Unidos, Argentina, Uruguai, Dinamarca, Canadá, Portugal, Áustria, Nova Zelândia, Austrália e Bélgica, o percentual situava-se entre 5 e $7 \%$. No Brasil, aproximava-se de $12 \%$ e no Equador, Coréia, Rússia e Venezuela, entre $14 \%$ e $16 \%$. Os maiores percentuais dessas causas correspondiam à África do Sul e a El Salvador com cerca de $20 \%$, e à Colômbia, com quase $26 \%$ (NAÇÕES UNIDAS 1999). 
Tabela 17

Coeficlentes de Mortalldade por Causas Externas, por Grupos de Causas

Países Selecionados 1991-1997

\begin{tabular}{|c|c|c|c|c|c|c|c|c|c|}
\hline $\begin{array}{c}\text { Países } \\
\text { Selecionados }\end{array}$ & Ano & $\begin{array}{c}\text { Acldentes } \\
\text { de } \\
\text { Transporte }\end{array}$ & Quedas & $\begin{array}{c}\text { Outros } \\
\text { Acidentes }\end{array}$ & Sulcidlo & Homlcidio & $\begin{array}{l}\text { Demais } \\
\text { Causas } \\
\text { Externas }\end{array}$ & $\begin{array}{c}\text { Total } \\
\text { Externas }\end{array}$ & $\begin{array}{c}\text { Percentual } \\
\text { (ExternasI } \\
\text { Total) } \\
\end{array}$ \\
\hline Rússia & 1996 & 19,5 & 6,2 & 87,6 & 39,1 & 26,6 & 30,0 & 207,9 & 14,8 \\
\hline Estônia & 1996 & 16,7 & 13,3 & 65,6 & 37,6 & 19,9 & 6,2 & 158,1 & 12,2 \\
\hline Lituânia & 1996 & 19,7 & 12,6 & 62,7 & 46,4 & 9,3 & 6,8 & 167,6 & 13,6 \\
\hline Ucrânla & 1996 & 13,6 & 6,6 & 70,0 & 29,9 & 15,0 & 23,4 & 157,3 & 10,3 \\
\hline Letônla & 1996 & 27,7 & 14,4 & $\mathbf{5 2 , 0}$ & 37,0 & 15,3 & 9,6 & 155,9 & 11,3 \\
\hline Blelorússia & 1993 & 16,6 & 6,6 & 68,8 & 27,9 & 10,4 & 10,1 & 130,4 & 10,6 \\
\hline Cotômbia & 1994 & 17,8 & 4,0 & 17,1 & 3,5 & 80,0 & 3,0 & 125,4 & 25,7 \\
\hline Hungria & 1997 & 16,9 & 33,6 & 1,3 & 31,7 & 16,9 & 1,9 & 102,2 & 7,4 \\
\hline El Salvador & 1991 & 20,3 & 6,3 & 23,6 & 8,9 & 27,4 & 16,7 & 101,2 & 20,0 \\
\hline Cazaquistilo & 1996 & 12,7 & 3,2 & 0,1 & 30,1 & 18,8 & 36,1 & 101,0 & 9,7 \\
\hline Africa do Sul & 1993 & & & 99,4 & & & & 99,4 & 19,6 \\
\hline Turcomenistāo & 1994 & 9,1 & 1,2 & 32,3 & 46,3 & 4,0 & 3,2 & 95,1 & 13,1 \\
\hline Eslovênla & 1996 & 18,2 & 20,1 & 18,2 & 30,6 & 2,1 & 1,9 & 91,0 & 9,7 \\
\hline Finlândla & 1996 & 7,9 & 17,9 & 26,0 & 27,2 & 2,9 & 3,8 & 85,7 & 8,9 \\
\hline Cuba & 1998 & 18,3 & 17,6 & 17,4 & 20,2 & 7,8 & $3, \mathbf{3}$ & 84,6 & 11,9 \\
\hline Rep. Tcheca & 1997 & 15,4 & 21,0 & 6,2 & 16,2 & 15,4 & 4,3 & 78,5 & 7,2 \\
\hline França & 1994 & 14,2 & 16,6 & 20,6 & 20,8 & 1,1 & 4,6 & $\mathbf{7 7 , 7}$ & 8,7 \\
\hline Coréla & 1996 & 38,4 & $\mathbf{6 , 3}$ & 17,6 & 10,7 & 1,9 & 2,0 & 75,8 & 14,4 \\
\hline Venezuela & 1994 & 22,6 & 4,3 & 13,7 & 6,1 & 15,8 & 13,3 & 74,7 & 16,0 \\
\hline DInamarca & 1996 & 10,4 & 23,6 & 8,5 & 17,0 & 10,4 & 3,6 & 73,4 & 6,4 \\
\hline Croácla & 1996 & 14,0 & 11,1 & 18,4 & 22,3 & $\mathbf{3 , 0}$ & 4,5 & 73,3 & 6,6 \\
\hline Polónla & 1996 & 17,1 & 12,2 & 19,0 & 14,1 & 2,6 & 6,6 & 70,6 & 7,1 \\
\hline Brasil & 1992 & 17,8 & 2,9 & 14,6 & 3,5 & 19,0 & 8,5 & 66,2 & 12,0 \\
\hline Equador & 1986 & 16,8 & 3,2 & 24,3 & 4,8 & 13,4 & 3,7 & 65,2 & 14,7 \\
\hline Bélgíca & 1892 & 16,1 & 13,0 & 11,8 & 18,7 & 1,7 & 2,7 & 64,0 & 6,2 \\
\hline Chile & 1894 & 12,0 & 2,9 & 17,9 & 6,7 & 2,9 & $\mathbf{2 2 , 0}$ & 63,4 & 11,8 \\
\hline México & 1996 & 16,0 & 4,9 & 19,4 & 3,2 & 17,2 & 3,1 & 62,8 & 13,2 \\
\hline Urugual & 1990 & 12,1 & $\mathbf{5 , 0}$ & 29,9 & 10,3 & 4,4 & 0,0 & 61,7 & 6,3 \\
\hline luguslávia & 1990 & 16,7 & 6,2 & 16,6 & 16,3 & 2,0 & 2,7 & 58,4 & 6,6 \\
\hline Portugal & 1996 & 22,5 & 5,6 & $\mathbf{9 , 0}$ & 6,6 & 1,3 & 13,3 & 58,3 & 5,4 \\
\hline Estados Unidos & 1996 & 16,1 & $\mathbf{6 , 3}$ & 14,1 & 11,9 & 8,6 & 1,4 & 57,4 & 6,6 \\
\hline Austrla & 1997 & 12,2 & 11,8 & 8,4 & 19,7 & 0,9 & 0,7 & 54,8 & 5,6 \\
\hline Argentina & 1993 & 10,8 & 2,8 & 18,7 & 6,6 & 4,4 & 11,3 & 54,6 & $\mathbf{7 , 0}$ \\
\hline Noruega & 1985 & $\mathbf{7 , 1}$ & 20,6 & 10,5 & 12,6 & 1,0 & 0,4 & 62,2 & 5,0 \\
\hline Japão & 1996 & 11,2 & 4,7 & 16,2 & 17,6 & 0,6 & 1,8 & $\mathbf{6 1 , 0}$ & 9,7 \\
\hline Nova Zelândla & 1984 & 16,7 & 6,7 & 9,4 & 14,7 & 2,0 & 0,3 & 49,8 & 6,4 \\
\hline Itálla & 1993 & 14,6 & 16,9 & 7,6 & 8,2 & 1,7 & 0,8 & 49,7 & 5,1 \\
\hline Usbequistāo & 1993 & 8,4 & 1,3 & 26,6 & 6,2 & 4,3 & 2,9 & 49,7 & 7,5 \\
\hline Costa Rica & 1994 & 16,7 & 6,7 & 12,8 & $\mathbf{6 , 0}$ & 6,6 & 2,8 & 49,6 & 12,2 \\
\hline Suécia & 1996 & 6,6 & 12,8 & 9,1 & 14,2 & 1,2 & 4,6 & 47,4 & 4,6 \\
\hline Alemanha & 1996 & 10,1 & 12,6 & 6,1 & 14,9 & 1,1 & 2,3 & 47,0 & 4,4 \\
\hline Canadá & 1995 & 10,5 & 8,3 & 11,3 & 13,5 & 1,7 & 1,0 & 46,3 & 6,4 \\
\hline Grécia & 1996 & 24,2 & 3,3 & 10,2 & 3,4 & 1,6 & 0,0 & 42,7 & 4,4 \\
\hline Fillpinas & 1993 & 6,4 & 1,1 & 6,0 & 1,3 & 11,5 & 17,3 & 42,6 & 9,0 \\
\hline Espanha & 1995 & 14,7 & 3,8 & 13,9 & 8,1 & 0,9 & 0,3 & 41,7 & 4,7 \\
\hline Nicarágua & 1984 & 9,1 & 1,4 & 14,4 & 3,3 & 5,5 & 7,7 & 41,4 & 13,9 \\
\hline Irlanda & 1995 & 11,7 & 6,9 & 8,6 & 11,2 & 0,7 & 0,3 & 39,4 & 4,4 \\
\hline Austrálla & 1995 & 10,6 & 6,4 & 8,6 & 12,0 & 1,6 & 0,6 & 38,8 & 5,6 \\
\hline Paragual & 1994 & 8,4 & 1,1 & 11,6 & 2,3 & 9,8 & 2,6 & 36,8 & 10,7 \\
\hline Kuwalt & 1994 & 20,3 & 2,6 & 7,3 & 1,9 & 1,7 & 1,4 & 35,2 & 16,5 \\
\hline Israel & 1996 & 9,0 & 2,4 & 9,6 & 5,4 & 1,0 & 7,2 & 34,6 & 5,7 \\
\hline Holanda & 1995 & $\mathbf{7 , 7}$ & 10,0 & 4,3 & 9,8 & 1,2 & 0,4 & 33,4 & 3,8 \\
\hline Reino Unido & 1994 & 6,4 & 7,1 & 7,2 & 7,5 & 1,0 & 3,6 & 32,8 & 3,1 \\
\hline China & 1996 & 3,6 & 2,0 & $\mathbf{5 , 9}$ & 12,5 & 1,0 & 1,6 & 26,6 & 5,2 \\
\hline Roménia & 1996 & & 8,2 & & 12,5 & 3,8 & 0,3 & 24,8 & 2,0 \\
\hline
\end{tabular}

Fonte: Naçōes Unidas, 1999. 
Os menores coeficientes de mortalidade foram registradas na Romênia e na China, com respectivamente, 25 e 26 óbitos por 100 mil habitantes, no Reino Unido, com 29 óbitos por 100 mil habitantes, a Holanda (33 por 100 mil) e Israel (35 por 100 mil). Na maior parte dos países desenvolvidos e também na Costa Rica e na Argentina, os coeficientes ficaram entre 40 e 60 óbitos por 100 mil habitantes e no Brasil em 66 óbitos por 100 mil pessoas em 1992 ( Tabela 17).

Os maiores coeficientes de mortalidade por causas externas, corresponderam à Bielorússia, com 130 óbitos por 100 mil, à Ucrânia com 157 por 100 mil, aos três países bálticos - Letônia, Lituânia Estônia - com cerca de 158, e principalmente à Rússia, com 208 óbitos por cem mil habitantes.

A Tabela 18 mostra os coeficientes de mortalidade por causas externas, em paises selecionados para 1980-95. Observa-se que, a partir de 1980, esses coeficientes vêm diminuindo em vários países como Alemanha, Áustria, Bélgica, Canadá, França, México e Portugal, entre outros. Por outro lado, os coeficientes estão aumentando na Colômbia, na Venezuela e nos países que compunham a União Soviética, como a Rússia, a Estônia e a Lituânia. Os valores mantém-se praticamente constantes e com baixos coeficientes, na Argentina, Costa Rica, Espanha, Grécia, Holanda, Japão e Itália, e mostram-se estáveis, porém, elevados, na Hungria e na Estônia.

Analisando a mortalidade por causas externas nos países da América a partir de 1980, YUNES e ZUBAREW(1999) constataram comportamento muito heterogêneo: Colômbia, Cuba, Porto Rico, Venezuela e Brasil registraram crescimento significativo desses coeficientes; Canadá, Chile, Equador, El Salvador e México apresentaram redução e nos demais houve estabilidade, com poucas alterações.

Os maiores coeficientes de mortalidade, na metade da década de 90 , foram encontrados para a Colômbia (120 óbitos por 100 mil habitantes), Cuba (84), Venezuela (73), Porto Rico (72) e Brasil (67). 
Tabela 18

Coeficientes de Mortalidade por Causas Externas Paises Selecionados

1980-95

\begin{tabular}{|c|c|c|c|c|c|c|c|c|c|c|c|c|c|c|c|c|}
\hline & & & & & & & & & & & & & & & & 1005 \\
\hline Alemanha & 69,0 & 67,9 & 68,1 & 67,3 & 62,3 & 58,1 & 56,3 & 54,0 & 52,9 & 56,4 & 57,9 & 58,3 & 55,6 & 52,5 & 50,3 & 48,1 \\
\hline Argentina & 58,1 & 58,4 & 53,3 & 57,3 & 53,2 & 47,8 & 53,6 & 52,8 & 53,9 & 54,0 & 51,1 & 51,7 & 53,3 & 54,6 & 55,2 & 51,9 \\
\hline Austrálla & 56,2 & 52,8 & 54,6 & 49,3 & 46,5 & 49,6 & 48,9 & 49,7 & 49,6 & 48,7 & 45,4 & 43,6 & 41,8 & 38,9 & 40,4 & 38,8 \\
\hline Austria & 91,2 & 90,0 & 92,0 & 93,5 & 88,7 & 85,4 & 81,8 & 81,0 & 78,7 & 76,8 & 72,1 & 69,0 & 65,0 & 63,0 & 64,4 & 60,0 \\
\hline Bélgica & 85,3 & 83,5 & 82,6 & 80,4 & 74,8 & 71,3 & 71,0 & 69,4 & 66,6 & 64,7 & 65,1 & 65,8 & 64,0 & ... & 41,0 & $\cdots$ \\
\hline Brasil & 59,0 & 59,3 & 59,3 & 61,7 & 63,9 & 65,2 & 71,5 & 69,0 & 69,1 & 72,2 & 69,9 & 69,5 & 66,7 & 68,6 & 69,9 & 73,9 \\
\hline Canadá & 65,5 & 63,8 & 57,5 & 56,6 & 55,6 & 53,0 & 54,2 & 53,4 & 50.7 & 50,5 & 47,0 & 47,0 & 45,9 & 46,7 & 45,0 & 45,9 \\
\hline Colombia & $\ldots$ & 66,5 & $\ldots$ & .. & 86,9 & 104,0 & 107,0 & 105,2 & 112,8 & 114,2 & 116,8 & 132,3 & 133,0 & 131,4 & 125,4 & 107,8 \\
\hline Costa Rica & 55,1 & 43,3 & 41,9 & 36,1 & 43,0 & 43,1 & 40,0 & 43,4 & 42,7 & 44,8 & 47,1 & 43,1 & 50,5 & 47,8 & 49,6 & 27,1 \\
\hline Espanha & 41,2 & 40,6 & 38,7 & 39,6 & 40,7 & 39,1 & 43,6 & 51,2 & 44,8 & 51,8 & 50,1 & 49,4 & 49,2 & 49,7 & 51,7 & 28,1 \\
\hline Estônia & $\ldots$ & 139,7 & 129,7 & $\ldots$ & $\ldots$ & 115,5 & 99,4 & 101,9 & 102,6 & 111,5 & 92,9 & 96,0 & 99,3 & 120,2 & 233,2 & 198,9 \\
\hline Estados Unidos & 70,5 & 67,7 & 63,6 & 61,4 & 61,2 & 60,8 & 62,5 & 61,8 & 62,2 & 60,9 & 60,0 & 59,1 & 57,1 & 58,4 & 57,9 & 56,5 \\
\hline Finlândia & 77,1 & 75,3 & 74,6 & 75,5 & 74,9 & 78,1 & 80,2 & 86,2 & 92,1 & 94,3 & 95,0 & 92,7 & 90,0 & 85,3 & 84,9 & 85,7 \\
\hline França & 93,6 & 93,0 & 92,8 & 93,3 & 91,5 & 90,2 & 89,7 & 83,7 & 84,1 & 85,4 & 85,1 & 82,8 & 81,1 & 81,0 & 77,7 & $\cdots$ \\
\hline Grécia & 48,8 & 49,2 & 49,3 & 50,7 & 50,1 & 49,4 & 46,2 & 54,1 & 47,9 & 49,0 & 43,6 & 40,7 & 39,1 & 41,5 & 42,3 & 43,5 \\
\hline Holanda & 43,1 & 41,4 & 41,4 & 42,3 & 41,7 & 38,4 & 38,3 & 37,1 & 35,4 & 37,8 & 35,4 & 36,1 & 35,9 & 34,2 & 34,3 & 33,4 \\
\hline Hungria & 115,7 & 118,2 & 114,9 & 120,9 & 120,6 & 124,7 & 122,1 & 122,3 & 118,0 & 124,0 & 128,2 & 124,6 & 126,7 & 119,4 & 115,4 & 111,4 \\
\hline Israel & 35,2 & 31,6 & 30,4 & 40,2 & 40,8 & 45,8 & 46,3 & 46,6 & 42,7 & 43,7 & 39,9 & 36,3 & 37,6 & 36,8 & 38,2 & 35,0 \\
\hline Italla & 56,2 & 51,4 & 50,9 & 50,6 & 47,3 & 50,3 & 49,2 & 49,3 & 49,8 & 49,0 & 50,5 & 53,1 & 51,4 & 49,7 & $\cdots$ & $\ldots$ \\
\hline Japało & 45,3 & 44,5 & 44,7 & 48,7 & 47,6 & 46,7 & 47,6 & 45,6 & 46,1 & 45,2 & 45,1 & 45,5 & 47,4 & 47,3 & 48,8 & $\ldots$ \\
\hline Letônia & $\ldots$ & 146,2 & 142,4 & $\ldots$ & $\cdots$ & 118,5 & 104,6 & 100,4 & 163,7 & 197,8 & 109,5 & 119,7 & 121,3 & 154,6 & 157,7 & 99,4 \\
\hline Lituânia & $\ldots$ & 123,8 & 118,5 & $\ldots$ & $\ldots$ & 109.2 & 92,1 & 91,5 & 158,9 & 175,2 & 86.7 & 104,1 & 99,6 & 167,5 & 186,0 & 176.0 \\
\hline México & 97,0 & 97.7 & 92,4 & 80,3 & 83,5 & 84,3 & 78,7 & 75,7 & 72,9 & 70,7 & 71,1 & 67,4 & 67,0 & 63,8 & 62,9 & 62,8 \\
\hline Noruega & 65,4 & 60,6 & 63,0 & 61,2 & 61,7 & 65,1 & 63,9 & 64,3 & 65,1 & 66,2 & 63,2 & 59,7 & 57,0 & 56,5 & 51,9 & $\ldots$ \\
\hline Portugal & 70,8 & 78,2 & 76,5 & 74,9 & 71,6 & 70,1 & 67,9 & 70,3 & 70,4 & 67,5 & 68,1 & 70,6 & 66,8 & 61,2 & 57,1 & 59,7 \\
\hline Reino Unido & 40,9 & 39,8 & 39,6 & 38,2 & 37,9 & 38,1 & 37,6 & 37,4 & 38,1 & 36,8 & 37,1 & 35,5 & 34,3 & 25,3 & 18,3 & 18,2 \\
\hline Rússia & $\ldots$ & 155.0 & 149.3 & ... & $\ldots$ & 130,3 & 40.0 & 92,8 & 156.9 & 179.0 & 82.0 & 86.1 & 104,2 & 131.6 & 141.6 & 136.3 \\
\hline Suécia & 69,1 & 61,5 & 58,6 & 61,0 & 60,7 & 59,2 & 59,8 & 60,2 & 62,0 & 60,8 & 58,4 & 57,0 & 52,7 & 51,8 & 53,6 & 49,0 \\
\hline Venezuela & 77,2 & 74,5 & 73,9 & 71,3 & $\cdots$ & 61,6 & 60,1 & 60,8 & 60,0 & 61,4 & 61,1 & $\ldots$ & 68,5 & 72,0 & 74,0 & $\ldots$ \\
\hline
\end{tabular}

(...) Dados nato disponivels

Enfocando principalmente a situação entre a população jovem, observouse que El Salvador, envolvido em conflito interno, apresentou a maior taxa de mortalidade entre todos os países da América. Em 1991 o coeficiente para a faixa de 20 a 24 anos chegou ao altíssimo nível de 1.355 óbitos por 100 mil habitantes. Outros países que registraram elevados coeficientes nessa faixa etária foram a Colômbia, com 400 óbitos por 100 mil habitantes, a Venezuela (250 por 100 mil) e Porto Rico e Brasil (200 por 100 mil).

Durante os anos 90, esse coeficiente diminuiu consideravelmente em EI Salvador, mas ainda manteve-se muito alto, chegando a 340 óbitos por 100 mil 
habitantes, em 1996. Nesse período, o Canadá foi o país que apresentou os menores coeficientes de mortalidade tanto para a população total como para a faixa de 20 a 24 anos, onde chegou a 43 óbitos por 100 mil habitantes, em 1995, sendo cerca de $50 \%$ menor que o registrado em 1980.

É importante observar a distribuição e a evolução das principais causas de morte externas, no decorrer do tempo, pois as medidas que possibilitam alterar seus niveis mostram-se muito especificas e distintas. A seguir, apresentam-se algumas considerações sobre as principais causas externas em alguns países.

\section{A mortalidade por acidentes de veiculos a motor}

Os acidentes de veículos a motor embora constituam-se nas principais causas de morte violentas de vários países, são os que vêm apresentando algumas das reduções mais consideráveis desde os anos 70 , em praticamente todos os países desenvolvidos e também em alguns de menor desenvolvimento, como Argentina, México, Venezuela e Brasil (Tabela 19). Isto tem sido possivel mediante a adoção de várias medidas voltadas para a melhoria da segurança dos veículos, dos passageiros e das vias urbanas e das rodovias. Porém, as diferenças nos coeficientes de mortalidade entre os países permanecem significantes, variando de 5 a 38 óbitos por 100 mil habitantes.

Em meados dos anos 90 os maiores coeficientes de mortalidade correspondiam à Coréia e à Letônia, com respectivamente 38 e 28 óbitos por 100 mil pessoas. Na Grécia, em Portugal e na Venezuela as taxas oscilavam entre 22 e 24 por 100 mil, enquanto El Salvador, Kuwait, Lituânia, Cuba e Eslovênia registravam entre 18 e 20 óbitos por 100 mil pessoas (Tabela 17).

Os altos coeficientes de mortalidade observados em Portugal eram atribuidos ao consumo de bebidas alcoólicas, às más condiçōes rodoviárias e uma menor fiscalização das autoridades no trânsito (CAUSAS DE MORTE NOS PAISES DESENVOLVIDOS 1999). Para o Brasil o coeficiente estava próximo de 18 óbitos por 100 mil pessoas, em 1992, semelhante ao registrado na Colômbia, em 1994. Os menores coeficientes de mortalidade foram observados para a 
Suécia, Reino Unido, Noruega, Holanda e Finlândia com coeficientes entre 5 e 8 óbitos por 100 mil pessoas.

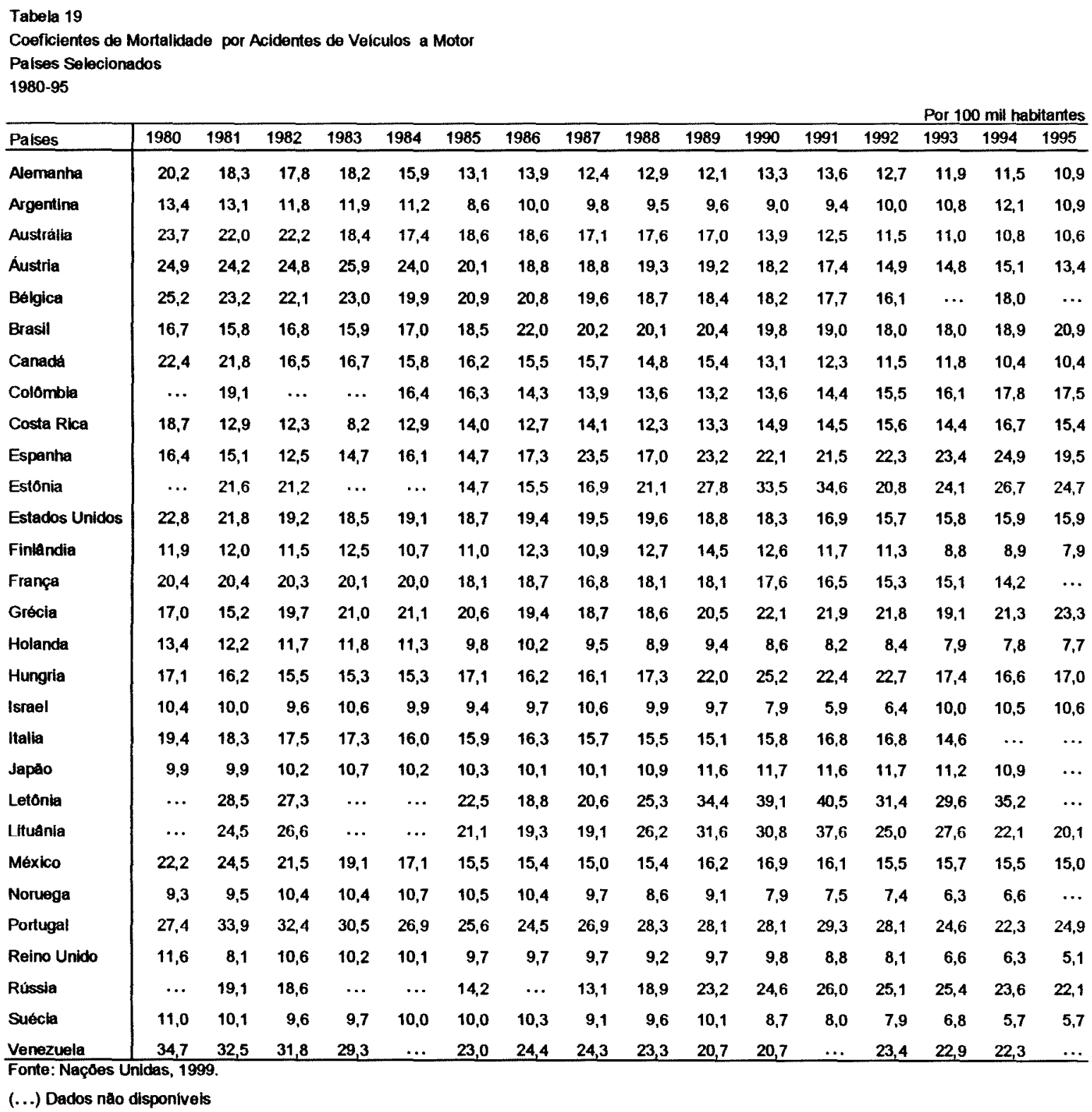

YUNES e ZUBAREW (1999) destacam que na América, Venezuela, EI Salvador, Equador, Cuba e Brasil registravam os maiores coeficientes de mortalidade, com 18 a 23 óbitos por 100 mil habitantes. Destes países, Equador apresentou considerável redução a partir de 1993, ressaltando-se ainda que os Estados Unidos estavam em situação intermediária, com cerca de 16 óbitos por 100 mil pessoas. Os países com os menores coeficientes de mortalidade, nos 
últimos anos eram Argentina, Canadá, Uruguai, Chile e Trinidad-Tobago, com coeficientes de 10 a 12 óbitos por 100 mil pessoas,

\section{A mortalidade por demais acidentes}

O grupo de óbitos provocados por "demais acidentes" é constituido, em maior parte, por afogamentos e quedas, seguidos pelas queimaduras, asfixias e envenenamentos por substâncias tóxicas.

Os coeficientes de mortalidade provocados pelas quedas - uma das principais causas desse grupo - diminuiram desde os anos $80 \mathrm{em}$ países como Áustria, Bélgica, França e Portugal, aumentaram em outros, como Estônia e Finlândia e mantiveram-se estáveis para Holanda, Japão, Noruega e Hungria. Os coeficientes observados para estes dois últimos países, bem como para a Dinamarca, República Theca e Eslovênia eram os mais elevados, situando-se entre 20 e 23 óbitos por 100 mil habitantes, com exceção da Hungria, onde alcançava 33 por 100 mil. Finlândia, Cuba e Itália registravam coeficientes próximos de 18 por 100 mil e a França de 16 por 100 mil. Os menores coeficientes situavam-se abaixo de 3 óbitos por cem mil habitantes, estando nesses casos países como Brasil, Chile, Argentina e Israel (Tabela 20). 
Por 100 mil habitantes

\begin{tabular}{|c|c|c|c|c|c|c|c|c|c|c|c|c|c|c|c|c|}
\hline Palses & 1980 & 1981 & 1982 & 1983 & 1984 & 1985 & 1986 & 1987 & 1988 & 1989 & 1990 & 1991 & 1992 & 1993 & 1994 & 1995 \\
\hline Alemanha & 9,1 & 8,6 & 9,6 & 9,9 & 8,8 & 7,8 & 7,1 & 6,4 & 6,4 & 8,3 & 8,2 & 7,5 & 7,4 & 6,9 & 6,5 & 5,9 \\
\hline Argentina & 24,0 & 25,0 & 22,0 & 22,6 & 22,8 & 19,7 & 22,4 & 20,8 & 21,5 & 20,9 & 19,3 & 19,2 & 18,8 & 18,7 & $\ldots$ & $\ldots$ \\
\hline Austrália & 12,3 & 11,2 & 12,0 & 11,8 & 10,0 & 10,8 & 9,8 & 9,9 & 10,3 & 10,1 & 9,5 & 9,4 & 9,3 & 9,2 & 8,8 & 8,6 \\
\hline Austria & 13,7 & 14,0 & 13,8 & 12,8 & 12,4 & 12,5 & 11,5 & 11,7 & 11,6 & 11,0 & 10,3 & 10,6 & 9,2 & 10,9 & 11,8 & 11,0 \\
\hline Bélgica & 14,9 & 16,0 & 14,9 & 12,8 & 10,7 & 10,4 & 10,4 & 10,7 & 11,0 & 10,9 & 11,7 & 12,6 & 11,8 & $\cdots$ & $\cdots$ & $\ldots$ \\
\hline Brasil & 14,3 & 14,9 & 14,6 & 17,7 & 16,5 & 16,3 & 17,4 & 16,4 & 16,1 & 16,1 & 15,1 & 15,6 & 14,6 & 15,0 & 14,8 & 14,8 \\
\hline Canadá & 16,8 & 15,8 & 14,6 & 13,5 & 14,4 & 13,1 & 12,5 & 12,8 & 11,5 & 11,8 & 11,3 & 11,6 & 10,9 & 11,4 & 11,2 & 11,2 \\
\hline Colómbia & $\ldots$ & $\ldots$ & $\ldots$ & $\ldots$ & 26,0 & 28,7 & 27,7 & 27,2 & 26,5 & 21,9 & 20,7 & 19,8 & 18,9 & 20,2 & 17,1 & $\ldots$ \\
\hline Costa Rica & 17,1 & 15,1 & 14,2 & 12,7 & 14,6 & 12,2 & 12,8 & 13,3 & 12,9 & 13,0 & 12,6 & 12,4 & 14,1 & 13,3 & 12,8 & .. \\
\hline Espanha & 13,4 & 14,1 & 13,9 & 14,7 & 13,6 & 13,5 & 14,6 & 16,2 & 16,3 & 16,9 & 16,0 & 15,8 & 15,3 & 14,1 & 13,7 & .. \\
\hline Estonia & $\ldots$ & 55,2 & 50,9 & & $\ldots$ & 50,6 & 39,4 & 42,8 & 39,0 & 38,0 & 8,8 & 7,9 & 9,0 & 10,7 & 108,8 & 87,8 \\
\hline Estados Unidos & 17,8 & 16,5 & 16,0 & 15,8 & 15,1 & 15,3 & 15,3 & 14,8 & 15,1 & 14,7 & 13,5 & 13,5 & 13,4 & 14,1 & 14,0 & $\cdots$ \\
\hline Finlandia & 21,1 & 21,3 & 21,3 & 201 & 20,0 & 21,9 & 21,9 & 26,1 & 29,0 & 26,7 & 26,8 & 26,7 & 25,9 & 24,7 & 24,8 & 26,0 \\
\hline França & 26,7 & 26,2 & 25,0 & 23,1 & 21,5 & 21,6 & 21,2 & 20,5 & 21,1 & 22,0 & 21,9 & 21,8 & 21,8 & 21,2 & 20,6 & $\ldots$ \\
\hline Grécia & 12,3 & 14,0 & 12,6 & 12,1 & 11,7 & 13,4 & 13,9 & 24,6 & 17,6 & 15,8 & 10,0 & 10,1 & 9,0 & 13,3 & 11,1 & 10,7 \\
\hline Holanda & 6,2 & 5,5 & 6,0 & 6,1 & 5,8 & 5,4 & 5,2 & 4,8 & 4,6 & 5,3 & 5,0 & 4,7 & 4,9 & 4,3 & 4,5 & 4,3 \\
\hline Hungria & 21,8 & 21,4 & 21,5 & 22,4 & 20,9 & 23,2 & 21,8 & 22,3 & 20,6 & 20,7 & 20,0 & 21,7 & 21,0 & 22,3 & 21,5 & 20,1 \\
\hline |srael & 9,3 & 8,5 & 9,6 & 14,4 & 17,2 & 21,0 & 21,3 & 19,4 & 15,8 & 15,8 & 14,8 & 13,1 & 13,4 & 9,5 & 8,8 & 6,2 \\
\hline Italia & 12,0 & 8,8 & 7,8 & 7,4 & 7,1 & 8,6 & 7,5 & 7,8 & 7,4 & 7,3 & 7,1 & 7,7 & 7,3 & 7,5 & $\ldots$ & $\ldots$ \\
\hline Japăo & 11,3 & 11,2 & 10,9 & 10,8 & 10,8 & 10,9 & 10,2 & 9,9 & 10,4 & 10,3 & 10,9 & 11,5 & 12,5 & 12,9 & 14,3 & $\ldots$ \\
\hline Letonia & $\ldots$ & 61,7 & 58,2 & $\ldots$ & $\ldots$ & 43,7 & 39,5 & 37,3 & 90,9 & 107,8 & 10,1 & 10,9 & 8,9 & 15,4 & 16,0 & $\ldots$ \\
\hline Lituania & $\ldots$ & 55,8 & 48,1 & $\ldots$ & $\ldots$ & 44,0 & 39,6 & 36,2 & 88,2 & 94,8 & 7,1 & 9,6 & 10,4 & 61,9 & 80,2 & 76,2 \\
\hline México & 40,5 & 46,1 & 43,4 & 36,0 & 36,5 & $\ldots$ & 34,5 & 32,3 & 29,0 & 25,7 & 25,1 & 23,2 & 22,4 & 20,2 & 19,6 & 19,4 \\
\hline Noruega & 19,8 & 14,5 & 16,2 & 13,8 & 12,7 & 16,0 & 14,8 & 14,3 & 13,0 & 15,4 & 16,5 & 12,6 & 12,9 & 12,1 & 10,5 & $\ldots$ \\
\hline Portugal & 16,1 & 18,9 & 17,4 & 15,0 & 14,1 & 14,8 & 12,6 & 9,7 & 8,7 & 10,5 & 9,8 & 10,4 & 10,6 & 10,0 & 10,2 & 9,5 \\
\hline Reino Unido & 8,2 & 9,9 & 8,4 & 7,4 & 7,4 & 7,5 & 7,6 & 7,2 & 7,3 & 6,8 & 7,2 & 6,9 & 6,5 & 6,7 & 7,0 & 6,8 \\
\hline Rússia & $\ldots$ & 76,2 & 69,7 & $\ldots$ & $\ldots$ & 61,6 & $\cdots$ & 47,1 & 92,4 & 103,1 & 0,4 & 0,1 & 0,4 & 1,4 & 1,9 & 2,2 \\
\hline Suécia & 9,6 & 9,8 & 10,6 & 12,3 & 11,1 & 10,1 & 11,2 & 11,0 & 11,3 & 10,8 & 10,9 & 10,5 & 9,9 & 10,0 & 15,2 & 9,5 \\
\hline Venezuela & 20,7 & $\ldots$ & $\ldots$ & 19,9 & $\ldots$ & 18,9 & 17,9 & 16,9 & 15,3 & 14,5 & 14,5 & $\ldots$ & 13,7 & 13,7 & 13,6 & $\ldots$ \\
\hline
\end{tabular}

Fonte: Naçoes Unidas, 199

(...) Dados năo disponiveis

Considerando-se os demais acidentes (excluindo as quedas), observa-se que os maiores coeficientes correspondiam à África do Sul, com quase 100 óbitos por 100 mil, seguida pela Rússia (87), Ucrânia (70), Estônia (65) e Lituânia (63). Os menores situavam-se entre 4 e 6 por mil em países como Alemanha e Holanda, enquanto no Brasil aproximava-se de 14 por cem mil (Tabela 17). Estes coeficientes devem ser analisados com ressalvas em alguns paises, uma vez que sua qualidade pode estar comprometida por deficièncias na classificação, o que poderia acarretar altas proporções de óbitos neste grupo. Este é o caso da África do Sul, onde observa-se que as informações referentes às causas externas, para 
1993, estavam totalmente englobadas neste grupo, o que evidentemente é um problema. O mesmo fato ocorre nos países que compunham a ex-União Soviética, cujos coeficientes mostram-se elevados e muito irregulares no decorrer do tempo.

Em relação aos países que contam com uma série mais contínua de informações, observa-se que os coeficientes vêm diminuindo no Canadá e na Noruega, mantèm-se elevados na França e na Finlândia e são baixos na Holanda e na Alemanha (Tabela 21).

\begin{tabular}{|c|c|c|c|c|c|c|c|c|c|c|c|c|c|c|c|c|}
\hline & & & & & & & & & & & & & & Por 10 & 0 mil hat & itantes \\
\hline Pais & 1980 & 1981 & 1982 & 1983 & 1984 & 1985 & 1986 & 1987 & 1988 & 1989 & 1990 & 1991 & 1992 & 1993 & 1994 & 1995 \\
\hline Alemanha & 9,1 & 8,6 & 9,6 & 9,9 & 8,8 & 7,8 & 7,1 & 6,4 & 6,4 & 8,3 & 8,2 & 7,5 & 7,4 & 6,9 & 6,5 & 5,9 \\
\hline Argentina & 24,0 & 25,0 & 22,0 & 22,6 & 22,8 & 19,7 & 22,4 & 20,8 & 21,5 & 20,9 & 19,3 & 19,2 & 18,8 & 18,7 & $\cdots$ & $\ldots$ \\
\hline Austrália & 12,3 & 11,2 & 12,0 & 11,8 & 10,0 & 10,8 & 9,8 & 9,9 & 10,3 & 10,1 & 9,5 & 9,4 & 9,3 & 9,2 & 8,8 & 8,6 \\
\hline Austria & 13,7 & 14,0 & 13,8 & 12,8 & 12,4 & 12,5 & 11,5 & 11,7 & 11,6 & 11,0 & 10,3 & 10,6 & 9,2 & 10,9 & 11,8 & 11,0 \\
\hline Bélgica & 14,9 & 16,0 & 14,9 & 12,8 & 10,7 & 10,4 & 10,4 & 10,7 & 11,0 & 10,9 & 11,7 & 12,6 & 11,8 & $\ldots$ & ... & $\ldots$ \\
\hline Brasil & 14,0 & $\ldots$ & $\ldots$ & 17,2 & 16,1 & $\ldots$ & 16,9 & 16,3 & 16,0 & 16,0 & $\ldots$ & 15,5 & 14,5 & $\ldots$ & $\ldots$ & $\ldots$ \\
\hline Canada & 16,8 & 15,8 & 14,6 & 13,5 & 14,4 & 13,1 & 12,5 & 12,8 & 11,5 & 11,8 & 11,3 & 11,6 & 10,9 & 11,4 & 11,2 & 11,2 \\
\hline Colombla & $\cdots$ & $\ldots$ & $\ldots$ & $\ldots$ & 26,0 & 28.7 & 27,7 & 27,2 & 26,5 & 21,9 & 20,7 & 19,8 & 18,9 & 20,2 & 17,1 & $\cdots$ \\
\hline Costa Rica & 17,1 & 15,1 & 14,2 & 12,7 & 14,6 & 12,2 & 12,8 & 13,3 & 12,9 & 13,0 & 12,6 & 12,4 & 14,1 & 13,3 & 12,8 & $\cdots$ \\
\hline Espanha & 13,4 & 14,1 & 13,9 & 14,7 & 13,6 & 13,5 & 14,6 & 16,2 & 16,3 & 16,9 & 16,0 & 15,8 & 15,3 & 14,1 & 13,7 & $\ldots$ \\
\hline Estonia & ... & 55,2 & 50,9 & $\ldots$ & $\ldots$ & 50,6 & 39,4 & 42,8 & 39,0 & 38,0 & 8,8 & 7,9 & 9,0 & 10,7 & 108,8 & 87,8 \\
\hline Estados Unidos & 17,8 & 16,5 & 16,0 & 15,8 & 15,1 & 15,3 & 15,3 & 14,8 & 15,1 & 14,7 & 13,5 & 13,5 & 13,4 & 14,1 & 14,0 & $\ldots$ \\
\hline Fintandia & 21,1 & 21,3 & 21,3 & 20,1 & 20,0 & 21,9 & 21,9 & 26,1 & 29,0 & 26,7 & 26,8 & 26,7 & 25,9 & 24,7 & 24,8 & 26,0 \\
\hline França & 26,7 & 26,2 & 25,0 & 23,1 & 21,5 & 21,6 & 21,2 & 20,5 & 21,1 & 22,0 & 21,9 & 21,8 & 21,8 & 21,2 & 20,6 & ... \\
\hline Grécia & 12,3 & 14,0 & 12,6 & 12,1 & 11,7 & 13,4 & 13,9 & 24,6 & 17,6 & 15,8 & 10,0 & 10,1 & 9,0 & 13,3 & 11,1 & 10,7 \\
\hline Holanda & 6,2 & 5,5 & 6,0 & 6,1 & 5,8 & 5,4 & 5,2 & 4,8 & 4,6 & 5,3 & 5,0 & 4,7 & 4,9 & 4,3 & 4,5 & 4,3 \\
\hline Hungria & 21,8 & 21,4 & 21,5 & 22,4 & 20,9 & 23,2 & 21,8 & 22,3 & 20,6 & 20,7 & 20,0 & 21,7 & 21,0 & 22,3 & 21,5 & 20,1 \\
\hline Israel & 9,3 & 8,5 & 9,6 & 14,4 & 17,2 & 21,0 & 21,3 & 19,4 & 15,8 & 15,8 & 14,8 & 13,1 & 13,4 & 9,5 & 8,8 & 6.2 \\
\hline Italia & 12,0 & 8,8 & 7,8 & 7,4 & 7,1 & 8,6 & 7,5 & 7,8 & 7,4 & 7,3 & 7,1 & 7,7 & 7,3 & 7,5 & $\cdots$ & $\cdots$ \\
\hline Japao & 11,3 & 11,2 & 10,9 & 10,8 & 10,8 & 10,9 & 10,2 & 9,9 & 10,4 & 10,3 & 10,9 & 11,5 & 12,5 & 12,9 & 14,3 & $\ldots$ \\
\hline Letonia & $\ldots$ & 61,7 & 58,2 & $\ldots$ & $\cdots$ & 43,7 & 39,5 & 37,3 & 90,9 & 107,8 & 10,1 & 10,9 & 8,9 & 15,4 & 16,0 & $\cdots$ \\
\hline Lituania & $\ldots$ & 55,8 & 48,1 & $\ldots$ & $\ldots$ & 44,0 & 39,6 & 36,2 & 88,2 & 94,8 & 7,1 & 9,6 & 10,4 & 61,9 & 80,2 & 76,2 \\
\hline México & 40,5 & 46,1 & 43,4 & 36,0 & $\ldots$ & 36,5 & 34,5 & 32,3 & 29,0 & 25,7 & 25,1 & 23,2 & 22,4 & 20,2 & 19,6 & 19,4 \\
\hline Noruega & 19,8 & 14,5 & 16,2 & 13,8 & 12,7 & 16,0 & 14,8 & 14,3 & 13,0 & 15,4 & 16,5 & 12,6 & 12,9 & 12,1 & 10.5 & $\ldots$ \\
\hline Portugal & 16,1 & 18,9 & 17,4 & 15,0 & 14,1 & 14,8 & 12,6 & 9,7 & 8,7 & 10,5 & 9,8 & 10,4 & 10,6 & 10,0 & 10,2 & 9,5 \\
\hline Reino Unido & 8,2 & 9,9 & 8,4 & 7,4 & 7,4 & 7,5 & 7,6 & 7,2 & 7,3 & 6,8 & 7,2 & 6,9 & 6,5 & 6,7 & 7,0 & 6,8 \\
\hline Rússia & $\cdots$ & 76,2 & 69,7 & $\ldots$ & $\ldots$ & 61,6 & $\ldots$ & 47,1 & 92,4 & 103,1 & 0,4 & 0,1 & 0,4 & 1,4 & 1,9 & 2,2 \\
\hline Suecia & 9,6 & 9,8 & 10,6 & 12,3 & 11,1 & 10,1 & 11,2 & 11,0 & 11,3 & 10,8 & 10,9 & 10,5 & 9,9 & 10,0 & 15,2 & 9,5 \\
\hline Venezuela & 20.7 & $\ldots$ & $\ldots$ & 19,9 & $\ldots$ & 18,9 & 17.9 & 16,9 & 15,3 & 14,5 & 14,5 & $\ldots$ & 13,7 & 13,7 & 13,6 & $\ldots$ \\
\hline
\end{tabular}

Fonte: Nactos Unidas, 1999

(...) Dados nalo disponiveis 
Na maior parte dos países para os quais se dispõe de informações sobre causas de morte, observa-se que as quedas aparecem como as principais no grupo dos demais acidentes. Em alguns, porém, os afogamentos são os mais importantes, como Argentina, Colômbia e México, especialmente entre a população masculina. Nos países do Leste europeu - Estônia, Hungria, Letônia, Lituânia, Polônia, Rússia e Ucrânia - muitos tipos de acidentes apresentam: elevados coeficientes de mortalidade, destacando-se os envenenamentos acidentais, os causados por fogo e chamas e o grupo que congrega todos os demais acidentes.

\section{A mortalidade por suicidios}

Os coeficientes de mortalidade por suicídios, são pouco importantes em vários países, especialmente da América Latina - com exceção de Cuba -, mas muito elevadas em outros, situando-se ao redor de 32 óbitos por $100 \mathrm{mil}$ habitantes, na Hungria, entre 37 e 40 por 100 mil, na Estônia, Letônia e Rússia e 46 por 100 mil na Lituânia e no Turcomenistão na metade da década de 90 . Os coeficientes eram elevados também na Finlândia, na Eslovênia, no Cazaquistão, na Ucrânia e na Bielorússia, com coeficientes de 27 a 30 por 100 mil, constituindose em alguns deles, na principal causa de morte violenta (Tabela 17). Isto tem sido motivo de grande preocupação em vários desses países chegando a ser considerado, na Estônia, um "problema de Saúde Pública". Segundo a Organização Mundial da Saúde, os coeficientes de mortalidade aproximaram-se de 85 óbitos por 100 mil habitantes entre a população masculina da Lituânia, em 1995; sendo o maior entre todos os países analisados.

Em Cuba o coeficiente estava próxima de 20 óbitos por 100 mil pessoas, em 1995, sendo superior em cerca de 6 vezes á do Brasil; três vezes à da Argentina $e$ duas vezes às do Uruguai $e$ à da Holanda e semelhante àqueles registrados para a Bélgica e a Áustria.

Devido à alta incidência de suicidios, muitos paises, entre os quais destacam-se França, Inglaterra, Irlanda e Lituânia, têm adotado, já há vários anos, 
medidas que visam diminuir estes coeficientes de mortalidade. No caso da França, ressaltam-se aquelas referentes a sensibilização (formação de profissionais médicos, educadores e assistentes sociais), ajuda moral e social (postos de escuta e de acolhida), melhorias dos serviços de urgência (ambulâncias, leitos de reanimação, controle de medicamentos), ajuda e tratamento psicológico, campanhas contra o alcoolismo e criação de comissões regionais e estudos de prevenção (CHESNAIS, 1980). Na Lituânia, as medidas assemelham-se às da França, acrescentando-se a disponibilização de maiores recursos para o tratamento das doenças mentais. A meta da Lituânia é reduzir o coeficiente de mortalidade de 46,8 óbitos por 100 mil entre as pessoas com mais de 15 anos, registrado em 1995, para 25 por 100 mil em 2005 (THE LITHUANIAN HEALTH PROGRAMME 2000). Até o momento, no entanto, os resultados obtidos ainda têm sido modestos, observando apenas uma ligeira diminuição nos coeficientes de mortalidade.

Em relação a outros países, encontram-se alguns resultados mais positivos, ainda que os coeficientes mantenham-se elevados. Na Hungria, o coeficiente passou de cerca de 45 óbitos por 100 mil habitantes no final da década de 80, para 32 por 100 mil em 1995 enquanto na Suécia decresceu de 19 para 15 por 100 mil, no mesmo período. Em outros países, no entanto, como França, Áustria, Bélgica e Finlândia os coeficientes permaneceram com certa constância e em níveis elevados, situando-se em torno de 20 óbitos por 100 mil habitantes. Nos países que compunham a antiga União Soviética, como Rússia, Estônia, Lituânia e Letônia, além dos altos coeficientes, registram-se consideráveis aumentos na década de 90.

Ainda que não se disponha de uma série mais contínua de informações, tem-se ressaltado muito a situação observada na China, onde os suicídios aparecem como a principal causa de morte violenta, cujos coeficientes tornam-se ainda mais elevados na área rural. Segundo informações da Organização Mundial de Saúde, em 1992, esse coeficiente era de 23,2 por 100 mil entre os homens que viviam na área rural da China, enquanto para as mulheres chegava a 30,6 por 100 mil (OMS 1994). Este comportamento faz com que a China seja o único país onde 
as taxas de mortalidade femininas por suicídios sejam superiores às masculinas e estaria vinculado às poucas perspectivas econômicas, à depressão e maus tratos (JIMENEZ 1998).

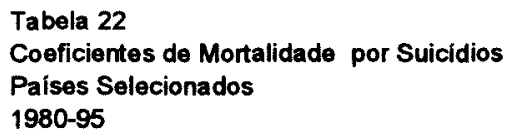

Por 100 mil habitantes

\begin{tabular}{|c|c|c|c|c|c|c|c|c|c|c|c|c|c|c|c|c|}
\hline Paises & 1980 & 1981 & 1982 & 1983 & 1984 & 1985 & 1986 & 1987 & 1988 & 1989 & 1990 & 1991 & 1992 & 1993 & 1994 & 1995 \\
\hline Alemanha & 20,9 & 21,7 & 21,3 & 21,3 & 20,5 & 20,7 & 19,0 & 19,0 & 17,6 & 18,5 & 17,5 & 17,5 & 16,7 & 15,6 & 15,6 & 15,8 \\
\hline Argentina & 7,0 & 7,7 & 6,9 & 6,3 & 6,3 & 6,6 & 7,5 & 7,4 & 7,5 & 7,1 & 6,6 & 5,9 & 6,6 & 6,6 & 6,7 & 6,4 \\
\hline Austrália & 10,9 & 11,2 & 11,7 & 11,2 & 11,0 & 11,6 & 12,4 & 13,8 & 13,1 & 12,3 & 12,9 & 13,2 & 12,9 & 11,5 & 12,8 & 12,0 \\
\hline Áustria & 25,6 & 26,9 & 27,3 & 27,0 & 26,9 & 27,7 & 28,3 & 27,3 & 24,4 & 24,9 & 23,6 & 22,6 & 22,3 & 21,3 & 22,1 & 22,2 \\
\hline Bélgica & 22,1 & 21,9 & 21,9 & 22,8 & 23,8 & 22,3 & 22,2 & 22,7 & 20,2 & 19,3 & 19,0 & 18,1 & 18,7 & $\cdots$ & 21,2 & ... \\
\hline Brasil & 3,3 & 3,4 & 3,2 & 3,6 & 3,4 & 3,2 & 3,2 & 3,4 & 3,2 & 3,2 & 3,4 & 3,5 & 3,5 & 3,7 & 3,9 & 4,2 \\
\hline Canadá & 14,0 & 14,0 & 14,3 & 15,1 & 13,7 & 12,9 & 14,5 & 13,5 & 13,0 & 12,8 & 12,2 & 12,8 & 13,0 & 13,1 & 12,8 & 13,4 \\
\hline Colômbia & $\ldots$ & 3,5 & $\ldots$ & ... & 3,8 & 3,6 & 3,5 & 3,1 & 3,0 & 2.7 & 2,7 & 3,1 & 3,3 & 3,3 & 3,5 & 3,0 \\
\hline Costa Rica & 5,4 & 4,3 & 3,9 & 5,4 & 4,7 & 5,0 & 4,8 & 4,3 & 5,0 & 5,8 & 5,7 & 4,5 & 5,2 & 5,5 & 5,0 & 6,3 \\
\hline Espanha & 4,4 & 4,6 & 4,9 & 5,7 & 6,5 & 6,5 & 7,1 & 7,2 & 7,6 & 7,7 & 7,5 & 7,5 & 7,1 & 7,8 & 8,1 & 8,6 \\
\hline Estônia & $\ldots$ & 36,7 & 32,3 & $\ldots$ & $\ldots$ & 30,9 & 27,7 & 25,6 & 24,5 & 25,6 & 27,1 & 27,0 & 32,2 & 38,2 & 41,0 & 40,1 \\
\hline Estados Unidos & 11,8 & 12,0 & 12,2 & 12,1 & 12,4 & 12,3 & 12,8 & 12,7 & 12,4 & 12,2 & 12,4 & 12,2 & 11,9 & 12,0 & 11,9 & 11,7 \\
\hline Finlândia & 25,7 & 23,8 & 24,1 & 24,4 & 25,2 & 24,6 & 26,6 & 27,6 & 28,3 & 28,5 & 30,3 & 29,8 & 28,8 & 27,6 & 27,3 & 27,2 \\
\hline França & 19,3 & 19,5 & 20,9 & 21,8 & 22,0 & 22,7 & 22,6 & 21,8 & 20,7 & 20,8 & 20,1 & 20,2 & 20,3 & 21,2 & 20,8 & $\cdots$ \\
\hline Grácia & 3,3 & 3,3 & 3,5 & 3,7 & 3,9 & 4,1 & 3,9 & 4.1 & 4,0 & 3,8 & 3,4 & 3,7 & 3,4 & 4,0 & 3,4 & 3,5 \\
\hline Holanda & 10,1 & 10,0 & 10,7 & 12,0 & 12,4 & 11,3 & 11,0 & 11,0 & 10,3 & 10,2 & 9,7 & 10,7 & 10,5 & 10,2 & 10,3 & 9,8 \\
\hline Hungria & 44,9 & 45,6 & 43,5 & 45,9 & 45,9 & 44,4 & 45,3 & 45,6 & 41,9 & 42,3 & 39,9 & 38,6 & 38,7 & 35,9 & 35,3 & 32,9 \\
\hline Israel & 6,0 & 5,3 & 5,2 & 6,0 & 5,4 & 5,5 & 6,5 & 6,2 & 6,8 & 7,8 & 6,5 & 7,3 & 7,4 & 7,1 & 7.7 & 6,5 \\
\hline Italia & 7,4 & 7,0 & 7,4 & 7,6 & 7,8 & 8,3 & 8,2 & 7,9 & 7,6 & 7,5 & 7,6 & 7,8 & 8,0 & 8,2 & $\ldots$ & $\ldots$ \\
\hline Japāo & 17,6 & 17,1 & 17,4 & 20,9 & 20,3 & 19,4 & 21,1 & 19,5 & 18,6 & 17,2 & 16,3 & 16,0 & 16,8 & 16,5 & 16,7 & $\cdots$ \\
\hline Letônia & $\ldots$ & 33,5 & 34,3 & $\cdots$ & $\ldots$ & 29,4 & 25,3 & 23,3 & 23,1 & 25,7 & 26,0 & 28,4 & 35,0 & 42,5 & 40,7 & 40,7 \\
\hline Lituânia & $\ldots$ & 33,6 & 33,9 & $\ldots$ & $\ldots$ & 34,1 & 25,5 & 29,1 & 26,6 & 27,1 & 26,0 & 30,5 & 34,6 & 42,1 & 45,8 & 45,6 \\
\hline México & 1,4 & 1,7 & 1.6 & 1.4 & 1,3 & 2,0 & 2,2 & 2,1 & 2,1 & 2,2 & 2,3 & 2,4 & 2,5 & 2,6 & 2,8 & 3,2 \\
\hline Noruega & 12,4 & 12,8 & 14,0 & 14,6 & 14,5 & 14,1 & 13,9 & 15,5 & 16,8 & 15,6 & 15,5 & 15,8 & 14,4 & 13,7 & 12,3 & $\cdots$ \\
\hline Portugal & 7,4 & 7,9 & 8,4 & 9,8 & 10,2 & 9,7 & 9,2 & 9,6 & 8,2 & 7,5 & 8,8 & 9,5 & 8,8 & 7,9 & 7,7 & 8,2 \\
\hline Reino Unido & 8,7 & 8,9 & 8.6 & 8,6 & 8.7 & 8,9 & 8,2 & 8.1 & 8,7 & 7,6 & 8,1 & 7,9 & 8,0 & 7,2 & 7,0 & 6,9 \\
\hline Rússia & $\ldots$ & 34,2 & 35,1 & $\cdots$ & $\ldots$ & 31,2 & 23,3 & 23,1 & 24,3 & 25,8 & 26,5 & 26,6 & 31,1 & 37,9 & 41,8 & 41,2 \\
\hline Suécia & 19,4 & 17,5 & 19,4 & 19,0 & 19,5 & 18,2 & 18,5 & 18,3 & 18,8 & 18,6 & 17,2 & 17,2 & 15,6 & 15,7 & 15,1 & 15,3 \\
\hline Venezuela & 4,8 & 4,3 & 4,3 & 4,8 & $\ldots$ & 4,5 & 4,6 & 4,2 & 4,6 & 4,8 & 5,0 & $\ldots$ & 4,7 & 4,6 & 5,1 & \\
\hline
\end{tabular}

(...) Dados nåo disponiveis

$\mathrm{Na}$ América, os maiores coeficientes de mortalidade por suicidios têm sido registrados em Cuba, com cerca de 20 óbitos por 100 mil pessoas, superando 
países como Canadá, Trinidad-Tobago e Estados Unidos (YUNES e ZUBAREW(1999).

Os menores coeficientes foram observados para Brasil, Colômbia e México, com 3 a 4 óbitos por 100 mil pessoas.

Em todos os países da América, os coeficientes masculinos mostravam-se bem superiores aos da população feminina.

\section{A mortalidade por homicídios}

Outro grande desafio que vem sendo enfrentado nos últimos anos, especialmente pelos países que se encontram em desenvolvimento e também alguns do Leste europeu, refere-se ao crescimento da criminalidade, que em termos de mortalidade reflete-se principalmente no aumento dos homicídios. Enquanto em vários países, especialmente da Europa e também Canadá, Austrália, Israel e Nova Zelândia, os coeficientes de mortalidade por homicídios mantêm-se, há vários anos próximos de 1 a 2 óbitos por 100 mil pessoas, em outros superavam na metade da década de 90, a 20 óbitos por 100 mil, como Brasil, Porto Rico, Armênia, El Salvador e Rússia, e alcançavam 80 óbitos por 100 mil na Colômbia (Tabela 17).

A exemplo do que ocorre nos países com elevados coeficientes de mortalidade por suicidios, a adoção de diversas medidas ainda não têm dado os resultados esperados $\mathrm{e}$, em alguns a situação tem-se agravado ainda mais nos últimos anos. Estes são os casos do Brasil, onde o coeficiente passou de cerca de 11 por 100 mil para aproximadamente 20 por 100 mil na década de 80 , na Colômbia (de 33 por 100 mil para quase 90, no início dos anos 90) e na Rússia, Estônia, Letônia e Lituânia cujos os coeficientes chegaram a triplicar ou duplicar em poucos anos, depois do esfacelamento da União Soviética (Tabela 22).

A redução desses coeficientes é um processo muito complexo, pois depende de um conjunto de medidas cujos resultados geralmente aparecem apenas em médio e longo prazos. Entre estas ações estão o combate ao alcoolismo, à corrupção, ao tráfico de drogas e ao crime organizado, o controle de 
armas, o aumento de efetivos policias e de equipamentos especializados, o treinamento técnico e pessoal, as melhorias das condições sociais e a geração de empregos.

\begin{tabular}{|c|c|c|c|c|c|c|c|c|c|c|c|c|c|c|c|c|}
\hline & & & & & & & & & & & & & & \multicolumn{3}{|c|}{ Por 100 mil habitantes } \\
\hline Palses & 1980 & 1981 & 1982 & 1983 & 1984 & 1985 & 1986 & 1987 & 1988 & 1989 & 1990 & 1991 & 1992 & 1993 & 1994 & 1995 \\
\hline Alemanha & 1,2 & 1,3 & 1,2 & 1,2 & 1,2 & 1,2 & 1,2 & 1,1 & 1,1 & 0,9 & 1,0 & 1,1 & 1,2 & 1,2 & 1,2 & 1,1 \\
\hline Argentina & 3,5 & 3,8 & 4,2 & 4,2 & 4.7 & 4,9 & 5.6 & 5,4 & 5,6 & 5,9 & 5.0 & 4,3 & 4,6 & 4,4 & 4,6 & 4,3 \\
\hline Austrália & 1,9 & 1,9 & 1,9 & 1,9 & 1,9 & 2,0 & 2,0 & 2.0 & 2,0 & 1,8 & 2,2 & 2,0 & 1,7 & 1,8 & 1,8 & 1,6 \\
\hline Áustria & 1,2 & 1,3 & 1,5 & 1,7 & 1,8 & 1,4 & 1,3 & 1,3 & 1,2 & 1,1 & 1,6 & 1,3 & 1,5 & 1,3 & 1,2 & 1,0 \\
\hline Bálgica & 1,5 & 1,4 & 1,5 & 1,8 & 1,7 & 2,1 & 2,1 & 1,6 & 1,6 & 1,4 & 1,4 & 1,4 & 1,7 & $\cdots$ & 1,8 & $\ldots$ \\
\hline Brasil & 11,7 & 12,6 & 12,6 & 13,8 & 15,3 & 15,0 & 15,3 & 16.9 & 16,8 & 20,3 & 22,2 & 20,9 & 19,1 & 20,2 & 21,2 & 23,9 \\
\hline Canadá & 2,1 & 2,3 & 2,4 & 2,4 & 2,3 & 2,1 & 2,0 & 2,1 & 1,8 & 2,0 & 2,0 & 2,2 & 2,1 & 1,8 & 1,7 & 1,7 \\
\hline Colombia & $\cdots$ & 37,4 & $\cdots$ & $\cdots$ & 33,3 & 43,1 & 50,8 & 51.0 & 60,5 & 68,1 & 74,4 & 89,6 & 89,9 & 87,0 & 80,0 & 60,8 \\
\hline Costa Rica & 5,8 & 4,7 & 4,3 & 3,9 & 4.7 & 4,9 & 4.0 & 4,7 & 4,0 & 4.4 & 4,8 & 4,5 & 5,5 & 5,5 & 5,6 & 5,4 \\
\hline Espanha & 1,0 & 0,9 & 0,8 & 1,0 & 1,2 & 1,1 & 1,1 & 1,2 & 0,9 & 0.9 & 1,0 & 0,9 & 0,9 & 1,0 & 0,9 & $\ldots$ \\
\hline Estonia & $\cdots$ & 8,5 & 8,2 & $\cdots$ & $\cdots$ & 6,6 & 6 & 5,7 & 6,0 & 7,8 & 11,0 & 10,8 & 19,6 & 25.8 & 28,2 & 22,2 \\
\hline Estados Unidos & 10,5 & 10,2 & 9,5 & 8,5 & 8,2 & 8,2 & 8,9 & 8,6 & 8,9 & 9,1 & 9,8 & 10,4 & 9,8 & 9,9 & 9,4 & 8,6 \\
\hline Finlandia & 3,3 & 2,7 & 2,8 & 3,1 & 2,7 & 2,7 & 3,3 & 2,7 & 2,8 & 3,2 & 3,2 & 3,1 & 3,4 & 3,3 & 3,2 & 2,9 \\
\hline França & 1.0 & 1,0 & 1,1 & 1,3 & 1,3 & 1,3 & 1,2 & 1.1 & 1,0 & 1,1 & 1,1 & 1.1 & 1,0 & 1,1 & 1,1 & $\cdots$ \\
\hline Grécia & 0,7 & 0,8 & 0,9 & 0,8 & 0,9 & 1,1 & 0,9 & 0,8 & 1,1 & 0,8 & 1,1 & 1,4 & 1,2 & 1,3 & 1,1 & 1,3 \\
\hline Holanda & 0,8 & 0,8 & 0,8 & 0,9 & 0,9 & 0,9 & 1,0 & 0,9 & 0,9 & 1,0 & 0,9 & 1,2 & 1,3 & 1,3 & 1,1 & 1,2 \\
\hline Hungria & 2,6 & 2,5 & 2,4 & 2,5 & 2,6 & 2,7 & 2,8 & 2,5 & 2,7 & 3,0 & 3,1 & 4,0 & 4,0 & 4,1 & 3,5 & 3,5 \\
\hline |srael & 1,8 & 1.9 & 1,7 & 2,0 & 1,4 & 2,1 & 1,8 & 1,3 & 1,3 & 2,4 & 1,7 & 1,2 & 1.1 & 2,3 & 2,2 & 1,4 \\
\hline Italia & 1,9 & 1,9 & 2,1 & 1,9 & 1,6 & 1.5 & 1,3 & 1,6 & 1,9 & 2,2 & 2,6 & 2,9 & 2,2 & 1,7 & $\ldots$ & $\cdots$ \\
\hline Japao & 1,0 & 1,0 & 0,9 & 1,0 & 0,9 & 0.8 & 0,8 & 0,8 & 0,7 & 0,6 & 0,6 & 0,6 & 0,6 & 0.6 & 0,6 & $\cdots$ \\
\hline Letỏnia & $\cdots$ & 7.1 & 6,0 & $\cdots$ & $\cdots$ & 5,3 & 4,3 & 4.4 & 5,9 & 8,8 & 9,2 & 11,5 & 16,0 & 24,7 & 23,0 & 18,2 \\
\hline Lituânia & $\cdots$ & 6,7 & 6.5 & $\cdots$ & $\cdots$ & 6,0 & 4,9 & 3,8 & 4,6 & 5,7 & 7,5 & 9.1 & 10,5 & 12,5 & 13,4 & 11,7 \\
\hline México & 17,6 & 17,7 & 17,9 & 17,0 & 47,9 & 18,6 & 19,9 & 19,3 & 18,3 & 18,2 & 17,5 & 17,2 & 18,5 & 17,6 & 17,0 & 17,2 \\
\hline Noruega & 1.1 & 1,3 & 1,0 & 1,2 & 1,1 & 1,0 & 1,6 & 1,4 & 1,2 & 1,3 & 1,2 & 1.5 & 1,1 & 1,0 & 0,8 & $\ldots$ \\
\hline Portugal & 1,3 & 1,2 & 1,3 & 1,5 & 1,7 & 1,4 & 1,4 & 1,3 & 1,4 & 1,5 & 1,7 & 1,6 & 1,5 & 1,5 & 1,5 & 1,6 \\
\hline Reino Unido & 0,8 & 0,4 & 0,7 & 0,6 & 0,7 & 0,7 & 0,7 & 1,0 & 1,0 & 1,1 & 0,7 & 0.7 & 0,9 & 1,0 & 0,7 & 0,7 \\
\hline Rússıa & $\ldots$ & 12,9 & 12,7 & $\cdots$ & $\cdots$ & 10,5 & 7,8 & $\cdots$ & 9,8 & 12,6 & 14,3 & 15,3 & 22,9 & 30,4 & 32,4 & 30,6 \\
\hline Suécia & 1,2 & 1,4 & 1,2 & 1,2 & 1,1 & 1,2 & 1,4 & 1,2 & 1,4 & 1,5 & 1,3 & 1,4 & 1,3 & 1,3 & 1,2 & 1,0 \\
\hline Venezuela & 11,7 & 9,7 & 11,5 & 12,9 & $\ldots$ & 9.4 & 8,0 & 7,8 & 8,8 & 12,1 & 13,0 & $\ldots$ & 13,2 & 14,8 & 15,7 & \\
\hline
\end{tabular}

YUNES e ZUBAREW (1999) destacam que vários países da América apresentam elevados coeficientes de mortalidade por homicidios. A situação mais conhecida é a da Colômbia, cujo coeficiente duplicou entre 1984 e 1988, passando de pouco mais de 30 óbitos por 100 mil para 60 por 100 mil. Em Porto Rico, Brasil e Venezuela, registraram-se também significativos aumentos, com os coeficientes chegando a cerca de 23 óbitos por 100 mil nos dois primeiros países. 
Já nos Estados Unidos, ocorreu diminuição após 1993, fato observado também na Argentina, a partir de 1989. O menor coeficiente de mortalidade corresponde ao Canadá, ficando em todo o período em torno de dois óbitos por 100 mil pessoas, seguido pela Argentina e Uruguai, com cerca de cinco óbitos por 100 mil pessoas, em meados dos anos 90 .

\section{Panorama Geral}

Diante do exposto, observa-se portanto que a mortalidade provocada por acidentes, suicidios e homicídios tem atingido níveis muito elevados em vários países, aparecendo como fato muito preocupante para suas populações e seus governos. Especialmente complexa é a situação de vários países da América Latina, onde o crescimento da criminalidade tem provocado consideráveis elevações dos níveis de mortalidade, principalmente entre os jovens. Este fato deve-se, principalmente, ao aumento dos homicídios, sendo a Colômbia o caso mais conhecido. Entretanto, outros países, como El Salvador, Brasil, Venezuela e México, a situação tem se agravado consideravelmente nos últimos anos.

No início dos anos 90 , três causas violentas - os acidentes de veículos a motor, homicidios e suicídios - apareciam entre as dez principais nos Estados Unidos, sendo que a violência chegou a ser considerada epidemia no país (SOUZA 1993).

Deve-se ressaltar ainda que, mesmo naqueles países com coeficientes globais de mortalidade relativamente baixos, existe a preocupação de reduzir os seus niveis. Isto porque, além de representar melhoria na qualidade de vida de seus habitantes, muitas vezes, pelo menos uma das causas pode ser reduzida quando comparada ao nivel observado em outros países. Exemplo dessa situação é o Japão, onde os coeficientes de mortalidade por homicídios e por acidentes de veículos são muito baixos, mas o de suicídios é bastante elevado. Em países que apresentavam algumas das taxas globais mais baixas dessas causas, como Israel, Holanda e Reino Unido, os suicídios e alguns tipos de acidentes registravam coeficientes de mortalidade relativamente elevados. 
A situação do Brasil, como foi destacada, é ainda mais complexa, pois, entre as causas externas, somente os suicídios e alguns tipos de acidentes são menores que a da maioria dos países. A mortalidade por acidentes de veículos ainda aparece elevada e a de homicídios situa-se entre as maiores do mundo.

\section{São Paulo e o Brasil no panorama mundial}

Como se pôde observar a situação do Brasil mostra-se muito complexa em um contexto mundial, pois entre as causas externas de morte, somente os suicidios e alguns tipos de acidentes possuem coeficientes menores que aqueles verificados para a maioria dos países. A mortalidade por acidentes de veículos a motor ainda aparece elevada e a de homicidios situa-se entre as maiores do mundo. A presença dos homicídios entre as principais causas de morte, com significativos percentuais e coeficientes de mortalidade, é um fator que torna esse panorama ainda mais difícil. Reconhece-se que, entre as causas externas, essas estão entre as mais difíceis de serem controladas e as medidas adotadas para tal fim geralmente apresentam resultados somente a médio e longo prazos. Quando se analisam as informações para o Estado de São Paulo e algumas de suas regiōes, verifica-se que a situação mostra-se ainda mais crítica. Além da Região Metropolitana que tradicionalmente apresentava altos coeficientes de mortalidade por homicídios, outras regiões também vêm apresentando grande crescimento desta taxa.

\section{Homicídios}

Quando se comparam os coeficientes de mortalidade por homicídios do Estado e de suas regiōes com outros países, verifica-se que somente a Colômbia encontrava-se na frente de muitas delas. Regiões como a Metropolitana de São Paulo, Santos, São José dos Campos e Ribeirão Preto apareciam entre as de maiores coeficientes. A Região de Campinas apresentava coeficiente semelhante ao da Rússia e a de Registro possuía taxa parecida com a do México. Mesmo as 
regiões com menores coeficientes de mortalidade ficavam com taxas próximas dos Estados Unidos, Cuba e Paraguai, mas muito acima de vários países europeus, do Japão e do Canadá.

Em relação aos coeficientes de mortalidade por homicídios segundo grupos etários, a situação permanece semelhante àquela verificada quando se comparam vários países (Gráfico 32 e Tabela 32 do Anexo).

O padrão é semelhante em todas as áreas apresentadas, com a ocorrência de coeficientes de mortalidade mais elevados nos grupos jovens, especialmente de 15 a 34 anos. O que diferencia as áreas são as taxas, que mostram-se muito altas em São Paulo, especialmente para os homens. Na maior parte dos grupos etários, os coeficientes de mortalidade da Região Metropolitana de São Paulo e do Estado de São Paulo, para a população masculina, mostram-se muito elevados, ficando abaixo apenas dos correspondentes à Colômbia. Os coeficientes do interior do Estado, embora estivessem bem abaixo das duas áreas anteriores, também são elevados, assemelhando-se aos da Rússia, que enfrenta grandes problemas de criminalidade. Somente para os homens de 5 a 14 anos e com mais de 55 anos que os coeficientes dos paises aproximam-se em niveis mais baixos.

Para as mulheres as taxas de mortalidade por homicídios são mais baixas, que aquelas registradas para a população masculina. Entretanto, quando comparadas aos de outros países, os coeficientes observados em São Paulo mostram-se, mais uma vez elevados, sendo menores apenas que os da Colômbia e Rússia. As taxas do interior do Estado estavam próximas das observadas para o México. 
Gráfico 32

Coeficientes de Mortalidade por Homicídios segundo Sexo e Grupos de Idade Países Selecionados e Estado de São Paulo

1992-98

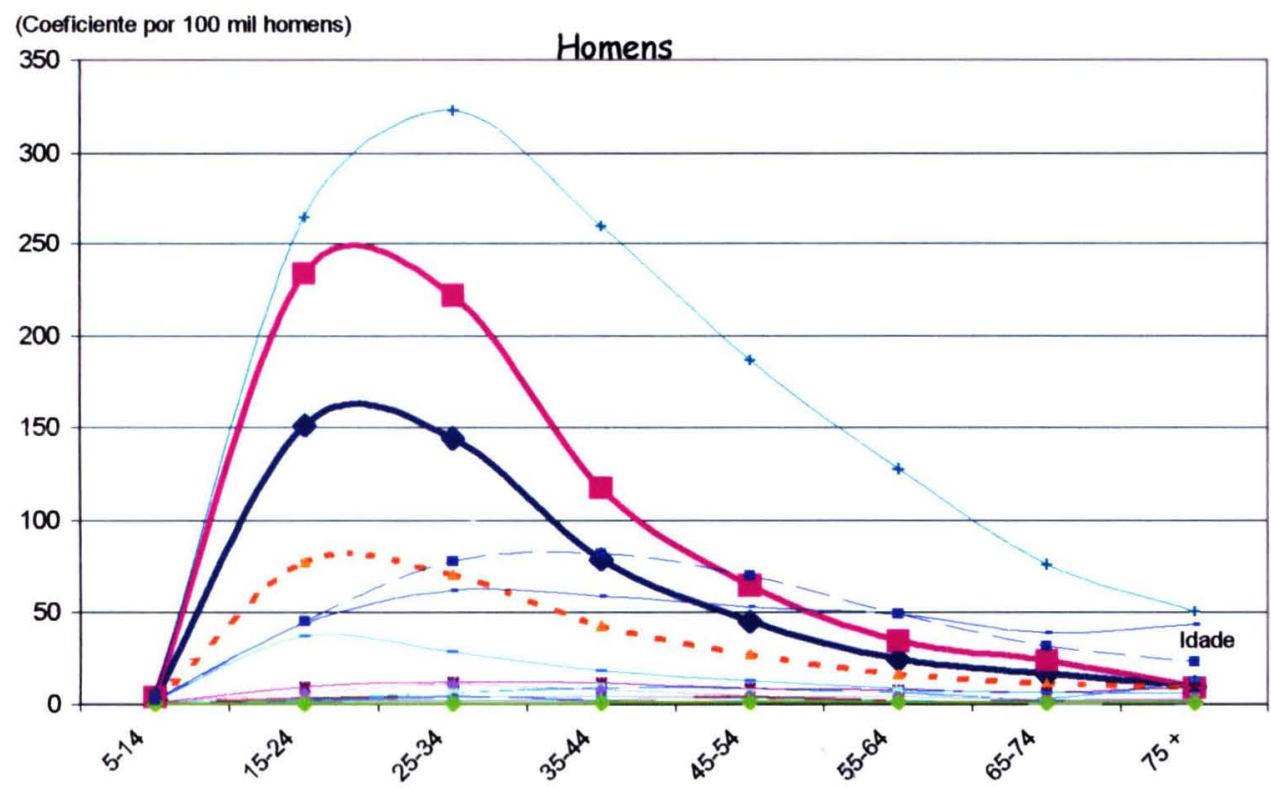

(Coeficiente por 100 mil mulheres) Mulheres

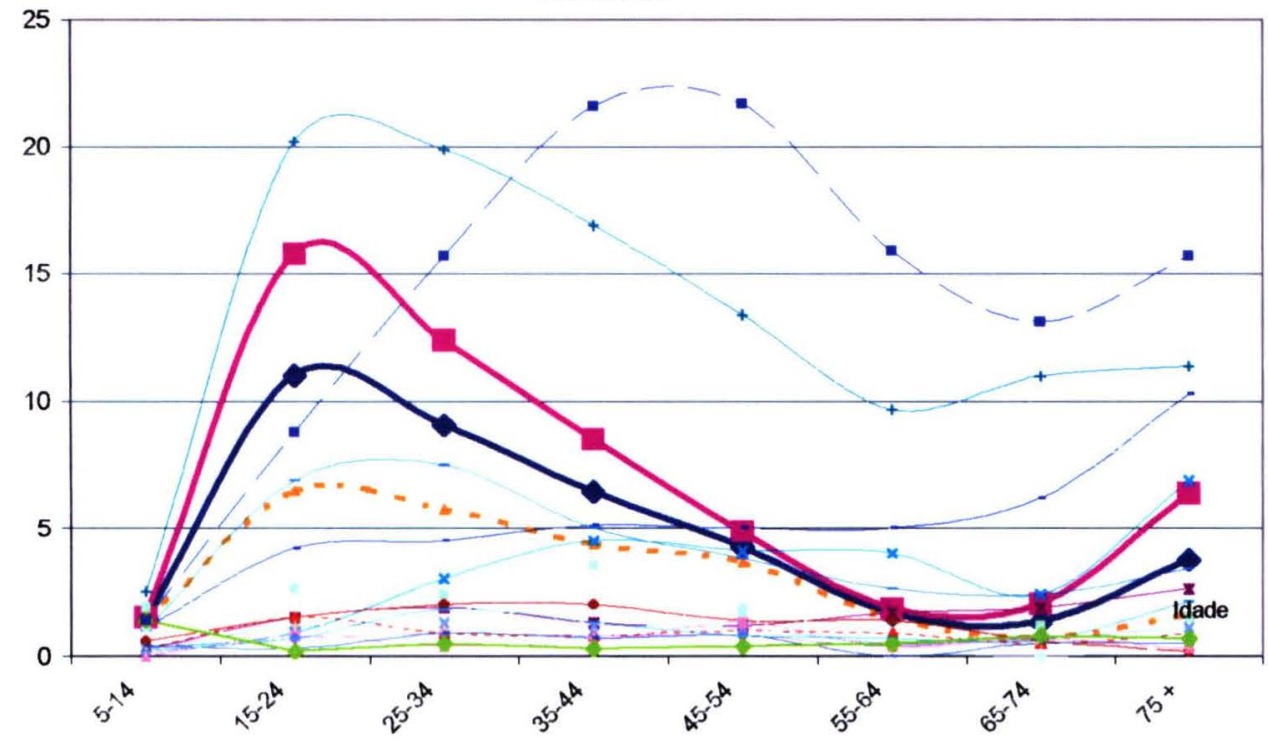

\begin{tabular}{|c|c|c|}
\hline 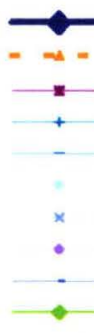 & $\begin{array}{l}\text { Estado de São Paulo } \\
\text { Interior de São Paulo } \\
\text { Argentina } \\
\text { Colômbia } \\
\text { EUA } \\
\text { Finlândia } \\
\text { Alemanha } \\
\text { Itália } \\
\text { Noruega } \\
\text { Japão }\end{array}$ & $\begin{array}{cl} & \text { RMSP } \\
* & \text { Hungria } \\
- & \text { Canada } \\
& \text { México } \\
& \text { Dinamarca } \\
* & \text { França } \\
\text { Grécia } \\
\text { Holanda } \\
\text { - Portugal } \\
\text { - Rússia }\end{array}$ \\
\hline
\end{tabular}

Fontes: Organização Mundial de Saúde e Fundação Seade. 


\section{Acidentes de Veículos a Motor}

Em relação aos acidentes de veículos a motor, observa-se que os coeficientes correspondentes à região de Registro não encontram similar entre os países que dispunham de informações. As regiōes de Barretos, Marília, São José dos Campos, Ribeirão Preto e São José do Rio Preto também apresentavam altos coeficientes de mortalidade por acidentes de transportes em 1998-99, superando quase todos os paises selecionados. $O$ coeficiente de mortalidade por acidentes de transportes, da Região Metropolitana de São Paulo era o menor entre as regiōes de São Paulo, mas ainda assim superava em quase duas vezes 0 de países como Canadá, Dinamarca e Alemanha e em cerca de três vezes aqueles referentes ao Reino Unido e á Suécia.

O padrão etário mostrava-se, mais uma vez, muito semelhante entre os países e as áreas de São Paulo (Gráfico 33 e Tabela 33 do Anexo).

Para os homens e mulheres, os coeficientes de mortalidade aumentavam até 15 a 24 anos e depois apresentam certa diminuição ou mantêm-se constantes até 55 anos, quando voltam a crescer consideravelmente. As taxas de mortalidade são muito elevadas entre as pessoas mais idosas, especialmente para aqueles com mais de 75 anos.

Mais uma vez chama a atenção os coeficientes de mortalidade por acidentes de veículos a motor mais elevados, para o Estado de São Paulo quando comparados aos paises relacionados. As taxas registradas para o interior são as mais altas, especialmente para a população masculina, sendo superadas apenas por aquelas referentes a Portugal e à Grécia nas faixas dos jovens, e à Rússia entre os adultos. Para as mulheres, os coeficientes estavam em posições intermediárias, abaixo dos Estados Unidos, México, Alemanha e Rússia. 


\section{Gráfico 33}

Coeficientes de Mortalidade por Acidentes de Veículos a Motor segundo Sexo e Grupos de Idade Paises Selecionados e Estado de São Paulo

1992-98
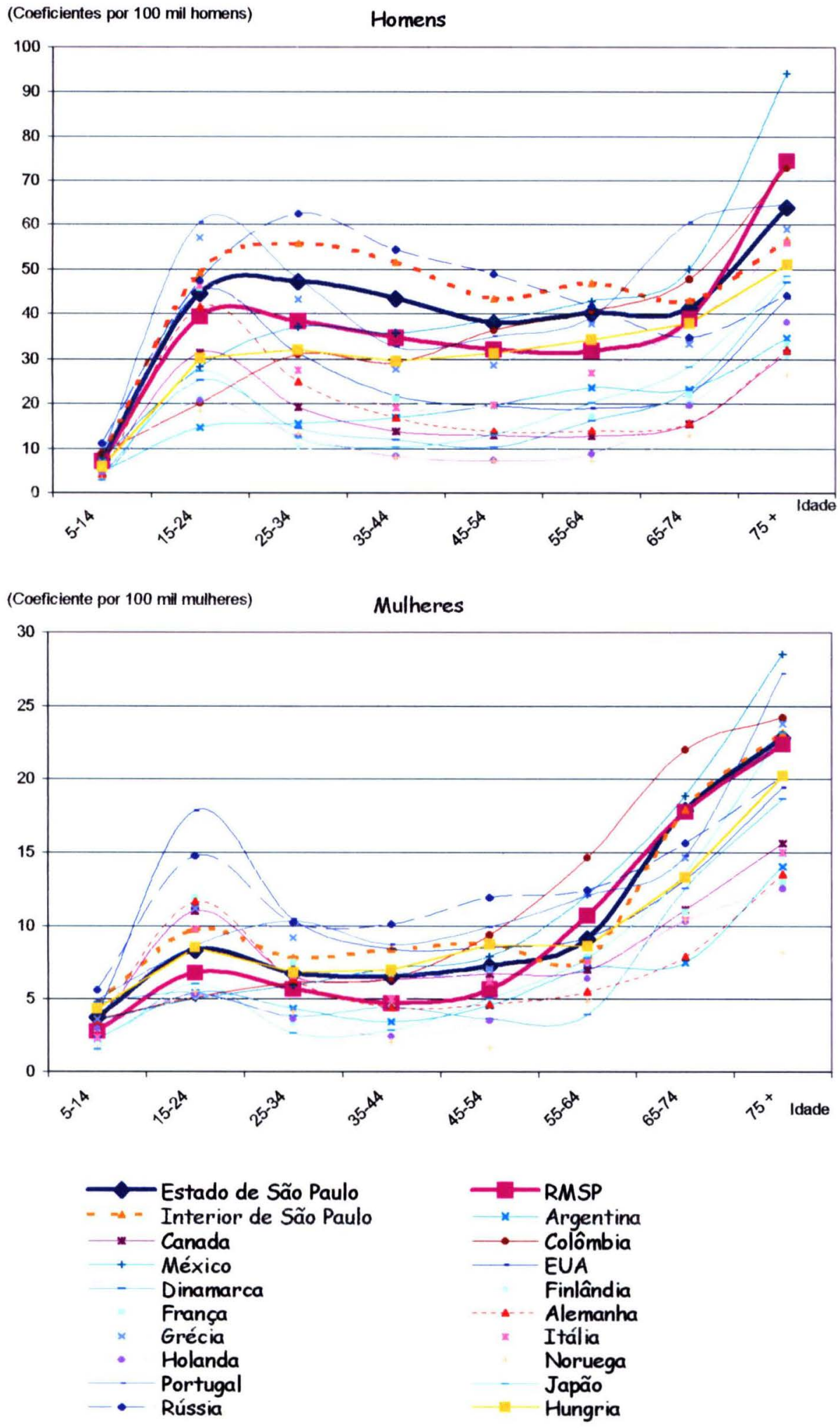

Fontes: Organização Mundial de Saúde e Fundação Seade. 


\section{Suicídio}

Para a mortalidade por suicídio, a situação do Estado de São Paulo é muito distinta da maior parte dos países. Os maiores coeficientes do Estado de São Paulo correspondiam às regiões Central e de Presidente Prudente, semelhantes aos observados na Espanha, Itália, Reino Unido e Argentina. Por outro lado, as regiões de Sorocaba, São José dos Campos, Ribeirão Preto, Santos, Campinas e a Região Metropolitana de São Paulo estavam entre aquelas com os menores coeficientes de mortalidade por suicídio do mundo. Somente o México, a Nicarágua, a Grécia e a Colômbia estavam em patamares pouco abaixo dessas regiōes. Entre os países, a Rússia, a Finlândia e a Hungria eram os que apresentavam os maiores coeficientes de mortalidade, com tendência de aumento nas idades mais avançadas, fato que se repete na maior parte dos países e também em São Paulo (Gráfico 34 e Tabela 34 do Anexo).

Para as mulheres, os coeficientes eram bem inferiores aos dos homens, também havendo tendência de aumento com a idade, especialmente nos países que apresentam maior mortalidade por suicídio. Entre esses, destacam-se novamente a Finlândia, a Hungria e a Rússia, além do Japão, da Alemanha e da França, especialmente entre as mais idosas. 
Gráfico 34

Coeficientes de Mortalidade por Suicídios segundo Sexo e Grupos de Idade

Países Selecionados e Estado de São Paulo

1992-98
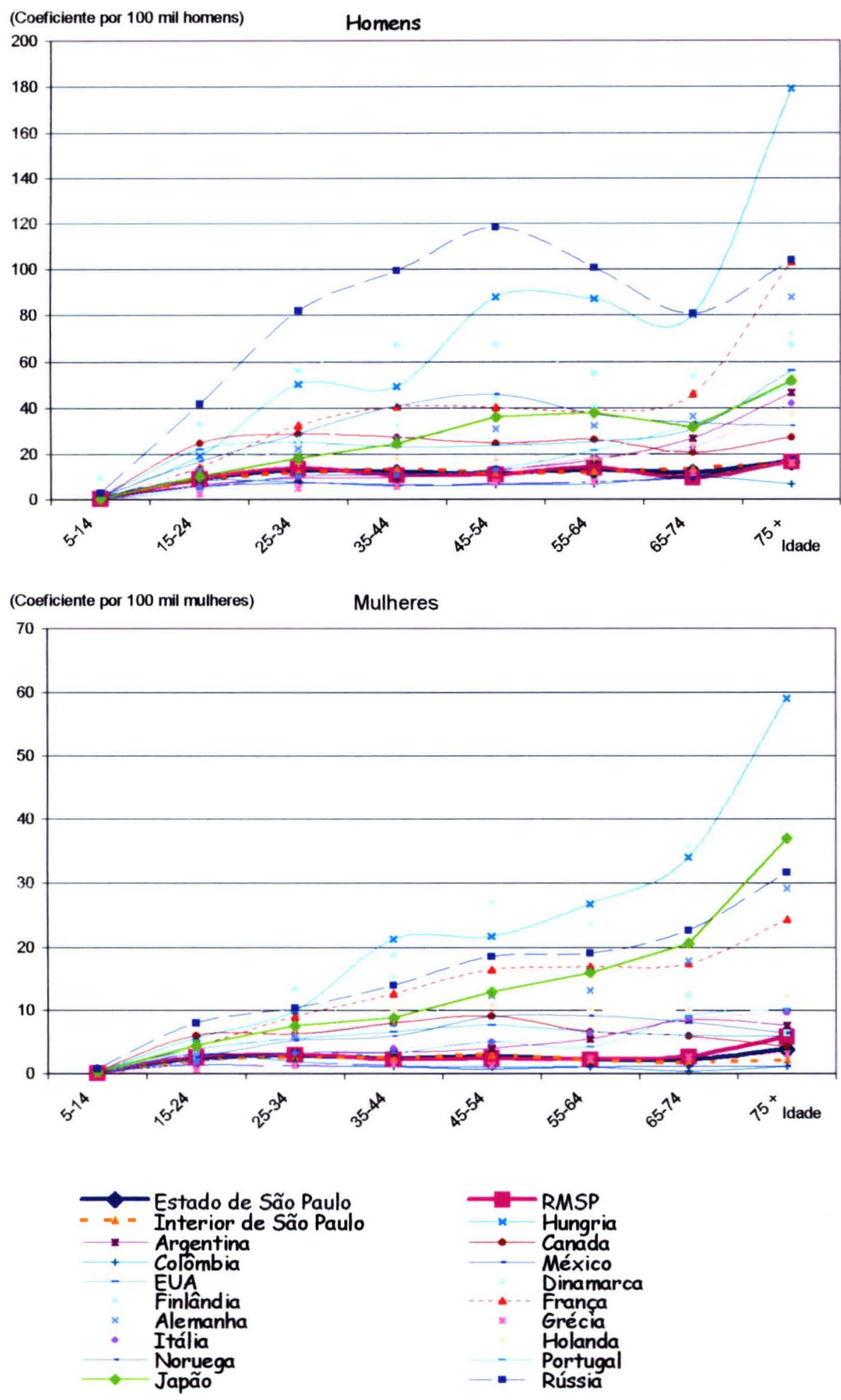

Fontes: Organização Mundial de Saúde e Fundação Seade. 


\section{Panorama Geral}

Constata-se, portanto, que os coeficientes de mortalidade por homicidios e por acidentes de veículos a motor, para muitas regiões de São Paulo, apresentam niveis muito elevados quando comparados a outros países. Ao se considerarem os municipios, as diferenças são ainda maiores, especialmente para os homicídios. Para os acidentes de veículos a motor, essa diferença não é tão acentuada, mas não se observam municipios com coeficientes baixos como os de alguns países europeus, o que indica uma situação muito insatisfatória em todo o Estado de São Paulo.

Os resultados mostram a necessidade de reduzir os coeficientes de mortalidade por causas externas no Brasil e no Estado de São Paulo. A taxa de mortalidade por estas causas, na Região de Franca - a menor do Estado - era quase duas vezes maior que as observadas no Reino Unido e na Holanda. Os maiores coeficientes como os das regiões de Santos, RMSP e Registro equiparam-se aos de alguns paises com elevados níveis de mortalidade como os do Leste europeu - como a Letônia e a Bielorússia - da Colômbia e da Hungria e são um pouco menores que os da Lituânia, Estônia, Ucrânia e, principalmente, da Rússia, que apresentavam os maiores niveis entre os que dispunham de informações. 


\section{CONSIDERAÇÕES FINAIS}


Entre os vários paises da América Latina, a situação do Brasil aparece entre as mais preocupantes, com as taxas de mortalidade por causas externas tendo passado de cerca de 50 óbitos por 100 mil habitantes, no final dos anos 70 , para quase 80 por 100 mil, na metade da década de 80 . Analogamente ao que se observa em outros paises, a população masculina tem sido mais atingida por este crescimento da violência. As taxas de mortalidade por causas externas, entre os homens, aumentou de cerca de 80 por 100 mil, no final dos anos 70 , para cerca de 120 , no final dos anos 80 , mantendo-se desde então nesse patamar. Para as mulheres, os coeficientes, embora tenham apresentado certa elevação, mantêm-se próximos de 25 óbitos por 100 mil, nestes últimos 20 anos.

Observa-se que grande parte do aumento registrado principalmente para a população masculina deve-se aos homicídios, pois alguns tipos de acidentes, inclusive de veículos, diminuiram nos últimos anos. Os coeficientes de mortalidade por homicídios têm aumentado de forma quase contínua desde o final dos anos 70 , passando de 10 óbitos por 100 mil habitantes para cerca de 30 por 100 mil duas décadas depois. Deve-se ressaltar, ainda, que os homicídios constituem-se na principal causa de morte externa no país, desde o final dos anos 80 , superando as demais causas externas.

Outras causas violentas também têm sido importantes, como os acidentes de veículos a motor, que somente nos últimos dez anos provocaram a morte de cerca de 300 mil pessoas. Os atropelamentos correspondem a uma de suas principais causas, atingindo especialmente as pessoas mais idosas. Em um pais onde o processo de envelhecimento tende a se tornar muito intenso nos próximos anos, isto pode ganhar dimensões ainda maiores. $O$ mesmo pode-se dizer sobre a mortalidade provocada pelas quedas, que atinge de forma muito significativa a população idosa, especialmente as mulheres.

No caso do Estado de São Paulo, o panorama é muito semelhante ao do Brasil, porém algumas causas aparecem de forma mais intensa. Em relação ao total das causas externas de morte, os coeficientes também apresentam 
crescimento entre 1970 e 1999, passando de 60 para 100 óbitos por 100 mil habitantes, com grande aumento a partir do início dos anos 80 . Para os homens, as taxas elevaram-se de 100 para 160 óbitos por 100 mil, ficando cerca de $25 \%$ acima da média nacional. Entre as causas violentas, os homicídios aparecem, desde o início dos anos 80 , na primeira colocação, com crescimento muito acentuado a partir do final dos anos 70 , quando os coeficientes passam de menos de 10 óbitos por 100 mil habitantes, para mais de 40 por 100 mil, em 1999. Esta taxa é muito elevada quando comparada às de outros paises como a Rússia, com 26 óbitos por 100 mil habitantes em 1996, ou mesmo El Salvador, com 27 por 100 mil em 1991. Quando se observam os niveis de países mais desenvolvidos, a razão fica entre 20 e 40, o que mostra a gravidade da situação. Para outras causas, como os acidentes em geral, os niveis são elevados, mas com diferenciais muito menores que os registrados para os homicídios. Nos últimos anos houve inclusive redução dos coeficientes, sendo que, no caso dos acidentes de veículos a motor, tem-se citado o Código Nacional de Trânsito como o principal responsável. No Estado de São Paulo, a diminuição dos coeficientes de mortalidade por acidentes de trânsito chegou a $20 \%$ entre 1998 e 1999. Os suicídios são a causa violenta com menor importância e com níveis muito abaixo dos observados em países como os do leste europeu, Hungria, Finlândia, Japão e mesmo Cuba.

Quando se analisa a situação nas regiōes do Estado, constata-se grande heterogeneidade, tanto na distribuição das causas como nos níveis e na própria evolução no decorrer do tempo. Em relação às taxas globais, verifica-se que estas são muito maiores nas regiōes de Registro e na RMSP e em seu entorno. Nos últimos anos os coeficientes correspondentes à Região de Santos aproximaram-se de 140 óbitos por 100 mil, cerca de $60 \%$ superior à média estadual. Em Registro verificam-se também taxas próximas de 120 óbitos por 100 mil, pouco acima daquela observada na Região Metropolitana de São Paulo. Tem ocorrido crescimento importante também nas regiões de São José 
dos Campos, Ribeirão Preto e Campinas, enquanto no oeste do Estado e nas regiões de Franca e na Central a expansão tem sido menos intensa.

A exemplo do Brasil, observa-se que os homicidios são os principais responsáveis por tais aumentos, principalmente nas regiōes citadas acima, com exceção de Registro, onde o crescimento da mortalidade por causas externas deve-se aos acidentes de transporte. Quando se observam as tabelas e os mapas que mostram as situações mais críticas, verifica-se a importância da Região Metropolitana de São Paulo, que possui vários de seus municípios relacionados. Outras áreas com elevados coeficientes têm-se formado no Estado, nestes últimos anos, principalmente no entorno de Campinas e de Santos.

Entre os municípios com as maiores coeficientes de mortalidade por homicídios destacam-se Diadema, Embu e Itapecerica da Serra, com mais de 90 óbitos por 100 mil habitantes, entre 1997 e 1999.

Observando-se o panorama da mortalidade por acidentes de transporte, constatam-se os elevados riscos de mortalidade para a população que vive próxima aos grandes eixos rodoviários. Chama a atenção, particularmente, o caso daqueles municípios situados às margens da Rodovia Régis Bittencourt, pelos altos níveis de mortalidade, sem paralelo em termos de países. Os coeficientes de mortalidade por acidentes de transporte, em municípios como Miracatu, Juquiá, Juquitiba e Registro, ultrapassam 50 óbitos por 100 mil habitantes, em 1997-99.

Elevadas taxas de mortalidade por causas externas também são observadas nas regiões de Santos e Registro devido aos demais acidentes. Estas são áreas com municípios litorâneos, onde os afogamentos representam importante causa.

Já os suicídios são um pouco mais importantes nas áreas do extremo oeste do Estado, como Jales e Adamantina. 
Assim, os elevados niveis de mortalidade por causas externas observados em algumas regiōes do Estado, até com sobreposição de algumas delas, causam importante impacto sobre a esperança de vida.

Para os homens, a eliminação das causas violentas representaria, na maior parte dos casos, pelo menos dois anos a mais nesse indicador. Em. regiões como Santos, porém, chegaria até a 4,7 anos, nível superior ao observado na RMSP, onde alcançaria 4,0 anos. Em Registro, esse ganho também seria superior a 4 anos, enquanto em São José dos Campos, Ribeirão Preto e Campinas ultrapassaram a 3 anos. Na maior parte dessas regiões, este impacto está relacionado aos homicídios, que aparecem como a principal causa externa de morte, como na Região Metropolitana de São Paulo, onde, isoladamente, representavam 2,6 anos de vida, ou em Santos, com 2,2 anos. Em outras áreas do Estado, ainda que os homicídios sejam importantes, seria a eliminação das mortes por acidentes que provocaria maior impacto sobre a esperança de vida ao nascer.

Assim, para que esse indicador continue a aumentar em São Paulo e em suas regiões nos próximos anos, é importante a implantação de medidas voltadas à redução de tais causas. Nos últimos anos, o crescimento das taxas de mortalidade por causas violentas fez com que algumas regiões apresentassem diminuição da esperança de vida ao nascer da população masculina, como ocorreu em Registro, Santos, Ribeirão Preto e São José dos Campos, entre 1980 e 1997, enquanto na RMSP este indicador permaneceu constante, fato que é incompatível com o nível de desenvolvimento dessas áreas. 


\section{BIBLIOGRAFIA}


Akerman M, Stephens C, Campanário P, MAIA PB. Saúde e meio ambiente. Uma análise de diferenciais intra-urbanos enfocando o Municipio de São Paulo: resultados finais. Revista de Saúde Pública 1994; 28(4):320-5.

Akerman M. Metodologia de construção de indicadores compostos: um exercício de negociação intersetorial. In: Barata RB, coordenador. Condições de vida e situação de saúde. 1996.

Albuquerque FRPC, Oliveira JC. Aspectos gerais da evolução dos óbitos por causas externas no Brasil. In: Componentes da dinâmica demográfica brasileira. Rio de Janeiro: IBGE; 1996 (Textos Selecionados)

Altmann AMG, Ferreira CEC. Evolução do censo demográfico e Registro Civil como fontes de dados para a análise de fecundidade e mortalidade no Brasil.(Dados coletados e estudos realizados). Revista Brasileira de Estatística 1979; 40(160):399-454.

Altmann AMG, Ferreira CEC. A situação dos registros vitais no Brasil..São Paulo: SEADE; 1982. (Informe Demográfico,7).

Antar N. União oferece ajuda para combater violência. O Estado de São Paulo São Paulo 24/03/01 (Cidades)

Arriaga E. América Latina: descenso de la mortalidad por sexo y edades y sus consecuencias sobre fecundidad. Conferencia Regional Latinoamericano de Población Mexico agosto 1970

Arriaga E. La mortalidad adulta en paises en desarrollo: una vision general. Notas de Población 1995; 23(61).

Barbosa LM, Andrade FCD. Aplicação das técnicas de riscos competitivos à mortalidade do Brasil e macrorregiões. In: Anais do XI Encontro Nacional de Estudos Populacionais; 2000 out 23-27; Caxambu-Brasil. Belo Horizonte: ABEP; 2000.

Barbosa V. Estudo descritivo do suicídio no Município de São Paulo . Revista de Saúde Pública 1974; 8:1-14. 
Brasil. Ministério da Agricultura, Indústria e Commercio. Annuario Estatístico do Brazil - 1908 -1912. Rio de Janeiro: 1916.

Bueno E. A viagem do descobrimento. Porto Alegre: Objetiva; 1998 140p.

Camarano AM, Beltrão KI, Araújo HE, Pinto MS Transformaçōes no padrão etário da mortalidade brasileira em 1979-1994 e seu impacto na força de trabalho. Brasilia:IPEA, 1997 (Texto para Discussão, 512)

Camargo ABM, MAIA PB. O comportamento recente da mortalidade em São Paulo, 1980-1993. In: Anais do IX Encontro Nacional de Estudos Populacionais; 1994 out 07-11; Belo Horizonte:ABEP;1994 v.1 p.73-97.

CAMPINAS. Prefeitura Municipal Observatório de Qualidade de Vida_dez. 1996

Cassorla RMS. Do suicídio: estudos brasileiros. Campinas: Papirus; 1991

Cassorla RMS , Smeke ELM. Autodestruição humana. Cadernos de Saúde Pública 1994; 10 (supl):61-73.

Castro MMP. Assassinatos de crianças e adolescentes no Estado de São Paulo. Revista Crítica de Ciências Sociais 1993; 36:81-102.

Causas de Morte nos Paises Desenvolvidos Disponível em: (http://www.cmv.pt) Acesso em 20/12/01

CEDEC Mapa de risco da violência: cidade de Salvador. São Paulo: 1997. CEDEC Mapa de risco da violência: cidade de Curitiba. São Paulo: 1996. CEDEC Mapa de risco da violência: cidade de Rio de Janeiro. São Paulo: 1997.

CEDEC Mapa de risco da violência: cidade de São Paulo. São Paulo: 1996.

Cesar IA, Rodrigues RN. A Transição Epidemiológica no Recife:1929-1990. In: Anais do IX Encontro Nacional de Estudos Populacionais; 1994 out 07-11; Caxambu, Brasil. Belo Horizonte: ABEP; 1994 v.1 p. 23-41.

Cesar IA, Rodrigues RN. A mortalidade por causas externas entre os adolescentes de Recife e Salvador nos anos 80 In: Anais do XI 
Encontro Nacional de Estudos Populacionais; 1998 out 19-23; Caxambu,Brasil. Belo Horizonte: ABEP; 1998 p.1947-1958.

Chesnais JC. A Violência no Brasil. Causas e recomendações políticas para sua prevenção. Ciência \& Saúde Coletiva 1999; 4(1):53-69.

Chesnais JC. Histoire de la violence en Occident de 1800 à nos jours. Paris: R. Laffont; 1981.

Chiang CL. Introduction to stocastic process in biostatistic. New York: John Wiley \& Sons: 1968.

Chiang CL. A stochastic study of the life table and its applications: I. Probability distributions of the biometric functions. Biometrics 1970; 25(4):767-76.

Chiang CL. Competing risks and conditional probabilities. Biometrics 1970; 25(4):767-76.

Coelho EC. A criminalidade urbana violenta. Dados . Revista de Ciências Sociais 1988; 31(2):145-83.

Cruz OG. Homicídios no Rio de Janeiro: análise da distribuição espacial e sua evolução. São Paulo; 1996. (Dissertação de Mestrado - Faculdade de Saúde Pública da USP).

Dachs JN. Violência em algumas capitais brasileiras: um exemplo de análise exploratória de dados. Revista Brasileira de Estatística 1980; 41:119136.

Durand J. Estimativas Históricas da População Mundial. In: Marcilio ML. Coordenador Demografia Histórica: orientações técnicas e metodológicas (uma análise), São Paulo: Novos Umbrais; 1977 p.199-247.

Editora Abril. Brasil 500 Anos São Paulo; 1998

Ferreira CEC. Tábuas abreviadas de mortalidade para o Estado de São Paulo - 1939/41, 1949/51, 1959/61 e 1969/71. São Paulo:SEADE; 1980 (Informe Demográfico,4). 
Ferreira CEC , Castiñeiras LL. O rápido aumento da mortalidade dos adultos jovens em São Paulo: uma trágica tendência. São Paulo em Perspectiva 1996; 10(2):34-41.

Ferreira CEC , Castiñeiras LL. Está diminuindo a esperança de vida paulista? In: Anais do XI Encontro Nacional de Estudos Populacionais; 1998 out 19-23; Caxambu, Brasil. Belo Horizonte:ABEP; 1998 p.1961-1974.

Ferreira CEC , Castiñeiras LL. Tábuas de vida regionais para o Estado de São Paulo 1997/1998/99 São Paulo; 2000 (mimeografado)

Fonseca LAM Mameri CP. Mortalidade por câncer no Estado de São Paulo. São Paulo: SEADE; 1994.

Frenk J, Lozano R , Bobadilla JL. La Transición Epidemiológica en América Latina. Notas de Población 1994; 22(60):79-101.

FUNDAÇÃO DE DESENVOLVIMENTO ADMINISTRATIVO Características regionais de saúde no Estado de São Paulo. São Paulo: FUNDAP; 1983.

FUNDAÇAO OSWALDO CRUZ Porque dados? Radis. Dados 1982. I.

FUNDAÇAO OSWALDO CRUZ Mortalidade nas capitais brasileiras: 19301980. Radis. Dados 1984.

FUNDAÇAO OSWALDO CRUZ Mortalidade por causas externas no Brasil . Radis. Dados 1985; 8

FUNDAÇAO OSWALDO CRUZ Regiões metropolitanas. violência na vida e na morte. Radis. Dados 1990; 14

FUNDAÇAO SEADE O Jovem na Grande São Paulo. São Paulo:SEADE; 1988 (Coleção Realidade Paulista,2).

Gawryszewski VP, A Mortalidade por causas externas no Municipio de São Paulo 1991. São Paulo; 1995 [Dissertação de Mestrado - Faculdade de Saúde Pública da USP].

Gawryszewski VP, Drumond Jr. M. A morte violenta no município de São Paulo em 1991. In: Relatório de participação da Secretaria Municipal de 
Saúde no II Congresso Brasileiro de Epidemiologia. São Paulo: Secretaria Municipal de Saúde ;1992.

Glover J. Humanity - A moral history of the twentieth century. Yale University Press; 2000

Gotlieb SLD. Mortalidade diferencial por causas: São Paulo. 1970. [Tese

Doutorado - Faculdade de Saúde Pública da USP].

Guedes ACD. A evolução da mortalidade por causas de morte no Distrito Federal entre 1980 e 1990. In: Anais do X Encontro Nacional de Estudos Populacionais; 1996 out 07-11; Caxambu, Brasil. Belo Horizonte: ABEP; 1996 v.4 p.1989-2016.

Henry L. Técnicas de análise em demografia histórica. Curitiba: Universidade Federal do Paraná; 1977.

Instituto Fernando Braudel de Economia Mundial Ranking da criminalidade nos maiores municipios de São Paulo Disponivel em: (http://braudel.org.br/ranking.htm). Acesso em 11/07/01

Irish Holocaust Disponivel em: (http://www.noraid.com/) Acesso em: 20/12/01 Jimenez D. China no logra frenar la epidemia de suicidios femeninos. Disponivel em: http://www.el-mundo.es) Acesso em: 21 nov 2000

Laurenti R. Transição demográfica e transição epidemiológica. In: Anais do $1^{\circ}$ Congresso Brasileiro de Epidemiologia; 1990; Campinas, Brasil Campinas; 1990 p.143-65.

Laurenti R, Guerra MAT, Baseotto, RA. Klincervicius MT. Alguns aspectos epidemiológicos da mortalidade por acidentes de veículos a motor na cidade de São Paulo, Brasil. Revista de Saúde Pública 1972; 6(4):339341.

Lira MMTA, Drumond Jr M. A mortalidade por causas externas no Brasil Brasilia: FUNASACENEPI; 2000(Estudos Epidemiológicos)

Machado CJ, Rigotti, Jl. Esperança de Vida e causas de morte em Belo Horizonte e na periferia da Região Metropolitana de Belo Horizonte - 1985- 
90. In: Anais do X Encontro Nacional de Estudos Populacionais; 1996 out 07-11; Caxambu-Brasil. Belo Horizonte: ABEP; 1996 v.4 p.2017-2051. Maia, PB. O Impacto das mortes violentas na esperança de vida do Município de São Paulo. (1979/1981 - 1990/1992). São Paulo; 1999 [Dissertação de Mestrado - Escola Paulista de Medicina da UFSP].

Massena RMR. A distribuição espacial da criminalidade violenta na Região Metropolitana do Rio de Janeiro. Revista Brasileira de Geografia 1986; 48(3):285-331.

Mattelart A. Manual de Analisis Demografico Santiago de Chile: Universidad Catolica de Chile 1964

Mello Jorge, MHP. Mortalidade por causas violentas no Município de São Paulo. São Paulo; 1979. [Tese de Doutorado - Faculdade de Saúde Pública da USP].

Mello Jorge MHP. Mortalidade por causas violentas no Município de São Paulo, Brasil:I- Mortes violentas no tempo. Revista de Saúde Pública 1980; 14(3):343-357.

Mello Jorge MHP. Mortalidade por causas violentas no Município de São Paulo, Brasil:Il- mortes acidentais. Revista de Saúde Pública 1980; 14(4):475-508.

Mello Jorge MHP. Mortalidade por causas violentas no Município de São Paulo, Brasil:III- mortes Intencionais. Revista de Saúde Pública 1981; 15(2):165-193.

Mello Jorge MHP. Mortalidade por causas violentas no Município de São Paulo, Brasil:IV: a situação em 1980. Revista de Saúde Pública 1982; 16(1):19-41.

Mello Jorge MHP, Gawryszewski VP, Latorre MRDO. Análise dos dados de Mortalidade. Revista de Saúde Pública 1997; 31(Supl):5-25. 
Mello Jorge MHP. Como morrem nossos jovens. In: Jovens acontecendo na trilha das políticas públicas. Brasília: Comissão Nacional de População e Desenvolvimento; 1998 p.209-289.

Merrick T W, Graham DH População e Desenvolvimento no Brasil. Rio de Janeiro: Zahar, 1981.

Minayo MCS Bibliografia comentada da produção científica brasileira sobre violência e saúde. Rio de Janeiro: Fundação Oswaldo Cruz; 1990

Minayo MCS. A violência na adolescência: um problema de saúde pública., Cadernos de Saúde Pública 1990; 6(3):278-292.

Minayo MCS. A violência social sob a perspectiva da saúde pública. In: 0 Impacto da violência social sobre a saúde. Cadernos de Saúde Pública 1994; 10(supl, 1):07-18.

Minayo MCS., Souza ER. Violência para todos. Cadernos de Saúde Pública 1993; 9(1):7-18.

MINISTÉRIO DA SAÚDE. Estatísticas de mortalidade, Brasil, 1977/96. Brasilia, DF:1980-98.

MINISTÉRIO DA SAÚDE. Política nacional de redução da morbimortalidade por acidentes e violências. Brasília, DF:2001.

Monteiro MFG. Atlas de mortalidade do estado do Rio de Janeiro, segundo seis grupos de causas de morte. In: Anais do $X$ Encontro Nacional de Estudos Populacionais; 1996 out 07-11; Caxambu-Brasil. Belo Horizonte: ABEP;1996 v.4 p.2073-2091.

Moreira MM. Estimativa do Registro de Óbitos no Brasil em 1979. São Paulo, 1982 (mimeografado).

Mortara G. Nota sobre a vida média nos diversos estados do Brasil. In: Contribuiçōes para o estudo da demografia do Brasil. Rio de Janeiro: IBGE; 1961 p.97-110.

Nações Unidas Demographic Yearbook 1994 . New York:1995. 
Nações Unidas. Health and mortality issues of global concern. New York: 1999 467p.

Omran AR. The epidemiologic transition: a theory of the epidemiology of population change. Memorial Fund Quaterly 1971; 49(1):509-38.

Omran AR. La Transicion epidemiologica. Una teoria de la epidemiologia del cambio poblacional. Atención Médica 1972;1:38-74.

Omran AR. A century of epidemiological transition in the United States. Preventive Medicine 1977; 6:30-51.

Omran AR. The Epidemiological transition theory. A preliminary update. Journal of Tropical Pediatrics 1983; 29:305-316.

OMS. Classificação Internacional de Doenças: $9^{a}$ Revisão 1975. São Paulo. Organização Mundial de Saúde / Centro Brasileiro de Classificação de Doenças, 1985.

OMS. World Health Statistics Annual 1994 Genève 1995

Ortiz LP. Mortalidade por causas evitáveis no Estado de São Paulo. 1975/76. São Paulo: SEADE, 1980 p.161-212 (Informe Demográfico,4).

Ortiz LP. Avaliação das estatísticas de menores de 1 ano. São Paulo; SEADE, 1983 p.33-68 (Informe Demográfico,8).

Ortiz LP. O Modelo de riscos competitivos no estudo da mortalidade infantil., Caxambu, 1998. In: Anais do XI Encontro Nacional de Estudos Populacionais; 1998 out 19-23; Caxambu-Brasil. Belo Horizonte:ABEP; 1998 p. 1793-1802.

Ortiz LP, Yazaki LM. Tábuas de mortalidade para o Estado e Regiões Administrativas de São Paulo, 1979/81. São Paulo: SEADE, 1984. p.1117 ( Informe Demográfico, 14).

Ortiz, LP, Yazaki, LM. Evoluçăo Recente da Mortalidade no Estado de São Paulo. São Paulo: SEADE, 1984. p.161-212 (Informe Demográfico,14). 
Ortiz LP, Yazaki LM. Tábuas de mortalidade por causas, 1979/81. São Paulo: SEADE; 1985 (Informe Demográfico,15) p. 15:145-186.

Paes N A. Tábua de vida de múltiplo decremento: o modelo de Chiang. São Paulo: 1982. [Dissertação de Mestrado - Instituto de Matemática e Estatistica da USP).

Paes NA. A mortalidade por causas no Brasil: qualidade e comportamento dos dados. In: Anais do XI Encontro Nacional de Estudos Populacionais; 1998 out 19-23; Caxambu-Brasil. Belo Horizonte: ABEP; 1998.

Paim J, Costa M. As desigualdades na distribuição dos óbitos no Município de Salvador, 1980. Cadernos de Saúde Pública 1986; 2\{3\}:312-333.

Paiva TM. Mortalidade por Causas Externas no Municipio de Santos. São Paulo; 1998. [Tese de Mestrado - Faculdade de Saúde Pública da USP].

Prata PR. A Transição epidemiológica no Brasil. Cadernos de Saúde Pública 1992; 8\{2\}:168-75.

Ramos R., Barbosa V. Estudos sobre a mortalidade por suicídio. Arquivos da Faculdade de Higiene 1965; 19:33-66.

Retratos do Brasil. A situação da infância brasileira. São Paulo: Política Editora de Livros, Jornais e Revistas Ltda, 1985

Ribeiro MAR. História sem fim... inventário da saúde pública. São Paulo: UNESP; 1993.

Ruzicka LT. The use of mortality and morbidity statistics for national health promotion. Londres: WHO; 1990.

Santo $\mathrm{AH}$. Equivalência entre revisão da Classificação Internacional de Doenças: causas básicas e múltiplas de morte Revista de Saúde Pública 2000; 34(1):21-28.

Santos JLF, Ortiz LP, Yazaki LM. Aplicação da técnica de riscos competitivos a dados brasileiros. São Paulo: SEADE; 1985 (Informe Demográfico,15) p. 15:5-44. 
São Paulo (Estado) Secretaria de Estado da Saúde São Paulo Mortalidade Materna e na Infância no Estado de São Paulo de 1960 a 1970 São Paulo; 1975

Sawyer DRTO. Mortalidade In: Santos JLF compilador, Levy MSF compilador Szmrecsanyi T compilador. Dinámica da População: teoria, métodos e técnicas de análise. São Paulo: TA Queiroz; 1980 p.209-235

Silveira MH, Gotlieb SLD. Acidentes, envenenamentos e violências como causa de morte dos residentes no município de São Paulo, Brasil. Revista de Saúde Pública 1970; 10: 45-55.

Singer P, Campos O., Oliveira EM. Prevenir e curar: o controle social através dos serviços de saúde. Rio de Janeiro: Forense Universitária; 1978.

Soares KVS, Cano EN, Mari JJ. Mortalidade por causas externas entre os jovens de São Paulo. In: Anais do Primeiro Congresso Brasileiro de Epidemiologia; Anais do Terceiro Congresso Ibero-Americano de Epidemiologia e Anais do Segundo Congresso Latino Americano de Epidemiologia; 1995; Salvador: ABRASCO/SIAE/ALAMES. p. 310 (Resumo).

Souza ER. Violência velada e revelada: estudo epidemiológico da mortalidade por causas externas em Duque de Caxias, Rio de Janeiro; Rio de Janeiro; 1991. [Dissertação de Mestrado - Escola Nacional de Saúde Pública ]

Souza E. Homicídios no Brasil: o grande vilão da saúde pública na década de 80. In: O impacto da violência social sobre a saúde. Cadernos de Saúde Pública 1994; 10 (supl.1): 45-60.

Souza ER., Minayo MC. O impacto da violência social na saúde pública do Brasil: década de 80. In: Minayo MCS. coordenador. Os muitos Brasis: saúde e população na década de 80 . São Paulo: HUCITEC/ABRASCO; 1995 p. 87-116. 
Sposati A. Mapa da exclusão/inclusão social da cidade de São Paulo. São Paulo: Educ; 1996.

Szwarcwald CL, Castilho EA. Mortalidade por causas externas no estado do Rio de Janeiro no período de 1976 a 1980 . Cadernos de Saúde Pública $1986 ; 2: 19-41$.

Terremotos Históricos Disponivel em:(http://lobocom.es princesa). Acessado em 09 jun. 2000.

The Black Death: Bubonic Plague Dezembro 1994 (http://byu.edu/ipt/projects/middleages/LifeTimes/Plague.html)

THe Lithuanian Health Programme Disponivel em: (http://sam.It/reform/reform.htm) Acesso em:03/02/00

30 Worst Atrocities of the $20^{\text {th }}$ Century Disponivel em: (http://users.erols.com/mwhite28) Acesso em 15 Dez. 2000

TIME-LIFE. A evolução das cidades Rio de Janeiro; 1993

Vasconcelos AMN. Estatísticas de mortalidade por causas: uma avaliação da qualidade da informação. In: Anais do $X$ Encontro Nacional de Estudos Populacionais; 1996 out 07-11; Caxambu-Brasil. Belo Horizonte: ABEP;1996 v.1 p.151-166.

Vasconcelos AMN. Lima DD A Mortalidade por acidentes de trânsito no Brasil. In: Anais do XI Encontro Nacional de Estudos Populacionais; 1998 out 19-23; Caxambu-Brasil. Belo Horizonte: ABEP; 1998.

Vermelho LL, Mello Jorge MHP. Mortalidade de jovens: análise do período de 1930 a 1991: a transição epidemiológica para a violência. Revista de Saúde Pública 1996; 30(4):319-331.

Waldvogel B, Capassi R. Mortalidade infantil segundo a geração e o sexo: determinação do coeficiente de separação para as regiões paulistas no período 1980-92 São Paulo;1994 (Informe Demográfico,26) p. 119-176 
Wong $O$ A competing risk model based on the life table procedure in epidemiological studies. International Journal of Epidemiology, 1996; 1977; 6(2):153-59.

WORLD HEALTH STATISTICS ANNUAL, 1994 Genève: WHO; 1995.

Yazaki LM. Causas de morte e esperança de vida ao nascer no Estado de São Paulo e Regiōes 1975-83. São Paulo: SEADE; 1990 (Coleção Realidade Paulista).

Yazaki LM, Ortiz LP. Estudo da mortalidade por Causas nas Regiões Brasileiras com base no Registro Civil - Tábuas de Múltiplo Decremento, 1979/80 São Paulo: SEADE; 1985 (Informe Demográfico,15) p. $15: 43-144$

Yazaki LM, Ortiz Flores, LP. A questão da mortalidade infanto-juvenil. In: $\mathbf{O}$ Jovem na Grande São Paulo. São Paulo: SEADE; 1988 p.151-177 (Coleção Realidade Paulista).

Yunes J Primo E. Características da mortalidade em adolescentes brasileiros das capitais das Unidades Federadas. Revista de Saúde Pública 1983; 17:263-78.

Yunes J, Rajs D. Tendencia de la mortalidad por causas violentas en la población general y entre los adolescentes y jóvenes de la región de las Américas . In: O Impacto da violência social sobre a saúde. Cadernos de Saúde Pública 1994; 10(supl1):07-18.

Yunes J, Ronchezel VSC. Evolução da mortalidade geral, infantil e proporcional no Brasil Revista de Saúde Pública 1974; 8(supl): 3-48

Yunes J, Somensi J; Ronchezel VSC. Tendência da mortalidade por causas no Brasil. In: Anais do Encontro Brasileiro de Estudos Populacionais; 1974 ; Rio de Janeiro - Brasil. Rio de Janeiro:IBGE; 1974.

Yunes J, Zubarew T. Mortalidad por causas violentas en adolescentes y jóvenes: un desafio para la región de las Américas. Revista Brasileira de Epidemiologia 1999; 2(3). 
ANEXO 
Tabela 1

Óbitos Segundo as Principais Causas

Capitais Brasileiras

1930-75

Em porcentagem

\begin{tabular}{lrrrrrr}
\hline \multicolumn{1}{c}{ Causas } & \multicolumn{7}{c}{ Anos } \\
\cline { 2 - 7 } & 1930 & 1940 & 1950 & 1960 & 1970 & 1975 \\
\hline & & & & & & \\
Doenças Infecciosas e Parasitárias & 45,6 & 43,5 & 35,9 & 25,9 & 15,7 & 15,1 \\
Neoplasias & 2,7 & 3,9 & 5,7 & 8,1 & 9,7 & 9,8 \\
Doenças do Aparelho Circulatório & 11,8 & 14,5 & 14,2 & 21,5 & 24,8 & 24,0 \\
Doenças do Aparelho Respiratório & 11,5 & 12,1 & 9,1 & 8,0 & 9,0 & 9,8 \\
Doenças do Aparelho Digestivo & 4,5 & 3,8 & 2,4 & 2,5 & 2,5 & 2,5 \\
Causas Externas & 2,6 & 2,4 & 3,3 & 4,8 & 7,5 & 8,3 \\
& & & & & & \\
\hline
\end{tabular}

Fonte: Dados compilados por Mário Magalhães da Silveira a partir de estatisticas de saúde do Ministério da Saúde. 
Tabela 2

Óbitos segundo as Principais Causas

Brasil

1977-98

Em porcentagem

\begin{tabular}{|c|c|c|c|c|c|c|c|c|}
\hline Ano & $\begin{array}{l}\text { Infecciosas e } \\
\text { Parasitárias }\end{array}$ & Neoplasias & $\begin{array}{l}\text { Aparelho } \\
\text { Circulatório }\end{array}$ & $\begin{array}{c}\text { Aparelho } \\
\text { Respiratório }\end{array}$ & $\begin{array}{l}\text { Aparelho } \\
\text { Digestivo }\end{array}$ & Perinatais & $\begin{array}{l}\text { Causas } \\
\text { Externas }\end{array}$ & $\begin{array}{c}\text { End., Nutr., } \\
\text { Metab. e } \\
\text { Transt. Imunit. }\end{array}$ \\
\hline 1977 & 15,8 & 10,2 & 30,9 & 11,2 & 3,9 & 7,2 & 10,8 & 3,6 \\
\hline 1978 & 15,1 & 10,2 & 31,4 & 10,8 & 3,8 & 7,3 & 11,1 & 3,8 \\
\hline 1979 & 12,9 & 10,2 & 31,4 & 10,1 & 4,1 & 9,0 & 11,5 & 4,4 \\
\hline 1980 & 11,8 & 10,4 & 32,1 & 10,1 & 4,3 & 8,8 & 11,9 & 4,3 \\
\hline 1981 & 10,8 & 10,6 & 32,5 & 9,9 & 4,3 & 9,3 & 12,1 & 4,2 \\
\hline 1982 & 10,1 & 11,0 & 32,5 & 9,9 & 4,3 & 9,3 & 12,5 & 4,2 \\
\hline 1983 & 9,5 & 11,1 & 33,2 & 9,8 & 4,4 & 8,8 & 12,9 & 4,2 \\
\hline 1984 & 9,7 & 11,0 & 33,3 & 10,1 & 4,5 & 7,9 & 13,1 & 4,4 \\
\hline 1985 & 8,0 & 11,4 & 34,5 & 10,0 & 4,6 & 7,5 & 13,8 & 4,3 \\
\hline 1986 & 8,0 & 11,4 & 33,5 & 10,4 & 4,7 & 7,1 & 14,9 & 4,3 \\
\hline 1987 & 7,5 & 11,9 & 33,7 & 9,8 & 4,8 & 7,2 & 14,7 & 4,4 \\
\hline 1988 & 7,1 & 11,7 & 34,5 & 10,5 & 4,8 & 6,6 & 14,3 & 4,6 \\
\hline 1989 & 6,8 & 12,1 & 34,4 & 9,9 & 4,8 & 6,2 & 15,4 & 4,7 \\
\hline 1990 & 6,2 & 12,4 & 34,3 & 10,6 & 4,7 & 5,7 & 15,1 & 5,1 \\
\hline 1991 & 5,8 & 13,1 & 34,0 & 9,7 & 5,0 & 5,7 & 15,5 & 5,4 \\
\hline 1992 & 5,8 & 13,3 & 34,1 & 10,3 & 5,0 & 5,3 & 14,6 & 5,8 \\
\hline 1993 & 5,8 & 12,9 & 33,8 & 11,0 & 5,1 & 5,1 & 14,4 & 6,1 \\
\hline 1994 & 5,7 & 13,1 & 33,3 & 11,1 & 5,0 & 5,1 & 14,6 & 6,3 \\
\hline 1995 & 5,2 & 13,2 & 32,7 & 11,1 & 5,0 & 5,1 & 15,3 & 6,6 \\
\hline 1996 & 6,8 & 13,4 & 32,3 & 11,5 & 5,1 & 4,8 & 15,4 & 4,7 \\
\hline 1997 & 6,2 & 13,9 & 32,4 & 10,9 & 5,2 & 4,9 & 15,5 & 4,9 \\
\hline 1998 & 6,2 & 14,0 & 32,4 & 11,6 & 5,2 & 4,6 & 14,9 & 5,0 \\
\hline
\end{tabular}

Fonte: Ministério da Saúde. 
Tabela 3

Óbitos segundo Principais Causas da População Masculina

Brasil

1977-98

Em porcentagem

\begin{tabular}{|c|c|c|c|c|c|c|c|c|}
\hline Ano & $\begin{array}{c}\text { Infecciosas } \\
e \\
\text { Parasitárias }\end{array}$ & Neoplasias & $\begin{array}{l}\text { Endóc., Nutr., } \\
\text { Metab. e } \\
\text { Transt. Imun. }\end{array}$ & $\begin{array}{l}\text { Aparelho } \\
\text { Circulatório }\end{array}$ & $\begin{array}{c}\text { Aparelho } \\
\text { Respiratório }\end{array}$ & $\begin{array}{l}\text { Aparelho } \\
\text { Digestivo }\end{array}$ & Perinatais & $\begin{array}{l}\text { Causas } \\
\text { Externas }\end{array}$ \\
\hline 1977 & 15,6 & 9,8 & 3,0 & 28,6 & 11,0 & 4,4 & 7,3 & 14,7 \\
\hline 1978 & 14,9 & 9,7 & 3,1 & 29,2 & 10,6 & 4,4 & 7,2 & 15,0 \\
\hline 1979 & 12,7 & 9,6 & 3,8 & 29,0 & 10,0 & 4,7 & 8,9 & 15,6 \\
\hline 1980 & 11,6 & 9,8 & 3,6 & 29,6 & 9,8 & 4,9 & 8,7 & 16,3 \\
\hline 1981 & 10,8 & 10,0 & 3,5 & 29,8 & 9,7 & 4,8 & 9,2 & 16,7 \\
\hline 1982 & 9,9 & 10,3 & 3,5 & 30,0 & 9,7 & 4,8 & 9,1 & 17,1 \\
\hline 1983 & 9,3 & 10,5 & 3,4 & 30,5 & 9,6 & 5,0 & 8,6 & 17,7 \\
\hline 1984 & 9,4 & 10,3 & 3,6 & 30,5 & 9,8 & 5,1 & 7,7 & 18,2 \\
\hline 1985 & 7,9 & 10,6 & 3,5 & 31,5 & 9,7 & 5,2 & 7,3 & 19,0 \\
\hline 1986 & 7,8 & 10,5 & 3,4 & 30,4 & 10,0 & 5,3 & 6,9 & 20,3 \\
\hline 1987 & 7,4 & 11,0 & 3,5 & 30,5 & 9,6 & 5,4 & 6,9 & 20,4 \\
\hline 1988 & 7,0 & 10,8 & 3,7 & 31,3 & 10,2 & 5,4 & 6,4 & 19,7 \\
\hline 1989 & 6,7 & 11,0 & 3,9 & 30,9 & 9,6 & 5,4 & 5,9 & 21,2 \\
\hline 1990 & 6,2 & 11,3 & 4,5 & 30,9 & 10,2 & 5,3 & 5,5 & 20,8 \\
\hline 1991 & 5,8 & 11,8 & 4,8 & 30,5 & 9,5 & 5,5 & 5,4 & 21,4 \\
\hline 1992 & 5,8 & 12,1 & 5,2 & 30,7 & 10,0 & 5,6 & 5,0 & 20,2 \\
\hline 1993 & 5,8 & 11,8 & 5,6 & 30,4 & 10,7 & 5,6 & 4,9 & 19,9 \\
\hline 1994 & 5,7 & 11,9 & 5,8 & 29,9 & 10,7 & 5,6 & 4,9 & 20,2 \\
\hline 1995 & 5,1 & 12,0 & 6,0 & 29,0 & 10,7 & 5,5 & 4,8 & 21,4 \\
\hline 1996 & 7,3 & 12,3 & 3,5 & 28,8 & 10,9 & 5,6 & 4,6 & 21,5 \\
\hline 1997 & 6,5 & 12,7 & 3,7 & 28,8 & 10,3 & 5,8 & 4,7 & 21,9 \\
\hline 1998 & 6,4 & 12,9 & 3,8 & 29,1 & 11,0 & 5,8 & 4,4 & 21,1 \\
\hline
\end{tabular}

Fonte: Ministério da Saúde. 
Tabela 3

Óbitos segundo Principais Causas, da População Feminina

Brasil

1977-98

Em porcentagem

\begin{tabular}{|c|c|c|c|c|c|c|c|c|}
\hline Ano & $\begin{array}{c}\text { Infecciosas } \\
e \\
\text { Parasitárias }\end{array}$ & Neoplasias & $\begin{array}{l}\text { Endóc., Nutr., } \\
\text { Metab. e } \\
\text { Transt. Imun. }\end{array}$ & $\begin{array}{c}\text { Aparelho } \\
\text { Circulatório }\end{array}$ & $\begin{array}{c}\text { Aparelho } \\
\text { Respiratório }\end{array}$ & $\begin{array}{l}\text { Aparelho } \\
\text { Digestivo }\end{array}$ & Perinatais & Externas \\
\hline 1977 & 16,1 & 10,9 & 4,4 & 34,2 & 11,5 & 3,1 & 7,1 & 5,5 \\
\hline 1978 & 15,5 & 10,9 & 4,6 & 34,6 & 11,1 & 3,1 & 7,3 & 5,7 \\
\hline 1979 & 13,0 & 11,0 & 5,3 & 34,8 & 10,3 & 3,4 & 9,1 & 5,7 \\
\hline 1980 & 12,0 & 11,2 & 5,4 & 35,6 & 10,5 & 3,5 & 8,8 & 5,8 \\
\hline 1981 & 10,9 & 11,5 & 5,3 & 36,2 & 10,2 & 3,5 & 9,3 & 5,8 \\
\hline 1982 & 10,3 & 12,0 & 5,3 & 36,1 & 10,2 & 3,5 & 9,5 & 5,9 \\
\hline 1983 & 9,8 & 12,1 & 5,4 & 37,2 & 10,2 & 3,6 & 9,0 & 6,0 \\
\hline 1984 & 10,0 & 12,1 & 5,7 & 37,5 & 10,5 & 3,6 & 8,1 & 5,9 \\
\hline 1985 & 8,2 & 12,6 & 5,6 & 38,8 & 10,5 & 3,8 & 7,7 & 6,3 \\
\hline 1986 & 8,2 & 12,8 & 5,5 & 38,1 & 10,8 & 3,8 & 7,3 & 6,8 \\
\hline 1987 & 7,7 & 13,3 & 5,7 & 38,5 & 10,2 & 4,0 & 7,4 & 6,5 \\
\hline 1988 & 7,2 & 13,1 & 5,8 & 39,2 & 11,0 & 4,0 & 6,9 & 6,3 \\
\hline 1989 & 6,9 & 13,8 & 5,8 & 39,6 & 10,3 & 4,0 & 6,5 & 6,5 \\
\hline 1990 & 6,3 & 14,1 & 6,1 & 39,5 & 11,1 & 3,9 & 6,0 & 6,5 \\
\hline 1991 & 5,9 & 15,0 & 6,4 & 39,3 & 10,2 & 4,2 & 6,0 & 6,7 \\
\hline 1992 & 5,8 & 15,1 & 6,7 & 39,2 & 10,7 & 4,2 & 5,5 & 6,3 \\
\hline 1993 & 5,8 & 14,6 & 6,8 & 38,9 & 11,5 & 4,3 & 5,3 & 6,3 \\
\hline 1994 & 5,8 & 14,9 & 7,1 & 38,3 & 11,6 & 4,2 & 5,3 & 6,4 \\
\hline 1995 & 5,3 & 15,0 & 7,4 & 38,0 & 11,7 & 4,2 & 5,3 & 6,6 \\
\hline 1996 & 6,1 & 15,1 & 6,5 & 37,5 & 12,3 & 4,3 & 5,0 & 6,7 \\
\hline 1997 & 5,8 & 15,6 & 6,7 & 37,6 & 11,8 & 4,2 & 5,1 & 6,4 \\
\hline 1998 & 5,9 & 15,7 & 6,8 & 37,3 & 12,6 & 4,3 & 4,7 & 6,0 \\
\hline
\end{tabular}

Fonte: Fundação Seade. 
Tabela 4

Coeficientes de Mortalidade por Causas Externas, segundo Sexo Brasil

1977-98

(por 100 mil hab.)

\begin{tabular}{|c|c|c|c|}
\hline Ano & Homens & Mulheres & Total \\
\hline 1977 & 77,1 & 20,9 & 49,0 \\
\hline 1978 & 81,7 & 22,4 & 52,0 \\
\hline 1979 & 88,5 & 23,3 & 55,8 \\
\hline 1980 & 94,4 & 23,8 & 59,0 \\
\hline 1981 & 95,5 & 23,4 & 59,3 \\
\hline 1982 & 96,0 & 23,2 & 59,3 \\
\hline 1983 & 100,7 & 23,3 & 61,7 \\
\hline 1984 & 105,2 & 23,1 & 63,9 \\
\hline 1985 & 107,2 & 23,9 & 65,2 \\
\hline 1986 & 117,3 & 26,4 & 71,5 \\
\hline 1987 & 114,4 & 24,4 & 69,0 \\
\hline 1988 & 114,3 & 24,6 & 69,1 \\
\hline 1989 & 120,9 & 24,3 & 72,2 \\
\hline 1990 & 116,5 & 24,1 & 69,9 \\
\hline 1991 & 115,9 & 23,9 & 69,5 \\
\hline 1992 & 111,3 & 22,7 & 66,5 \\
\hline 1993 & 113,8 & 24,0 & 68,5 \\
\hline 1994 & 116,1 & 24,4 & 69,8 \\
\hline 1995 & 122,9 & 25,4 & 73,7 \\
\hline 1996 & 126,4 & 26,5 & 75,9 \\
\hline 1997 & 126,5 & 24,7 & 75,0 \\
\hline 1998 & 122,9 & 23,7 & 72,7 \\
\hline
\end{tabular}

Fonte: Ministério da Saúde. 
Tabela 5

Coeficientes de Mortalidade por Causas Externas, por Tipos

Brasil

1979-98

Por 100 mil hab.

\begin{tabular}{rrrrrr}
\hline Ano & Homicidios & $\begin{array}{c}\text { Acidentes } \\
\text { de } \\
\text { Transporte }\end{array}$ & $\begin{array}{c}\text { Suicídios e } \\
\text { Lesóes Auto- } \\
\text { Infligidas }\end{array}$ & $\begin{array}{c}\text { Afogamento } \\
\text { Submersão } \\
\text { Acidentais }\end{array}$ & $\begin{array}{c}\text { Quedas } \\
\text { Acidentais }\end{array}$ \\
\hline 1979 & 9,9 & 19,0 & 3,1 & 4,0 & 1,7 \\
1980 & 12,1 & 17,7 & 3,4 & 4,3 & 1,7 \\
1981 & 13,0 & 17,0 & 3,5 & 4,5 & 2,7 \\
1982 & 13,1 & 17,9 & 3,3 & 4,7 & 2,0 \\
1983 & 14,4 & 17,0 & 3,8 & 5,5 & 1,9 \\
1984 & 16,0 & 18,2 & 3,6 & 5,4 & 1,7 \\
1985 & 15,6 & 19,7 & 3,4 & 5,3 & 1,9 \\
1986 & 15,9 & 23,4 & 3,3 & 4,9 & 1,9 \\
1987 & 17,5 & 21,4 & 3,6 & 4,7 & 1,8 \\
1988 & 17,4 & 21,3 & 3,3 & 4,2 & 2,2 \\
1989 & 21,0 & 21,5 & 3,3 & 4,7 & 2,7 \\
1990 & 23,0 & 20,9 & 3,5 & 5,1 & 3,3 \\
1991 & 21,7 & 20,1 & 3,7 & 4,7 & 3,3 \\
1992 & 19,7 & 18,9 & 3,7 & 4,7 & 3,0 \\
1993 & 20,8 & 19,0 & 3,8 & 4,5 & 2,6 \\
1994 & 21,9 & 19,9 & 4,0 & 4,7 & 2,8 \\
1995 & 24,5 & 21,9 & 4,4 & 4,6 & 3,6 \\
1996 & 25,3 & 23,1 & 4,4 & 4,5 & 2,8 \\
1997 & 26,0 & 22,9 & 4,4 & 4,6 & 3,0 \\
1998 & 26,7 & 19,7 & 4,4 & 4,2 & 3,1 \\
\hline 509 & & & & & \\
\hline
\end{tabular}

Fonte: Ministério da Saúde. 
Tabela 6

Distribuição dos Óbitos por Causas Externas de Morte, segundo Tipos

Brasil

1979-98

Em porcentagem

\begin{tabular}{|c|c|c|c|c|c|c|}
\hline Ano & Homicídios & $\begin{array}{l}\text { Acidentes de } \\
\text { Transporte }\end{array}$ & $\begin{array}{c}\text { Demais } \\
\text { Acidentes }\end{array}$ & $\begin{array}{l}\text { Demais } \\
\text { Externas }\end{array}$ & $\begin{array}{l}\text { Suicídios e } \\
\text { Lesões Auto- } \\
\text { Infligidas }\end{array}$ & Total \\
\hline 1979 & 17,2 & 32,8 & 24,0 & 20,7 & 5,3 & 100,0 \\
\hline 1980 & 19,8 & 29,0 & 26,3 & 19,3 & 5,5 & 100,0 \\
\hline 1981 & 21,2 & 27,6 & 28,5 & 17,0 & 5,7 & 100,0 \\
\hline 1982 & 21,2 & 28,9 & 27,1 & 17,4 & 5,3 & 100,0 \\
\hline 1983 & 22,3 & 26,5 & 31,0 & 14,4 & 5,9 & 100,0 \\
\hline 1984 & 24,0 & 27,4 & 27,7 & 15,6 & 5,4 & 100,0 \\
\hline 1985 & 23,0 & 29,0 & 27,1 & 15,9 & 5,0 & 100,0 \\
\hline 1986 & 21,3 & 31,4 & 26,3 & 16,4 & 4,5 & 100,0 \\
\hline 1987 & 24,5 & 29,8 & 25,8 & 15,0 & 5,0 & 100,0 \\
\hline 1988 & 24,3 & 29,7 & 25,8 & 15,5 & 4,7 & 100,0 \\
\hline 1989 & 28,1 & 28,8 & 25,3 & 13,4 & 4,4 & 100,0 \\
\hline 1990 & 31,8 & 28,9 & 25,6 & 8,9 & 4,8 & 100,0 \\
\hline 1991 & 30,1 & 27,9 & 26,5 & 10,4 & 5,1 & 100,0 \\
\hline 1992 & 28,7 & 27,5 & 25,7 & 12,9 & 5,3 & 100,0 \\
\hline 1993 & 29,5 & 26,8 & 25,0 & 13,3 & 5,4 & 100,0 \\
\hline 1994 & 30,4 & 27,5 & 24,6 & 11,9 & 5,5 & 100,0 \\
\hline 1995 & 32,3 & 28,9 & 24,2 & 8,9 & 5,7 & 100,0 \\
\hline 1996 & 32,6 & 29,8 & 23,6 & 8,2 & 5,7 & 100,0 \\
\hline 1997 & 33,9 & 29,9 & 22,8 & 7,7 & 5,8 & 100,0 \\
\hline 1998 & 35,6 & 26,4 & 20,9 & 11,2 & 5,9 & 100,0 \\
\hline
\end{tabular}

Fonte: Ministério da Saúde. 
Tabela 7

Coeficientes de Mortalidade por Causas Externas por Sexo, segundo Tipos

Brasil

1979-98

Por 100 mil hab.

\begin{tabular}{|c|c|c|c|c|c|c|c|c|c|c|}
\hline \multirow[b]{2}{*}{ Anos } & \multicolumn{5}{|c|}{ Homens } & \multicolumn{5}{|c|}{ Mulheres } \\
\hline & $\begin{array}{l}\text { Acidentes de } \\
\text { Transporte }\end{array}$ & $\begin{array}{l}\text { Quedas } \\
\text { Acidentais }\end{array}$ & $\begin{array}{l}\text { Afogamento e } \\
\text { Submersão } \\
\text { Acidentais }\end{array}$ & $\begin{array}{l}\text { Suicídios e } \\
\text { Lesões Auto- } \\
\text { Infligidas }\end{array}$ & Homicídios & $\begin{array}{l}\text { Acidentes } \\
\text { de } \\
\text { Transporte }\end{array}$ & $\begin{array}{l}\text { Quedas } \\
\text { Acidentais }\end{array}$ & $\begin{array}{l}\text { Afogamento e } \\
\text { Submersão } \\
\text { Acidentais }\end{array}$ & $\begin{array}{l}\text { Suicídios e } \\
\text { Lesões Auto- } \\
\text { Infligidas }\end{array}$ & Homicídios \\
\hline 1979 & 28,5 & 2,1 & 6,5 & 4,1 & 17,2 & 8,2 & 1,2 & 1,2 & 1,8 & 2,0 \\
\hline 1980 & 26,7 & 2,1 & 6,9 & 4,6 & 21,2 & 7,7 & 1,2 & 1,4 & 2,0 & 2,3 \\
\hline 1981 & 25,6 & 3,5 & 7,3 & 4,8 & 22,8 & 7,2 & 1,6 & 1,5 & 2,0 & 2,4 \\
\hline 1982 & 26,9 & 2,4 & 7,5 & 4,6 & 22,8 & 7,5 & 1,4 & 1,5 & 1,7 & 2,4 \\
\hline 1983 & 25,8 & 2,3 & 9,0 & 5,3 & 25,0 & 7,0 & 1,4 & 1,6 & 2,0 & 2,7 \\
\hline 1984 & 27,7 & 1,9 & 8,8 & 5,1 & 28,2 & 7,4 & 1,4 & 1,6 & 1,8 & 2,7 \\
\hline 1985 & 29,8 & 2,2 & 8,4 & 4,9 & 27,6 & 8,3 & 1,6 & 1,7 & 1,6 & 2,7 \\
\hline 1986 & 35,3 & 2,1 & 7,9 & 4,7 & 28,1 & 9,8 & 1,5 & 1,6 & 1,7 & 2,7 \\
\hline 1987 & 32,5 & 2,1 & 7,8 & 5,2 & 31,2 & 8,9 & 1,4 & 1,4 & 1,7 & 2,8 \\
\hline 1988 & 32,3 & 2,6 & 6,9 & 4,9 & 31,0 & 8,9 & 1,7 & 1,3 & 1,6 & 2,9 \\
\hline 1989 & 32,8 & 3,4 & 7,8 & 4,9 & 37,7 & 9,0 & 1,8 & 1,4 & 1,5 & 3,3 \\
\hline 1990 & 31,9 & 4,3 & 8,4 & 5,1 & 41,3 & 8,8 & 2,1 & 1,5 & 1,7 & 3,5 \\
\hline 1991 & 30,6 & 4,4 & 7,8 & 5,5 & 38,6 & 8,4 & 2,0 & 1,4 & 1,6 & 3,7 \\
\hline 1992 & 29,1 & 3,8 & 7,7 & 5,6 & 35,4 & 7,7 & 2,0 & 1,4 & 1,6 & 3,2 \\
\hline 1993 & 28,9 & 3,0 & 7,4 & 5,8 & 37,3 & 8,1 & 1,9 & 1,4 & 1,6 & 3,4 \\
\hline 1994 & 30,2 & 3,5 & 7,7 & 6,1 & 39,2 & 8,5 & 2,0 & 1,4 & 1,7 & 3,7 \\
\hline 1995 & 33,7 & 4,9 & 7,6 & 6,7 & 43,9 & 9,1 & 2,1 & 1,5 & 1,8 & 4,2 \\
\hline 1996 & 36,0 & 4,3 & 7,5 & 6,9 & 45,4 & 9,6 & 1,3 & 1,4 & 1,8 & 4,6 \\
\hline 1997 & 36,3 & 4,5 & 7,7 & 7,0 & 46,9 & 8,9 & 1,3 & 1,3 & 1,7 & 4,4 \\
\hline 1998 & 30,9 & 4,4 & 6,9 & 6,9 & 48,1 & 7,7 & 1,6 & 1,2 & 1,8 & 4,3 \\
\hline
\end{tabular}

Fonte: Ministério da Saúde. 
Tabela 8

Coeficientes de Mortalidade por Causas Externas, segundo Sexo e Grupos de Idade Brasil

1979-98

Por 100 mil hab.

\begin{tabular}{|c|c|c|c|c|c|c|c|c|}
\hline \multirow{2}{*}{ Ano } & \multicolumn{4}{|c|}{ Homens } & \multicolumn{4}{|c|}{ Mulheres } \\
\hline & 1979 & 1986 & 1992 & 1998 & 1979 & 1986 & 1992 & 1998 \\
\hline$<1$ ano & 31,5 & 37,9 & 41,4 & 46,3 & 26,2 & 31,9 & 35,5 & 36,0 \\
\hline 1 a 4 & 22,3 & 26,0 & 20,5 & 20,2 & 15,8 & 17,1 & 13,5 & 13,0 \\
\hline 5 a 14 & 24,9 & 28,4 & 23,6 & 19,7 & 12,6 & 13,6 & 9,7 & 9,9 \\
\hline 15 a 24 & 102,1 & 150,9 & 142,2 & 167,0 & 22,0 & 26,0 & 20,6 & 23,0 \\
\hline 25 a 34 & 140,0 & 191,9 & 174,1 & 192,3 & 23,4 & 27,2 & 23,2 & 22,3 \\
\hline 35 a 44 & 145,3 & 165,1 & 154,3 & 164,9 & 24,9 & 26,9 & 22,1 & 22,8 \\
\hline 45 a 54 & 135,9 & 160,4 & 135,7 & 146,2 & 27,9 & 29,4 & 25,0 & 24,9 \\
\hline 55 a 64 & 122,6 & 149,5 & 126,6 & 133,3 & 32,9 & 34,4 & 29,8 & 27,4 \\
\hline 65 a 74 & 136,3 & 148,3 & 128,0 & 136,5 & 53,4 & 54,0 & 42,5 & 45,9 \\
\hline 75 e + & 207,0 & 229,5 & 199,9 & 212,9 & 129,3 & 135,2 & 127,6 & 139,7 \\
\hline
\end{tabular}

Fonte: Ministério da Saúde. 
Tabela 9

Óbitos Gerais segundo as Principais Causas de Morte

Estado de São Paulo

1971-99

Em porcentagem

\begin{tabular}{|c|c|c|c|c|c|c|c|}
\hline Ano & $\begin{array}{l}\text { Infecciosas e } \\
\text { Parasitárias }\end{array}$ & Neoplasias & $\begin{array}{l}\text { Glandulas } \\
\text { Endócrinas }\end{array}$ & $\begin{array}{l}\text { Aparelho } \\
\text { Circulatório }\end{array}$ & $\begin{array}{c}\text { Aparelho } \\
\text { Respiratório }\end{array}$ & $\begin{array}{l}\text { Aparelho } \\
\text { Digestivo }\end{array}$ & $\begin{array}{l}\text { Causas } \\
\text { Externas }\end{array}$ \\
\hline 1971 & 15,4 & 10,0 & 3,9 & 32,6 & 12,3 & 3,4 & 8,4 \\
\hline 1972 & 15,6 & 10,0 & 4,3 & 32,0 & 12,1 & 3,5 & 8,8 \\
\hline 1973 & 15,1 & 9,7 & 3,9 & 32,1 & 12,6 & 3,6 & 9,3 \\
\hline 1974 & 16,1 & 9,8 & 3,9 & 31,7 & 11,8 & 3,5 & 9,4 \\
\hline 1975 & 16,6 & 10,2 & 4,2 & 31,4 & 11,8 & 3,4 & 9,1 \\
\hline 1976 & 14,6 & 10,0 & 4,2 & 33,2 & 12,2 & 3,5 & 9,1 \\
\hline 1977 & 14,5 & 11,0 & 3,9 & 33,0 & 11,5 & 3,8 & 9,1 \\
\hline 1978 & 13,3 & 11,1 & 3,9 & 33,9 & 11,6 & 3,8 & 9,1 \\
\hline 1979 & 10,0 & 11,3 & 4,5 & 34,6 & 10,4 & 4,3 & 9,5 \\
\hline 1980 & 8,8 & 11,4 & 4,3 & 35,5 & 11,2 & 4,6 & 10,1 \\
\hline 1981 & 8,2 & 11,6 & 4,4 & 35,1 & 11,2 & 4,5 & 10,4 \\
\hline 1982 & 8,0 & 11,9 & 4,4 & 34,8 & 11,6 & 4,6 & 10,4 \\
\hline 1983 & 6,2 & 12,3 & 4,3 & 35,8 & 10,6 & 4,9 & 12,1 \\
\hline 1984 & 6,7 & 12,2 & 4,6 & 35,1 & 11,2 & 5,0 & 12,1 \\
\hline 1985 & 5,3 & 12,5 & 4,4 & 36,4 & 10,9 & 5,1 & 12,8 \\
\hline 1986 & 5,2 & 12,7 & 4,5 & 35,0 & 11,4 & 5,2 & 13,5 \\
\hline 1987 & 4,8 & 12,9 & 4,5 & 35,2 & 10,9 & 5,3 & 13,8 \\
\hline 1988 & 4,7 & 12,8 & 4,9 & 35,8 & 11,7 & 5,4 & 12,5 \\
\hline 1989 & 4,6 & 13,0 & 5,0 & 35,7 & 11,2 & 5,3 & 13,6 \\
\hline 1990 & 4,3 & 13,3 & 5,9 & 35,1 & 11,7 & 5,0 & 13,4 \\
\hline 1991 & 4,0 & 14,0 & 6,4 & 34,6 & 10,9 & 5,3 & 13,8 \\
\hline 1992 & 3,9 & 14,4 & 6,8 & 34,6 & 11,4 & 5,4 & 12,8 \\
\hline 1993 & 3,8 & 14,0 & 7,3 & 34,2 & 12,1 & 5,4 & 12,7 \\
\hline 1994 & 3,8 & 14,0 & 7,5 & 33,6 & 12,2 & 5,5 & 13,1 \\
\hline 1995 & 3,7 & 14,0 & 7,9 & 32,3 & 12,1 & 5,5 & 14,4 \\
\hline 1996 & 6,7 & 14,3 & 4,3 & 32,8 & 11,7 & 5,6 & 14,8 \\
\hline 1997 & 5,9 & 15,0 & 4,5 & 32,8 & 11,3 & 5,6 & 14,8 \\
\hline 1998 & 5,5 & 15,4 & 4,4 & 33,0 & 11,5 & 5,7 & 14,7 \\
\hline 1999 & 5,3 & 15,6 & 4,8 & 32,8 & 11,2 & 5,7 & 15,3 \\
\hline
\end{tabular}

Fonte: Fundação Seade. 
Tabela 10

Coeficientes de Mortalidade da População Masculina, segundo Principais Causas

Estado de São Paulo

1971-99

Por 100 mil homens

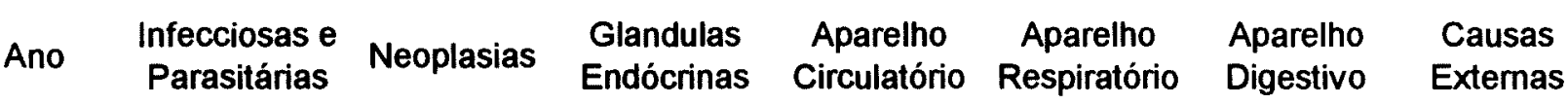

\begin{tabular}{|c|c|c|c|c|c|c|c|}
\hline 1971 & 144,2 & 94,9 & 31,0 & 299,0 & 117,0 & 39,0 & 96,6 \\
\hline 1972 & 147,0 & 93,1 & 33,3 & 291,9 & 112,8 & 38,9 & 100,4 \\
\hline 1973 & 151,5 & 96,4 & 32,1 & 305,3 & 124,0 & 42,2 & 110,9 \\
\hline 1974 & 156,5 & 93,7 & 31,1 & 294,6 & 115,4 & 39,6 & 110,0 \\
\hline 1975 & 156,7 & 95,3 & 33,0 & 284,5 & 112,6 & 37,7 & 104,9 \\
\hline 1976 & 133,7 & 91,4 & 32,1 & 291,6 & 113,0 & 38,0 & 102,1 \\
\hline 1977 & 121,3 & 92,5 & 27,2 & 267,4 & 98,1 & 37,5 & 97,6 \\
\hline 1978 & 111,0 & 91,6 & 26,0 & 269,2 & 98,1 & 37,4 & 96,1 \\
\hline 1979 & 82,8 & 89,9 & 31,6 & 268,7 & 87,2 & 40,5 & 98,9 \\
\hline 1980 & 71,6 & 89,6 & 28,8 & 270,7 & 90,9 & 42,4 & 105,2 \\
\hline 1981 & 66,3 & 89,9 & 28,0 & 262,5 & 88,9 & 40,8 & 106,5 \\
\hline 1982 & 62,6 & 89,7 & 28,3 & 255,2 & 90,8 & 41,3 & 104,8 \\
\hline 1983 & 49,6 & 93,9 & 27,2 & 265,5 & 84,7 & 44,9 & 125,0 \\
\hline 1984 & 54,3 & 94,8 & 29,5 & 264,6 & 90,6 & 47,3 & 128,7 \\
\hline 1985 & 41,9 & 94,0 & 27,2 & 264,4 & 85,6 & 46,2 & 130,9 \\
\hline 1986 & 42,0 & 96,6 & 28,5 & 257,9 & 91,2 & 47,8 & 140,2 \\
\hline 1987 & 37,9 & 95,7 & 28,7 & 253,8 & 85,9 & 46,7 & 141,4 \\
\hline 1988 & 39,3 & 98,3 & 33,7 & 267,9 & 96,0 & 49,5 & 133,1 \\
\hline 1989 & 37,8 & 97,8 & 35,0 & 262,2 & 89,5 & 47,8 & 141,3 \\
\hline 1990 & 35,1 & 99,8 & 44,9 & 258,4 & 93,3 & 46,0 & 140,7 \\
\hline 1991 & 31,4 & 98,9 & 47,7 & 239,1 & 82,7 & 45,3 & 137,4 \\
\hline 1992 & 31,1 & 102,5 & 52,2 & 240,8 & 88,0 & 46,8 & 128,4 \\
\hline 1993 & 31,3 & 105,8 & 59,3 & 250,1 & 94,6 & 48,8 & 132,2 \\
\hline 1994 & 31,7 & 105,2 & 62,1 & 247,6 & 96,9 & 50,4 & 137,8 \\
\hline 1995 & 30,6 & 106,5 & 63,9 & 237,3 & 96,9 & 50,9 & 154,4 \\
\hline 1996 & 62,0 & 110,8 & 26,8 & 243,4 & 93,9 & 51,7 & 163,2 \\
\hline 1997 & 52,1 & 113,1 & 27,1 & 235,1 & 87,2 & 51,6 & 158,6 \\
\hline 1998 & 46,8 & 113,4 & 26,2 & 232,5 & 86,2 & 50,9 & 155,6 \\
\hline 1999 & 45,3 & 115,1 & 28,4 & 232,2 & 84,0 & 51,1 & 163,0 \\
\hline
\end{tabular}

Fonte: Fundação Seade. 
Tabela 11

Coeficiente de Mortalidade da População Feminina, segundo Principais Causas

Estado de São Paulo

1971-99

Por 100 mil mulheres

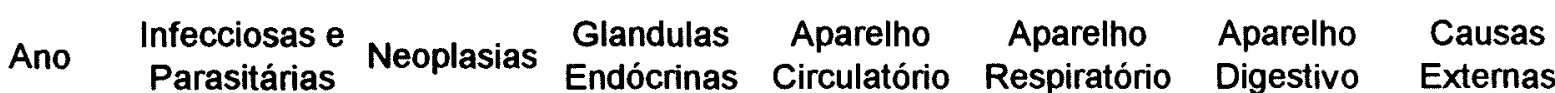

\begin{tabular}{|c|c|c|c|c|c|c|c|}
\hline 1971 & 114,5 & 72,9 & 34,1 & 248,6 & 89,8 & 18,6 & 27,6 \\
\hline 1972 & 112,7 & 74,0 & 38,1 & 240,6 & 87,8 & 18,9 & 30,1 \\
\hline 1973 & 111,1 & 72,3 & 36,3 & 251,4 & 95,1 & 20,5 & 32,6 \\
\hline 1974 & 115,6 & 71,6 & 35,3 & 242,8 & 84,9 & 20,1 & 32,8 \\
\hline 1975 & 117,9 & 72,7 & 35,9 & 234,3 & 82,4 & 18,7 & 30,8 \\
\hline 1976 & 101,4 & 70,3 & 35,7 & 243,6 & 84,1 & 19,1 & 30,4 \\
\hline 1977 & 92,6 & 70,2 & 29,7 & 219,6 & 71,9 & 18,4 & 26,6 \\
\hline 1978 & 82,1 & 69,7 & 30,4 & 222,8 & 70,7 & 17,2 & 27,4 \\
\hline 1979 & 58,6 & 69,8 & 32,5 & 222,0 & 61,0 & 20,0 & 27,1 \\
\hline 1980 & 51,2 & 69,0 & 31,5 & 224,0 & 65,5 & 21,3 & 26,4 \\
\hline 1981 & 46,1 & 68,2 & 31,9 & 217,5 & 63,8 & 20,9 & 26,5 \\
\hline 1982 & 43,5 & 69,2 & 29,9 & 208,9 & 63,5 & 20,1 & 25,5 \\
\hline 1983 & 33,4 & 70,9 & 30,6 & 214,6 & 57,9 & 20,9 & 27,6 \\
\hline 1984 & 38,0 & 71,5 & 33,1 & 215,8 & 62,1 & 21,3 & 26,6 \\
\hline 1985 & 28,1 & 70,7 & 30,9 & 216,0 & 58,0 & 21,3 & 26,7 \\
\hline 1986 & 28,2 & 73,9 & 31,4 & 209,8 & 61,4 & 21,7 & 29,3 \\
\hline 1987 & 25,8 & 74,3 & 30,8 & 209,0 & 57,6 & 22,6 & 28,6 \\
\hline 1988 & 25,5 & 76,1 & 32,6 & 220,3 & 63,8 & 24,2 & 27,6 \\
\hline 1989 & 23,0 & 75,7 & 31,1 & 213,3 & 59,4 & 22,6 & 27,6 \\
\hline 1990 & 22,4 & 79,4 & 34,5 & 213,8 & 64,7 & 21,6 & 27,6 \\
\hline 1991 & 18,7 & 77,8 & 33,6 & 198,2 & 55,7 & 22,2 & 27,0 \\
\hline 1992 & 18,7 & 80,9 & 35,2 & 199,7 & 58,1 & 22,7 & 25,1 \\
\hline 1993 & 19,9 & 81,0 & 38,3 & 206,0 & 66,7 & 23,4 & 27,2 \\
\hline 1994 & 19,8 & 82,5 & 39,4 & 203,6 & 67,0 & 23,4 & 26,6 \\
\hline 1995 & 20,0 & 83,9 & 43,4 & 200,6 & 67,9 & 24,0 & 27,6 \\
\hline 1996 & 30,1 & 85,0 & 32,5 & 206,3 & 66,1 & 25,1 & 28,3 \\
\hline 1997 & 27,2 & 86,7 & 32,8 & 202,3 & 64,1 & 23,7 & 27,6 \\
\hline 1998 & 25,2 & 86,9 & 31,5 & 197,9 & 63,5 & 24,2 & 24,5 \\
\hline 1999 & 24,2 & 89,8 & 34,2 & 197,4 & 62,8 & 23,8 & 25,5 \\
\hline
\end{tabular}

Fonte: Fundação Seade. 
Tabela 12

Coeficientes de Mortalidade por Causas Externas, segundo Sexo

Estado de São Paulo

$1970-2000$

Por 100 mil hab.

\begin{tabular}{rrrr} 
Ano & Homens & Mulheres & Total \\
\hline & & & \\
\hline 1970 & 95,9 & 27,3 & 61,7 \\
1971 & 96,6 & 27,6 & 62,2 \\
1972 & 100,4 & 30,1 & 65,4 \\
1973 & 110,9 & 32,6 & 71,8 \\
1974 & 110,0 & 32,8 & 71,5 \\
1975 & 104,9 & 30,8 & 67,9 \\
1976 & 102,1 & 30,4 & 66,4 \\
1977 & 97,6 & 26,6 & 62,1 \\
1978 & 93,1 & 27,4 & 60,3 \\
1979 & 98,9 & 27,1 & 63,0 \\
1980 & 105,2 & 26,4 & 65,8 \\
1981 & 106,5 & 26,5 & 66,4 \\
1982 & 104,8 & 25,5 & 65,1 \\
1983 & 125,0 & 27,6 & 76,1 \\
1984 & 128,7 & 26,6 & 77,4 \\
1985 & 130,9 & 26,7 & 78,6 \\
1986 & 140,2 & 29,3 & 84,4 \\
1987 & 141,4 & 28,6 & 84,6 \\
1988 & 133,1 & 27,6 & 79,9 \\
1989 & 141,3 & 27,6 & 83,9 \\
1990 & 140,7 & 27,6 & 83,6 \\
1991 & 137,4 & 27,0 & 81,6 \\
1992 & 128,4 & 25,1 & 76,1 \\
1993 & 132,2 & 27,2 & 79,0 \\
1994 & 137,8 & 26,6 & 81,4 \\
1995 & 154,4 & 27,6 & 90,0 \\
1996 & 163,2 & 28,3 & 94,6 \\
1997 & 158,6 & 27,6 & 91,9 \\
1998 & 155,6 & 24,5 & 88,8 \\
1999 & 163,0 & 25,5 & 92,9 \\
\hline 1900 & 159,1 & 25,2 & 90,8 \\
\hline 1945
\end{tabular}

Fonte: Fundação Seade. 
Tabela 13

Coeficientes de Mortalidade por Causas Externas, segundo Tipos Estado de São Paulo

1969-99

Por 100 mil hab.

\begin{tabular}{|c|c|c|c|c|c|}
\hline Ano & $\begin{array}{l}\text { Acidentes } \\
\text { de Veiculos }\end{array}$ & $\begin{array}{l}\text { Demais } \\
\text { Acidentes }\end{array}$ & Suicidios & Homicídios & $\begin{array}{l}\text { Demais } \\
\text { Externas }\end{array}$ \\
\hline 1969 & 22,0 & 19,2 & 6,5 & 6,4 & 4,2 \\
\hline 1970 & 23,7 & 21,1 & 6,5 & 6,6 & 3,8 \\
\hline 1971 & 24,5 & 21,1 & 6,3 & 6,3 & 4,1 \\
\hline 1972 & 26,2 & 21,4 & 5,8 & 6,9 & 5,0 \\
\hline 1973 & 28,0 & 24,1 & 5,4 & 7,0 & 7,4 \\
\hline 1974 & 25,0 & 24,2 & 4,6 & 6,1 & 11,5 \\
\hline 1975 & 22,5 & 22,7 & 3,8 & 6,3 & 12,6 \\
\hline 1976 & 22,5 & 22,9 & 3,9 & 6,4 & 10,4 \\
\hline 1977 & 21,1 & 22,0 & 5,1 & 8,2 & 5,7 \\
\hline 1978 & 21,7 & 18,3 & 4,3 & 8,1 & 9,3 \\
\hline 1979 & 21,8 & 18,2 & 4,3 & 9,4 & 9,4 \\
\hline 1980 & 21,6 & 20,0 & 4,5 & 12,8 & 7,0 \\
\hline 1981 & 20,1 & 18,6 & 4,6 & 15,1 & 8,1 \\
\hline 1982 & 20,5 & 18,2 & 4,3 & 14,7 & 7,3 \\
\hline 1983 & 19,3 & 27,1 & 5,1 & 21,9 & 2,7 \\
\hline 1984 & 21,0 & 22,8 & 4,7 & 24,9 & 4,1 \\
\hline 1985 & 23,1 & 22,3 & 4,4 & 24,8 & 4,0 \\
\hline 1986 & 27,2 & 22,9 & 4,4 & 24,6 & 5,5 \\
\hline 1987 & 24,8 & 23,1 & 4,7 & 26,6 & 5,2 \\
\hline 1988 & 23,1 & 22,9 & 4,1 & 24,3 & 5,5 \\
\hline 1989 & 23,1 & 24,3 & 3,9 & 28,4 & 4,2 \\
\hline 1990 & 23,0 & 22,1 & 4,3 & 29,1 & 5,1 \\
\hline 1991 & 22,5 & 21,5 & 4,4 & 28,8 & 4,3 \\
\hline 1992 & 20,6 & 19,6 & 4,5 & 26,1 & 5,3 \\
\hline 1993 & 20,6 & 20,2 & 4,8 & 26,8 & 6,8 \\
\hline 1994 & 21,1 & 22,9 & 5,0 & 29,8 & 3,1 \\
\hline 1995 & 23,3 & 23,4 & 5,2 & 34,2 & 4,6 \\
\hline 1996 & 25,9 & 20,2 & 5,1 & 36,1 & 8,3 \\
\hline 1997 & 26,0 & 18,9 & 5,2 & 36,1 & 7,0 \\
\hline 1998 & 20,6 & 17,9 & 5,0 & 39,7 & 6,9 \\
\hline 1999 & 20,0 & 18,5 & 4,2 & 41,7 & 8,6 \\
\hline
\end{tabular}

Fonte: Fundação Seade. 
Tabela 14

Coeficientes de Mortalidade por Causas Externas, por Tipos, segundo Sexo

Estado de Săo Paulo

1969-99

Por 100 mil hab

\begin{tabular}{|c|c|c|c|c|c|c|c|c|c|c|}
\hline \multirow[b]{2}{*}{ Ano } & \multicolumn{5}{|c|}{ Homens } & \multicolumn{5}{|c|}{ Mulheres } \\
\hline & $\begin{array}{c}\text { Acidentes } \\
\text { de } \\
\text { Veiculos }\end{array}$ & $\begin{array}{c}\text { Demais } \\
\text { Acidentes }\end{array}$ & Suicidios & Homicidios & $\begin{array}{c}\text { Demais } \\
\text { Externas }\end{array}$ & $\begin{array}{l}\text { Acidentes } \\
\text { de } \\
\text { Veiculos }\end{array}$ & $\begin{array}{c}\text { Demais } \\
\text { Acidentes }\end{array}$ & Suicídios & Homicidios & $\begin{array}{l}\text { Demais } \\
\text { Externas }\end{array}$ \\
\hline 1969 & 34,0 & 29,6 & 9,4 & 10,3 & 6,7 & 9,7 & 8,7 & 3,6 & 2,4 & 1,8 \\
\hline 1970 & 36,8 & 32,8 & 9,7 & 10,7 & 5,9 & 10,4 & 9,3 & 3,4 & 2,6 & 1,6 \\
\hline 1971 & 38,2 & 32,7 & 8,7 & 10,6 & 6,3 & 10,6 & 9,4 & 3,7 & 2,0 & 1,8 \\
\hline 1972 & 39,5 & 33,4 & 8,0 & 11,7 & 7,9 & 12,8 & 9,4 & 3,5 & 2,1 & 2,2 \\
\hline 1973 & 42,8 & 37,3 & 7,6 & 11,5 & 11,6 & 13,1 & 10,8 & 3,2 & 2,5 & 3,0 \\
\hline 1974 & 37,9 & 37,1 & 6,2 & 10,4 & 18,4 & 12,1 & 11,3 & 3,0 & 1,9 & 4,6 \\
\hline 1975 & 33,8 & 35,3 & 5,4 & 10,9 & 19,6 & 11,1 & 9,9 & 2,3 & 1,8 & 5,6 \\
\hline 1976 & 34,5 & 35,1 & 5,3 & 10,8 & 16,2 & 10,4 & 10,7 & 2,6 & 2,1 & 4,7 \\
\hline 1977 & 32,9 & 34,5 & 7,2 & 14,0 & 9,0 & 9,2 & 9,5 & 3,0 & 2,4 & 2,4 \\
\hline 1978 & 32,7 & 28,6 & 5,8 & 13,8 & 15,1 & 10,6 & 8,0 & 2,9 & 2,4 & 3,5 \\
\hline 1979 & 34,0 & 28,0 & 6,1 & 16,3 & 14,5 & 9,7 & 8,4 & 2,4 & 2,4 & 4,3 \\
\hline 1980 & 33,4 & 31,5 & 6,3 & 23,0 & 11,1 & 9,8 & 8,4 & 2,7 & 2,7 & 2,9 \\
\hline 1981 & 31,1 & 28,9 & 6,3 & 27,4 & 12,8 & 9,1 & 8,4 & 2,8 & 2,9 & 3,3 \\
\hline 1982 & 31,9 & 28,6 & 6,3 & 26,7 & 11,3 & 9,2 & 7,8 & 2,3 & 2,8 & 3,3 \\
\hline 1983 & 30,9 & 42,4 & 7,2 & 40,0 & 4,4 & 7,7 & 12,0 & 3,0 & 4,0 & 1,0 \\
\hline 1984 & 33,1 & 36,1 & 6,8 & 46,0 & 6,7 & 8,9 & 9,6 & 2,5 & 4,0 & 1,5 \\
\hline 1985 & 36,4 & 35,5 & 6,6 & 45,9 & 6,4 & 9,9 & 9,3 & 2,2 & 3,8 & 1,6 \\
\hline 1986 & 42,7 & 36,5 & 6,4 & 45,7 & 8,9 & 11,8 & 9,3 & 2,3 & 3,7 & 2,1 \\
\hline 1987 & 39,1 & 37,2 & 6,9 & 49,6 & 8,6 & 10,8 & 9,3 & 2,6 & 4,0 & 1,9 \\
\hline 1988 & 36,7 & 36,1 & 6,0 & 45,2 & 8,9 & 9,7 & 9,9 & 2,1 & 3,8 & 2,1 \\
\hline 1989 & 36,5 & 38,8 & 5,9 & 53,2 & 6,8 & 10,0 & 10,1 & 1,9 & 4,1 & 1,5 \\
\hline 1990 & 36,4 & 34,7 & 6,7 & 54,6 & 8,4 & 9,8 & 9,7 & 2,1 & 4,1 & 1,9 \\
\hline 1991 & 36,0 & 33,8 & 7,0 & 53,6 & 7,0 & 9,4 & 9,5 & 1,8 & 4,6 & 1,7 \\
\hline 1992 & 32,7 & 31,0 & 7,1 & 48,9 & 8,7 & 8,8 & 8,5 & 2,0 & 3,8 & 2,0 \\
\hline 1993 & 32,1 & 31,4 & 7,7 & 50,1 & 11,0 & 9,3 & 9,2 & 2,0 & 4,1 & 2,7 \\
\hline 1994 & 33,1 & 36,2 & 8,1 & 55,5 & 5,0 & 9,2 & 9,8 & 1,9 & 4,6 & 1,1 \\
\hline 1995 & 37,3 & 37,7 & 8,5 & 63,4 & 7,7 & 9,3 & 9,2 & 2,0 & 5,5 & 1,5 \\
\hline 1996 & 41,9 & 33,1 & 8,1 & 67,0 & 13,2 & 10,0 & 8,2 & 2,0 & 5,5 & 2,6 \\
\hline 1997 & 42,1 & 30,6 & 8,4 & 66,3 & 10,6 & 9,7 & 8,3 & 1,9 & 5,8 & 2,0 \\
\hline 1998 & 33,9 & 29,2 & 8,1 & 73,5 & 10,2 & 7,2 & 7,9 & 1,8 & 5,7 & 2,0 \\
\hline 1999 & 33,0 & 30,3 & 7,1 & 81,7 & 10,0 & 7,7 & 8,3 & 1,5 & 6.1 & 2,1 \\
\hline
\end{tabular}


Tabela 15

Coeficientes de Mortalidade por Homicídios, segundo Sexo e Grupos de Idade

Estado de São Paulo

1971-99

\begin{tabular}{|c|c|c|c|c|c|c|c|c|c|c|}
\hline \multirow{3}{*}{ Idade } & & & & & & & & & Por 10 & mil hab. \\
\hline & \multicolumn{5}{|c|}{ Homens } & \multicolumn{5}{|c|}{ Mulheres } \\
\hline & 1971 & 1979 & 1986 & 1992 & 1999 & 1971 & 1979 & 1986 & 1992 & 1999 \\
\hline$<1$ ano & 3,6 & 1,0 & 2,9 & 1,4 & 0,6 & 4,7 & 2,1 & 3,7 & 2,1 & 2,5 \\
\hline 1 a 4 & 0,5 & 0,2 & 1,2 & 0,6 & 1,3 & 0,7 & 0,3 & 0,3 & 1,1 & 0,4 \\
\hline 5 a 14 & 0,7 & 0,7 & 3,7 & 3,1 & 4,6 & 0,6 & 0,5 & 1,2 & 1,1 & 1,5 \\
\hline 15 a 24 & 14,4 & 26,1 & 100,9 & 108,4 & 172,9 & 2,9 & 3,6 & 6,4 & 5,5 & 11,2 \\
\hline 25 a 34 & 21,9 & 30,1 & 80,6 & 86,8 & 158,5 & 3,0 & 4,2 & 6,1 & 6,6 & 10,0 \\
\hline 35 a 44 & 17,2 & 26,6 & 47,9 & 53,5 & 88,6 & 2,9 & 4,2 & 4,6 & 4,7 & 7,5 \\
\hline 45 a 54 & 15,3 & 20,0 & 34,1 & 34,3 & 49,5 & 1,3 & 2,4 & 2,7 & 3,8 & 4,1 \\
\hline 55 a 64 & 11,1 & 14,4 & 23,4 & 19,9 & 30,8 & 2,3 & 0,9 & 2,0 & 2,0 & 2,9 \\
\hline 65 a 74 & 7,8 & 9,7 & 14,5 & 15,4 & 16,4 & 0,9 & 0,8 & 1,3 & 2,2 & 1,7 \\
\hline $75 \mathrm{e}+$ & 6,3 & 2,9 & 7,2 & 7,0 & 14,9 & 1,9 & 3,2 & 2,1 & 2,5 & 3,3 \\
\hline
\end{tabular}

Fonte: Fundação Seade. 
Tabela 16

Coeficientes de Mortalidade por Acidentes de Veículos a Motor, segundo Sexo e Grupos de Idade

Estado de São Paulo

1971-99

\begin{tabular}{|c|c|c|c|c|c|c|c|c|c|c|}
\hline \multirow{2}{*}{ Ano } & \multicolumn{5}{|c|}{ Homens } & \multicolumn{5}{|c|}{ Mulheres } \\
\hline & 1971 & 1979 & 1986 & 1992 & 1999 & 1971 & 1979 & 1986 & 1992 & 1999 \\
\hline$<1$ ano & 5,1 & 3,5 & 3,9 & 5,6 & 4,6 & 5,7 & 2,4 & 7,4 & 3,1 & 5,1 \\
\hline 1 a 4 & 7,9 & 8,7 & 8,1 & 7,8 & 4,8 & 5,3 & 5,3 & 6,6 & 5,7 & 4,5 \\
\hline 5 a 14 & 12,3 & 12,6 & 11,8 & 10,1 & 8,3 & 7,1 & 7,7 & 6,6 & 5,2 & 4,0 \\
\hline 15 a 24 & 31,6 & 35,0 & 46,9 & 36,7 & 44,0 & 9,5 & 8,7 & 12,2 & 9,1 & 9,3 \\
\hline 25 a 34 & 51,1 & 43,0 & 53,9 & 42,9 & 44,7 & 9,7 & 8,2 & 11,6 & 8,6 & 6,6 \\
\hline 35 a 44 & 57,9 & 46,7 & 49,9 & 43,0 & 42,4 & 10,7 & 9,2 & 11,8 & 8,1 & 7,0 \\
\hline 45 a 54 & 68,0 & 50,6 & 56,7 & 39,3 & 37,6 & 14,5 & 13,4 & 15,4 & 10,9 & 7,9 \\
\hline 55 a 64 & 76,8 & 56,1 & 57,1 & 46,5 & 39,8 & 21,4 & 17,2 & 17,8 & 14,2 & 11,4 \\
\hline 65 a 74 & 103,7 & 73,4 & 62,2 & 51,8 & 42,3 & 33,3 & 26,5 & 29,5 & 16,9 & 14,7 \\
\hline $75 e+$ & 97,7 & 95,0 & 87,1 & 70,5 & 68,3 & 41,4 & 35,7 & 33,7 & 23,5 & 28,5 \\
\hline
\end{tabular}

Fonte: Fundação Seade. 
Tabela 17

Coeficientes de Mortalidade por "Demais Acidentes", segundo Sexo e Grupos de Idade

Estado de São Paulo

1971-99

Por 100 mil hab.

\begin{tabular}{|c|c|c|c|c|c|c|c|c|c|c|}
\hline \multirow{2}{*}{ Idade } & \multicolumn{5}{|c|}{ Homens } & \multicolumn{5}{|c|}{ Mulheres } \\
\hline & 1971 & 1979 & 1986 & 1992 & 1999 & 1971 & 1979 & 1986 & 1992 & 1999 \\
\hline$<1$ ano & 35,0 & 29,0 & 47,7 & 47,4 & 33,9 & 26,6 & 28,2 & 39,1 & 40,7 & 30,5 \\
\hline 1 a 4 & 17,4 & 14,7 & 16,4 & 14,7 & 10,5 & 12,9 & 10,6 & 9,1 & 8,8 & 7.5 \\
\hline 5 a 14 & 14,9 & 11,8 & 14,3 & 12,8 & 10,1 & 5,3 & 5,2 & 5,2 & 3,5 & 3,8 \\
\hline 15 a 24 & 39,5 & 35,0 & 44,4 & 37,5 & 31,8 & 6,4 & 5,5 & 6,4 & 4,3 & 3,4 \\
\hline 25 a 34 & 39,3 & 31,4 & 41,7 & 31,5 & 30,6 & 5,6 & 3,5 & 5,4 & 4,3 & 3,6 \\
\hline 35 a 44 & 41,8 & 33,3 & 41,6 & 36,0 & 36,2 & 6,1 & 4,0 & 6,0 & 4,3 & 4,2 \\
\hline 45 a 54 & 39,2 & 33,8 & 45,8 & 33,2 & 34,1 & 7,2 & 5,3 & 7,3 & 6,8 & 5,2 \\
\hline 55 a 64 & 38,7 & 36,7 & 48,3 & 37,0 & 42,8 & 12,5 & 7,6 & 11,1 & 9,7 & 7,6 \\
\hline 65 a 74 & 49,4 & 44,6 & 53,3 & 52,7 & 59,2 & 26,7 & 26,7 & 21,7 & 22,5 & 24,6 \\
\hline $75 e+$ & 125,2 & 100,8 & 141,6 & 135,7 & 158,0 & 132,1 & 126,1 & 102,8 & 113,2 & 135,8 \\
\hline
\end{tabular}

Fonte: Fundação Seade. 
Tabela 18

Coeficientes de Mortalidade por Suicídios, segundo Sexo e Grupos de Idade

Estado de São Paulo

1971-99

\begin{tabular}{|c|c|c|c|c|c|c|c|c|c|c|}
\hline \multirow{2}{*}{ Idade } & \multicolumn{5}{|c|}{ Homens } & \multicolumn{5}{|c|}{ Mulheres } \\
\hline & 1971 & 1979 & 1986 & 1992 & 1999 & 1971 & 1979 & 1986 & 1992 & 1999 \\
\hline$<1$ ano & 0,0 & 0,0 & 0.0 & 0,0 & 0,0 & 0,0 & 0,0 & 0,0 & 0,0 & 0,0 \\
\hline 1 a 4 & 0,0 & 0,0 & 0.0 & 0,0 & 0,0 & 0,0 & 0,0 & 0,0 & 0,0 & 0,0 \\
\hline 5 a 14 & 0,2 & 0,2 & 0,3 & 0,1 & 0,1 & 0,5 & 0,6 & 0,3 & 0,2 & 0,2 \\
\hline 15 a 24 & 8,3 & 6,8 & 7.0 & 8,3 & 7,6 & 7,2 & 3,1 & 3,2 & 1,9 & 1,7 \\
\hline 25 a 34 & 13,1 & 9,4 & 10,3 & 9,9 & 11,4 & 6,3 & 3,2 & 3,1 & 3,0 & 1,6 \\
\hline 35 a 44 & 14,1 & 11,1 & 8,8 & 10,0 & 10,9 & 4,1 & 3,7 & 3,3 & 3,1 & 2,5 \\
\hline 45 a 54 & 16,9 & 9,8 & 9,3 & 11,0 & 10,2 & 3,1 & 4,2 & 3,5 & 3,8 & 2,5 \\
\hline 55 a 64 & 24,3 & 10,6 & 11,6 & 11,4 & 9,0 & 5,9 & 3,3 & 3,4 & 3,1 & 2,1 \\
\hline 65 a 74 & 27,4 & 11,7 & 17,7 & 14,0 & 10,4 & 6,6 & 2,8 & 2,7 & 2,5 & 1,5 \\
\hline $75 e+$ & 21,9 & 18,4 & 15,5 & 20,1 & 19,1 & 3,9 & 7,6 & 5,9 & 3,5 & 1,4 \\
\hline
\end{tabular}


Tabela 19

Coeficientes de Mortalidade por Causas Externas, segundo Sexo e Grupos de Idade

Estado de São Paulo

1971-99

Por 100 mil hab.

\begin{tabular}{|c|c|c|c|c|c|c|c|c|c|c|}
\hline \multirow{2}{*}{ Idade } & \multicolumn{5}{|c|}{ Homens } & \multicolumn{5}{|c|}{ Mulheres } \\
\hline & 1971 & 1979 & 1986 & 1992 & 1999 & 1971 & 1979 & 1986 & 1992 & 1999 \\
\hline$<1$ ano & 46,8 & 44,6 & 62.0 & 56,2 & 47,6 & 39,7 & 40,6 & 52,9 & 50,0 & 47,0 \\
\hline 1 a 4 & 25,1 & 27,6 & 30,7 & 24,5 & 17,3 & 18,9 & 19,1 & 17,0 & 16,7 & 13,6 \\
\hline 5 a 14 & 29,9 & 30,3 & 33,6 & 27,0 & 24,1 & 14,3 & 16,3 & 14,3 & 10,7 & 10,0 \\
\hline 15 a 24 & 101,1 & 123,6 & 213,4 & 205,6 & 266,5 & 28,5 & 24,9 & 30,2 & 22,5 & 27,8 \\
\hline 25 a 34 & 135,9 & 130,1 & 203,7 & 184,8 & 258,5 & 26,1 & 23,3 & 28,3 & 24,8 & 23,6 \\
\hline 35 a 44 & 139,3 & 139,1 & 165,3 & 151,3 & 192,7 & 26,1 & 25,8 & 28,3 & 22,4 & 23,1 \\
\hline 45 a 54 & 155,3 & 137,8 & 162,0 & 131,4 & 143,0 & 28,5 & 30,3 & 31,3 & 27,7 & 21,4 \\
\hline 55 a 64 & 161,6 & 134,3 & 161,9 & 127,5 & 134,2 & 45,5 & 34,4 & 37,5 & 32,1 & 26,6 \\
\hline 65 a 74 & 211,7 & 169,8 & 162,3 & 143,4 & 138,7 & 70,8 & 66,2 & 59,2 & 49,1 & 45,9 \\
\hline $75 \mathrm{e}+$ & 261,8 & 249,5 & 285,7 & 264,4 & 282,3 & 192,3 & 187,8 & 152,5 & 149,1 & 178,8 \\
\hline
\end{tabular}

Fonte: Fundação Seade. 
Tabela 20

Coeficientes de Mortalidade da Populaçăo Masculina por Causas Externas, segundo Tipos e Grupos de Idade

Estado de São Paulo

1971-99

\begin{tabular}{|c|c|c|c|c|c|c|c|c|c|c|c|c|}
\hline \multirow[b]{2}{*}{ Idade } & \multicolumn{4}{|c|}{1971} & \multicolumn{4}{|c|}{1979} & \multicolumn{4}{|c|}{1986} \\
\hline & $\begin{array}{c}\text { Acidentes } \\
\text { de } \\
\text { Transporte }\end{array}$ & $\begin{array}{c}\text { Demais } \\
\text { Acidentes }\end{array}$ & Homicidios & Suicidios & $\begin{array}{c}\text { Acidentes } \\
\text { de } \\
\text { Transporte }\end{array}$ & $\begin{array}{c}\text { Demais } \\
\text { Acidentes }\end{array}$ & Homicidios & Suicidios & $\begin{array}{l}\text { Acidentes } \\
\text { de } \\
\text { Transporte }\end{array}$ & $\begin{array}{l}\text { Demais } \\
\text { Acidentes }\end{array}$ & Homicidios & Suicidios \\
\hline$<1$ ano & 5,0 & 35,0 & 3,6 & 0,0 & 5,3 & 29,0 & 1,0 & 0,0 & 7,8 & 47,7 & 2,9 & 0,0 \\
\hline 1 a 4 & 5,9 & 17,4 & 0,5 & 0,0 & 9,0 & 14,7 & 0,2 & 0,0 & 11,1 & 16,4 & 1,2 & 0,0 \\
\hline 5 a 14 & 12,7 & 14,9 & 0,7 & 0,2 & 13,4 & 11,8 & 0,7 & 0,2 & 13,7 & 14,3 & 3,7 & 0,3 \\
\hline 15 a 24 & 33,1 & 39,5 & 14,4 & 8,3 & 37,5 & 35,0 & 26,1 & 6,8 & 50,6 & 44,4 & 100,9 & 7,0 \\
\hline 25 a 34 & 53,8 & 39,3 & 21,9 & 13,1 & 41,3 & 31,4 & 30,1 & 9,4 & 58,5 & 41,7 & 80,6 & 10,3 \\
\hline 35 a 44 & 56,3 & 41,8 & 17,2 & 14,1 & 46,6 & 33,3 & 26,6 & 11,1 & 54,0 & 41,6 & 47,9 & 8,8 \\
\hline 45 a 54 & 70,6 & 39,2 & 15,3 & 16,9 & 54,2 & 33,8 & 20,0 & 9,8 & 58,7 & 45,8 & 34,1 & 9,3 \\
\hline 55 a 64 & 74,8 & 38,7 & 11,1 & 24,3 & 50,9 & 36,7 & 14,4 & 10,6 & 66,2 & 48,3 & 23,4 & 11,6 \\
\hline 65 a 74 & 110,5 & 49,4 & 7,8 & 27,4 & 75,8 & 44,6 & 9,7 & 11,7 & 67,8 & 53,3 & 14,5 & 17,7 \\
\hline $75 \mathrm{e}+$ & 98,0 & 125,2 & 6,3 & 21,9 & 100,1 & 100,8 & 2,9 & 18,4 & 103,4 & 141,6 & 7,2 & 15,5 \\
\hline
\end{tabular}

Por 100 mil homens

\begin{tabular}{|c|c|c|c|c|c|c|c|c|}
\hline \multirow[b]{2}{*}{ Idade } & \multicolumn{4}{|c|}{1992} & \multicolumn{4}{|c|}{1999} \\
\hline & $\begin{array}{l}\text { Acidentes } \\
\text { de } \\
\text { Transporte }\end{array}$ & $\begin{array}{c}\text { Demais } \\
\text { Acidentes }\end{array}$ & Homicidios & Suicidios & $\begin{array}{l}\text { Acidentes } \\
\text { de } \\
\text { Transporte }\end{array}$ & $\begin{array}{c}\text { Demais } \\
\text { Acidentes }\end{array}$ & Homicidios & Suicidios \\
\hline$<1$ ano & 2,7 & 47,4 & 1,4 & 0,0 & 4,6 & 33,9 & 0,6 & 0,0 \\
\hline 1 a 4 & 7,4 & 14,7 & 0,6 & 0,0 & 4,8 & 10,5 & 1,3 & 0,0 \\
\hline 5 a 14 & 9,9 & 12,8 & 3,1 & 0,1 & 8,3 & 10,1 & 4,6 & 0,1 \\
\hline 15 a 24 & 40,7 & 37,5 & 108,4 & 8,3 & 44,0 & 31,8 & 172,9 & 7,6 \\
\hline $25: 34$ & 44,3 & 31,5 & 86,8 & 9,9 & 44,7 & 30,6 & 158,5 & 11,4 \\
\hline 35 a 44 & 40,9 & 36,0 & 53,5 & 10,0 & 42,4 & 36,2 & 88,6 & 10,9 \\
\hline 45 a 54 & 40,9 & 33,2 & 34,3 & 11,0 & 37,6 & 34,1 & 49,5 & 10,2 \\
\hline 55 a 64 & 47,0 & 37,0 & 19,9 & 11,4 & 39,8 & 42,8 & 30,8 & 9,0 \\
\hline 65 a 74 & 47,0 & 52,7 & 15,4 & 14,0 & 42,3 & 59,2 & 16,4 & 10,4 \\
\hline 75 e + & 77,2 & 135,7 & 7,0 & 20,1 & 68,3 & 158,0 & 14,9 & 19,1 \\
\hline
\end{tabular}

Fonte: Fundaçăo Seade. 
Tabela 21

Coeficientes de Mortalidade da População Feminina por Causas Externas, segundo Tipos e Grupos de Idade Estado de Sáo Paulo

1971-99

\begin{tabular}{|c|c|c|c|c|c|c|c|c|c|c|c|c|}
\hline \multirow[b]{2}{*}{ Idade } & \multicolumn{4}{|c|}{1971} & \multicolumn{4}{|c|}{1979} & \multicolumn{4}{|c|}{1986} \\
\hline & $\begin{array}{l}\text { Acidentes } \\
\text { de } \\
\text { Transporte }\end{array}$ & $\begin{array}{c}\text { Demais } \\
\text { Acidentes }\end{array}$ & Homicidios & Suicidios & $\begin{array}{c}\text { Acidentes } \\
\text { de } \\
\text { Transporte }\end{array}$ & $\begin{array}{c}\text { Demais } \\
\text { Acidentes }\end{array}$ & Homicidios & Suicidios & $\begin{array}{l}\text { Acidentes } \\
\text { de } \\
\text { Transporte }\end{array}$ & $\begin{array}{c}\text { Demais } \\
\text { Acidentes }\end{array}$ & Homicidios & Suicidios \\
\hline$<1$ ano & 5,1 & 26,6 & 4,7 & 0,0 & 2,4 & 28,2 & 2,1 & 0,0 & 7,4 & 39,1 & 3,7 & 0,0 \\
\hline 1 a 4 & 4,9 & 12,9 & 0,7 & 0,0 & 5,3 & 10,6 & 0,3 & 0,0 & 6,6 & 9,1 & 0,3 & 0,0 \\
\hline 5 a 14 & 7,1 & 5,3 & 0,6 & 0,5 & 7,7 & 5,2 & 0,5 & 0,6 & 6,6 & 5,2 & 1,2 & 0,3 \\
\hline 15 a 24 & 10,2 & 6,4 & 2,9 & 7,2 & 8,7 & 5,5 & 3,6 & 3,1 & 12,2 & 6,4 & 6,4 & 3,2 \\
\hline 25 a 34 & 10,0 & 5,6 & 3,0 & 6,3 & 8,2 & 3,5 & 4,2 & 3,2 & 11,6 & 5,4 & 6,1 & 3,1 \\
\hline 35 a 44 & 10,7 & 6,1 & 2,9 & 4,1 & 9,2 & 4,0 & 4,2 & 3,7 & 11,8 & 6,0 & 4,6 & 3,3 \\
\hline 45 a 54 & 14,9 & 7,2 & 1,3 & 3,1 & 13,4 & 5,3 & 2,4 & 4,2 & 15,4 & 7,3 & 2,7 & 3,5 \\
\hline 55 a 64 & 19,8 & 12,5 & 2,3 & 5,9 & 17,2 & 7,6 & 0,9 & 3,3 & 17,8 & 11,1 & 2,0 & 3,4 \\
\hline 65 a 74 & 29,3 & 26,7 & 0,9 & 6,6 & 26,5 & 26,7 & 0,8 & 2,8 & 29,5 & 21,7 & 1,3 & 2,7 \\
\hline $75 e+$ & 48,6 & 132,1 & 1,9 & 3,9 & 35,7 & 126,1 & 3,2 & 7,6 & 33,7 & 102,8 & 2,1 & 5,9 \\
\hline
\end{tabular}

\begin{tabular}{|c|c|c|c|c|c|c|c|c|}
\hline & & & & & & & Por $100 \mathrm{~m}$ & il mulheres \\
\hline \multirow[b]{2}{*}{ Idade } & \multicolumn{4}{|c|}{1992} & \multicolumn{4}{|c|}{1999} \\
\hline & $\begin{array}{c}\text { Acidentes } \\
\text { de } \\
\text { Transporte }\end{array}$ & $\begin{array}{l}\text { Demais } \\
\text { Acidentes }\end{array}$ & Homicidios & Suicidios & $\begin{array}{l}\begin{array}{c}\text { Acidentes } \\
\text { de } \\
\text { Transporte }\end{array} \\
\end{array}$ & $\begin{array}{c}\text { Demais } \\
\text { Acidentes }\end{array}$ & Homicidios & Suicidios \\
\hline$<1$ ano & 3,1 & 40,7 & 2,1 & 0,0 & 5,1 & 30,5 & 2,5 & 0,0 \\
\hline 1 a 4 & 5,7 & 8,8 & 1,1 & 0,0 & 4,5 & 7,5 & 0,4 & 0,0 \\
\hline 5 a 14 & 5,2 & 3,5 & 1,1 & 0,2 & 4,0 & 3,8 & 1,5 & 0,2 \\
\hline 15 a 24 & 9,1 & 4,3 & 5,5 & 1,9 & 9,3 & 3,4 & 11,2 & 1,7 \\
\hline 25 a 34 & 8,6 & 4,3 & 6,6 & 3,0 & 6,6 & 3,6 & 10,0 & 1,6 \\
\hline 35 a 44 & 8,1 & 4,3 & 4,7 & 3,1 & 7,0 & 4,2 & 7,5 & 2,5 \\
\hline 45 a 54 & 10,9 & 6,8 & 3,8 & 3,8 & 7,9 & 5,2 & 4,1 & 2,5 \\
\hline 55 a 64 & 14,2 & 9,7 & 2,0 & 3,1 & 11,4 & 7,6 & 2,9 & 2,1 \\
\hline 65 a 74 & 16,9 & 22,5 & 2,2 & 2,5 & 14,7 & 24,6 & 1,7 & 1,5 \\
\hline $75 \mathrm{e}+$ & 23,5 & 113,2 & 2,5 & 3,5 & 28,5 & 135,8 & 3,3 & 1,4 \\
\hline
\end{tabular}

Fonte: Fundaçăo Seade. 
Tabela 22

Comparação entre as Probabilidades de Morte Observadas (qx) e Líquida (qxo) Eliminando-se os Grupos de Causas como Fator de Risco de Morte, por Sexo Estado de São Paulo 1998-99

\begin{tabular}{|c|c|c|c|c|c|c|c|c|c|c|c|c|}
\hline \multirow[b]{2}{*}{ Idade } & \multicolumn{6}{|c|}{ Homens } & \multicolumn{6}{|c|}{ Mulheres } \\
\hline & Observada & $\begin{array}{c}\text { Infecciosas } \\
\text { e } \\
\text { Parasitárias }\end{array}$ & Neoplasias & $\begin{array}{l}\text { Aparelho } \\
\text { Circulatório }\end{array}$ & $\begin{array}{c}\text { Aparelho } \\
\text { Respiratório }\end{array}$ & $\begin{array}{l}\text { Causas } \\
\text { Externas }\end{array}$ & Observada & $\begin{array}{c}\text { Infecciosas } \\
e \\
\text { Parasitárias }\end{array}$ & Neoplasias & $\begin{array}{l}\text { Aparelho } \\
\text { Circulatório }\end{array}$ & $\begin{array}{l}\text { Aparelho } \\
\text { Respiratório }\end{array}$ & $\begin{array}{l}\text { Causas } \\
\text { Externas }\end{array}$ \\
\hline 0 & 0,0194 & 0,0182 & 0,0193 & 0,0192 & 0,0176 & 0,0190 & 0,0176 & 0,0165 & 0,0175 & 0,0174 & 0,0160 & 0,0171 \\
\hline 1 & 0,0033 & 0,0028 & 0,0031 & 0,0032 & 0,0027 & 0,0025 & 0,0029 & 0,0024 & 0,0027 & 0,0028 & 0,0023 & 0,0024 \\
\hline 5 & 0,0019 & 0,0017 & 0,0016 & 0,0018 & 0,0017 & 0,0010 & 0,0013 & 0,0012 & 0,0011 & 0,0012 & 0,0011 & 0,0009 \\
\hline 10 & 0,0025 & 0,0024 & 0,0023 & 0,0024 & 0,0023 & 0,0010 & 0,0015 & 0,0015 & 0,0013 & 0,0015 & 0,0014 & 0,0009 \\
\hline 15 & 0,0123 & 0,0121 & 0,0119 & 0,0120 & 0,0120 & 0,0018 & 0,0027 & 0,0026 & 0,0025 & 0,0026 & 0,0025 & 0,0014 \\
\hline 20 & 0,0179 & 0,0172 & 0,0174 & 0,0175 & 0,0175 & 0,0028 & 0,0035 & 0,0031 & 0,0032 & 0,0032 & 0,0033 & 0,0021 \\
\hline 25 & 0,0194 & 0,0173 & 0,0189 & 0,0187 & 0,0188 & 0,0059 & 0,0049 & 0,0038 & 0,0044 & 0,0044 & 0,0046 & 0,0037 \\
\hline 30 & 0,0216 & 0,0181 & 0,0209 & 0,0200 & 0,0206 & 0,0102 & 0,0064 & 0,0051 & 0,0054 & 0,0054 & 0,0060 & 0,0052 \\
\hline 35 & 0,0248 & 0,0215 & 0,0234 & 0,0217 & 0,0235 & 0,0148 & 0,0086 & 0,0075 & 0,0069 & 0,0068 & 0,0080 & 0,0075 \\
\hline 40 & 0,0304 & 0,0275 & 0,0277 & 0,0245 & 0,0286 & 0,0221 & 0,0121 & 0,0111 & 0,0092 & 0,0084 & 0,0112 & 0,0110 \\
\hline 45 & 0,0398 & 0,0369 & 0,0346 & 0,0294 & 0,0374 & 0,0325 & 0,0178 & 0,0168 & 0,0131 & 0,0122 & 0,0166 & 0,0168 \\
\hline 50 & 0,0543 & 0,0513 & 0,0453 & 0,0373 & 0,0509 & 0,0481 & 0,0273 & 0,0260 & 0,0198 & 0,0181 & 0,0254 & 0,0263 \\
\hline 55 & 0,0770 & 0,0738 & 0,0621 & 0,0501 & 0,0714 & 0,0710 & 0,0404 & 0,0388 & 0,0303 & 0,0254 & 0,0372 & 0,0392 \\
\hline 60 & 0,1121 & 0,1081 & 0,0893 & 0,0711 & 0,1022 & 0,1062 & 0,0628 & 0,0607 & 0,0484 & 0,0384 & 0,0569 & 0,0616 \\
\hline 65 & 0,1572 & 0,1528 & 0,1256 & 0,0984 & 0,1407 & 0,1519 & 0,0931 & 0,0904 & 0,0737 & 0,0569 & 0,0839 & 0,0913 \\
\hline 70 & 0,2299 & 0,2249 & 0,1884 & 0,1430 & 0,2021 & 0,2243 & 0,1444 & 0,1408 & 0,1193 & 0,0850 & 0,1295 & 0,1420 \\
\hline 75 & 0,3390 & 0,3325 & 0,2866 & 0,2167 & 0,2941 & 0,3325 & 0,2915 & 0,2855 & 0,2535 & 0,1700 & 0,2599 & 0,2875 \\
\hline 80 & 1,0000 & 1,0000 & 1,0000 & 1,0000 & 1,0000 & 1,0000 & 1,0000 & 1,0000 & 1,0000 & 1,0000 & 1,0000 & 1,0000 \\
\hline
\end{tabular}


Tabela 23

Coeficientes de Mortalidade por Homicidios

Regiões Administrativas de São Paulo

1980-99

\begin{tabular}{|c|c|c|c|c|c|c|c|c|c|c|c|c|c|c|c|}
\hline Ano & RMSP & $\begin{array}{l}\text { RA de } \\
\text { Registro }\end{array}$ & $\begin{array}{l}\text { RA de } \\
\text { Santos }\end{array}$ & $\begin{array}{c}\text { RA de } \\
\text { São José } \\
\text { dos } \\
\text { Campos }\end{array}$ & $\begin{array}{l}\text { RA de } \\
\text { Sorocaba }\end{array}$ & $\begin{array}{l}\text { RA de } \\
\text { Campinas }\end{array}$ & $\begin{array}{l}\text { RA de } \\
\text { Ribeirão } \\
\text { Preto }\end{array}$ & $\begin{array}{l}\text { RA de } \\
\text { Bauru }\end{array}$ & $\begin{array}{l}\text { RA de } \\
\text { São José } \\
\text { do Rio } \\
\text { Preto }\end{array}$ & $\begin{array}{c}\text { RA de } \\
\text { Araçatuba }\end{array}$ & $\begin{array}{c}\text { RA de } \\
\text { Presidente } \\
\text { Prudente }\end{array}$ & $\begin{array}{l}\text { RA de } \\
\text { Marilia }\end{array}$ & $\begin{array}{c}\text { RA } \\
\text { Central }\end{array}$ & $\begin{array}{l}\text { RA de } \\
\text { Barretos }\end{array}$ & $\begin{array}{l}\text { RA de } \\
\text { Franca }\end{array}$ \\
\hline 1980 & 17,9 & 9,2 & 12,3 & 12,6 & 6,2 & 7,1 & 7,5 & 3,9 & 5,6 & 9,8 & 6,5 & 6,9 & 7,4 & 5,2 & 5,4 \\
\hline 1981 & 21,6 & 11,7 & 13,4 & 12,7 & 7,8 & 8,5 & 8,9 & 5,0 & 5,1 & 9,1 & 10,8 & 6,4 & 5,4 & 8,7 & 5,2 \\
\hline 1982 & 20,3 & 17,7 & 15,8 & 11,6 & 8,1 & 8,7 & 10,1 & 5,8 & 5,0 & 9,2 & 8,3 & 8,7 & 8,9 & 5,3 & 6,0 \\
\hline 1983 & 30,0 & 16,3 & 22,9 & 13,5 & 7,9 & 11,1 & 9,4 & 6,6 & 6,6 & 9,6 & 11,5 & 8,1 & 7,3 & 5,5 & 5,4 \\
\hline 1984 & 36,8 & 16,0 & 22,6 & 13,8 & 11,8 & 12,7 & 11,0 & 5,7 & 5,4 & 10,2 & 10,8 & 10,3 & 8,6 & 9,1 & 6,2 \\
\hline 1985 & 36,3 & 21,1 & 22,3 & 14,0 & 11,0 & 11,3 & 11,0 & 8,2 & 5,6 & 9,5 & 10,8 & 9,1 & 8,1 & 5,2 & 5,8 \\
\hline 1986 & 36,9 & 18,3 & 24,4 & 12,2 & 11,7 & 11,3 & 8,2 & 7,0 & 5,6 & 5,7 & 11,9 & 9,6 & 7,1 & 4,1 & 4,4 \\
\hline 1987 & 40,6 & 25,6 & 18,5 & 14,3 & 11,1 & 12,0 & 9,9 & 7,4 & 7,6 & 7,3 & 11,5 & 11,5 & 6,7 & 5,0 & 7,6 \\
\hline 1988 & 37,3 & 21,9 & 21,6 & 13,9 & 11,3 & 10,4 & 7,9 & 5,0 & 7,7 & 6,9 & 8,3 & 10,3 & 8,8 & 6,4 & 6,6 \\
\hline 1989 & 44,2 & 16,9 & 25,6 & 17,5 & 14,2 & 13,8 & 11,8 & 7,1 & 6,3 & 9,1 & 9,5 & 8,5 & 10,0 & 9,1 & 4,5 \\
\hline 1990 & 45,8 & 25,6 & 23,6 & 19,0 & 12,8 & 12,3 & 11,4 & 8,2 & 6,8 & 9,7 & 9,2 & 9,4 & 8,9 & 8,9 & 7,8 \\
\hline 1991 & 45,4 & 19,0 & 25,8 & 18,3 & 12,7 & 13,5 & 11,1 & 9,1 & 5,1 & 7,7 & 7,9 & 9,3 & 7,4 & 8,4 & 6,1 \\
\hline 1992 & 40,4 & 17,3 & 24,8 & 18,1 & 11,0 & 13,5 & 11,2 & 6,3 & 6,3 & 9,4 & 7,6 & 7,8 & 8,1 & 6,6 & 6,5 \\
\hline 1993 & 40,7 & 20,9 & 23,4 & 19,0 & 13,1 & 14,9 & 15,8 & 7,2 & 6,0 & 6,8 & 9,9 & 8,5 & 8,2 & 6,0 & 6,8 \\
\hline 1994 & 46,0 & 19,2 & 26,1 & 23,6 & 12,6 & 15,8 & 16,2 & 6,6 & 5,9 & 7,2 & 9,7 & 8,4 & 9,2 & 6,7 & 5,6 \\
\hline 1995 & 53,7 & 16,0 & 30,2 & 22,1 & 12,6 & 18,2 & 19,1 & 9,4 & 5,5 & 8,6 & 9,7 & 11,3 & 11,5 & 6,1 & 4,5 \\
\hline 1996 & 55,2 & 21,0 & 36,5 & 26,9 & 13,8 & 18,5 & 27,9 & 9,9 & 5,5 & 7,8 & 9,7 & 12,0 & 11,3 & 7,6 & 5,7 \\
\hline 1997 & 54,2 & 21,5 & 45,7 & 28,7 & 15,1 & 18,4 & 25,2 & 10,3 & 6,0 & 8,6 & 11,9 & 11,7 & 7,6 & 7,8 & 5,9 \\
\hline 1998 & 58,7 & 13,3 & 48,7 & 32,6 & 16,2 & 23,5 & 24,9 & 9,6 & 8,4 & 15,5 & 10,9 & 11,8 & 11,1 & 4,4 & 7,8 \\
\hline 1999 & 65,4 & 20,8 & 55,5 & 31,3 & 15,8 & 26,7 & 30,0 & 12,5 & 7,4 & 13,9 & 12,0 & 13,0 & 14,5 & 7,7 & 6,4 \\
\hline
\end{tabular}


Tabela 24

Coeficientes de Mortalidade por Acidentes de Transporte

Regiões Administrativas do Estado de São Paulo

1980-99

\begin{tabular}{|c|c|c|c|c|c|c|c|c|c|c|c|c|c|c|c|}
\hline & & & & & & & & & & & & & & Por $100 \mathrm{~m}$ & il hab. \\
\hline Ano & RMSP & $\begin{array}{c}\text { RA de } \\
\text { Registro }\end{array}$ & $\begin{array}{l}\text { RA de } \\
\text { Santos }\end{array}$ & $\begin{array}{c}\text { RA de Sảo } \\
\text { José dos } \\
\text { Campos }\end{array}$ & $\begin{array}{c}\text { RA de } \\
\text { Sorocaba }\end{array}$ & $\begin{array}{c}\text { RA de } \\
\text { Campinas }\end{array}$ & $\begin{array}{c}\text { RA de } \\
\text { Ribeirão } \\
\text { Preto }\end{array}$ & $\begin{array}{l}\text { RA de } \\
\text { Bauru }\end{array}$ & $\begin{array}{c}\text { RA de São } \\
\text { José do } \\
\text { Rio Preto }\end{array}$ & $\begin{array}{c}\text { RA de } \\
\text { Araçatuba }\end{array}$ & $\begin{array}{c}\text { RA de } \\
\text { Presidente } \\
\text { Prudente }\end{array}$ & $\begin{array}{l}\text { RA de } \\
\text { Marilia }\end{array}$ & $\begin{array}{c}\text { RA } \\
\text { Central }\end{array}$ & $\begin{array}{c}\text { RA de } \\
\text { Barretos }\end{array}$ & $\begin{array}{l}\text { RA de } \\
\text { Franca }\end{array}$ \\
\hline 1980 & 25,0 & 33,0 & 13,8 & 25,5 & 19,2 & 16,9 & 20,9 & 15,3 & 11,5 & 13,0 & 18,6 & 19,1 & 19,6 & 17,6 & 21,5 \\
\hline 1981 & 23,6 & 23,9 & 15,5 & 22,6 & 19,6 & 13,9 & 20,2 & 14,8 & 12,8 & 11,7 & 15,0 & 16,8 & 12,6 & 21,1 & 20,7 \\
\hline 1982 & 23,4 & 32,8 & 17,6 & 22,3 & 19,5 & 14,0 & 22,9 & 13,7 & 12,2 & 11,9 & 17,4 & 22,2 & 20,3 & 22,3 & 20,7 \\
\hline 1983 & 20,2 & 32,7 & 15,4 & 22,5 & 15,4 & 12,8 & 24,4 & 14,5 & 15,7 & 11,7 & 16,3 & 27,8 & 18,2 & 18,6 & 15,4 \\
\hline 1984 & 22,9 & 28,6 & 16,4 & 23,6 & 16,1 & 15,7 & 25,5 & 13,8 & 14,9 & 16,0 & 23,2 & 22,7 & 18,6 & 22,5 & 22,3 \\
\hline 1985 & 23,6 & 30,5 & 21,8 & 23,0 & 19,4 & 20,7 & 29,0 & 17,1 & 21,4 & 20,2 & 18,2 & 25,0 & 22,3 & 25,2 & 19,6 \\
\hline 1986 & 27,5 & 48,3 & 26,3 & 28,0 & 22,5 & 23,6 & 35,5 & 20,4 & 26,1 & 26,4 & 21,9 & 25,8 & 27,7 & 27,1 & 22,3 \\
\hline 1987 & 25,4 & 47,9 & 23,4 & 26,3 & 23,7 & 22,6 & 30,5 & 17,1 & 19,5 & 21,4 & 17,2 & 21,4 & 21,4 & 23,3 & 22,5 \\
\hline 1988 & 22,9 & 34,4 & 19,9 & 30,4 & 23,5 & 22,1 & 23,7 & 20,8 & 17,6 & 23,6 & 17,6 & 23,9 & 21,0 & 24,2 & 18,0 \\
\hline 1989 & 22,4 & 36,6 & 21,4 & 27,8 & 24,0 & 22,9 & 32,5 & 20,8 & 20,9 & 16,9 & 23,0 & 24,9 & 23,1 & 23,9 & 20,3 \\
\hline 1990 & 23,2 & 43,6 & 24,9 & 26,2 & 21,9 & 22,5 & 26,0 & 19,9 & 21,0 & 19,4 & 15,4 & 26,0 & 17,4 & 26,2 & 14,1 \\
\hline 1991 & 22,8 & 39,3 & 21,9 & 26,8 & 21,3 & 20,7 & 27,0 & 22,5 & 21,0 & 17,1 & 19,8 & 25,9 & 20,7 & 21,0 & 16,5 \\
\hline 1992 & 20,4 & 35,4 & 19,3 & 25,0 & 19,6 & 20,4 & 22,1 & 19,5 & 18,4 & 17,9 & 17,3 & 21,1 & 18,5 & 27,3 & 23,2 \\
\hline 1993 & 19,0 & 34,1 & 20,1 & 26,8 & 18,8 & 22,3 & 27,0 & 19,6 & 23,5 & 15,8 & 20,9 & 22,1 & 19,5 & 26,9 & 17,6 \\
\hline 1994 & 19,4 & 33,7 & 24,1 & 26,2 & 18,9 & 22,9 & 25,1 & 18,8 & 22,3 & 14,0 & 28,8 & 21,8 & 22,3 & 25,2 & 20,3 \\
\hline 1995 & 22,2 & 32,1 & 24,1 & 28,0 & 21,6 & 25,9 & 27,4 & 19,1 & 22,4 & 18,1 & 22,2 & 26,4 & 20,4 & 26,1 & 24,3 \\
\hline 1996 & 24,2 & 49,2 & 28,6 & 34,1 & 23,8 & 26,6 & 31,0 & 20,4 & 27,9 & 25,3 & 25,0 & 32,2 & 27,7 & 24,3 & 25,5 \\
\hline 1997 & 22,9 & 56,1 & 30,8 & 35,8 & 25,4 & 28,8 & 33,3 & 23,9 & 29,3 & 26,7 & 24,2 & 28,9 & 24,2 & 27,8 & 21,9 \\
\hline 1998 & 17,2 & 48,6 & 22,3 & 27,9 & 22,5 & 24,6 & 25,6 & 18,8 & 24,8 & 18,5 & 20,5 & 24,0 & 22,7 & 24,7 & 17,3 \\
\hline 1999 & 17,6 & 44,0 & 20,4 & 23,2 & 23,2 & 23,3 & 25,2 & 22,7 & 25,9 & 17,3 & 22,5 & 28,6 & 18,0 & 28,7 & 19,5 \\
\hline
\end{tabular}

Fonte: Fundação Seade. 
Tabela 25

Coeficientes de Mortalidade por Suicidios

Regiões Administrativas do Estado de São Paulo

1980-99

Por 100 mil hab.

Região Administrativa

$\begin{array}{lllll}1980 / 83 & 1984 / 87 & 1988 / 91 & 1992 / 95 & 1996 / 99\end{array}$

\begin{tabular}{llllll} 
RMSP & 4,4 & 4,4 & 4,1 & 4,6 & 4,8 \\
RA de Registro & 4,7 & 5,2 & 7,6 & 4,9 & 5,7 \\
RA de Santos & 3,1 & 4,2 & 3,6 & 5,1 & 4,7 \\
RA de São José dos Campos & 3,6 & 3,4 & 3,4 & 4,5 & 4,2 \\
RA de Sorocaba & 5,3 & 5,0 & 4,5 & 5,7 & 4,7 \\
RA de Campinas & 4,4 & 4,2 & 3,5 & 4,4 & 4,5 \\
RA de Ribeirão Preto & 4,9 & 5,3 & 4,1 & 5,7 & 4,7 \\
RA de Bauru & 5,4 & 4,0 & 4,9 & 5,6 & 5,5 \\
RA de São José do Rio Preto & 5,5 & 5,0 & 4,5 & 5,8 & 5,7 \\
RA de Araçatuba & 4,6 & 4,5 & 5,5 & 5,6 & 5,3 \\
RA de Presidente Prudente & 7,3 & 6,1 & 5,2 & 4,8 & 6,2 \\
RA de Marilia & 5,3 & 4,9 & 5,4 & 6,0 & 5,7 \\
RA Central & 5,5 & 4,5 & 4,3 & 5,8 & 6,9 \\
RA de Barretos & 4,6 & 5,5 & 4,6 & 5,1 & 6,2 \\
RA de Franca & 5,6 & 5,2 & 3,7 & 5,3 & 5,5 \\
\hline Fonte: Fundação Seade. & & & & &
\end{tabular}

Fonte: Fundação Seade. 
Tabela 26

Coeficientes de Mortalidade por " Demais Acidentes"

Regiões Administrativas do Estado de São Paulo

1980-95

Por 100 mil hab.

\begin{tabular}{|c|c|c|c|c|c|c|c|c|c|c|c|c|c|c|c|}
\hline Ano & RMSP & $\begin{array}{l}\text { RA de } \\
\text { Registro }\end{array}$ & $\begin{array}{l}\text { RA de } \\
\text { Santos }\end{array}$ & $\begin{array}{c}\text { RA de } \\
\text { São José } \\
\text { dos } \\
\text { Campos }\end{array}$ & $\begin{array}{l}\text { RA de } \\
\text { Sorocaba }\end{array}$ & $\begin{array}{c}\text { RA de } \\
\text { Campinas }\end{array}$ & $\begin{array}{l}\text { RA de } \\
\text { Ribeirão } \\
\text { Preto }\end{array}$ & $\begin{array}{l}\text { RA de } \\
\text { Bauru }\end{array}$ & $\begin{array}{l}\text { RA de } \\
\text { São José } \\
\text { do Rio } \\
\text { Preto }\end{array}$ & $\begin{array}{c}\text { RA de } \\
\text { Araçatuba }\end{array}$ & $\begin{array}{l}\text { RA de } \\
\text { Presidente } \\
\text { Prudente }\end{array}$ & $\begin{array}{l}\text { RA de } \\
\text { Marilia }\end{array}$ & $\begin{array}{c}\text { RA } \\
\text { Central }\end{array}$ & $\begin{array}{l}\text { RA de } \\
\text { Barretos }\end{array}$ & $\begin{array}{l}\text { RA de } \\
\text { Franca }\end{array}$ \\
\hline 1980 & 19,0 & 36,2 & 24,1 & 21,4 & 20,8 & 22,1 & 19,4 & 18,3 & 19,0 & 20,6 & 17,5 & 18,4 & 22,2 & 23,9 & 15,9 \\
\hline 1981 & 17,3 & 31,8 & 20,9 & 23,0 & 22,8 & 22,1 & 16,0 & 15,9 & 16,7 & 19,2 & 18,4 & 14,7 & 17,3 & 18,2 & 14,0 \\
\hline 1982 & 16,2 & 30,7 & 25,9 & 19,4 & 22,3 & 21,2 & 18,2 & 18,2 & 17,8 & 22,8 & 19,0 & 17,3 & 14,5 & 16,6 & 11,8 \\
\hline 1983 & 24,1 & 45,4 & 42,0 & 27,8 & 33,5 & 28,9 & 25,5 & 24,5 & 20,3 & 25,9 & 19,3 & 21,6 & 23,2 & 23,8 & 17,0 \\
\hline 1984 & 20,8 & 38,1 & 45,4 & 25,3 & 25,2 & 26,2 & 19,6 & 19,6 & 17,4 & 20,9 & 20,1 & 17,4 & 16,1 & 20,1 & 14,1 \\
\hline 1985 & 20,3 & 32,5 & 35,2 & 26,2 & 23,9 & 23,7 & 17,2 & 23,6 & 23,1 & 22,2 & 19,4 & 20,2 & 18,4 & 22,6 & 20,5 \\
\hline 1986 & 20,6 & 40,1 & 38,0 & 27,6 & 25,5 & 25,9 & 15,8 & 18,9 & 22,8 & 24,0 & 18,2 & 20,9 & 19,5 & 25,2 & 16,2 \\
\hline 1987 & 21,2 & 34,1 & 38,3 & 24,0 & 25,5 & 26,5 & 14,3 & 22,3 & 20,6 & 19,3 & 19,0 & 22,2 & 20,5 & 19,9 & 21,1 \\
\hline 1988 & 23,5 & 41,4 & 30,3 & 23,6 & 22,4 & 23,7 & 16,3 & 17,7 & 19,0 & 18,2 & 16,3 & 18,4 & 18,9 & 23,9 & 18,2 \\
\hline 1989 & 26,0 & 30,2 & 35,4 & 26,7 & 21,7 & 24,3 & 16,7 & 16,8 & 18,6 & 20,6 & 18,4 & 16,8 & 18,0 & 17,1 & 20,3 \\
\hline 1990 & 24,2 & 29,6 & 26,3 & 19,8 & 21,4 & 20,6 & 16,3 & 18,7 & 16,5 & 19,5 & 16,0 & 20,6 & 18,2 & 18,4 & 14,1 \\
\hline 1991 & 23,2 & 31,3 & 28,6 & 17,9 & 19,2 & 22,3 & 13,1 & 15,2 & 21,8 & 14,4 & 14,9 & 19,2 & 17,0 & 15,1 & 18,6 \\
\hline 1992 & 20,7 & 34,7 & 21,6 & 18,0 & 19,3 & 20,1 & 14,4 & 15,9 & 15,4 & 18,7 & 14,9 & 18,2 & 15,9 & 14,9 & 17,8 \\
\hline 1993 & 21,0 & 30,6 & 26,6 & 18,3 & 20,9 & 20,4 & 15,1 & 16,7 & 16,7 & 14,2 & 12,7 & 17,4 & 16,0 & 18,3 & 20,7 \\
\hline 1994 & 22,3 & 40,2 & 33,4 & 18,4 & 25,1 & 24,8 & 17,5 & 23,7 & 20,7 & 21,6 & 17,4 & 18,6 & 17,6 & 20,0 & 26,2 \\
\hline 1995 & 22,5 & 37,0 & 40,4 & 23,3 & 24,4 & 23,2 & 19,5 & 26,2 & 19,2 & 19,8 & 23,6 & 17,5 & 19,1 & 20,0 & 22,3 \\
\hline
\end{tabular}

Fonte: Fundação Seade. 
Tabela 27

Coeficientes de Mortalidade por Causas Externas

Regiões Administrativas do Estado de São Paulo

1980-99

Por 100 mil hab.

\begin{tabular}{|c|c|c|c|c|c|c|c|c|c|c|c|c|c|c|c|}
\hline Ano & RMSP & $\begin{array}{l}\text { RA de } \\
\text { Registro }\end{array}$ & $\begin{array}{l}\text { RA de } \\
\text { Santos }\end{array}$ & $\begin{array}{l}\text { RA de São } \\
\text { José dos } \\
\text { Campos }\end{array}$ & $\begin{array}{l}\text { RA de } \\
\text { Sorocaba }\end{array}$ & $\begin{array}{c}\text { RA de } \\
\text { Campinas }\end{array}$ & $\begin{array}{l}\text { RA de } \\
\text { Ribeirão } \\
\text { Preto }\end{array}$ & $\begin{array}{l}\text { RA de } \\
\text { Bauru }\end{array}$ & $\begin{array}{l}\text { RA de São } \\
\text { José do } \\
\text { Rio Preto }\end{array}$ & $\begin{array}{c}\text { RA de } \\
\text { Araçatuba }\end{array}$ & $\begin{array}{l}\text { RA de } \\
\text { Presidente } \\
\text { Prudente }\end{array}$ & $\begin{array}{l}\text { RA de } \\
\text { Marilia }\end{array}$ & $\begin{array}{c}\text { RA } \\
\text { Central }\end{array}$ & $\begin{array}{l}\text { RA de } \\
\text { Barretos }\end{array}$ & $\begin{array}{l}\text { RA de } \\
\text { Franca }\end{array}$ \\
\hline 1980 & 71,0 & 91,9 & 82,2 & 71,8 & 59,9 & 58,4 & 56,5 & 50,6 & 50,0 & 52,9 & 53,5 & 57,9 & 60,6 & 61,7 & 54,7 \\
\hline 1981 & 72,2 & 80,1 & 86,7 & 72,3 & 64,2 & 58,5 & 57,4 & 49,7 & 52,1 & 51,2 & 57,0 & 50,5 & 48,0 & 59,6 & 52,1 \\
\hline 1982 & 69,3 & 89,5 & 83,6 & 69,8 & 67,3 & 55,5 & 61,3 & 53,0 & 49,3 & 54,1 & 57,5 & 59,3 & 54,8 & 58,4 & 48,7 \\
\hline 1983 & 81,0 & 101,6 & 88,7 & 70,3 & 66,6 & 59,6 & 67,4 & 55,1 & 50,9 & 54,5 & 55,9 & 67,4 & 56,0 & 56,2 & 43,9 \\
\hline 1984 & 88,2 & 91,7 & 95,4 & 69,8 & 64,6 & 62,7 & 64,0 & 48,9 & 49,0 & 56,4 & 66,1 & 58,2 & 51,6 & 67,1 & 51,4 \\
\hline 1985 & 87,7 & 94,9 & 87,9 & 69,5 & 65,0 & 62,9 & 66,0 & 59,6 & 58,1 & 60,0 & 59,0 & 64,7 & 56,2 & 63,8 & 54,1 \\
\hline 1986 & 95,0 & 115,4 & 100,4 & 76,3 & 70,3 & 69,2 & 68,2 & 53,2 & 63,9 & 67,9 & 60,3 & 64,6 & 61,1 & 65,3 & 53,8 \\
\hline 1987 & 96,6 & 116,1 & 96,1 & 74,5 & 72,0 & 69,5 & 62,5 & 54,8 & 57,6 & 56,2 & 57,3 & 65,1 & 55,4 & 57,1 & 60,0 \\
\hline 1988 & 92,4 & 112,6 & 81,9 & 77,7 & 69,4 & 65,3 & 54,9 & 52,2 & 53,6 & 60,9 & 50,3 & 62,3 & 57,7 & 62,9 & 53,8 \\
\hline 1989 & 100,2 & 93,3 & 92,5 & 78,2 & 70,9 & 69,2 & 69,5 & 54,7 & 53,1 & 52,2 & 56,5 & 60,0 & 60,5 & 56,6 & 53,0 \\
\hline 1990 & 101,9 & 109,1 & 87,2 & 72,6 & 66,6 & 66,2 & 62,2 & 57,2 & 54,1 & 59,0 & 48,5 & 65,7 & 52,6 & 63,8 & 51,9 \\
\hline 1991 & 99,2 & 104,1 & 88,3 & 70,8 & 64,2 & 65,6 & 58,8 & 55,4 & 57,4 & 49,4 & 52,3 & 64,7 & 53,5 & 53,8 & 51,4 \\
\hline 1992 & 91,2 & 96,2 & 79,2 & 69,9 & 61,9 & 62,9 & 57,3 & 52,1 & 50,8 & 55,4 & 46,7 & 55,7 & 52,0 & 58,7 & 56,0 \\
\hline 1993 & 92,4 & 97,2 & 89,8 & 75,3 & 66,8 & 69,0 & 67,4 & 52,7 & 56,8 & 47,7 & 51,0 & 59,6 & 52,0 & 64,3 & 55,0 \\
\hline 1994 & 95,6 & 101,7 & 96,0 & 78,1 & 64,9 & 71,3 & 70,1 & 57,2 & 56,3 & 51,8 & 62,6 & 56,2 & 58,9 & 60,2 & 57,9 \\
\hline 1995 & 109,3 & 97,5 & 108,5 & 86,9 & 68,7 & 74,6 & 77,4 & 62,4 & 56,8 & 56,3 & 62,5 & 63,2 & 60,7 & 58,9 & 58,9 \\
\hline 1996 & 113,6 & 125,2 & 123,6 & 94,9 & 73,1 & 77,1 & 87,7 & 60,1 & 63,6 & 65,5 & 60,7 & 71,1 & 65,7 & 60,8 & 61,4 \\
\hline 1997 & 107,6 & 124,3 & 127,8 & 96,8 & 73,7 & 79,5 & 89,8 & 65,0 & 61,5 & 64,6 & 64,5 & 67,9 & 58,1 & 61,1 & 54,5 \\
\hline 1998 & 105,4 & 101,7 & 127,9 & 92,1 & 71,0 & 78,4 & 78,2 & 59,1 & 57,4 & 63,5 & 54,8 & 62,2 & 56,8 & 57,3 & 50,9 \\
\hline 1999 & 112,9 & 107,4 & 133,3 & 87,4 & 70,6 & 80,7 & 83,9 & 65,6 & 60,2 & 57,1 & 61,5 & 65,8 & 61,5 & 63,1 & 49,6 \\
\hline
\end{tabular}

Fonte: Fundação Seade. 
Tabela 28

Probabilidades de Morte Observadas $\left(q_{x}\right)$ e Liquida $\left(q_{x 0}\right)$ Eliminando-se os Grupos de Causas Externas como Fator de Risco de Morte da Populaça Masculina, segundo a Idade

Regiảo Motropolitana de São Paulo, Bauru, Campinas e Franca

1998-99

\begin{tabular}{|c|c|c|c|c|c|c|c|c|c|c|c|c|}
\hline \multirow{2}{*}{ Idade } & \multicolumn{6}{|c|}{ RMSP } & \multicolumn{6}{|c|}{ Bauru } \\
\hline & Obs & Ext & Ac. V. & Dac & Suic & Hom & Obs & Ext & Ac. $V$. & Dac & Suic & Hom \\
\hline 0 & 0,0231 & 0,0225 & 0,0230 & 0,0227 & 0,0231 & 0,0230 & 0,0220 & 0,0205 & 0,0218 & 0,0206 & 0,0220 & 0,0219 \\
\hline 1 & 0,0032 & 0,0024 & 0,0030 & 0,0028 & 0,0032 & 0,0031 & 0,0027 & 0,0019 & 0,0023 & 0,0022 & 0,0027 & 0,0027 \\
\hline 5 & 0,0019 & 0,0011 & 0,0016 & 0,0015 & 0,0019 & 0,0018 & 0,0017 & 0,0009 & 0,0014 & 0,0012 & 0,0017 & 0,0017 \\
\hline 10 & 0,0027 & 0,0011 & 0,0022 & 0,0021 & 0,0027 & 0,0022 & 0,0019 & 0,0010 & 0,0015 & 0,0015 & 0,0019 & 0,0019 \\
\hline 15 & 0,0155 & 0,0020 & 0,0140 & 0,0141 & 0,0152 & 0,0057 & 0,0057 & 0,0015 & 0,0043 & 0,0047 & 0,0056 & 0,0045 \\
\hline 20 & 0,0226 & 0,0028 & 0,0204 & 0,0211 & 0,0221 & 0,0078 & 0,0095 & 0,0022 & 0,0074 & 0,0077 & 0,0088 & 0,0071 \\
\hline 25 & 0.0237 & 0,0059 & 0.0218 & 0.0224 & 0.0231 & 0.0106 & 0.0129 & 0,0058 & 0,0105 & 0.0113 & 0,0122 & 0.0112 \\
\hline 30 & 0,0245 & 0,0101 & 0,0226 & 0,0230 & 0,0239 & 0,0147 & 0,0170 & 0,0102 & 0,0149 & 0,0154 & 0,0164 & 0,0150 \\
\hline 35 & 0,0267 & 0,0151 & 0,0250 & 0,0251 & 0,0262 & 0,0197 & 0,0199 & 0,0131 & 0,0177 & 0,0182 & 0,0188 & 0,0187 \\
\hline 40 & 0,0321 & 0,0225 & 0,0304 & 0,0305 & 0,0316 & 0,0270 & 0,0283 & 0,0226 & 0,0261 & 0,0267 & 0,0278 & 0,0272 \\
\hline 45 & 0,0421 & 0,0337 & 0,0405 & 0,0404 & 0,0416 & 0,0382 & 0,0417 & 0,0350 & 0,0392 & 0,0391 & 0,0413 & 0,0406 \\
\hline 50 & 0,0551 & 0,0482 & 0,0536 & 0,0535 & 0,0546 & 0,0525 & 0,0563 & 0,0514 & 0,0540 & 0,0552 & 0,0559 & 0,0556 \\
\hline 55 & 0,0791 & 0,0729 & 0,0776 & 0,0775 & 0,0787 & 0,0771 & 0,0788 & 0,0732 & 0,0771 & 0,0772 & 0,0775 & 0,0782 \\
\hline 60 & 0,1150 & 0,1086 & 0,1135 & 0,1128 & 0,1146 & 0,1134 & 0,1131 & 0,1091 & 0,1112 & 0.1124 & 0,1126 & 0,1126 \\
\hline 65 & 0,1632 & 0,1577 & 0,1617 & 0,1612 & 0,1628 & 0,1621 & 0,1497 & 0,1446 & 0,1475 & 0,1475 & 0,1495 & 0,1493 \\
\hline 70 & 0,2370 & 0,2316 & 0,2355 & 0,2346 & 0,2366 & 0,2364 & 0,2287 & 0,2237 & 0,2283 & 0,2255 & 0,2280 & 0,2283 \\
\hline 75 & 0,3477 & 0,3407 & 0,3455 & 0,3450 & 0,3471 & 0,3471 & 0,3383 & 0,3347 & 0,3380 & 0,3354 & 0,3380 & 0,3383 \\
\hline 80 & 1,0000 & 1.0000 & 1,0000 & 1,0000 & 1,0000 & 1,0000 & 1,0000 & 1,0000 & 1,0000 & 1,0000 & 1,0000 & 1,0000 \\
\hline
\end{tabular}

\begin{tabular}{|c|c|c|c|c|c|c|c|c|c|c|c|c|}
\hline \multirow{2}{*}{ Idade } & \multicolumn{6}{|c|}{ Campinas } & \multicolumn{6}{|c|}{ Franca } \\
\hline & Obs & Ext & Ac. $V$. & Dac & Suic & Hom & Obs & Ext & Ac. $V$ & Dac & Suic & Hom \\
\hline 0 & 0,0201 & 0,0196 & 0,0200 & 0,0198 & 0,0201 & 0,0200 & 0,0190 & 0,0186 & 0,0190 & 0,0187 & 0,0190 & 0,0190 \\
\hline 1 & 0,0028 & 0,0020 & 0,0026 & 0,0023 & 0,0028 & 0,0028 & 0,0030 & 0,0021 & 0,0027 & 0,0025 & 0,0030 & 0,0030 \\
\hline 5 & 0,0019 & 0,0009 & 0,0015 & 0,0014 & 0,0019 & 0,0019 & 0,0012 & 0,0004 & 0,0009 & 0,0008 & 0,0012 & 0,0012 \\
\hline 10 & 0,0022 & 0,0008 & 0,0017 & 0,0015 & 0,0021 & 0,0020 & 0,0017 & 0,0011 & 0,0012 & 0,0016 & 0,0017 & 0,0017 \\
\hline 15 & 0,0099 & 0,0018 & 0,0079 & 0,0084 & 0,0097 & 0,0062 & 0,0060 & 0,0018 & 0,0044 & 0,0050 & 0,0057 & 0,0048 \\
\hline 20 & 0,0146 & 0,0027 & 0,0112 & 0,0130 & 0,0141 & 0,0088 & 0,0077 & 0,0026 & 0,0055 & 0,0064 & 0,0075 & 0,0064 \\
\hline 25 & 0,0154 & 0,0053 & 0,0129 & 0,0138 & 0,0150 & 0,0107 & 0,0091 & 0,0049 & 0,0077 & 0,0083 & 0,0082 & 0,0085 \\
\hline 30 & 0,0185 & 0,0095 & 0,0161 & 0,0169 & 0,0179 & 0,0147 & 0,0155 & 0,0088 & 0,0130 & 0,0140 & 0,0146 & 0,0145 \\
\hline 35 & 0,0223 & 0,0139 & 0,0198 & 0,0205 & 0,0218 & 0,0194 & 0.0181 & 0,0130 & 0,0165 & 0,0167 & 0,0173 & 0,0173 \\
\hline 40 & 0,0287 & 0,0210 & 0,0264 & 0,0269 & 0,0281 & 0,0265 & 0,0253 & 0,0202 & 0.0243 & 0,0235 & 0,0244 & 0,0243 \\
\hline 45 & 0,0363 & 0,0303 & 0,0344 & 0,0348 & 0,0358 & 0,0347 & 0,0330 & 0,0277 & 0,0310 & 0,0315 & 0,0321 & 0,0323 \\
\hline 50 & 0,0524 & 0,0461 & 0,0503 & 0,0506 & 0,0520 & 0,0512 & 0,0511 & 0,0468 & 0,0490 & 0,0500 & 0,0510 & 0,0506 \\
\hline 55 & 0,0733 & 0,0674 & 0,0712 & 0,0716 & 0,0727 & 0,0722 & 0,0709 & 0,0665 & 0,0688 & 0,0694 & 0,0703 & 0,0707 \\
\hline 60 & 0,1063 & 0,1006 & 0,1039 & 0,1046 & 0,1059 & 0,1056 & 0,1048 & 0,0999 & 0,1028 & 0,1028 & 0,1041 & 0,1048 \\
\hline 65 & 0,1518 & 0,1469 & 0,1503 & 0,1499 & 0,1512 & 0,1512 & 0,1545 & 0,1529 & 0,1539 & 0,1542 & 0,1542 & 0,1542 \\
\hline 70 & 0,2270 & 0,2212 & 0,2251 & 0,2244 & 0,2266 & 0,2264 & 0,2130 & 0,2101 & 0,2113 & 0,2118 & 0,2130 & 0,2130 \\
\hline 75 & 0,3437 & 0,3379 & 0,3420 & 0,3408 & 0,3433 & 0,3434 & 0,3246 & 0,3164 & 0.3218 & 0,3205 & 0,3239 & 0,3246 \\
\hline 80 & 1,0000 & 1,0000 & 1,0000 & 1,0000 & 1,0000 & 1,0000 & 1,0000 & 1,0000 & 1,0000 & 1,0000 & 1,0000 & 1,0000 \\
\hline
\end{tabular}

Fonte: Fundaçăo Seade. 
Tabela 29

Probabilidades de Morte Observadas $\left(q_{x}\right)$ e Liquida $\left(q_{x o}\right)$ Eliminando-se os Grupos de Causas Externas como Fator de Risco de Morte da População Feminina, segundo a Idade

Regiāo Metropolitana de Sảo Paulo, Bauru, Campinas e Franca 1998-99

\begin{tabular}{|c|c|c|c|c|c|c|c|c|c|c|c|c|}
\hline \multirow{2}{*}{ Idade } & \multicolumn{6}{|c|}{ RMSP } & \multicolumn{6}{|c|}{ Bauru } \\
\hline & Obs & Ext & Ac. V. & Dac & Suic & Hom & Obs & Ext & Ac. V. & Dac & Suic & Hom \\
\hline 0 & 0,0197 & 0,0192 & 0,0196 & 0,0194 & 0,0197 & 0,0196 & 0,0156 & 0,0152 & 0,0155 & 0,0159 & 0,0156 & 0,0155 \\
\hline 1 & 0,0029 & 0,0024 & 0,0028 & 0,0026 & 0,0029 & 0,0028 & 0,0026 & 0,0021 & 0,0023 & 0,0024 & 0,0026 & 0,0026 \\
\hline 5 & 0,0012 & 0,0008 & 0,0011 & 0,0011 & 0,0012 & 0,0012 & 0,0009 & 0,0006 & 0,0008 & 0,0008 & 0,0009 & 0,0009 \\
\hline 10 & 0,0015 & 0,0010 & 0,0014 & 0,0013 & 0,0015 & 0,0014 & 0,0016 & 0,0007 & 0,0010 & 0,0014 & 0,0016 & 0,0015 \\
\hline 15 & 0,0031 & 0,0015 & 0,0027 & 0,0029 & 0,0030 & 0,0022 & 0,0017 & 0,0010 & 0,0013 & 0,0016 & 0,0016 & 0,0015 \\
\hline 20 & 0,0039 & 0,0023 & 0,0036 & 0,0037 & 0,0038 & 0,0031 & 0,0031 & 0,0022 & 0,0027 & 0,0029 & 0,0029 & 0,0030 \\
\hline 25 & 0,0052 & 0,0039 & 0,0049 & 0,0051 & 0,0051 & 0.0045 & 0,0047 & 0,0040 & 0,0045 & 0,0044 & 0,0047 & 0,0047 \\
\hline 30 & 0,0065 & 0,0054 & 0,0063 & 0,0064 & 0,0064 & 0,0059 & 0,0058 & 0,0044 & 0,0053 & 0,0056 & 0,0057 & 0,0053 \\
\hline 35 & 0,0089 & 0,0077 & 0,0086 & 0,0087 & 0,0087 & 0,0083 & 0,0071 & 0,0069 & 0,0070 & 0,0072 & 0,0071 & 0,0071 \\
\hline 40 & 0,0128 & 0,0117 & 0,0125 & 0,0126 & 0,0127 & 0,0124 & 0,0111 & 0,0101 & 0,0109 & 0,0110 & 0,0107 & 0,0109 \\
\hline 45 & 0,0182 & 0,0172 & 0,0179 & 0,0180 & 0,0181 & 0,0180 & 0,0193 & 0,0181 & 0,0187 & 0,0190 & 0,0191 & 0,0192 \\
\hline 50 & 0,0280 & 0,0270 & 0,0276 & 0,0278 & 0,0279 & 0,0278 & 0,0280 & 0,0270 & 0,0278 & 0,0273 & 0,0279 & 0,0280 \\
\hline 55 & 0,0409 & 0,0397 & 0,0404 & 0,0406 & 0,0407 & 0,0407 & 0,0399 & 0,0390 & 0,0397 & 0,0396 & 0,0396 & 0,0399 \\
\hline 60 & 0,0630 & 0,0618 & 0,0625 & 0,0625 & 0,0629 & 0,0629 & 0,0577 & 0,0567 & 0,0574 & 0,0573 & 0,0576 & 0,0577 \\
\hline 65 & 0,0925 & 0,0907 & 0,0918 & 0,0917 & 0,0924 & 0,0924 & 0,1012 & 0,0999 & 0,1007 & 0,1005 & 0,1012 & 0,1012 \\
\hline 70 & 0.1452 & 0,1426 & 0,1443 & 0,1439 & 0,1452 & 0,1451 & 0,1386 & 0,1361 & 0,1375 & 0,1373 & 0,1386 & 0,1386 \\
\hline 75 & 0,4278 & 0,4229 & 0,4266 & 0,4249 & 0,4277 & 0,4276 & 0,4471 & 0,4434 & 0,4471 & 0,4438 & 0,4466 & 0,4471 \\
\hline 80 & 1,0000 & 1,0000 & 1,0000 & 1,0000 & 1,0000 & 1,0000 & 1,0000 & 1,0000 & 1,0000 & 1,0000 & 1,0000 & 1,0000 \\
\hline \multirow{2}{*}{ Idade } & \multicolumn{6}{|c|}{ Campinas } & \multicolumn{6}{|c|}{ Franca } \\
\hline & Obs & Ext & Ac. V. & Dac & Suic & Hom & Obs & Ext & Ac. V. & Dac & Suic & Hom \\
\hline 0 & 0,0155 & 0,0150 & 0,0154 & 0,0151 & 0,0155 & 0,0154 & 0,0137 & 0,0133 & 0,0136 & 0,0134 & 0,0137 & 0,0135 \\
\hline 1 & 0,0028 & 0,0021 & 0,0025 & 0,0024 & 0,0028 & 0.0027 & 0,0029 & 0,0023 & 0,0026 & 0,0027 & 0,0029 & 0,0029 \\
\hline 5 & 0,0011 & 0,0007 & 0,0010 & 0,0009 & 0,0011 & 0,0011 & 0,0013 & 0,0010 & 0,0012 & 0,0012 & 0,0013 & 0,0012 \\
\hline 10 & 0,0015 & 0,0008 & 0,0012 & 0,0013 & 0,0015 & 0,0014 & 0,0011 & 0,0008 & 0,0009 & 0,0011 & 0,0011 & 0,0011 \\
\hline 15 & 0,0021 & 0,0011 & 0,0016 & 0,0019 & 0,0020 & 0,0018 & 0,0019 & 0,0013 & 0,0015 & 0,0019 & 0,0019 & 0,0019 \\
\hline 20 & 0,0029 & 0,0018 & 0,0025 & 0,0028 & 0,0029 & 0,0026 & 0,0029 & 0,0018 & 0,0022 & 0,0027 & 0,0029 & 0,0027 \\
\hline 25 & 0,0042 & 0,0031 & 0,0037 & 0,0041 & 0,0041 & 0.0039 & 0,0037 & 0,0030 & 0.0036 & 0,0035 & 0,0036 & 0,0035 \\
\hline 30 & 0,0055 & 0,0045 & 0,0051 & 0,0053 & 0,0054 & 0,0053 & 0,0057 & 0,0050 & 0,0053 & 0,0056 & 0,0056 & 0,0056 \\
\hline 35 & 0,0075 & 0,0065 & 0,0071 & 0,0074 & 0,0074 & 0,0072 & 0,0089 & 0,0073 & 0,0085 & 0,0087 & 0,0084 & 0,0087 \\
\hline 40 & 0,0100 & 0,0090 & 0,0096 & 0,0098 & 0,0099 & 0,0098 & 0,0108 & 0,0102 & 0,0103 & 0,0107 & 0,0108 & 0,0108 \\
\hline 45 & 0,0166 & 0,0153 & 0,0162 & 0,0162 & 0,0164 & 0,0164 & 0,0162 & 0,0154 & 0,0158 & 0,0159 & 0,0162 & 0,0161 \\
\hline 50 & 0,0246 & 0,0235 & 0,0243 & 0,0244 & 0.0244 & 0,0243 & 0,0292 & 0,0280 & 0,0285 & 0,0290 & 0,0290 & 0,0290 \\
\hline 55 & 0,0390 & 0.0379 & 0.0385 & 0.0387 & 0,0389 & 0.0389 & 0.0369 & 0.0359 & 0.0367 & 0.0365 & 0,0367 & 0.0369 \\
\hline 60 & 0,0612 & 0,0601 & 0,0608 & 0,0606 & 0,0611 & 0,0611 & 0,0616 & 0,0611 & 0,0613 & 0,0613 & 0,0616 & 0,0616 \\
\hline 65 & 0,0937 & 0,0923 & 0,0932 & 0,0930 & 0,0937 & 0,0936 & 0,0888 & 0,0867 & 0,0885 & 0,0873 & 0,0888 & 0,0888 \\
\hline 70 & 0,1431 & 0,1410 & 0.1425 & 0,1419 & 0,1430 & 0,1431 & 0,1433 & 0,1418 & 0,1429 & 0.1429 & 0.1426 & 0,1433 \\
\hline 75 & 0,2682 & 0,2652 & 0,2675 & 0,2663 & 0,2682 & 0.2682 & 0,4465 & 0,4429 & 0,4447 & 0,4447 & 0,4465 & 0,4465 \\
\hline 80 & 1,0000 & 1,0000 & 1,0000 & 1,0000 & 1,0000 & 1,0000 & 1,0000 & 1,0000 & 1,0000 & 1,0000 & 1,0000 & 1,0000 \\
\hline
\end{tabular}


Tabela 30

Probabilidades de Morte Observadas $\left(q_{x}\right)$ e liquida $\left(q_{x_{0}}\right)$ Eliminando-se as

Causas Extemas como Fator de Risco de Morte da População Masculina, segundo a Idade Região Metropolitana de São Paulo, Bauru, Campinas e Franca 1998-99

\begin{tabular}{|c|c|c|c|c|c|c|c|c|}
\hline \multirow{2}{*}{ Idade } & \multicolumn{4}{|c|}{ Observada } & \multicolumn{4}{|c|}{ Sem as externas } \\
\hline & Bauru & Campinas & RMSP & Franca & Bauru & Campinas & RMSP & Franca \\
\hline 0 & 0,0220 & 0,0201 & 0,0231 & 0,0190 & 0,0205 & 0,0196 & 0,0225 & 0,0186 \\
\hline 1 & 0,0027 & 0,0028 & 0,0032 & 0,0030 & 0,0019 & 0,0020 & 0,0024 & 0,0021 \\
\hline 5 & 0,0017 & 0,0019 & 0,0019 & 0,0012 & 0,0009 & 0,0009 & 0,0011 & 0,0004 \\
\hline 10 & 0,0019 & 0,0022 & 0,0027 & 0,0017 & 0,0010 & 0,0008 & 0,0011 & 0,0011 \\
\hline 15 & 0,0057 & 0,0099 & 0,0155 & 0,0060 & 0,0015 & 0,0018 & 0,0020 & 0,0018 \\
\hline 20 & 0,0095 & 0,0146 & 0,0226 & 0,0077 & 0,0022 & 0,0027 & 0,0028 & 0,0026 \\
\hline 25 & 0,0129 & 0,0154 & 0,0237 & 0,0091 & 0,0058 & 0,0053 & 0,0059 & 0,0049 \\
\hline 30 & 0,0170 & 0,0185 & 0,0245 & 0,0155 & 0,0102 & 0,0095 & 0,0101 & 0,0088 \\
\hline 35 & 0,0199 & 0,0223 & 0,0267 & 0,0181 & 0,0131 & 0,0139 & 0,0151 & 0,0130 \\
\hline 40 & 0,0283 & 0,0287 & 0,0321 & 0,0253 & 0,0226 & 0,0210 & 0,0225 & 0,0202 \\
\hline 45 & 0,0417 & 0,0363 & 0,0421 & 0,0330 & 0,0350 & 0,0303 & 0,0337 & 0,0277 \\
\hline 50 & 0,0563 & 0,0524 & 0,0551 & 0,0511 & 0,0514 & 0,0461 & 0,0482 & 0,0468 \\
\hline 55 & 0,0788 & 0,0733 & 0,0791 & 0,0709 & 0,0732 & 0,0674 & 0,0729 & 0,0665 \\
\hline 60 & 0,1131 & 0,1063 & 0,1150 & 0,1048 & 0,1091 & 0,1006 & 0,1086 & 0,0999 \\
\hline 65 & 0,1497 & 0,1518 & 0,1632 & 0,1545 & 0,1446 & 0,1469 & 0,1577 & 0,1529 \\
\hline 70 & 0,2287 & 0,2270 & 0,2370 & 0,2130 & 0,2237 & 0,2212 & 0,2316 & 0,2101 \\
\hline 75 & 0,3383 & 0,3437 & 0,3477 & 0,3246 & 0,3347 & 0,3379 & 0,3407 & 0,3164 \\
\hline 80 & 1,0000 & 1,0000 & 1,0000 & 1,0000 & 1,0000 & 1,0000 & 1,0000 & 1,0000 \\
\hline
\end{tabular}

Fonte: Fundação Seade. 
Tabela 31

Probabilidades de Morte Observadas $\left(q_{x}\right)$ e líquida $\left(q_{x o}\right)$ Eliminando-se as

Causas Externas como Fator de Risco de Morte da População Feminina, segundo a Idade

1998-99

\begin{tabular}{cccccccccc}
\hline \multirow{2}{*}{ Idade } & \multicolumn{5}{c}{ Observada } & \multicolumn{5}{c}{ Sem as externas } \\
\cline { 2 - 9 } & Bauru & Campinas & RMSP & Franca & Bauru & Campinas & RMSP & Franca \\
\hline 0 & 0,0156 & 0,0155 & 0,0197 & 0,0137 & 0,0152 & 0,0150 & 0,0192 & 0,0133 \\
1 & 0,0026 & 0,0028 & 0,0029 & 0,0029 & 0,0021 & 0,0021 & 0,0024 & 0,0023 \\
5 & 0,0009 & 0,0011 & 0,0012 & 0,0013 & 0,0006 & 0,0007 & 0,0008 & 0,0010 \\
10 & 0,0016 & 0,0015 & 0,0015 & 0,0011 & 0,0007 & 0,0008 & 0,0010 & 0,0008 \\
15 & 0,0017 & 0,0021 & 0,0031 & 0,0019 & 0,0010 & 0,0011 & 0,0015 & 0,0013 \\
20 & 0,0031 & 0,0029 & 0,0039 & 0,0029 & 0,0022 & 0,0018 & 0,0023 & 0,0018 \\
25 & 0,0047 & 0,0042 & 0,0052 & 0,0037 & 0,0040 & 0,0031 & 0,0039 & 0,0030 \\
30 & 0,0058 & 0,0055 & 0,0065 & 0,0057 & 0,0044 & 0,0045 & 0,0054 & 0,0050 \\
35 & 0,0071 & 0,0075 & 0,0089 & 0,0089 & 0,0069 & 0,0065 & 0,0077 & 0,0073 \\
40 & 0,0111 & 0,0100 & 0,0128 & 0,0108 & 0,0101 & 0,0090 & 0,0117 & 0,0102 \\
45 & 0,0193 & 0,0166 & 0,0182 & 0,0162 & 0,0181 & 0,0153 & 0,0172 & 0,0154 \\
50 & 0,0280 & 0,0246 & 0,0280 & 0,0292 & 0,0270 & 0,0235 & 0,0270 & 0,0280 \\
55 & 0,0399 & 0,0390 & 0,0409 & 0,0369 & 0,0390 & 0,0379 & 0,0397 & 0,0359 \\
60 & 0,0577 & 0,0612 & 0,0630 & 0,0616 & 0,0567 & 0,0601 & 0,0618 & 0,0611 \\
65 & 0,1012 & 0,0937 & 0,0925 & 0,0888 & 0,0999 & 0,0923 & 0,0907 & 0,0867 \\
70 & 0,1386 & 0,1431 & 0,1452 & 0,1433 & 0,1361 & 0,1410 & 0,1426 & 0,1418 \\
75 & 0,4471 & 0,2682 & 0,4278 & 0,4465 & 0,4434 & 0,2652 & 0,4229 & 0,4429 \\
80 & 1,0000 & 1,0000 & 1,0000 & 1,0000 & 1,0000 & 1,0000 & 1,0000 & 1,0000 \\
\hline
\end{tabular}

Fonte: Fundação Seade. 
Tabela 32

Coeficientes de Mortalidade por Homicídios segundo Sexo e Grupos de Idade

Paises Selecionados e Estado de São Paulo

1992-98

Por 100 mil hab.

\begin{tabular}{|c|c|c|c|c|c|c|c|c|}
\hline \multirow[t]{2}{*}{ Áreas e Sexo } & \multicolumn{8}{|c|}{ Idade } \\
\hline & $5-14$ & $15-24$ & $25-34$ & $35-44$ & $45-54$ & $55-64$ & $65-74$ & $75+$ \\
\hline Homens & & & & & & & & \\
\hline Estado de São Paulo & 2,8 & 151,5 & 144,3 & 78,9 & 44,9 & 24,2 & 16,3 & 9,1 \\
\hline RMSP & 3,9 & 233,3 & 221,3 & 117,3 & 64,6 & 34,4 & 23,4 & 8,7 \\
\hline Interior de São Paulo & 1,7 & 77,5 & 70,5 & 42,9 & 27,1 & 16,1 & 11,2 & 9,3 \\
\hline Hungria & 0,1 & 2,8 & 6,3 & 8,3 & 8,6 & 6,2 & 3,0 & 12,5 \\
\hline Argentina & 0,7 & 9,5 & 12,3 & 11,5 & 8,6 & 7,8 & 6,1 & 9,8 \\
\hline Canada & 0,6 & 3,3 & 4,4 & 4,1 & 3,8 & 1,9 & 1,5 & 1,6 \\
\hline Colômbia & 6,7 & 264,4 & 322,8 & 259,5 & 186,3 & 128,0 & 76,4 & 50,7 \\
\hline México & 2,8 & 43,8 & 62,1 & 58,8 & 53,0 & 48,9 & 38,8 & 43,4 \\
\hline EUA & 1,8 & 36,8 & 28,5 & 18,1 & 12,7 & 8,6 & 6,1 & 5,6 \\
\hline Dinamarca & 1,0 & 2,5 & 2,4 & 1,1 & 1,4 & 2,0 & - & 0,8 \\
\hline Finlândia & 0,9 & 2,2 & 6,2 & 8,8 & 5,8 & 6,6 & 2,4 & 2,3 \\
\hline França & 0,1 & 1,3 & 1,8 & 1,9 & 1,9 & 1,2 & 0,9 & 1,2 \\
\hline Alemanha & 0,2 & 1,3 & 1,8 & 1,9 & 1,9 & 1,5 & 0.6 & 1,7 \\
\hline Grécia & - & 2,0 & 2,5 & 2,7 & 3,0 & 1,6 & 2,4 & 2,9 \\
\hline Itália & 0,3 & 6,0 & 10,6 & 7,8 & 4,6 & 3,9 & 2,3 & 2,3 \\
\hline Holanda & 0.4 & 1,9 & 3,8 & 2,6 & 1,3 & 1,3 & 1,4 & 0,4 \\
\hline Noruega & 0,4 & 1,9 & 4,5 & 1,6 & 1,2 & 0,6 & 1,7 & - \\
\hline Portugal & 0,2 & 1,7 & 3,3 & 4,3 & 2,9 & 2,0 & 0.5 & 0,5 \\
\hline Japão & 0,4 & 0,4 & 0,5 & 0.9 & 1,2 & 1,0 & 0.7 & 0,8 \\
\hline Rússia & 2,2 & 44,9 & 77,9 & 81,9 & 69,9 & 49,2 & 31,7 & 23,1 \\
\hline
\end{tabular}

Mulheres

\begin{tabular}{|c|c|c|c|c|c|c|c|c|}
\hline Estado de Sảo Paulo & 1,4 & 11,0 & 9,1 & 6,4 & 4,2 & 1,6 & 1,3 & 3,8 \\
\hline RMSP & 1,5 & 15,8 & 12,4 & 8,5 & 4,9 & 1,8 & 2,0 & 6,4 \\
\hline Interior de São Paulo & 1,3 & 6,5 & 5,8 & 4,4 & 3,6 & 1,5 & 0,7 & 1,6 \\
\hline Hungria & 0,3 & 0,9 & 3,0 & 4,5 & 4,1 & 4,0 & 2,4 & 6,9 \\
\hline Argentina & 0,3 & 1,5 & 1,9 & 1,3 & 1,2 & 1,7 & 1,9 & 2,6 \\
\hline Canada & 0,6 & 1,5 & 2,0 & 2,0 & 1,4 & 1,4 & 0,6 & 0,2 \\
\hline Colômbia & 2,5 & 20,2 & 19,9 & 16,9 & 13,4 & 9,7 & 11,0 & 11,4 \\
\hline México & 1,1 & 4,2 & 4,5 & 5,1 & 5,0 & 5,0 & 6,2 & 10,3 \\
\hline EUA & 1,0 & 6,9 & 7,5 & 5,0 & 3,8 & 2,6 & 2,4 & 3,4 \\
\hline Dinamarca & 1,1 & 0,9 & 1,0 & 0,8 & 1,9 & 0,4 & 0,0 & 0,4 \\
\hline Finlândia & 1,9 & 2,6 & 2,4 & 3,5 & 1,5 & 0,4 & 1,2 & 1,5 \\
\hline França & 0,3 & 1,5 & 0,9 & 0,8 & 1,0 & 0,9 & 0,5 & 0,9 \\
\hline Alemanha & 0,3 & 1,1 & 1,3 & 1,2 & 1,1 & 0,5 & 0,7 & 1,1 \\
\hline Grécia & 0,0 & 0,8 & 0,4 & 0,6 & 1,3 & 0,4 & 0,7 & 0,3 \\
\hline Itália & 0,1 & 0,7 & 0,9 & 0,8 & 0,8 & 0,4 & 0,8 & 0,7 \\
\hline Holanda & 0,2 & 1,2 & 1,0 & 0,7 & 0,4 & 0,3 & 0,5 & 0,5 \\
\hline Noruega & 0,4 & 0,3 & 0,9 & 0,7 & 0,8 & 0,0 & 0,5 & 0,5 \\
\hline Portugal & 0,2 & 0,7 & 1,8 & 1,3 & 0,8 & 0,7 & 0,6 & 2,1 \\
\hline Japão & 1,4 & 0,2 & 0,5 & 0,3 & 0,4 & 0,5 & 0,8 & 0,7 \\
\hline Rússia & 1,4 & 8,8 & 15,7 & 21,6 & 21,7 & 15,9 & 13,1 & 15,7 \\
\hline
\end{tabular}

Fontes: Organização Mundial de Saúde e Fundação Seade. 
Tabela 33

Coeficientes de Mortalidade por Acidentes de Veículo a Motor segundo Sexo e Grupos de Idade Países Selecionados e Estado de São Paulo 1992-98

Por 100 mil hab.

\begin{tabular}{|c|c|c|c|c|c|c|c|c|}
\hline \multirow[t]{2}{*}{ Áreas e Sexo } & \multicolumn{8}{|c|}{ Idade } \\
\hline & $5-14$ & $15-24$ & $25-34$ & $35-44$ & $45-54$ & $55-64$ & $65-74$ & $75+$ \\
\hline \multicolumn{9}{|l|}{ Homens } \\
\hline Estado de São Paulo & 7,4 & 44,5 & 47,2 & 43,3 & 37,9 & 40,1 & 41,3 & 63,9 \\
\hline RMSP & 7,0 & 39,3 & 38,4 & 34,6 & 32,0 & 31,8 & 39,0 & 74,5 \\
\hline Interior de São Paulo & 7,9 & 49,1 & 55,6 & 51,5 & 43,3 & 46,9 & 42,9 & 56,5 \\
\hline Hungria & 5,8 & 30,2 & 32,0 & 29,5 & 31,2 & 34,3 & 37,9 & 51,1 \\
\hline Argentina & 4,7 & 14,6 & 15,5 & 16,9 & 19,7 & 23,6 & 23,2 & 34,6 \\
\hline Canada & 5,4 & 31,4 & 19,3 & 13,8 & 13,0 & 12,9 & 15,5 & 31,4 \\
\hline Colômbia & 8,9 & 20,2 & 30,9 & 29,2 & 36,3 & 40,6 & 47,7 & 72,9 \\
\hline México & 7,7 & 28,2 & 37,0 & 35,8 & 38,7 & 42,8 & 50,0 & 94,1 \\
\hline EUA & 6,7 & 44,8 & 31,2 & 21,8 & 19,5 & 19,0 & 22,3 & 43,5 \\
\hline Dinamarca & 4,2 & 25,1 & 14,5 & 11,9 & 10,3 & 16,2 & 23,1 & 47,0 \\
\hline Finlândia & 4,3 & 21,6 & 10,7 & 8,6 & 13,6 & 9,0 & 20,4 & 30,8 \\
\hline França & 4,4 & 45,7 & 31,5 & 21,1 & 19,4 & 17,2 & 22,0 & 33,2 \\
\hline Alemanha & 4,1 & 41,4 & 24,9 & 16,9 & 13,9 & 14,0 & 15,7 & 31,9 \\
\hline Grécia & 6,9 & 57,0 & 43,2 & 27,7 & 28,6 & 37,8 & 33,3 & 59,0 \\
\hline Itália & 5,2 & 46,4 & 27,5 & 19,2 & 19,8 & 26,9 & 37,6 & 56,0 \\
\hline Holanda & 4,6 & 20,7 & 12,8 & 8,3 & 7,4 & 8,8 & 19,7 & 38,2 \\
\hline Noruega & 3,0 & 18,3 & 13,4 & 7,9 & 7,1 & 7,2 & 13,0 & 26,5 \\
\hline Portugal & 8,8 & 60,5 & 47,8 & 32,6 & 35,0 & 39,2 & 60,4 & 64,7 \\
\hline Japão & 2,7 & 27,1 & 12,4 & 10,3 & 13,1 & 20,2 & 28,2 & 48,4 \\
\hline Rússia & 11,2 & 47,4 & 62,3 & 54,3 & 48,8 & 41,7 & 34,8 & 44,1 \\
\hline
\end{tabular}

\section{Mulheres}

\begin{tabular}{|c|c|c|c|c|c|c|c|c|}
\hline Estado de São Paulo & 3,7 & 8,3 & 6,7 & 6,5 & 7,2 & 9,1 & 17,8 & 22,8 \\
\hline RMSP & 2,7 & 6,8 & 5,7 & 4,7 & 5,6 & 10,7 & 17,7 & 22,4 \\
\hline Interior de São Paulo & 4,7 & 9,7 & 7,8 & 8,4 & 8,8 & 7,8 & 17,9 & 23,2 \\
\hline Hungria & 4,3 & 8,5 & 6,8 & 7,0 & 8,7 & 8,6 & 13,3 & 20,2 \\
\hline Argentina & 2,2 & 5,4 & 4,3 & 3,4 & 4,5 & 7,1 & 7,5 & 14,0 \\
\hline Canada & 3,2 & 11,0 & 6,5 & 6,3 & 6,7 & 7,0 & 11,1 & 15,6 \\
\hline Colômbia & 3,6 & 5,1 & 6,1 & 6,4 & 9,4 & 14,6 & 22,0 & 24,2 \\
\hline México & 3,5 & 5,0 & 5,9 & 7,1 & 7,9 & 12,1 & 18,8 & 28,5 \\
\hline EUA & 3,9 & 17,8 & 10,4 & 8,4 & 8,5 & 9,2 & 13,1 & 19,4 \\
\hline Dinamarca & 4,7 & 5,4 & 3,8 & 4,4 & 3,6 & 3,9 & 12,5 & 18,6 \\
\hline Finlândia & 1,9 & 5,2 & 3,3 & 4,5 & 4,7 & 6,4 & 13,2 & 14,7 \\
\hline França & 2,9 & 11,9 & 7,5 & 6,7 & 7,0 & 7,9 & 10,9 & 12,9 \\
\hline Alemanha & 3,4 & 11,6 & 6,3 & 4,4 & 4,6 & 5,5 & 7,9 & 13,5 \\
\hline Grécia & 3,6 & 11,2 & 9,2 & 6,9 & 7,1 & 12,3 & 14,6 & 23,8 \\
\hline Itália & 2,3 & 9,8 & 6,6 & 5,0 & 6,2 & 7,6 & 10,4 & 15,0 \\
\hline Holanda & 3,0 & 5,3 & 3,6 & 2,4 & 3,5 & 6,4 & 10,3 & 12,5 \\
\hline Noruega & 1,6 & 5,5 & 4,1 & 2,0 & 1,6 & 4,8 & 10,4 & 8,2 \\
\hline Portugal & 4,9 & 8,6 & 10,3 & 8,7 & 9,9 & 12,0 & 14,7 & 27,2 \\
\hline Japão & 1,5 & 6,0 & 2,6 & 2,8 & 5,0 & 7,8 & 13,6 & 23,2 \\
\hline Rússia & 5,6 & 14,7 & 10,2 & 10,1 & 11,9 & 12,4 & 15,6 & 20,2 \\
\hline
\end{tabular}

Fontes: Organização Mundial de Saúde e Fundação Seade. 
Tabela 34

Coeficientes de Mortalidade por Suicidios segundo Sexo e Grupos de Idade Paises Selecionados e Estado de São Paulo

1992-98

\begin{tabular}{|c|c|c|c|c|c|c|c|c|}
\hline \multirow{2}{*}{ Áreas e Sexo } & \multicolumn{8}{|c|}{ Idade } \\
\hline & $5-14$ & $15-24$ & $25-34$ & 35-44 & $45-54$ & $55-64$ & $65-74$ & $75+$ \\
\hline \multicolumn{9}{|l|}{ Homens } \\
\hline Estado de São Paulo & 0,1 & 8,8 & 12,5 & 11,9 & 11,2 & 12,8 & 11,7 & 16,2 \\
\hline RMSP & 0,2 & 8,9 & 13,3 & 10,5 & 10,8 & 13,7 & 9,4 & 16,4 \\
\hline Interior de São Paulo & 0,0 & 8,7 & 11,8 & 13,2 & 11,6 & 12,1 & 13,5 & 16,0 \\
\hline Hungria & 1,0 & 19,1 & 50,3 & 49,1 & 87,9 & 87,0 & 80,2 & 179,1 \\
\hline Argentina & 0,8 & 6,5 & 9,4 & 9,7 & 12,9 & 17,3 & 26,8 & 46,5 \\
\hline Canada & 1,3 & 24,7 & 28,8 & 27,3 & 24,7 & 26,2 & 20,5 & 27,2 \\
\hline Colômbia & 0,6 & 8,3 & 7,6 & 5,8 & 6,2 & 6,7 & 9,8 & 6,8 \\
\hline México & 0,4 & 5,7 & 7,1 & 6,4 & 6,7 & 7,6 & 9,8 & 18,0 \\
\hline EUA & 1,1 & 21,9 & 25,0 & 23,0 & 23,7 & 25,3 & 30,7 & 56,0 \\
\hline Dinamarca & 0,7 & 13,4 & 26,1 & 32,2 & 44,6 & 41,0 & 53,7 & 72,0 \\
\hline Finlândia & 9,0 & 33,0 & 56,0 & 67,4 & 67,3 & 54,7 & 45,1 & 67,3 \\
\hline França & 0,5 & 14,0 & 32,4 & 40,4 & 40,3 & 38,8 & 46,1 & 103,3 \\
\hline Alemanha & 0,6 & 13,0 & 22,2 & 26,9 & 31,0 & 32,2 & 36,3 & 87,9 \\
\hline Grécia & 0,3 & 2,7 & 4,9 & 5,6 & 7,4 & 7,5 & 11,4 & 16,1 \\
\hline Itália & 0,2 & 5,7 & 10,0 & 10,5 & 12,5 & 18,3 & 23,0 & 41,9 \\
\hline Holanda & 0,1 & 9,1 & 15,8 & 18,1 & 17,3 & 17,7 & 23,7 & 37,2 \\
\hline Noruega & 1,3 & 16,6 & 28,8 & 40,6 & 45,8 & 37,3 & 33,6 & 32,3 \\
\hline Portugal & 0,3 & 4,3 & 10,3 & 10,9 & 13,4 & 21,4 & 32,7 & 50,1 \\
\hline Japão & 0,4 & 10,1 & 18,1 & 24,5 & 36,1 & 37,8 & 31,7 & 51,8 \\
\hline Rússia & 2,8 & 41,7 & 82,1 & 99,4 & 118,2 & 100,7 & 80,7 & 103,8 \\
\hline
\end{tabular}

Mulheres

\begin{tabular}{l|rrrrrrrr}
\hline \hline & \multicolumn{1}{|c}{$5-14$} & $15-24$ & $25-34$ & $35-44$ & $45-54$ & $55-64$ & $65-74$ & $75+$ \\
\hline Estado de São Paulo & 0,1 & 2,3 & 2,7 & 2,3 & 2,7 & 2,2 & 2,1 & 3,8 \\
RMSP & 0,0 & 2,5 & 2,9 & 2,2 & 2,4 & 2,2 & 2,6 & 5,8 \\
Interior de São Paulo & 0,3 & 2,1 & 2,5 & 2,5 & 2,9 & 2,1 & 1,7 & 2,1 \\
Hungria & 0,2 & 5,5 & 9,9 & 21,2 & 21,7 & 26,7 & 34,0 & 59,0 \\
Argentina & 0,3 & 2,3 & 3,3 & 3,3 & 4,0 & 5,4 & 8,5 & 7,6 \\
Canada & 0,4 & 6,0 & 6,2 & 7,9 & 9,1 & 6,6 & 5,9 & 4,2 \\
Colômbia & 0,2 & 3,0 & 1,9 & 1,2 & 1,0 & 1,0 & 0,4 & 1,1 \\
México & 0,2 & 1,3 & 1,2 & 1,0 & 0,7 & 1,0 & 1,1 & 1,1 \\
EUA & 0,3 & 3,8 & 5,4 & 6,5 & 7,6 & 6,5 & 6,0 & 5,9 \\
Dinamarca & 0,4 & 2,3 & 7,1 & 15,3 & 27,0 & 23,6 & 35,7 & 31,6 \\
Finlândia & 0,3 & 3,2 & 13,3 & 18,7 & 18,6 & 18,9 & 12,3 & 6,4 \\
França & 0,1 & 4,3 & 8,9 & 12,6 & 16,4 & 16,9 & 17,4 & 24,3 \\
Alemanha & 0,3 & 3,3 & 5,8 & 7,9 & 12,3 & 13,1 & 17,9 & 29,1 \\
Grécia & 0,0 & 0,6 & 1,3 & 1,5 & 1,3 & 2,3 & 2,6 & 3,1 \\
Itália & 0,1 & 1,6 & 3,2 & 4,0 & 5,0 & 6,4 & 8,7 & 9,6 \\
Holanda & 0,2 & 3,8 & 6,7 & 10,0 & 10,8 & 10,1 & 10,1 & 12,3 \\
Noruega & 0,2 & 2,5 & 5,1 & 5,8 & 8,9 & 9,1 & 8,1 & 6,3 \\
Portugal & 0,2 & 2,0 & 3,3 & 3,2 & 4,9 & 4,1 & 9,1 & 10,2 \\
Japäo & 0,3 & 4,4 & 7,5 & 8,8 & 12,9 & 15,9 & 20,6 & 37,0 \\
Rússia & 0,8 & 7,9 & 10,3 & 13,9 & 18,5 & 19,0 & 22,6 & 31,6 \\
\hline Fontes: Orang
\end{tabular}

Fontes: Organizaçăo Mundial de Saúde e Fundação Seade. 